\title{
Non-invasive measurements in wheezing preschool children
}

Citation for published version (APA):

van de Kant, K. D. G. (2011). Non-invasive measurements in wheezing preschool children. [Doctoral Thesis, Maastricht University]. Datawyse / Universitaire Pers Maastricht.

https://doi.org/10.26481/dis.20111215kk

Document status and date:

Published: 01/01/2011

DOI:

10.26481/dis.20111215kk

Document Version:

Publisher's PDF, also known as Version of record

\section{Please check the document version of this publication:}

- A submitted manuscript is the version of the article upon submission and before peer-review. There can be important differences between the submitted version and the official published version of record.

People interested in the research are advised to contact the author for the final version of the publication, or visit the DOI to the publisher's website.

- The final author version and the galley proof are versions of the publication after peer review.

- The final published version features the final layout of the paper including the volume, issue and page numbers.

Link to publication

\footnotetext{
General rights rights.

- You may freely distribute the URL identifying the publication in the public portal. please follow below link for the End User Agreement:

www.umlib.nl/taverne-license

Take down policy

If you believe that this document breaches copyright please contact us at:

repository@maastrichtuniversity.nl

providing details and we will investigate your claim.
}

Copyright and moral rights for the publications made accessible in the public portal are retained by the authors and/or other copyright owners and it is a condition of accessing publications that users recognise and abide by the legal requirements associated with these

- Users may download and print one copy of any publication from the public portal for the purpose of private study or research.

- You may not further distribute the material or use it for any profit-making activity or commercial gain

If the publication is distributed under the terms of Article $25 \mathrm{fa}$ of the Dutch Copyright Act, indicated by the "Taverne" license above, 
Non-invasive measurements in wheezing preschool children 
(C) Copyright KDG van de Kant, Maastricht 2011

Cover design: Inez Art (www.inez-art.com)

Cover photography: Hans Patelski

Layout: Tiny Wouters

Printed by: Datawyse | Universitaire Pers Maastricht

ISBN: 9789461590954

The research presented in this thesis was conducted at the School for Public Health and Primary Care: CAPHRI, Department Paediatrics, of Maastricht University. CAPHRI participates in the Netherlands School of Primary Care Research CaRe. CAPHRI was classified as 'excellent' by the external evaluation committee of leading international experts that reviewed CAPHRI in December 2010.

This PhD research was funded by grants from the Dutch Asthma Foundation (NAF 3.4.05.033), Stichting Astma Bestrijding (SAB 2006/018), and Maastricht University Medical Centre (PF 294). Financial support for the printing of this thesis was kindly provided by: Stichting Astma Bestrijding, TEVA Pharma NL, Phadia BV, GlaxoSmithKline BV, Maastricht Instruments BV, Novartis Pharma BV, Luminex BV, Boehringer Ingelheim BV, Chiesi Pharmaceuticals BV, and DSM Resolve. 
Voor Papa, Mama en Puck

Aan Hans

Juni 2007

Dapper loopt Luna de onderzoekskamer in. 'Kim, gaan we vandaag weer ballonnen opblazen, belletjes en klikjes toveren?' vraagt ze met grote, vrolijke ogen. Ze klimt op de stoel die ik zo hoog mogelijk zet. 'Nou ben ik groter dan papa', lacht ze enthousiast. Ik zet het masker op haar gezicht. Haar ogen beginnen te glinsteren, Kabouter Plop

begint. Ik zie tevreden hoe ze het masker op haar gezicht vergeet, evenals de condensor en het zoemende geluid van het koelapparaat, hoe de kleppen van het masker rustig op en neer bewegen en de eerste druppels condensaat zich in de buis verzamelen. Na het onderzoek vertel ik Luna voorzichtig dat we nog een beetje bloed gaan prikken. 'Pfff Kim, dat kan helemaal niet, ik ben pas drie jaar dus ik heb nog geen bloed!' zegt ze belerend waarna ze de kamer uit huppelt, mij in vrolijke verbazing achterlatend.

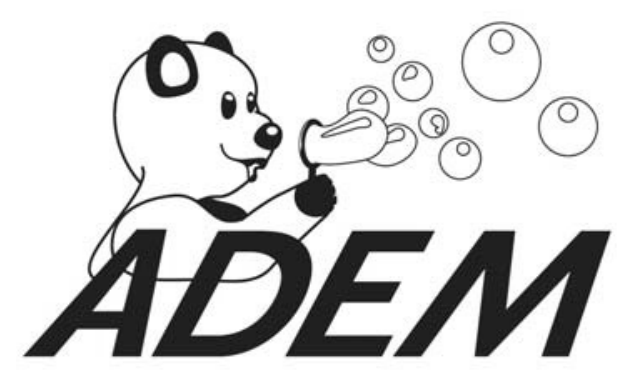





\title{
Non-invasive measurements in wheezing preschool children
}

\author{
PROEFSCHRIFT
}

Ter verkrijging van de graad van doctor

aan de Universiteit Maastricht, op gezag van de Rector Magnificus,

Prof. Mr. G.P.M.F. Mols,

volgens het besluit van het College van Decanen,

in het openbaar te verdedigen

op donderdag 15 december 2011 om 12.00 uur

door

Kim Dorien Geertruida van de Kant

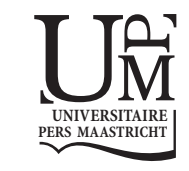


Promotores:

Prof. dr. E. Dompeling

Prof. dr. C.P. van Schayck

\section{Copromotor:}

Dr. Q. Jöbsis

\section{Beoordelingscommissie:}

Prof. dr. C.A. Bruggeman (voorzitter)

Prof. dr. W.M.C. van Aalderen (Universiteit van Amsterdam)

Dr. M. Mommers

Prof. dr. P.J. Sterk (Universiteit van Amsterdam)

Prof. dr. G. Wesseling 


\section{Contents}

$\begin{array}{lll}\text { Chapter } 1 & \text { General introduction } & 9\end{array}$

Chapter $2 \quad$ Early diagnosis of asthma in young children by using 23 non-invasive biomarkers of airway inflammation and early lung function measurements: study protocol of a case-control study

Chapter 3 Wheezing in preschool children is associated with increased levels of cytokines / chemokines in Exhaled Breath Condensate

Chapter 4 The clinical use of exhaled Volatile Organic Compounds in pulmonary diseases: a systematic review

Chapter $5 \quad$ Exhaled breath profiling in the diagnosis of wheezy preschool children: a proof of principle study

Chapter $6 \quad$ Mechanisms of preschool wheeze: the role of bacteria, regulatory $\mathrm{T}$-cells, and airway inflammation

Chapter $7 \quad$ Can exhaled inflammatory markers predict a steroid response in wheezing preschool children?

Chapter $8 \quad$ Elevated inflammatory markers at preschool age precede persistent wheezing at school age

Chapter $9 \quad$ General discussion

Summary 163

Samenvatting

Dankwoord

Curriculum Vitae 


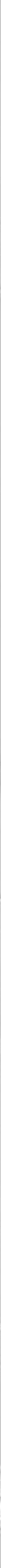


Chapter 1

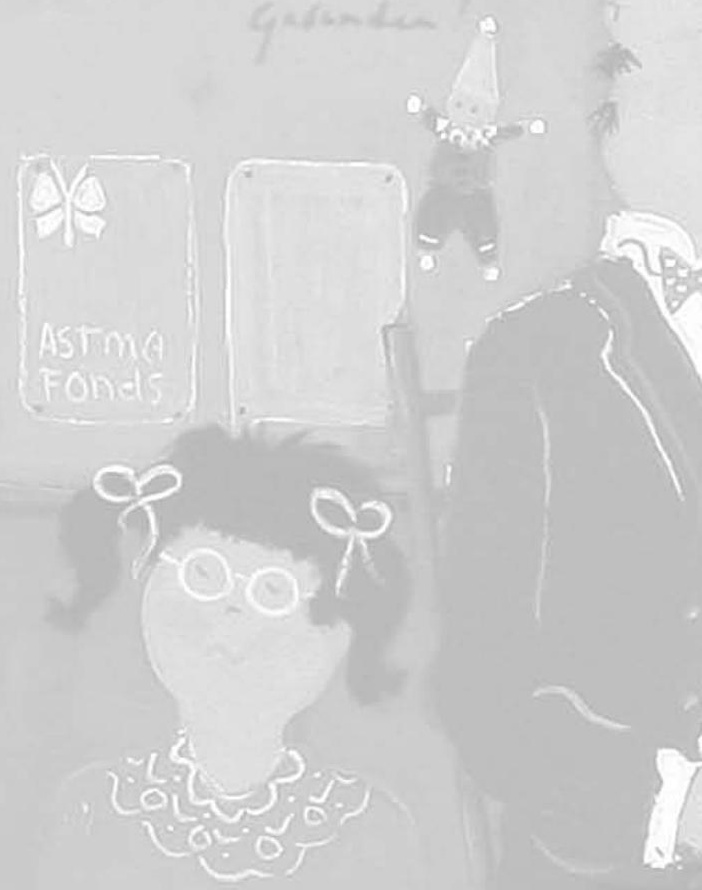

General introduction 


\section{Wheeze in preschool children}

Respiratory symptoms are common in young children. Around $30 \%$ of all children suffer from recurrent episodes of respiratory symptoms, such as wheezing, in early life. ${ }^{1}$ Although asthma is the most prevalent chronic disease in children, fortunately only the minority (around 30\%) of preschool children with recurrent wheeze will persist with wheezing and will have asthma in later life. ${ }^{2}$ The majority of wheezing preschool children will have transient symptoms related to frequent viral respiratory tract infections without an increased risk for asthma. Nevertheless, preschool wheeze places an important burden in terms of morbidity, quality of life, use of the health care system and health care costs. Currently, it is not possible to distinguish children with transient symptoms from children with asthma before the age of six years, leaving physicians with a challenging task concerning the diagnosis and management of preschool wheeze.

\section{Wheezing phenotypes}

Due to the heterogeneous character, various phenotypes of childhood wheeze have been defined. These phenotypes are mostly based on time course, frequency, severity, or triggers of symptoms. ${ }^{3,4}$ A widely used classification was developed by researchers of the Tucson birth cohort study dividing children into early transient wheeze (symptoms starting before three years of age and no symptoms at six years of age), late-onset wheeze (no wheeze before three years but symptoms reported at six years) and persistent wheeze (wheeze in the first three years that persisted at six years of age). ${ }^{5}$ Despite its frequent use in epidemiological studies, the clinical use of this classification is limited as it can only be assessed retrospectively. A more clinical useful classification was provided by the 'European Respiratory Society' taskforce subgrouping children into episodic (viral) wheeze (wheezing during discrete episodes, often in association with clinical evidence of a viral cold) and multi-trigger wheeze (wheezing both during and outside discrete infectious episodes). ${ }^{6}$ However, it becomes increasingly clear that these two phenotypes are an oversimplification of the broad spectrum of wheezing illness. Moreover, there is limited evidence that both phenotypes have a different underlying pathophysiology and have a different response to treatment. ${ }^{7}$ Besides, these phenotypes can change over time. ${ }^{8}$ Recent research focussed on multi-dimensional phenotyping to increase insight in the underlying mechanisms of wheezing ilness. ${ }^{3}$ Statistical techniques, such as cluster analysis, were performed to classify children on a wide range of features, which resulted in novel wheezing groups, such as atopic persistent wheeze and prolonged intermittent wheeze. $^{9-12}$ 


\section{Mechanisms of preschool wheeze}

Despite its high prevalence, little is known about the underlying mechanisms of preschool wheeze, as it is difficult to perform complex physiological studies in young children. The aetiology of preschool wheeze is complex and probably develops due to the interaction between genetic predisposition and environmental exposures (Figure 1.1). ${ }^{13}$ Most wheezing episodes are associated with viral respiratory tract infections, in which rhinovirus and respiratory syncytial virus are mainly responsible. ${ }^{13,14}$ In addition, bacterial infections may play a role in the initiation of wheezing episodes. ${ }^{15}$

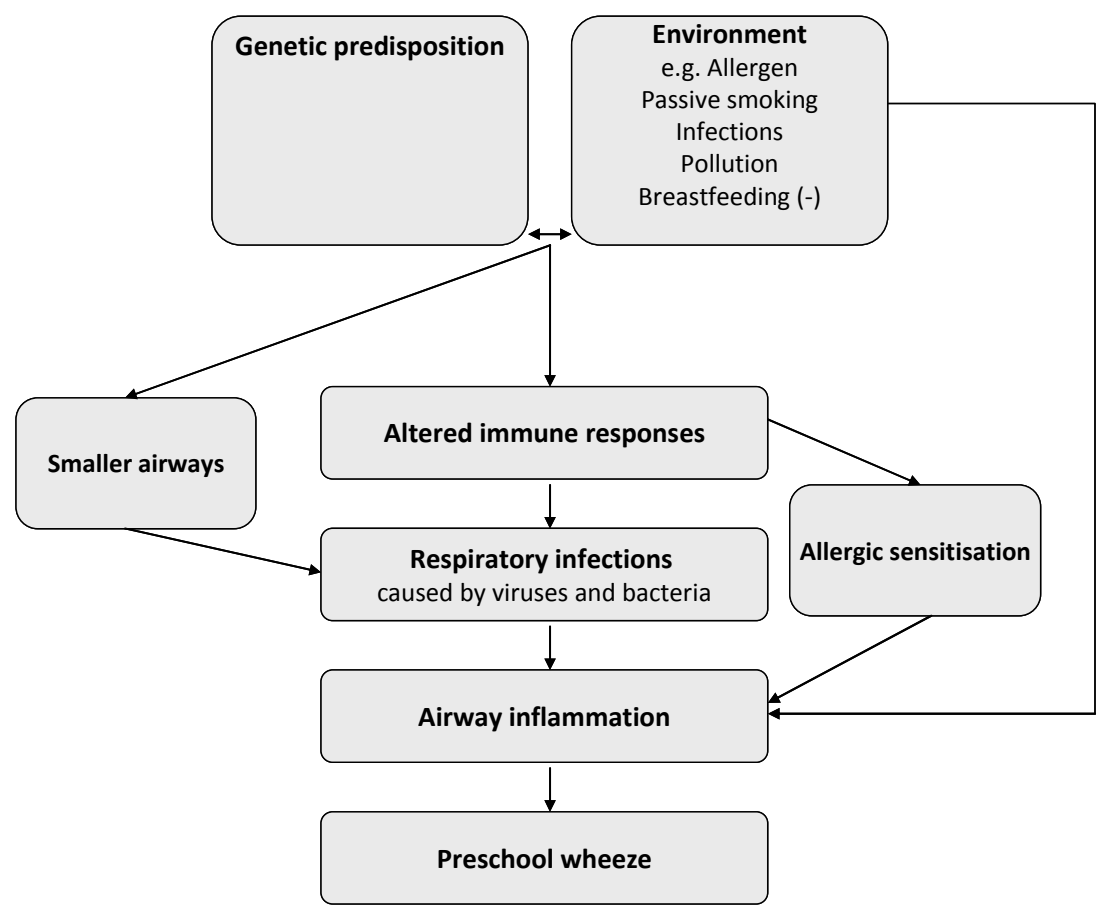

Figure 1.1 Hypothetical model of the aetiology of preschool wheeze.

Influence of genetic predisposition and environmental agents, viruses, bacteria and allergic sensitisation in the development of recurrent wheeze and childhood asthma.

Children with transient wheezing symptoms only have symptoms during respiratory infections below the age of three years. As these children demonstrated a diminished lung function, they are believed to have smaller airways making them more prone to wheeze during infections. ${ }^{5}$ As these children grow older, their airways grow in size leading to improved lung function and making them less vulnerable to wheeze during infections. This transient wheeze phenotype is not related to atopy, and 
bronchoalveolar lavage data demonstrated predominately neutrophilic airway inflammation. ${ }^{13,16}$

Children with persistent wheeze have normal lung function at birth, but demonstrate reduced lung function at the age of six years. ${ }^{5,17}$ This decrease in lung function might be the result of ongoing chronic inflammatory processes that lead to airway alterations. ${ }^{18}$ Persistent wheeze is often associated with atopic sensitization in early life. ${ }^{19}$ It is argued that atopic children with persistent symptoms have an impaired immune responsiveness.

Regulatory $T\left(T_{\text {reg }}\right)$ cells play an important role in the maturation of the infant immune system and are involved in the regulation of immune responses to environmental triggers. ${ }^{20,21}$ It is conceivable that a decrease in number or function of $T_{\text {reg }}$ cells could play a role in an inadequate immune response to viruses, bacteria and allergens. ${ }^{20,22}$ This may result in chronic airway inflammation and may promote the development of persistent symptoms. In one study, lower $\mathrm{T}_{\text {reg }}$ cell counts were found in wheezing infants. $^{23}$ Atopic children with persistent symptoms demonstrated enhanced eosinophilic airway inflammation. ${ }^{16,24}$

However, as stated before, wheeze is a heterogeneous symptom and multiple pathological processes may be involved. In order to unravel the pathophysiological pathways of preschool wheeze, assessment of biomarkers in the airways will be of help.

\section{Treatment of preschool wheeze}

Currently, it is difficult for a clinician to determine the best treatment for a preschool child with wheezing symptoms. Inhaled corticosteroids (ICS) are the common treatment in childhood asthma. However, as the pathophysiology of preschool wheeze is heterogeneous, there is a large variability in response to ICS in wheezing children. ICS are effective in preschool children who wheeze due to asthma. ${ }^{25}$ In contrast, ICS are not very effective in preschool children who solely wheeze due to a viral respiratory tract infection. ${ }^{26,27}$ Given that it is difficult to distinguish wheezing phenotypes at a young age, it is hard to predict who will benefit from ICS and to identify those who will not respond. A reliable prediction of an ICS response can prevent under-treatment in asthmatics and reduce over-treatment in viral wheezers. Next to close follow-up of symptom history, the assessment of risk factors (such as atopy, family history of asthma, eosinophilia) can be useful to identify preschool wheezers at risk for asthma who potentially will benefit from ICS. ${ }^{28}$ However, this is not always fulfilling. Currently, there are no biological tests available that can predict a treatment response in wheezing children. As ICS are believed to improve symptoms and lung function due to their anti-inflammatory effect, it can be hypothesised that the use of inflammatory biomarkers in the airways will help to identify ICS responders. 


\section{Techniques to study preschool wheeze}

As stated, there are multiple ways to classify children with wheezing symptoms into specific phenotypes. However, phenotyping based on underlying pathophysiology has yet to be performed. The inclusion of pathophysiological parameters in sub-groups of children with preschool wheeze is attractive as it can help to improve our understanding of the progress of wheezing illness as well as direct our treatment decisions. Nevertheless, research in this direction is hampered due to problems with measurements of lung function and airway inflammation in young children. Most lung function tests require active cooperation which is difficult to accomplish in preschool children. Besides, the currently available techniques to measure airway inflammation, such as bronchial biopsies and bronchoalveolar lavages, are invasive and therefore not suitable for routine use in children. As a consequence, there is a continuous search for non-invasive alternatives (Figure 1.2).

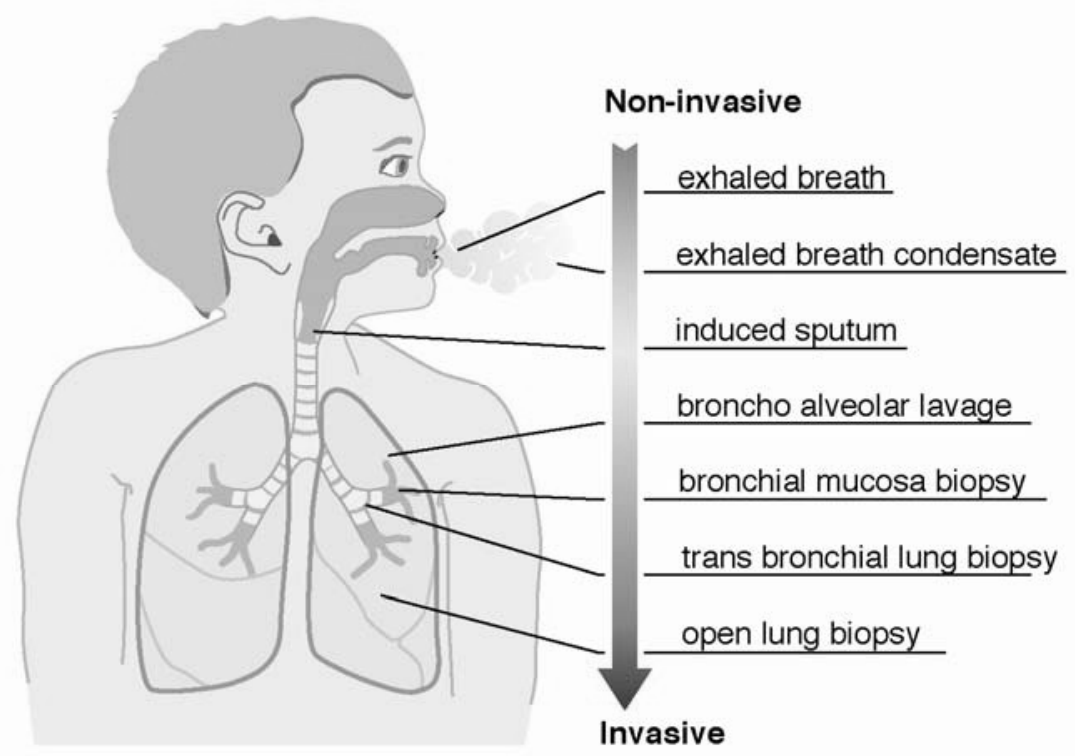

Figure 1.2 Techniques to assess airway inflammation.

The various methods to measure airway inflammation, ranging from completely non-invasive (exhaled breath) to very invasive (open lung biopsy). 


\section{Non-invasive techniques}

One of the non-invasive techniques that receives increasing interest, is the analysis of inflammatory markers in exhaled breath. Promising findings of research performed in the 1990s stimulated ever more research groups to explore the potential use of exhaled compounds in the diagnosis and monitoring of various pulmonary diseases. One of the most appealing aspects of exhaled inflammatory markers is the simple, safe and non-invasive character of assessment. Next to exhaled inflammatory markers, lung function techniques that are feasible to use in preschool children were developed.

\section{Exhaled Nitric Oxide}

Of all exhaled biomarkers, Nitric Oxide is most extensively studied. Nitric Oxide is produced by Nitric Oxide Synthase (NOS) in resident cells such as epithelial and endothelial airway cells. ${ }^{29}$ It plays an important role in the regulation of pulmonary function and circulation by e.g. smooth muscle relaxation and vasodilatation. Levels of Fractional exhaled Nitric Oxide (FeNO) are increased in children with asthma, especially during acute exacerbations. ${ }^{29,30}$ In concordance, elevated FeNO levels were found in preschool children with recurrent wheeze compared to healthy controls. ${ }^{31,32}$ FeNO is considered a non-invasive marker of eosinophilic airway inflammation as it correlates with eosinophilia in induced sputum and decreases with ICS treatment. ${ }^{29}$ Off-line collected FeNO measurements can be applied in young children and international guidelines for the measurement of FeNO in adults and children are available. ${ }^{33}$ Despite the initial enthusiasm about FeNO as diagnostic and monitoring tool in childhood asthma, limitations of FeNO emerged. Various studies demonstrated limit benefit of FeNO when used as additional parameter to guide anti-inflammatory treatment in children with asthma. ${ }^{34,35}$ Moreover, the use of FeNO as inflammatory marker may not be sufficient when studying the broad range of preschool wheeze as other inflammatory pathways, such as neutrophilic airway inflammation, are believed to play an important role. Consequently, the search for additional exhaled inflammatory markers in preschool wheeze needs to continue.

\section{Exhaled Volatile Organic Compounds}

Next to FeNO other volatile compounds, so called Volatile Organic Compounds (VOCs), can be studied in exhaled breath. VOCs are an assorted group of carbon-based chemicals that are volatile at room temperature and are formed during several (patho)physiological processes, such as airway inflammation. ${ }^{36,37}$ An important group of VOCs are hydrocarbons. During inflammatory processes, Reactive Oxygen Species (ROS) are produced. These ROS react with lipids in cell membranes leading to lipid peroxidation and degradation of the membrane. Hydrocarbons are the stable breakdown products of this lipid peroxidation. ${ }^{36,37}$ Once VOCs are formed, they enter the bloodstream and are excreted into the breath. 
As VOCs are formed during inflammatory processes, assessment of exhaled VOCs is believed to be a potential non-invasive method to directly measure airway inflammation. There are various techniques to collect, detect, and analyse exhaled VOCs. The most commonly used techniques are gas-chromatography and the electronic nose (eNose). Promising findings demonstrated that VOCs profiles could accurately differentiate children with asthma and cystic fibrosis from controls. ${ }^{38-40}$ However, no reports were published on the feasibility and use of VOCs in preschool children with wheezing symptoms.

\section{Exhaled Breath Condensate}

Next to volatile compounds in exhaled breath, the study of non-volatile compounds in Exhaled Breath Condensate (EBC) gained popularity. EBC is formed when exhaled breath is cooled in a condenser system. Although the formed EBC droplets mainly consist of water vapour, a small fraction consists of non-volatile molecules. These molecules are hypothesised to originate from the epithelial lining fluid of the airways. ${ }^{41}$ The turbulence in the airways during respiration is believed to lead to the release of small aerosols of the epithelial lining fluid. ${ }^{42}$ Aberrant composition of aerosols detected in EBC may well reflect changes in epithelial lining fluid and therefore might serve as proxy measure of airway inflammation. Indeed, elevated levels of various inflammatory molecules in EBC (including 8-isoprostane, cytokines, chemokines, leukotriens and adhesion molecules) were found in children with asthma compared to controls. ${ }^{43-46}$ Although it is known that EBC collection is a safe and simple procedure in adults and school children, data about the feasibility and use of EBC collection in wheezing preschool children are scarce. A limited number of groups (including our group) demonstrated that both nasally and orally EBC collection is possible in sedated and non-sedated infants. ${ }^{47-51}$ Our research group was able to improve the collection of $E B C$ in young children by using a closed-glass condenser with breath recirculation. ${ }^{51}$ These initial findings pave the way to further explore the use of EBC markers in wheezing illness.

\section{Early lung function techniques}

Measurement of lung function plays an important role in clinical assessment and disease management in older children with respiratory symptoms. However, lung function tests used in clinical practice are limited by age, as forced breathing manoeuvres are required. The development of tidal-breathing methods in the last decade made the assessment of lung function in preschool children possible. Promising lung function techniques that can easily be applied in young children are measurements of airway resistance using the interrupter resistance technique (Rint) or Forced Oscillation Technique (FOT). ${ }^{52-55}$ These techniques are performed during tidal breathing thereby requiring only minimal cooperation and demonstrate acceptable reproducibility. ${ }^{53,56,57}$ Elevated airway resistance levels were found in children with 
persistent wheezing symptoms compared to children with transient wheeze. ${ }^{52,54}$ Although an international taskforce developed recommendations for measuring lung function in preschool children, most techniques are still predominantly applied in a research setting and not in clinical practice as their additional clinical value is not established yet. $^{58}$

\section{Objectives and outline of this thesis}

As explained in the previous paragraphs, respiratory symptoms, such as wheeze, are common in preschool children. Preschool wheeze is a complex and heterogeneous symptom that is accompanied by clinical and scientific challenges. An important clinical challenge is to distinct 'transient wheezers' from 'persistent wheezers' already at preschool age. As a consequence, proper treatment decisions in young children with wheezing symptoms are difficult to make. A scientific gap exists between the limited information about the underlying pathophysiological mechanisms of preschool wheeze and the (non-invasive) techniques to evaluate airway inflammation in preschool children. Non-invasive measurements of inflammatory markers in exhaled breath are increasingly proposed as potential useful diagnostic and monitoring tools in adults and school children with various lung diseases. Whether this also applies to wheezing preschool children is hardly studied. The main objective of this thesis is to assess whether exhaled inflammatory markers and early lung function measurements can help to assess inflammatory pathways, response to treatment and wheezing phenotypes in preschool children.

The research described in this thesis is based on the first three years of the ADEM study (Asthma DEtection and Monitoring study). The ADEM study is a case-control study that started in 2006 in the province of Limburg, the Netherlands. The primary objective of the ADEM study is to develop a non-invasive instrument for an early and reliable asthma diagnosis by using exhaled inflammatory biomarkers and early lung function measurements. In chapter 2 the study protocol of the ADEM study is described.

In chapter $\mathbf{3}$ we study the feasibility of EBC measurements in preschool children. Moreover, we assess whether FeNO levels, inflammatory markers in EBC, and airway resistance are associated with recurrent wheeze in preschool children.

The analysis of VOCs in exhaled breath has not been performed in preschool children yet. However, VOCs profiling has been successfully applied in the diagnosis of different lung diseases, such as lung cancer, ${ }^{59}$ cystic fibrosis, ${ }^{38}$ asthma, ${ }^{40}$ and chronic obstructive pulmonary disease. ${ }^{60,61}$ In chapter 4 we review the current knowledge on VOCs with respect to their potential clinical use in pulmonary diseases. Potential clinical 
applications, limitations and considerations regarding VOCs in the field of pulmonary diseases in both adults and children are discussed.

In chapter 5, the first proof of principle study regarding the feasibility of exhaled VOCs measurements in preschool children is described. Moreover, in this chapter the potential of a VOCs profile to differentiate between preschool children with and without wheezing symptoms is discussed.

In chapter 6 we evaluate the relation between EBC markers, presence of bacteria and $\mathrm{T}_{\text {reg }}$ cells in preschool children with and without wheezing symptoms.

The potential clinical use of inflammatory markers in preschool wheeze is discussed in chapter 7. In this chapter we investigate whether EBC markers can predict a steroid response in preschool wheezing children.

In chapter 8, we prospectively define whether inflammatory markers in EBC and airway resistance assessed at preschool age, are associated with wheezing phenotypes at the age of five years.

Finally, in chapter 9 we provide a general discussion on the main findings of this thesis and recommendations for future studies. 


\section{References}

1. Bisgaard H, Szefler S. Prevalence of asthma-like symptoms in young children. Pediatr Pulmonol 2007;42:723-8.

2. Taussig LM, Wright AL, Holberg CJ, Halonen M, Morgan WJ, Martinez FD. Tucson Children's Respiratory Study: 1980 to present. J Allergy Clin Immunol 2003;111:661-75.

3. Spycher BD, Silverman M, Kuehni CE. Phenotypes of childhood asthma: are they real? Clin Exp Allergy 2010;40:1130-41.

4. Henderson J, Granell R, Sterne J. The search for new asthma phenotypes. Arch Dis Child 2009;94: 333-6.

5. Martinez FD, Wright AL, Taussig LM, Holberg CJ, Halonen M, Morgan WJ. Asthma and wheezing in the first six years of life. The Group Health Medical Associates. N Engl J Med 1995;332:133-8.

6. Brand PL, Baraldi E, Bisgaard H, Boner AL, Castro-Rodriguez JA, Custovic A, de Blic J, de Jongste JC, Eber E, Everard ML, Frey U, Gappa M, Garcia-Marcos L, Grigg J, Lenney W, Le Souef P, McKenzie S, Merkus PJ, Midulla F, Paton JY, Piacentini G, Pohunek P, Rossi GA, Seddon P, Silverman M, Sly PD, Stick S, Valiulis A, van Aalderen WM, Wildhaber JH, Wennergren G, Wilson N, Zivkovic Z, Bush A. Definition, assessment and treatment of wheezing disorders in preschool children: an evidence-based approach. Eur Respir J 2008;32:1096-110.

7. Schultz A, Brand PL. Episodic Viral Wheeze and Multiple Trigger Wheeze in preschool children: A useful distinction for clinicians? Paediatr Respir Rev 2011;12:160-4.

8. Schultz A, Devadason SG, Savenije OE, Sly PD, Le Souef PN, Brand PL. The transient value of classifying preschool wheeze into episodic viral wheeze and multiple trigger wheeze. Acta Paediatr 2010;99: 56-60.

9. Spycher BD, Silverman M, Brooke AM, Minder CE, Kuehni CE. Distinguishing phenotypes of childhood wheeze and cough using latent class analysis. Eur Respir J 2008;31:974-81.

10. Henderson J, Granell R, Heron J, Sherriff A, Simpson A, Woodcock A, Strachan DP, Shaheen SO, Sterne JA. Associations of wheezing phenotypes in the first 6 years of life with atopy, lung function and airway responsiveness in mid-childhood. Thorax 2008;63:974-80.

11. Smith JA, Drake R, Simpson A, Woodcock A, Pickles A, Custovic A. Dimensions of respiratory symptoms in preschool children: population-based birth cohort study. Am J Respir Crit Care Med 2008;177: 1358-63.

12. Savenije OE, Granell R, Caudri D, Koppelman GH, Smit HA, Wijga A, de Jongste JC, Brunekreef B, Sterne JA, Postma DS, Henderson J, Kerkhof M. Comparison of childhood wheezing phenotypes in 2 birth cohorts: ALSPAC and PIAMA. J Allergy Clin Immunol 2011;127:1505-12.

13. Tregoning JS, Schwarze J. Respiratory viral infections in infants: causes, clinical symptoms, virology, and immunology. Clin Microbiol Rev 2010;23:74-98.

14. Silvestri M, Sabatini F, Defilippi AC, Rossi GA. The wheezy infant -- immunological and molecular considerations. Paediatr Respir Rev 2004;5 Suppl A:S81-7.

15. Bisgaard H, Hermansen MN, Bonnelykke K, Stokholm J, Baty F, Skytt NL, Aniscenko J, Kebadze T, Johnston SL. Association of bacteria and viruses with wheezy episodes in young children: prospective birth cohort study. BMJ 2010;341:c4978.

16. Marguet C, Jouen-Boedes F, Dean TP, Warner JO. Bronchoalveolar cell profiles in children with asthma, infantile wheeze, chronic cough, or cystic fibrosis. Am J Respir Crit Care Med 1999;159:1533-40.

17. Lowe LA, Simpson A, Woodcock A, Morris J, Murray CS, Custovic A. Wheeze phenotypes and lung function in preschool children. Am J Respir Crit Care Med 2005;171:231-7.

18. Gelfand EW. Pediatric asthma: a different disease. Proc Am Thorac Soc 2009;6:278-82.

19. Illi S, von Mutius E, Lau S, Niggemann B, Gruber C, Wahn U. Perennial allergen sensitisation early in life and chronic asthma in children: a birth cohort study. Lancet 2006;368:763-70.

20. Damoiseaux J. Regulatory T cells: back to the future. Neth J Med 2006;64:4-9.

21. Lloyd CM, Hawrylowicz CM. Regulatory T cells in asthma. Immunity 2009;31:438-49.

22. Xystrakis $\mathrm{E}$, Boswell $\mathrm{SE}$, Hawrylowicz $\mathrm{CM}$. T regulatory cells and the control of allergic disease. Expert Opin Biol Ther 2006;6:121-33. 
23. Borrego LM, Arroz MJ, Videira P, Martins C, Guimaraes H, Nunes G, Papoila AL, Trindade H. Regulatory cells, cytokine pattern and clinical risk factors for asthma in infants and young children with recurrent wheeze. Clin Exp Allergy 2009;39:1160-9.

24. Drews AC, Pizzichini MM, Pizzichini E, Pereira MU, Pitrez PM, Jones MH, Sly PD, Stein RT. Neutrophilic airway inflammation is a main feature of induced sputum in nonatopic asthmatic children. Allergy 2009;64:1597-601.

25. Castro-Rodriguez JA, Rodrigo GJ. Efficacy of inhaled corticosteroids in infants and preschoolers with recurrent wheezing and asthma: a systematic review with meta-analysis. Pediatrics 2009;123: e519-25.

26. Bisgaard H, Hermansen MN, Loland L, Halkjaer LB, Buchvald F. Intermittent inhaled corticosteroids in infants with episodic wheezing. N Engl J Med 2006;354:1998-2005.

27. Bacharier LB, Phillips BR, Zeiger RS, Szefler SJ, Martinez FD, Lemanske RF, Sorkness CA, Bloomberg GR, Morgan WJ, Paul IM, Guilbert T, Krawiec M, Covar R, Larsen G, Mellon M, Moss MH, Chinchilli VM, Taussig LM, Strunk RC. Episodic use of an inhaled corticosteroid or leukotriene receptor antagonist in preschool children with moderate-to-severe intermittent wheezing. J Allergy Clin Immunol 2008;122: 1127-35.

28. Castro-Rodriguez JA. The Asthma Predictive Index: a very useful tool for predicting asthma in young children. J Allergy Clin Immunol 2010;126:212-6.

29. Barnes PJ, Dweik RA, Gelb AF, Gibson PG, George SC, Grasemann H, Pavord ID, Ratjen F, Silkoff PE, Taylor DR, Zamel N. Exhaled nitric oxide in pulmonary diseases: a comprehensive review. Chest 2010;138:682-92.

30. Pijnenburg MW, de Jongste JC. Exhaled nitric oxide in childhood asthma: a review. Clin Exp Allergy 2008;38:246-59.

31. Gabriele C, Nieuwhof EM, van der Wiel EC, Hofhuis W, Moll HA, Merkus PJ, de Jongste JC. Exhaled nitric oxide differentiates airway diseases in the first two years of life. Pediatr Res 2006;60:461-5.

32. Baraldi E, Dario C, Ongaro R, Scollo M, Azzolin NM, Panza N, Paganini N, Zacchello F. Exhaled nitric oxide concentrations during treatment of wheezing exacerbation in infants and young children. Am J Respir Crit Care Med 1999;159:1284-8.

33. ATS/ERS Recommendations for Standardized Procedures for the Online and Offline Measurement of Exhaled Lower Respiratory Nitric Oxide and Nasal Nitric Oxide, 2005. Am J Respir Crit Care Med 2005;171:912-30.

34. Szefler SJ, Mitchell H, Sorkness CA, Gergen PJ, O'Connor GT, Morgan WJ, Kattan M, Pongracic JA, Teach SJ, Bloomberg GR, Eggleston PA, Gruchalla RS, Kercsmar CM, Liu AH, Wildfire JJ, Curry MD, Busse WW. Management of asthma based on exhaled nitric oxide in addition to guideline-based treatment for inner-city adolescents and young adults: a randomised controlled trial. Lancet 2008;372:1065-72.

35. de Jongste JC, Carraro S, Hop WC, Baraldi E. Daily telemonitoring of exhaled nitric oxide and symptoms in the treatment of childhood asthma. Am J Respir Crit Care Med 2009;179:93-7.

36. Buszewski B, Kesy M, Ligor T, Amann A. Human exhaled air analytics: biomarkers of diseases. Biomed Chromatogr 2007;21:553-66.

37. Miekisch W, Schubert JK, Noeldge-Schomburg GF. Diagnostic potential of breath analysis--focus on volatile organic compounds. Clin Chim Acta 2004;347:25-39.

38. Robroeks CM, van Berkel JJ, Dallinga JW, Jöbsis Q, Zimmermann L, Hendriks HJ, Wouters MF, van der Grinten CP, van de Kant KD, van Schooten FJ, Dompeling E. Metabolomics Of Volatile Organic Compounds In Cystic Fibrosis Patients and Controls. Pediatr Res 2010;68:75-80.

39. Barker M, Hengst M, Schmid J, Buers HJ, Mittermaier B, Klemp D, Koppmann R. Volatile organic compounds in the exhaled breath of young patients with cystic fibrosis. Eur Respir J 2006;27:929-36.

40. Dallinga JW, Robroeks CM, van Berkel JJ, Moonen EJ, Godschalk RW, Jöbsis Q, Dompeling E, Wouters $\mathrm{EF}$, van Schooten FJ. Volatile organic compounds in exhaled breath as a diagnostic tool for asthma in children. Clin Exp Allergy 2010;40:68-76.

41. Hunt J. Exhaled breath condensate: an evolving tool for noninvasive evaluation of lung disease. J Allergy Clin Immunol 2002;110:28-34.

42. Effros RM, Hoagland KW, Bosbous M, Castillo D, Foss B, Dunning M, Gare M, Lin W, Sun F. Dilution of respiratory solutes in exhaled condensates. Am J Respir Crit Care Med 2002;165:663-9. 
43. Robroeks CM, Rijkers GT, Jöbsis Q, Hendriks HJ, Damoiseaux JG, Zimmermann LJ, van Schayck OP, Dompeling E. Increased cytokines, chemokines and soluble adhesion molecules in exhaled breath condensate of asthmatic children. Clin Exp Allergy 2010;40:77-84.

44. Zanconato S, Carraro S, Corradi M, Alinovi R, Pasquale MF, Piacentini G, Zacchello F, Baraldi E. Leukotrienes and 8-isoprostane in exhaled breath condensate of children with stable and unstable asthma. J Allergy Clin Immunol 2004;113:257-63.

45. Brunetti L, Francavilla R, Tesse R, Fiermonte P, Fiore FP, Lore M, Margiotta M, Armenio L. Exhaled breath condensate cytokines and $\mathrm{pH}$ in pediatric asthma and atopic dermatitis. Allergy Asthma Proc 2008;29:461-7.

46. Shahid SK, Kharitonov SA, Wilson NM, Bush A, Barnes PJ. Exhaled 8-isoprostane in childhood asthma. Respir Res 2005;6:79.

47. Moeller A, Franklin P, Hall GL, Horak F, Jr., Wildhaber JH, Stick SM. Measuring exhaled breath condensates in infants. Pediatr Pulmonol 2006;41:184-7.

48. Walsh BK, Mackey DJ, Pajewski T, Yu Y, Gaston BM, Hunt JF. Exhaled-breath condensate pH can be safely and continuously monitored in mechanically ventilated patients. Respir Care 2006;51: 1125-31.

49. Vogelberg C, Wurfel C, Knoetzsch A, Kahlert A, Range U, Leupold W. Exhaled breath condensate $\mathrm{pH}$ in infants and children with acute and recurrent wheezy bronchitis. Pediatr Pulmonol 2007;42: 1166-72.

50. Bloemen K, Koppen G, Govarts E, Colles A, van den Heuvel R, Nelen V, Witters E, Desager K, Schoeters G. Application of non-invasive biomarkers in a birth cohort follow-up in relation to respiratory health outcome. Biomarkers 2010;15:583-93.

51. Rosias PP, Robroeks CM, van de Kant KD, Rijkers GT, Zimmermann LJ, van Schayck CP, Heynens JW, Jöbsis $Q$, Dompeling E. Feasibility of a new method to collect exhaled breath condensate in pre-school children. Pediatr Allergy Immunol 2010;21:e235-44.

52. Oostveen E, Dom S, Desager K, Hagendorens M, de Backer W, Weyler J. Lung function and bronchodilator response in 4-year-old children with different wheezing phenotypes. Eur Respir J 2010;35:865-72.

53. Merkus PJ, Stocks J, Beydon N, Lombardi E, Jones M, McKenzie SA, Kivastik J, Arets BG, Stanojevic S. Reference ranges for interrupter resistance technique: the asthma UK initiative. Eur Respir J 2010;36:157-63.

54. Brussee JE, Smit HA, Koopman LP, Wijga AH, Kerkhof M, Corver K, Vos AP, Gerritsen J, Grobbee DE, Brunekreef B, Merkus PJ, de Jongste JC. Interrupter resistance and wheezing phenotypes at 4 years of age. Am J Respir Crit Care Med 2004;169:209-13.

55. Kooi EM, Schokker S, van der Molen T, Duiverman EJ. Airway resistance measurements in pre-school children with asthmatic symptoms: the interrupter technique. Respir Med 2006;100:955-64.

56. Merkus PJ, Mijnsbergen JY, Hop WC, de Jongste JC. Interrupter resistance in preschool children: measurement characteristics and reference values. Am J Respir Crit Care Med 2001;163:1350-5.

57. Oostveen E, MacLeod D, Lorino H, Farre R, Hantos Z, Desager K, Marchal F. The forced oscillation technique in clinical practice: methodology, recommendations and future developments. Eur Respir J 2003;22:1026-41.

58. Beydon N, Davis SD, Lombardi E, Allen JL, Arets HG, Aurora P, Bisgaard H, Davis GM, Ducharme FM, Eigen H, Gappa M, Gaultier C, Gustafsson PM, Hall GL, Hantos Z, Healy MJ, Jones MH, Klug B, Lodrup Carlsen KC, McKenzie SA, Marchal F, Mayer OH, Merkus PJ, Morris MG, Oostveen E, Pillow JJ, Seddon PC, Silverman M, Sly PD, Stocks J, Tepper RS, Vilozni D, Wilson NM. An official American Thoracic Society/European Respiratory Society statement: pulmonary function testing in preschool children. Am J Respir Crit Care Med 2007;175:1304-45.

59. Dragonieri S, Annema JT, Schot R, van der Schee MP, Spanevello A, Carratu P, Resta O, Rabe KF, Sterk PJ. An electronic nose in the discrimination of patients with non-small cell lung cancer and COPD. Lung Cancer 2009;64:166-70.

60. Fens N, Zwinderman AH, van der Schee MP, de Nijs SB, Dijkers E, Roldaan AC, Cheung D, Bel EH, Sterk PJ. Exhaled Breath Profiling Enables Discrimination of Chronic Obstructive Pulmonary Disease and Asthma. Am J Respir Crit Care Med 2009;180:1076-82.

61. van Berkel JJ, Dallinga JW, Moller GM, Godschalk RW, Moonen EJ, Wouters EF, van Schooten FJ. A profile of volatile organic compounds in breath discriminates COPD patients from controls. Respir Med 2010;104:557-63. 



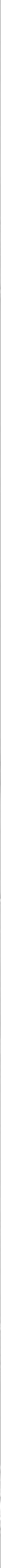




\section{Chapter 2}
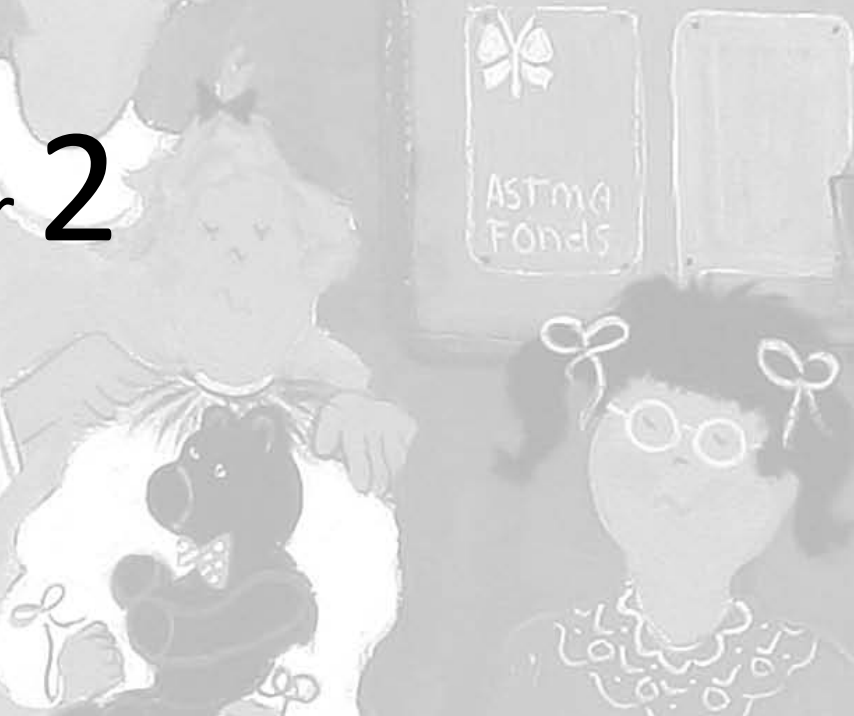

Early diagnosis of asthma in young children by using non-invasive biomarkers of airway inflammation and early lung function measurements: study protocol of a case-control study

van de Kant KDG, Klaassen EMM, Jöbsis Q, Nijhuis AJ, van Schayck CP, Dompeling E BMC Public Health 2009;9:210

*This chapter describes the study protocol of the ADEM study (Asthma DEtection and Monitoring study). The research described in this thesis is based on the first three years of the ADEM study. 


\section{Abstract}

\section{Background}

Asthma is the most common chronic disease in childhood, characterised by chronic airway inflammation. There are problems with the diagnosis of asthma in young children since the majority of the children with recurrent asthma-like symptoms is symptom free at six years, and does not have asthma. With the conventional diagnostic tools it is not possible to differentiate between preschool children with transient symptoms and children with asthma. The analysis of biomarkers of airway inflammation in exhaled breath is a non-invasive and promising technique to diagnose asthma and monitor inflammation in young children. Moreover, relatively new lung function tests (airway resistance using the interrupter technique) have become available for young children. The primary objective of the ADEM study (Asthma DEtection and Monitoring study) is to develop a non-invasive instrument for an early asthma diagnosis in young children, using exhaled inflammatory markers and early lung function measurements. In addition, aetiological factors, including gene polymorphisms and gene expression, in relation to the development of asthma are studied.

\section{Methods / design}

A case-control study is started in 202 children with recurrent respiratory symptoms and 50 control subjects without respiratory symptoms. At six years, a definite diagnosis of asthma is made (primary outcome measure) on basis of lung function assessments and current respiratory symptoms ('gold standard'). From inclusion until the definite asthma diagnosis, repeated measurements of lung function tests and inflammatory markers in exhaled breath (condensate), blood and faeces are performed. The study is registered and ethically approved.

\section{Discussion}

This manuscript describes the study protocol of the ADEM study. The new diagnostic techniques applied in this study could make an early diagnosis of asthma possible. An early and reliable asthma diagnosis at two and three years will have consequences for the management of the large group of young children with asthma-like symptoms. It will avoid both over-treatment of children with transient wheeze and under-treatment of children with asthma. This might have a beneficial influence on the prognosis of asthma in these young children. Besides, insight into the pathophysiology and aetiology of asthma will be obtained. 


\section{Background}

Asthma is one of the major chronic health problems in children. Worldwide, approximately $30 \%$ of all young children have at least one episode of asthmatic symptoms like wheezing, coughing, and dyspnoea. ${ }^{1,2}$ Although asthmatic symptoms are common in preschool children, only $30 \%$ will have asthma at the age of six years and over. The rest of the children with recurrent respiratory symptoms is symptomfree at six years and does not have asthma but transient, viral associated wheeze. ${ }^{1,3,4} \mathrm{~A}$ reliable diagnosis of asthma in young children is difficult. With the conventional diagnostic measures it is currently not possible to discriminate between 'true asthmatics' and children with 'transient wheezing' in association with frequent viral infections. An early asthma diagnosis is important for the proper treatment of young children with respiratory symptoms. An effective therapy of asthma by means of antiinflammatory treatment with inhaled corticosteroids (ICS) is available. This treatment has a beneficial influence on airway inflammation, respiratory symptoms, asthma exacerbations, quality of life, and lung function. ${ }^{5}$ Probably, ICS are not very effective in children with transient wheezing, which may cause unnecessary treatment with preventable costs and side-effects. ${ }^{6,7}$ Therefore, an early diagnosis will prevent overtreatment of transient wheezers and under-treatment of true asthmatics, and will improve asthma control.

\section{Measuring inflammation}

Although chronic airway inflammation is the most common feature in asthma, measurement of inflammation plays a small role in the diagnosis and monitoring of asthma. Currently, the 'gold standard' to measure airway inflammation is bronchoscopy with biopsy and/or bronchoalveolar lavage. However, this is far too invasive for routine use in (young) children. Since a non-invasive method to measure inflammation is lacking, diagnosis and management of asthma in young children are currently based on subjective clinical features and medical examination. Therefore, there is an increasing interest in non-invasive techniques to assess inflammation, especially in children.

\section{Inflammatory biomarkers in exhaled breath (condensate)}

The last decade, non-invasive techniques are developed to assess inflammation in the airways. One of these new techniques is assessment of inflammatory biomarkers in exhaled breath. This technique is currently possible in children, and is promising for an early asthma diagnosis and monitoring of the disease. ${ }^{8-10}$ The most studied marker in exhaled breath is Nitric Oxide. Elevated levels of Fractional exhaled Nitric Oxide (FeNO) are found in both adults and children with asthma, as a consequence of up-regulation of the enzyme iNOS. ${ }^{9}$ In addition to FeNO, other gases can be measured in exhaled breath including Volatile Organic Compounds (VOCs). Inflammation in the airways 
gives rise to Reactive Oxygen Species (ROS) that can degradate cell membranes through peroxidation of lipids. ${ }^{11,12}$ Due to degradation of cell membranes, VOCs, such as alkanes, alkane derivates, and aldehydes are formed. Increased levels of alkanes (such as ethane and pentane), and aldehydes are described in exhaled breath during (exacerbations of) asthma. ${ }^{13-15}$ Besides gases in exhaled breath, non-volatile compounds in Exhaled Breath Condensate (EBC) can be measured in children. ${ }^{10,16-19}$ $E B C$ is collected by cooling exhaled breath in a condenser. During this non-invasive procedure, small droplets of breath condensate are formed. Besides water vapour, droplets consist of aerosol particles that are released from the epithelial lining fluid of the airways. They contain non-volatile inflammatory markers, and there is evidence that abnormalities in condensate composition reflect biochemical changes of the epithelial lining fluid. ${ }^{20}$ In EBC, inflammatory markers, such as cytokines, chemokines and adhesion molecules, can be measured. Increased concentrations of various markers in EBC were found in patients with asthma. ${ }^{10,16-18,21}$

\section{Early lung function measurements}

In the past ten years new lung function techniques became available in young children. Techniques to evaluate airway resistance such as the interrupter technique (Rint), impulse oscillation, and forced oscillation technique are increasingly applied in young children. ${ }^{22-24}$ In contrast to the forced expiration manoeuvres, these measurements are performed during tidal breathing. The measurements are possible in children of one year and over. However, feasibility increases with age. ${ }^{22}$ These techniques are used in children with asthma to assess baseline airway resistance, reversibility on bronchodilators, bronchial hyperresponsiveness, and responses to ICS.

\section{Response to inhaled corticosteroid treatment}

A good responsiveness to ICS is a hallmark of asthma. ${ }^{25}$ This response might discriminate between asthmatic and non-asthmatic children. Several international guidelines advocate a trial of ICS in preschool children with recurrent wheeze. However, the diagnostic value of the response to ICS for asthma is not clear in these children.

\section{Regulatory T-cells}

The inflammatory response in asthma is highly complex in which many inflammatory cells are involved. T-helper (Th) cells play a central role in the inflammatory response in asthma, and can be roughly divided in the pro-inflammatory Th2 cells and antiinflammatory Th1 cells. ${ }^{26-29}$ Regulatory $T\left(T_{\text {reg }}\right)$ cells inhibit both Th1 and Th2 cells resulting in a balance of the immune system. An imbalance between Th2 and Th1 cells occurs in asthma with an increase of Th2, and a decrease of Th1 cells. ${ }^{26,27}$ This imbalance might be due to a decrease in number or function of $\mathrm{T}_{\text {reg }}$ cells. ${ }^{28,29}$ 


\section{Genetic background}

Asthma has a multifactorial aetiology in which genetic factors, environmental influences, and their interaction play an important role. Over the last two decades the genetic background of asthma has become increasingly clear through twin studies, and studies in subjects with a family history of atopy and asthma. Around 30 to 100 genes are involved in asthma. ${ }^{30,31}$ Although a lot of progress has been made in the field of asthma genetics, the influence of many candidate genes in relation to asthma susceptibility in young children needs to be further defined. Gene polymorphism in the coding sequences of genes may affect the function of a protein. Polymorphisms in the regulatory and promoter sequences of genes may influence the expression characteristics of a gene, making gene expression an important area in asthma research. Linking specific genetic polymorphisms and gene expression to wheezing phenotypes in children and to inflammatory levels in EBC and lung function indices can lead to a better understanding of the early pathogenesis of asthma in young children (Figure 2.1). Subsequently, this will identify children with enhanced risk.

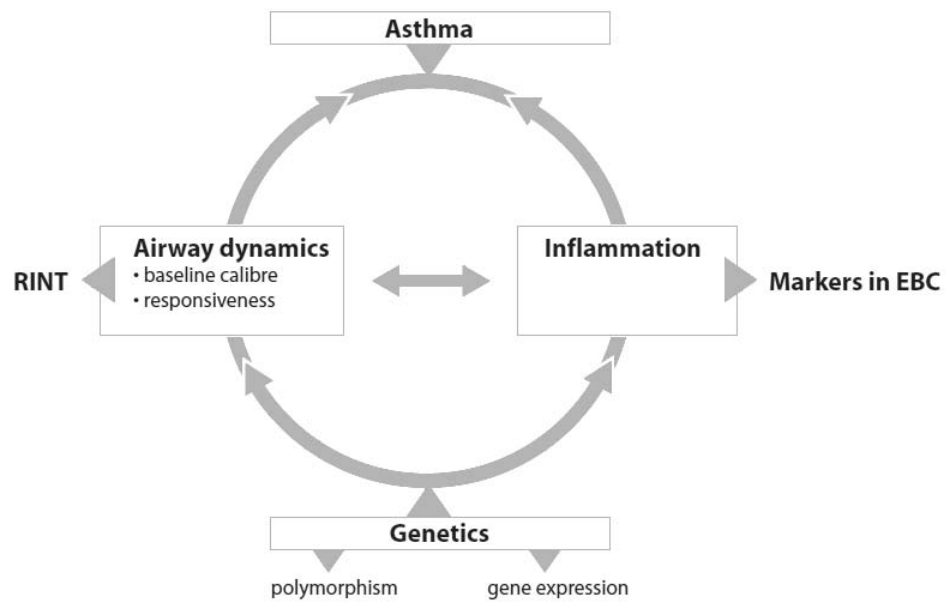

Figure 2.1 Relation between genetic background and pathophysiology in asthma.

Central features in the pathophysiology of asthma are chronic airway inflammation and airway (hyper) responsiveness. These features can be measured by markers in Exhaled Breath Condensate $(E B C)$ and Rint, respectively, and are influenced by genetic factors.

\section{Environmental factors in relation to asthma}

The hygiene hypothesis suggests a relation between exposure to microbes in early childhood and the development of allergies and asthma. According to this hypothesis, infections protect against asthma. ${ }^{32,33}$ However, this is not in line with increasing evidence that certain infections might also promote asthma development. ${ }^{33} \mathrm{~A}$ unifying 
concept is still lacking, and the precise relationship between infections and the development of asthma is not clear.

\section{Hypothesis}

The primary hypothesis of the ADEM study (Asthma DEtection and Monitoring study), is that an early asthma diagnosis is possible by using non-invasive measurements of biomarkers of airway inflammation and oxidative stress in exhaled breath (condensate), and early lung function measurements (airway resistance). Besides, this study tests the hypothesis that certain gene polymorphisms and gene expressions, early infections, and $\mathrm{T}_{\text {reg }}$ cells in blood are related to the development of asthma.

\section{Aim and research questions}

The primary aim of the study is to develop a non-invasive instrument for an early asthma diagnosis in young children. Besides, aetiological factors (such as $T_{\text {reg }}$ cells, gene polymorphisms, gene expression and infections at early age) are studied in relation to the early development of asthma.

\section{The primary research question is:}

Which non-invasive inflammatory biomarkers in exhaled breath (condensate) or early lung function indices (pre- and post-bronchodilator airway resistance) can reliably predict asthma at an early age?

\section{The secondary research questions are:}

1. What are the differences in inflammatory biomarkers and lung function indices between asthmatic and non-asthmatic children?

2. Which of the selected gene polymorphism and/or gene expression are related to asthma susceptibility in young children?

3. Is early colonisation of the airways and intestines related to the development of asthma?

4. What are the differences in number of $\mathrm{T}_{\text {reg }}$ cells between asthmatic and nonasthmatic children?

5. What is the relation between gene coding and gene expression of inflammatory markers (e.g. genes coding for Interleukin (IL)-4, IL-13 and Tumour Necrosis Factor$\alpha(T N F-\alpha)$ ), levels of inflammatory markers in EBC, and lung function indices during the development of asthma in young children?

To answer these research questions, markers in different media are measured (Table 2.1). 
Table $2.1 \quad$ Overview of measurements per visit.

\begin{tabular}{|c|c|c|c|c|c|c|}
\hline Media/Method & Marker & ED I & ED II & ED III & $\begin{array}{l}\text { Follow- } \\
\text { up }\end{array}$ & $\begin{array}{l}\text { Definite } \\
\text { diagnosis }\end{array}$ \\
\hline Exhaled breath & $\begin{array}{l}\text { - Fractional exhaled Nitric Oxide } \\
\text { - Volatile Organic Compounds }\end{array}$ & - & - & - & - & $\bullet$ \\
\hline $\begin{array}{l}\text { Exhaled Breath } \\
\text { Condensate }\end{array}$ & $\begin{array}{l}\text { Cytokines: IL-1 } \alpha,-2,-4,-5,-10,-13 \text {, } \\
\text { IFN- } \gamma \text {, TNF- } \alpha \\
\text { - Chemokines: Eotaxin, Rantes, IL- } \\
8 \\
\text { - Adhesion molecules: sICAM } \\
\text { - Acidity }(p H)\end{array}$ & • & • & • & • & • \\
\hline Blood & $\begin{array}{l}\text { - Total Immunoglobulin E (IgE), } \\
\text { and specific IgE } \\
\text { - Regulatory T cells } \\
\text { - Gene polymorphism: e.g. in IL-4, } \\
\text { IL-13, TNF- } \alpha, A D A M 33 \\
\text { - Gene expression: e.g. in IL-4, IL- } \\
\text { 13, TNF- } \alpha \\
\text { - Anti bodies against: } \\
\text { Mycoplasma-, Chlamydia- } \\
\text { pneumoniae }\end{array}$ & $\begin{array}{l}\cdot \\
\bullet \\
\bullet \\
\bullet \\
\bullet\end{array}$ & & & & $\bullet$ \\
\hline Saliva & $\begin{array}{l}\text { - Colonisation: Streptococcus } \\
\text { pneumoniae, Haemophilus } \\
\text { (para)influenzae, } \\
\text { Staphylococcus aureus. }\end{array}$ & $\bullet$ & & & & - \\
\hline Faeces & $\begin{array}{l}\text { - Colonisation: E.Coli, Clostridium } \\
\text { difficile }\end{array}$ & $\bullet$ & & & & \\
\hline Lung function test & $\begin{array}{l}\text { - Airway resistance before and } \\
\text { after bronchodilator: Rint } \\
\text { - Dynamic spirometry before and } \\
\text { after bronchodilator: MEFV, } \\
\mathrm{FEV}_{1}, \mathrm{FVC}, \mathrm{MEF}_{50} \\
\text { - Histamine provocation test }\end{array}$ & $\bullet$ & $\bullet$ & $\bullet$ & $\bullet$ & - \\
\hline Questionnaire & $\begin{array}{l}\text { - Parental administrated } \\
\text { respiratory symptoms (ISAAC) } \\
\text { - Demographic factors: e.g. } \\
\text { smoking, pets. } \\
\text { - Parental administrated Quality } \\
\text { of life (FSII) }\end{array}$ & - & • & $\bullet$ & - & - \\
\hline
\end{tabular}

$\mathrm{ED} \mathrm{I/II/III} \mathrm{=} \mathrm{Consecutive} \mathrm{measurements} \mathrm{in} \mathrm{Early} \mathrm{Diagnosis} \mathrm{phase}$

\section{Methods / Design}

\section{Study design}

The study design is a long-term case-control study during four years. The study consists of four phases: 1) the selection phase; 2 ) the early diagnosis phase; 3 ) the follow-up phase; and 4) the definite diagnosis phase at six years (Figure 2.2). 


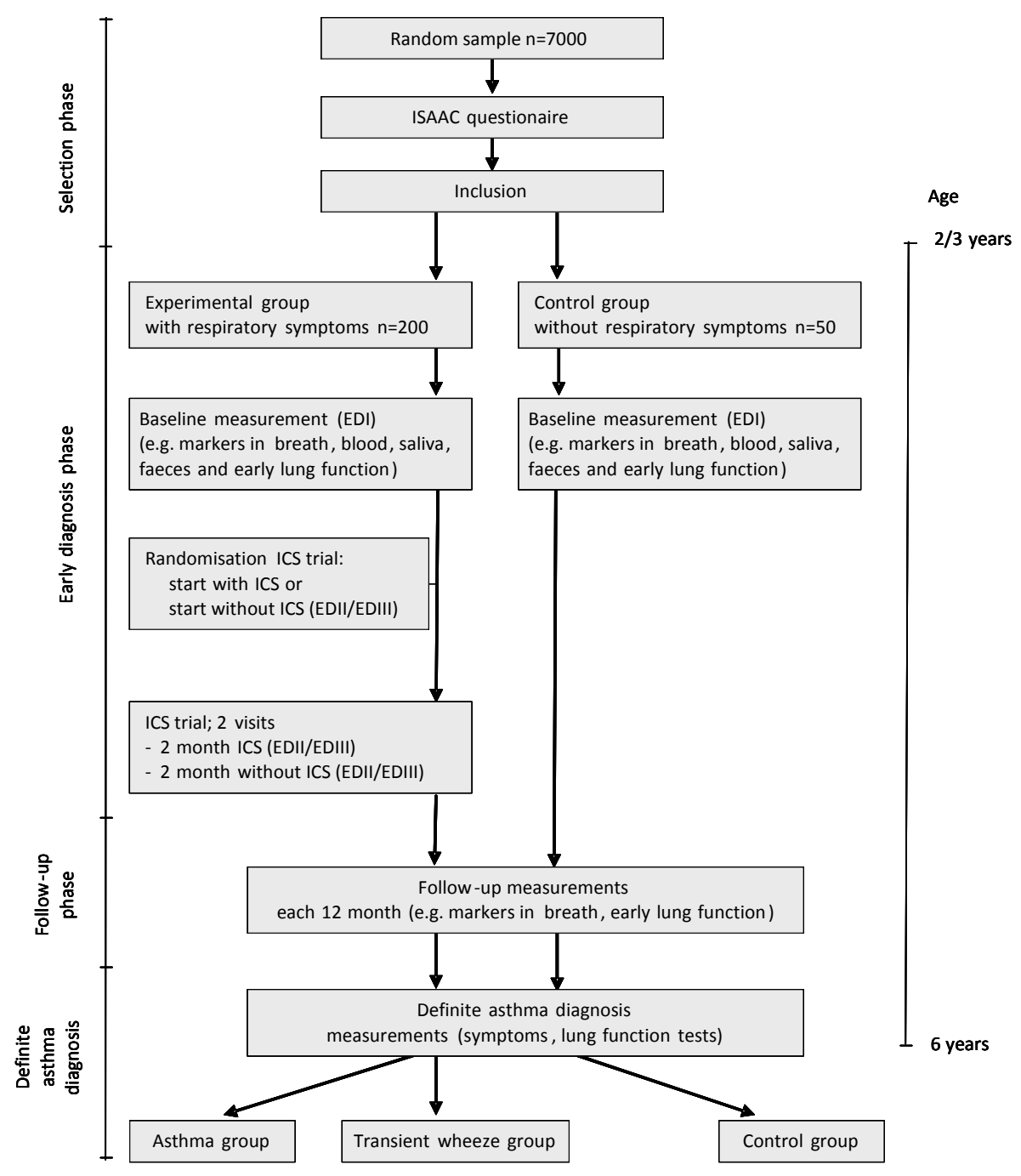

Figure 2.2 Study design

ED I/II/III=Consecutive measurements in Early Diagnosis phase; ICS=Inhaled corticosteroids.

In the selection phase, a random sample of children aged two and three years of primary care practice and of two cities in Limburg, the Netherlands, receives a standardised questionnaire on respiratory symptoms (ISAAC). ${ }^{34}$ From the results of this questionnaire, a group of 202 children with recurrent asthma-like symptoms (experimental group), and 50 children with no respiratory symptoms (control group) are selected. In the early diagnosis phase, a two-month trial with ICS is performed. In addition, repeated measurements of early predictors, like exhaled biomarkers of 
inflammation/oxidative stress, and lung function tests are assessed. During the followup phase, the development of respiratory symptoms, lung function indices, and inflammatory biomarkers are studied. At six years of age, a definite diagnosis of asthma is made, based on various lung function measurements and current respiratory symptoms ('gold standard'). At this stage, early measurements of (non-invasive) inflammatory biomarkers and lung function measurements are related to the final diagnosis of asthma in order to select the combination of biomarkers which can reliable assess asthma. The study design is described in more detail below.

\section{Selection phase}

Subjects are recruited from two sources. The first source consists of general practices from the Registration Network of Family Practices of the Maastricht University Medical Centre (MUMC). This department is used for other studies and has extensive research logistics, including 55 general practitioners and 110,000 patients. ${ }^{36}$ In addition, a community-based random sample of children aged two and three years is selected of two cities in Limburg (Maastricht and Heerlen).

Parents receive information about the study, along with the informed consent form. When parents are willing to participate with their child in the study, they are asked to fill in an internationally standardised questionnaire on respiratory symptoms (ISAAC). ${ }^{34}$ From the results of the ISAAC questionnaire, 202 children with recurrent respiratory symptoms (experimental group) and 50 with no respiratory symptoms (control group) are selected.

\section{Experimental group}

In total, 202 children aged two and three years with recurrent respiratory symptoms participate in the experimental group. The inclusion criterion for this group is that children experienced at least two episodes of wheeze during life, based on the parents-completed questionnaire. ${ }^{34}$ Exclusion criteria are mental retardation, cardiac anomalies, congenital malformations, other diseases of the lungs/airways, Crohn's disease or rheumatic arthritis, and the inability to perform lung function measurements or exhaled breath collection. The use of ICS is not an exclusion criterion. However, ICS are stopped at least four weeks before the start of the measurements.

\section{Control group}

In addition, 50 children aged two and three years without wheeze and other recurrent respiratory symptoms are selected, based on the parents-completed questionnaire. ${ }^{34}$ Exclusion criteria are similar as for the experimental group.

After written informed consent, children and parents are invited for a visit to the lung function laboratory. The lung function assistant and/or research physician further 
evaluates suitability for participation. A questionnaire on demographic data, medical history of the child, family history, day-care attendance, housing, prescribed drug therapy, exposure to pets, and passive smoking is completed.

\section{Early diagnosis phase}

In the early diagnosis phase, repeated measurements of early predictors, including lung function tests and markers of inflammation/oxidative stress in exhaled breath (condensate), blood and faeces are performed in both experimental and control group (Table 2.1).

Besides, a trial with ICS is part of the diagnosis phase for the children in the experimental group. This trial consists of a treatment period of two months with ICS therapy (Beclometasone extra fine two times 100 microgram a day via the Aerochamber ${ }^{\circledast}$ ), and a two-month period without ICS. Based on randomisation, half the children start with ICS, the other half starts the period without ICS. All other antiinflammatory medication is stopped. Clinical visits and measurements for the ICS trial occur at $\mathrm{t}=0,2$, and 4 months.

\section{Follow-up phase}

The purpose of the third phase is to monitor development of respiratory symptoms, inflammatory biomarkers, and lung function in both the experimental and control group. At twelve-month intervals, each child visits the lung function laboratory for measurements of inflammatory biomarkers and lung function tests. Relevant therapy (e.g. dose and period) is registered. If possible, ICS are stopped four weeks before the measurements.

In practices of the participating general practitioners, a computer program for the study is installed. With this program, general practitioners register standardised diagnoses of asthma, atopic dermatitis and allergic rhino conjunctivitis on-line. Diagnoses are based on international Classification of Health Problems in Primary Care (ICHPPC) definitions.

Children are treated according to the guidelines for treatment of asthma of the Dutch Society of General Practice. ${ }^{37}$ These national guidelines approach the international GINA guidelines of asthma diagnosis and treatment. ${ }^{25}$

\section{Definite asthma diagnosis phase}

At six years, a definite diagnosis of asthma is made (primary outcome measure and 'gold standard') upon the presence of current asthma symptoms in combination with characteristic lung function abnormalities (reversibility on a $B_{2}$ agonist and/or bronchial hyperresponsiveness). Airway reversibility is defined as an increase in forced expiratory volume in one second $\left(\mathrm{FEV}_{1}\right)$ of at least $9 \%$ after 400 microgram of extra fine salbutamol (Airomir ${ }^{\circledR}$ Teva Pharma NL, Haarlem, the Netherlands). Bronchial 
hyperresponsiveness is present when a $20 \%$ fall in $\mathrm{FEV}_{1}$ is obtained with a provocative concentration of histamine $\left(\mathrm{PC}_{20}\right)$ of $8 \mathrm{mg} / \mathrm{ml}$ or less. Early measurements of (noninvasive) inflammatory biomarkers and lung function measurements are related to the final diagnosis of asthma. The definite diagnosis of asthma divides the children in the experimental group into an 'asthma group' and a 'transient wheeze group'.

\section{Study parameters}

As described before, repeated measurements are performed from inclusion until the asthma diagnosis. One hour before each experiment, eating and exercise are not allowed. The parameters that are measured are listed below and in Table 2.1.

\section{Fractional exhaled Nitric Oxide}

FeNO is off-line collected in a $500 \mathrm{ml}$ inert balloon during tidal breathing. Exhaled breath is collected via a face mask that is connected to a two-way non-rebreathing valve. $^{38}$ The valve is connected to a filter that allows inspiration of NO-free ambient air to avoid contamination by ambient NO. To avoid nasal contamination a septum between nose and mouth is placed in the mask. After a washout period of five tidal breaths, an NO-inert bag is connected on the expiratory port of the valve to collect exhaled breath. FeNO levels in the bag are determined by off-line sampling using the NIOX (Aerocrine, Solna, Sweden).

\section{Chromatogram of exhaled breath}

During tidal breathing, expired air is collected in a one-litre inert bag by means of the two-way valve system described above. After collection, the bag is immediately emptied across a small tube with active carbon, with rapid adsorption and stabilisation of volatile markers. A profile of inflammatory biomarkers in exhaled breath is assessed by means of gas chromatography time-of-flight mass spectrometer (GC-TOF-MS). ${ }^{39}$

\section{Inflammatory markers in Exhaled Breath Condensate}

To collect EBC in young children, a special system is designed in close collaboration with the Department of Instrument Development Engineering \& Evaluation of the MUMC. ${ }^{19}$ Figure 2.3 shows a schematic representation of this closed glass condenser. Children breathe tidally for ten minutes through a mask connected to the two-way non-rebreathing valve. EBC is collected using a cooled double-jacketed glass condenser that is connected to the valve via a tube. The two-way valve and tubing serve as a trap to minimise salivary contamination. Circulating ice water cools the condenser to $0^{\circ} \mathrm{C}$. During this procedure small droplets of breath condensate are formed and are collected in a tube. During the procedure, children can watch cartoons. Exhaled breath that does not directly condense is collected in an inert bag that is connected to the condenser. To avoid that the exhaled air condenses in the bag, the bag is placed in a 
heated box $\left(37^{\circ} \mathrm{C}\right)$. When the child finishes the procedure, the exhaled breath that is temporarily collected in the inert bag is conducted through the condenser (recirculation) to increase the amount of condensate. After collection, EBC is rapidly frozen using dry ice and is stored at $-80^{\circ} \mathrm{C}$ until analysis. Inflammatory markers (e.g. Interferon- $\gamma$ (IFN- $\nu$ ), TNF- $\alpha$, Interleukins (IL), soluble Intercellular Adhesion Molecule (sICAM)) are assayed using multiplex immunoassay (Luminex technology ${ }^{\bullet}$ Luminex Corporation, Austin, TX, USA). ${ }^{40}$

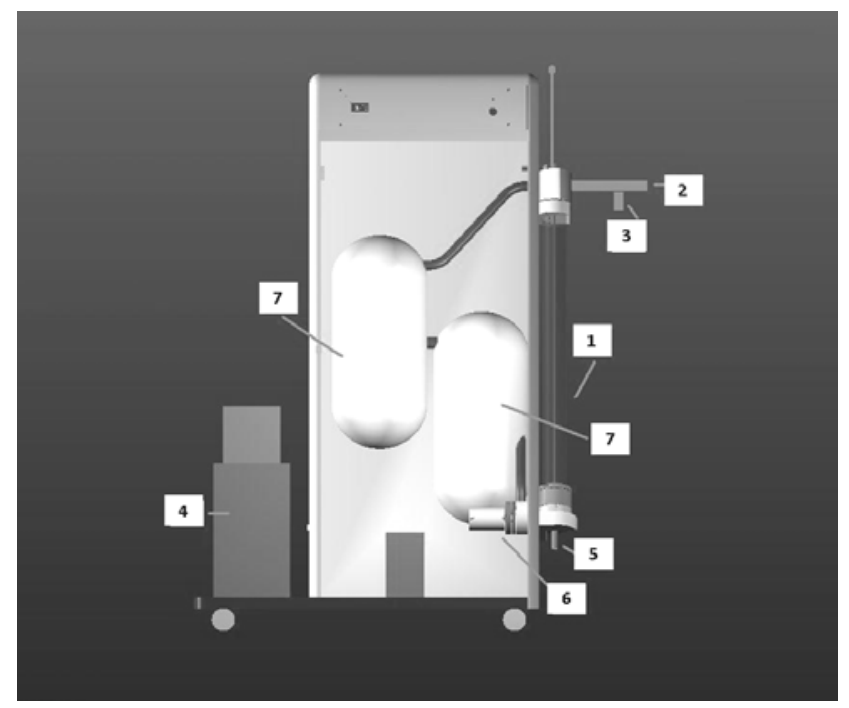

Figure 2.3 Schematic representation of the glass closed condenser

1. Inclined glass condenser with a moveable plunger; 2 . Swan-neck tubing (saliva trap) and two-way non-rebreathing valve, connected to a face mask with separated nose and mouth cavity; 3 . Entrance of inspired room air; 4. Cooling unit; 5 . Sample vial to collect EBC; 6 . Ventilator system for recirculation of non-condensed exhaled breath; 7. Heated (at $37^{\circ} \mathrm{C}$ ) inert Tedlar $^{\mathrm{TM}}$ gas sample bag to collect the residual non-condensed exhaled breath.

\section{Polymorphisms in inflammatory genes}

Saliva is used for DNA collection. DNA is isolated according to the protocol of Oragene (Oragene, Ottowa, Canada). For genotyping matrix-assisted laser desorption/ ionization-time of flight (MALDI-TOF) mass spectrometry is used (Sequenom Inc., San Diego, USA). Sequences are evaluated in the ProxSNP and PreXTEND software (www.realsnp.com). The reactions are designed using Sequenom Assay Designer 3.1 software. Genotyping is executed according to the iPLEX method. In short, multiplexed polymerase chain reaction (PCR) is performed in $5 \mu$ volume using the Sequenom PCR kit. Deactivation of unincorporated deoxyribonucleotide triphosphates (dNTPs) is achieved using shrimp alkaline phosphatase. The iPLEX reagent kit carries out primer extension. To remove residual salt from the reactions a cation exchange resin is added. 
Approximately $15 \mathrm{nl}$ of the primer extension reaction are loaded onto a matrix pad of a SpectroCHIP (Sequenom). MassARRAY Compact Analyzer is used to analyse the SpectroCHIPs (Sequenom). The PCR primer and extension primer sequences are available on request. The genotyping calls are made using Typer Analyzer 4.0 software. The Single Nucleotide Polymorphisms (SNPs) that are studied are selected from Pubmed in combination with the HapMap database (www.hapmap.org). Inclusion of genes for SNPs analysis is based on the following criteria: association with asthma based on biomedical literature and a minor allele frequency of at least five percent in the (asthmatic) population. Genes selected for analysis are: Filaggrin, TNF- $\alpha$, Interleukin 4 receptor alpha (IL4RA), IL-4, IL-5, IL-8, IL-10, IL-13, IL-33, ICAM, A Disintegrin And Metallopeptidase domain 33 (ADAM33), Orosomucoid 1-like 3 (ORMDL3), Toll-like receptor (TLR) 2, TLR4, TLR9, Cluster of Differentiation 14 (CD14), Secretoglobin family $1 A$ member 1 (SCGB1A1/CC16), Cysteinyl Leukotriene Receptor 1 (CYSLTR1), Leukotriene C4 (LTC4), Protocadherin-1 (PCDH1), Interleukin 1 receptor-like 1 (IL1RL1), Plasminogen Activator Urokinase Receptor (PLAUR).

\section{Venous blood sampling}

At the first visit of the study, venous blood is sampled for:

1. Total Immunoglobulin E (IgE) and specific IgE for pollen, cats, dogs, house dust mite, Aspergillus Fumigatus (Pharmacia, Uppsala, Sweden);

2. Presence of $\mathrm{T}_{\text {reg }}$ cells (described below);

3. Gene-expression of relevant markers (described below);

4. Infection serology (Mycoplasma-, Chlamydia- pneumoniae).

In addition, total and specific IgE are also determined at the last visit.

\section{Regulatory T-cells}

$T_{\text {reg }}$ cells are quantified in the circulation by flow cytometry. The phenotype of the $T_{\text {reg }}$ is defined as being positive for CD3, CD4, and CD25 (IL-2R $\alpha$ ), while being negative for CD127 (IL-7R $\alpha$ ). Cells with this phenotype have been shown to be positive for FoxP3, ${ }^{41}$ a transcription factor which is closely related to the suppressive function of $\mathrm{T}_{\text {reg. }}$.

\section{Gene expression of markers of inflammation}

In addition to gene polymorphisms, gene expression markers of inflammation are determined in the early diagnosis phase of the study. Total RNA from venous blood is isolated that is used to generate cDNAs by poly-A and random priming reverse transcription. The cDNAs are stored and used for the production of copy RNA pools. Real-Time Quantitative PCR is used to assess up- or down-regulated expression of genes (AROS, Aarhus, Denmark). Inclusion of genes for gene expression is based on the same criteria as the inclusion of genes for SNP's analysis and on an altered gene expression in asthma suggested in the literature. Genes studied are: $I L-4, I L-5, I L-8$, IL-10, IL-12, IL-13, IL-17A, TNF- $\alpha$, ICAM, TLR2, TLR4, TLR5, TLR9, Eotaxin (CCL11), Rantes 
(CCL5), Macrophage migration Inhibitory Factor (MIF), Macrophage Inflammatory Protein $1 \alpha$ (MIP1 $\alpha)$, Gluthathiontransferase (GST), Catalase (CAT), Superoxide Dismutase (SOD3), Nitric Oxide Synthase 1 (NOS1), Signal Transducer and Activator of Transcription 6 (STAT6), NF-kappa-B inhibitor alpha (IKBalpha), Chitinase (CHIA), Forkhead box P3 (FoxP3), Monocyte chemotactic protein-1 (MCP1,CCL2), chemokine (CC motif) ligand 23 (CCL23), Cyclooxygenase (COX2), Transforming Growth Factor-Beta1 (TGFB1).

\section{Infection serology}

At the start and at the end of the study, a nose and throat swab is collected to analyse possible colonisations of Streptococcus pneumoniae, Haemophilus (para)influenzae and/or Staphylococcus aureus. At the first visit, antibodies of Chlamydia and Mycoplasma pneumoniae are analysed in venous blood using ELISA. In addition, faeces samples are tested for E. coli and Clostridium difficile.

\section{Lung function tests of airway resistance}

Measurements of airway resistance are performed by means of the Rint (MicroRint, Micro Medical Ltd, Rochester, United Kingdom). ${ }^{22}$ While children are sitting in an upright position, they are asked to breathe tidally through a facemask. Seven airflow interruptions are made on the peak flow of expiration. The median Rint value and the flow- and pressure curves are displayed. The median Rint value of at least five successful interruptions is used for analysis. Thereafter, 300 microgram of extra fine salbutamol is inhaled via the Aerochamber (Airomir , Teva Pharma NL, Haarlem, the Netherlands). After 15 minutes, Rint measurements are repeated to assess the reversibility to a $B_{2}$ agonist.

\section{Dynamic spirometry, bronchial hyperresponsiveness and reversibility}

At the end of the study, additional lung function tests are performed as described before. ${ }^{36}$ Maximal expiratory flow volume curves (MEFV) curves are assessed in each child by means of the Flowscreen (Jaeger, Wuerzburg, Germany). The highest FEV ${ }_{1}$, forced vital capacity $(\mathrm{FVC})$, and maximal expiratory flow at 50\% FVC $\left(\mathrm{MEF}_{50}\right)$ of three technically satisfactory MEFV curves are used for analysis. After three baseline MEFV curves, an aerosol of buffered saline is inhaled, followed by aerosols of histamine acid phosphate in doubling concentrations from 0.03 to $16 \mathrm{mg} / \mathrm{ml}$ at five minute intervals. Dynamic spirometry is repeated once after 30 , and after 90 seconds following each inhalation. The inhalation of histamine is discontinued in case of a $20 \%$ fall in $\mathrm{FEV}_{1}$ $\left(\mathrm{PC}_{20}\right)$ or when $16 \mathrm{mg} / \mathrm{ml}$ histamine has been administered. Thereafter, 400 microgram of extra fine salbutamol is inhaled (Airomir', Teva Pharma NL, Haarlem, the Netherlands). After 15 minutes, three MEFV curves are assessed in a comparable way. The change in $\mathrm{FEV}_{1}$ is expressed as a percentage of the predicted value. 


\section{Questionnaires on respiratory symptoms and quality of life}

Presence of cough, breathlessness, and wheezing are registered according to the internationally standardised ISAAC questionnaire. ${ }^{34}$ Besides, a questionnaire designed for preschool children to record patterns of wheeze and other respiratory symptoms is completed by parents. ${ }^{42}$ In addition, medical history in relation to respiratory symptoms is assessed by a physician. ${ }^{43}$ The quality of life in children is measured by the parent administered general health related quality of life (FSII) questionnaire. ${ }^{35}$

\section{Samples size calculations}

In a population of infants with recurrent asthma-like symptoms, the prevalence of asthma at six years is known to be $30 \%{ }^{1}$ In this study, this will result in at least 50 asthmatic children given the 202 children with recurrent respiratory symptoms aged two and three years at the start, and a 10\% drop-out rate. The standard error of the sensitivity given a chance on a positive test result of 0.8 will be $4.0 \%$. The standard error of the specificity with 150 children without disease will be $3.0 \%$ given a chance on a positive test result of 0.8 . If the positive predictive value of the test is 0.7 and the negative predictive value 0.2 in a population of $\mathrm{N}=200$, the statistical power for the relation between the test and the definite diagnosis of asthma is $98 \%$.

\section{Data collection}

The collected data are checked and cleaned by the centre for data and information management (MEMIC) of the MUMC. All data are stored in a database at MEMIC.

\section{Data analysis}

The data are analysed using quantitative statistics. Normally distributed data are expressed as mean and standard error. Not normally distributed data are expressed as median with inter quartile ranges.

\section{Statistics of the primary research question}

The primary research question is whether non-invasive inflammatory biomarkers in exhaled breath and lung function indices can reliably predict asthma at an early age. For this purpose, biomarkers collected in the experimental group during the early diagnosis phase are used. These parameters are related to the definite diagnosis of asthma by means of multiple logistic regression analysis, and discriminant analysis.

\section{Statistics of the secondary research questions}

To answer the second research questions, data from both experimental group and control group are used. Differences in parameters between the three groups (asthma, 'transient wheezers', and controls) are tested with analysis of variance (one-way 
ANOVA or Kruskal-Wallis test in case of parametric and non-parametric data, respectively). For normally distributed data, Student's t-tests are used for further analysis. Mann-Whitney tests are used to test for differences among non-parametric data. Differences are defined as significant when $p<0.05$.

\section{Ethics}

Ethical approval is obtained from the Dutch National Medical Ethical Committee (CCMO). All parents give written informed consent. At the end of the study all parents are informed about the personal primary outcome measure (asthma diagnosis) of their child, and general results of the study. The study protocol is extensively studied by the funding organizations: the Dutch Asthma Foundation, Stichting Astma Bestrijding, and MUMC. This study is registered by clinicaltrial.gov (NCT 00422747).

\section{Discussion}

We presented the protocol of the ADEM study that aims at an early asthma diagnosis in young children using non-invasive biomarkers of airway inflammation and early lung function measurements. The design of the study is a case-control study in 202 children with recurrent respiratory symptoms and 50 control subjects with no respiratory symptoms. Our primary hypothesis is that an early asthma diagnosis is possible using non-invasive measurements of inflammatory biomarkers in exhaled breath (condensate), and lung function tests. Besides, aetiological factors including gene polymorphisms, gene expression, $\mathrm{T}_{\text {reg }}$ cells and microbial colonisation of airways and intestines are studied in relation to the development of asthma.

The development of a new diagnostic tool for asthma at an early age, based on noninvasive inflammatory biomarkers in exhaled breath, and lung function can lead to an early asthma diagnosis. This will result in better treatment and probable a better prognosis of asthma in children. Moreover, exclusion of asthma at an early age prevents over-treatment in the children with transient wheezing, which will reduce possible side effects and economic costs.

The design and setting of the ADEM study is ideally suited to study the relation between different parameters that are measured in early life, and the susceptibility for asthma. This will increase insight in, for example, the relation between the genetic background and the pathophysiology of asthma in young children.

There are several critical success factors to be mentioned. The study performs measurements in children aged two to six years. Although the measurements are not invasive, the question arises whether the measurements are feasible in these young children. In a previous study in 70 preschool children, we established a success rate of 
EBC measurements of $83 \%$ using the same condenser. ${ }^{19}$ With respect to early lung functions measurements, Merkus et al. found a feasibility of $88 \%$ of Rint measurements in children aged two years and over. ${ }^{22}$ We hope to achieve success rates of the measurements of at least $90 \%$ taken into account the non-invasive character of the measurements, and our experience and learning curve in the field of measurements of exhaled breath (condensate) and lung function tests in children. ${ }^{19,36}$

A trial with ICS is part of the diagnosis phase for the children in the experimental group. A trial period with ICS is often advocated but the precise diagnostic value is not clear from earlier studies. ${ }^{25}$ The children in the experimental group consist of children who experienced at least two episodes of wheeze during life. This can imply that some children are symptom free at the start of the ICS trial. Therefore, we expect a lower compliance in the group children without current respiratory symptoms. Compliance will be measured by weighting the ICS inhalators before and after the trial.

Children in this study are followed up for three to four years. This long-term study can induce loss-to-follow-up, which is dependent on compliance and the involvement of the parents with the study. In our power analysis we calculated a loss-to-follow-up of ten percent. Other studies of our research group with a comparable design had a similar drop-out rate. ${ }^{44}$

In this study various parameters are measured. Because of the large number of parameters that are measured, it is important to distinguish the primary outcome measure from the aetiological factors that are studied. The results of the aetiological part of this study have a more exploring character and should be tested more extensively in future research.

\section{Conclusion}

As an early diagnosis of asthma is currently difficult, both under-diagnosis and undertreatment of asthmatic children as well as over-treatment of transient wheezers occur frequently. So far, assessments of inflammatory biomarkers play a minor role in the diagnosis of asthma. The development of a new diagnostic tool for asthma at an early age, based on non-invasive inflammatory biomarkers in exhaled breath and early lung function measurements is a promising technique. These new diagnostic techniques are applied in this study and might make an early diagnosis of asthma possible. This will result in earlier and better treatment of childhood asthma. 


\section{References}

1. Martinez FD, Wright AL, Taussig LM, Holberg CJ, Halonen M, Morgan WJ. Asthma and wheezing in the first six years of life. The Group Health Medical Associates. N Engl J Med 1995;332:133-8.

2. Bisgaard H, Szefler S. Prevalence of asthma-like symptoms in young children. Pediatr Pulmonol 2007; 42:723-8.

3. Kurukulaaratchy RJ, Fenn MH, Waterhouse LM, Matthews SM, Holgate ST, Arshad SH. Characterization of wheezing phenotypes in the first 10 years of life. Clin Exp Allergy 2003;33:573-8.

4. Taussig LM, Wright AL, Holberg CJ, Halonen M, Morgan WJ, Martinez FD. Tucson Children's Respiratory Study: 1980 to present. J Allergy Clin Immunol 2003;111:661-75.

5. Castro-Rodriguez JA, Rodrigo GJ. Efficacy of inhaled corticosteroids in infants and preschoolers with recurrent wheezing and asthma: a systematic review with meta-analysis. Pediatrics 2009;123: e519-25.

6. Kaditis AG, Winnie G, Syrogiannopoulos GA. Anti-inflammatory pharmacotherapy for wheezing in preschool children. Pediatr Pulmonol 2007;42:407-20.

7. McKean M, Ducharme F. Inhaled steroids for episodic viral wheeze of childhood. Cochrane Database Syst Rev 2000 CD001107.

8. Baraldi E, Ghiro L, Piovan V, Carraro S, Zacchello F, Zanconato S. Safety and success of exhaled breath condensate collection in asthma. Arch Dis Child 2003;88:358-60.

9. Pijnenburg MW, de Jongste JC. Exhaled nitric oxide in childhood asthma: a review. Clin Exp Allergy 2008;38:246-59.

10. Robroeks CM, van de Kant KD, Jöbsis Q, Hendriks HJ, van Gent R, Wouters EF, Damoiseaux JG, Bast A, Wodzig WK, Dompeling E. Exhaled nitric oxide and biomarkers in exhaled breath condensate indicate the presence, severity and control of childhood asthma. Clin Exp Allergy 2007;37:1303-11.

11. Doelman CJ, Bast A. Oxygen radicals in lung pathology. Free Radic Biol Med 1990;9:381-400.

12. Phillips M, Gleeson K, Hughes JM, Greenberg J, Cataneo RN, Baker L, McVay WP. Volatile organic compounds in breath as markers of lung cancer: a cross-sectional study. Lancet 1999;353:1930-3.

13. Paredi P, Kharitonov SA, Barnes PJ. Elevation of exhaled ethane concentration in asthma. Am J Respir Crit Care Med 2000;162:1450-4.

14. Olopade CO, Zakkar M, Swedler WI, Rubinstein I. Exhaled pentane levels in acute asthma. Chest 1997;111:862-5.

15. Corradi M, Folesani G, Andreoli R, Manini P, Bodini A, Piacentini G, Carraro S, Zanconato S, Baraldi E. Aldehydes and glutathione in exhaled breath condensate of children with asthma exacerbation. Am J Respir Crit Care Med 2003;167:395-9.

16. Baraldi E, Ghiro L, Piovan V, Carraro S, Ciabattoni G, Barnes PJ, Montuschi P. Increased exhaled 8isoprostane in childhood asthma. Chest 2003;124:25-31.

17. Csoma Z, Kharitonov SA, Balint B, Bush A, Wilson NM, Barnes PJ. Increased leukotrienes in exhaled breath condensate in childhood asthma. Am J Respir Crit Care Med 2002;166:1345-9.

18. Formanek W, Inci D, Lauener RP, Wildhaber JH, Frey U, Hall GL. Elevated nitrite in breath condensates of children with respiratory disease. Eur Respir J 2002;19:487-91.

19. Rosias PP, Robroeks CM, van de Kant KD, Rijkers GT, Zimmermann LJ, van Schayck CP, Heynens JW, Jöbsis Q, Dompeling E. Feasibility of a new method to collect exhaled breath condensate in pre-school children. Pediatr Allergy Immunol 2010;21:e235-44.

20. Effros RM, Hoagland KW, Bosbous M, Castillo D, Foss B, Dunning M, Gare M, Lin W, Sun F. Dilution of respiratory solutes in exhaled condensates. Am J Respir Crit Care Med 2002;165:663-9.

21. Kostikas K, Koutsokera A, Papiris S, Gourgoulianis KI, Loukides S. Exhaled breath condensate in patients with asthma: implications for application in clinical practice. Clin Exp Allergy 2008: 38;557-65.

22. Merkus PJ, Arets HG, Joosten T, Siero A, Brouha M, Mijnsbergen JY, de Jongste JC, van der Ent CK. Measurements of interrupter resistance: reference values for children 3-13 yrs of age. Eur Respir J 2002;20:907-11.

23. Bridge PD, Ranganathan S, McKenzie SA. Measurement of airway resistance using the interrupter technique in preschool children in the ambulatory setting. Eur Respir J 1999;13:792-6. 
24. Nielsen KG, Bisgaard H. Discriminative capacity of bronchodilator response measured with three different lung function techniques in asthmatic and healthy children aged 2 to 5 years. Am J Respir Crit Care Med 2001;164:554-9.

25. Global Initiative for asthma (GINA). Global strategy for asthma management and prevention. National Institute of Health, National Heart, Lung, and Blood Institute 2008.

26. Robinson DS, Hamid Q, Ying S, Tsicopoulos A, Barkans J, Bentley AM, Corrigan C, Durham SR, Kay AB. Predominant TH2-like bronchoalveolar T-lymphocyte population in atopic asthma. N Engl J Med 1992; 326:298-304.

27. Busse WW, Lemanske RF, Jr. Asthma. N Engl J Med 2001;344:350-62.

28. Damoiseaux J. Regulatory T cells: back to the future. Neth J Med 2006;64:4-9.

29. Xystrakis E, Boswell SE, Hawrylowicz CM. T regulatory cells and the control of allergic disease. Expert Opin Biol Ther 2006;6:121-33.

30. Ober C, Hoffjan S. Asthma genetics 2006: the long and winding road to gene discovery. Genes Immun 2006;7:95-100.

31. Koppelman GH, te Meerman GJ, Postma DS. Genetic testing for asthma. Eur Respir J 2008;32:775-82.

32. Strachan DP. Hay fever, hygiene, and household size. BMJ 1989;299:1259-60.

33. Schaub B, Lauener R, von Mutius E. The many faces of the hygiene hypothesis. J Allergy Clin Immunol 2006;117:969-77.

34. Worldwide variation in prevalence of symptoms of asthma, allergic rhinoconjunctivitis, and atopic eczema: ISAAC. The International Study of Asthma and Allergies in Childhood (ISAAC) Steering Committee. Lancet 1998;351:1225-32.

35. Stein RE, Jessop DJ. Functional status II(R). A measure of child health status. Med Care. 1990;28: 1041-55.

36. Kuiper S, Maas T, van Schayck CP, Muris JW, Schonberger HJ, Dompeling E, Gijsbers B, van Weel C, Knottnerus JA. The primary prevention of asthma in children study: design of a multifaceted prevention program. Pediatr Allergy Immunol 2005;16:321-31.

37. Bindels PJ, Grol MH, Ponsioen BP, Salome PL, Wiersma T, Goudswaard AN. [Summary of the practice guideline 'Asthma in children' (second revision) from the Dutch College of General Practitioners]. Ned Tijdschr Geneeskd 2008;152:550-5.

38. Gabriele C, Asgarali R, Jaddoe VW, Hofman A, Moll HA, de Jongste JC. Smoke exposure, airway symptoms and exhaled nitric oxide in infants: the Generation R study. Eur Respir J 2008;32:307-13.

39. van Berkel JJ, Dallinga JW, Moller GM, Godschalk RW, Moonen E, Wouters EF, van Schooten FJ. Development of accurate classification method based on the analysis of volatile organic compounds from human exhaled air. J Chromatogr B Analyt Technol Biomed Life Sci 2008;861:101-7.

40. Rosias PP, Robroeks CM, Kester A, den Hartog GJ, Wodzig WK, Rijkers GT, Zimmermann LJ, van Schayck $C P$, Jöbsis $Q$, Dompeling $E$. Biomarker reproducibility in exhaled breath condensate collected with different condensers. Eur Respir J 2008;31:934-42.

41. Liu W, Putnam AL, Xu-Yu Z, Szot GL, Lee MR, Zhu S, Gottlieb PA, Kapranov P, Gingeras TR, Fazekas de St Groth B, Clayberger C, Soper DM, Ziegler SF, Bluestone JA. CD127 expression inversely correlates with FoxP3 and suppressive function of human CD4+ T reg cells. J Exp Med 2006;203:1701-11.

42. Powell CV, McNamara P, Solis A, Shaw NJ. A parent completed questionnaire to describe the patterns of wheezing and other respiratory symptoms in infants and preschool children. Arch Dis Child 2002; 87:376-9.

43. Hammer SC, Robroeks CM, van Rij C, Heynens J, Droog R, Jöbsis Q, Hendriks HJ, Dompeling E. Actual asthma control in a paediatric outpatient clinic population: Do patients perceive their actual level of control? Pediatr Allergy Immunol. 2008;19:626-33.

44. Schonberger HJ, Dompeling E, Knottnerus JA, Maas T, Muris JW, van Weel C, van Schayck CP. The PREVASC study: the clinical effect of a multifaceted educational intervention to prevent childhood asthma. Eur Respir J 2005;25:660-70. 


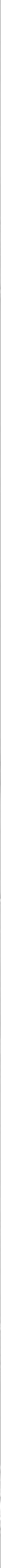




\section{chapter 3}
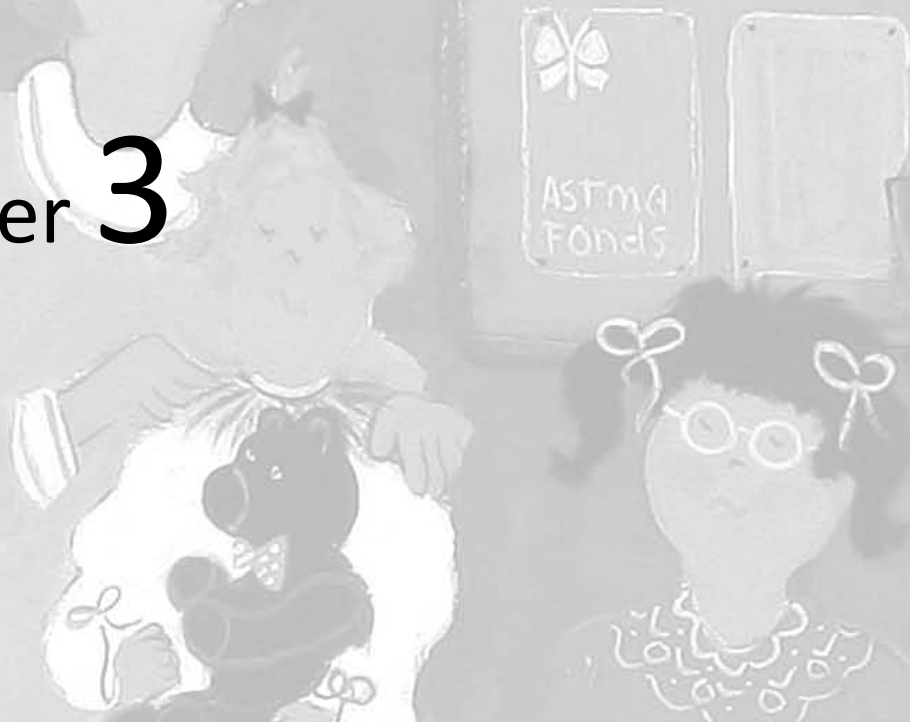

Wheezing in preschool children is associated with increased levels of cytokines / chemokines in Exhaled Breath Condensate

van de Kant KDG, Klaassen EMM, Jöbsis Q, Koers K, Rijkers GT, van der Grinten CP, van Schayck CP, Lima Passos V, Dompeling E 


\section{Abstract}

\section{Background}

Little is known about airway inflammation in wheezing preschool children. Airway inflammation in young children may be assessed using markers in Exhaled Breath Condensate (EBC) and Fractional exhaled Nitric Oxide (FeNO).

\section{Objectives}

To assess whether FeNO levels, inflammatory markers in EBC ( $\mathrm{pH}$, Interleukin(IL)-1 $\alpha$, IL-2, IL-4, IL-5, IL-8, IL-10, IL-13, Tumour Necrosis Factor- $\alpha$, soluble Intercellular Adhesion Molecule (sICAM), Rantes, Eotaxin), and airway resistance are associated with wheezing in preschool children.

\section{Methods}

We selected 258 preschool children (mean age \pm SEM; $3.3 \pm 0.1$ years): 57 children who never wheezed, 78 children with 1-3 wheezing episodes, and 123 children who experienced $>3$ wheezing episodes during life. FeNO was collected off-line in an inert balloon during tidal breathing. EBC was collected using a closed glass condenser system with breath recirculation unit. EBC markers were measured using multiplex immunoassay. Airway resistance before and after a short-acting $B_{2}$ agonist was measured with the MicroRint .

\section{Results}

EBC collection, FeNO, and airway resistance measurements were possible in 98\%, 99\%, and $96 \%$ of the children respectively. All interleukins (IL-1 $\alpha$, IL-2, IL-4, IL-5, IL-8, IL-10, IL-13) and sICAM were significantly different between the three groups, with highest levels in children with $>3$ wheezing episodes $(p<0.05)$. Off-line collected FeNO levels and airway resistance did not differ.

\section{Conclusions}

EBC collection, off-line FeNO, and airway resistance measurements are feasible in preschool children. The various elevated EBC markers indicate increased airway inflammation in preschool children with recurrent wheezing. The analysis of EBC is helpful as a non-invasive tool to assess airway inflammation in these children. 


\section{Introduction}

Although asthma is a common disease in children, only a minority of young children with respiratory symptoms, such as wheeze, will develop persistent symptoms. Mostly, preschool wheeze is associated with viral respiratory tract infections. These children are usually symptom free at six years of age. Airway inflammation is a central feature in asthma. Whether and, if so, to what degree airway inflammation is already a characteristic in wheezing preschool children is unknown. The current tools to assess airway inflammation, such as lung biopsy and bronchoalveolar lavage (BAL), are too invasive for routine use in young children. There is an increasing interest in the noninvasive assessment of inflammatory markers in exhaled breath such as Fractional exhaled Nitric Oxide (FeNO), and solutes in Exhaled Breath Condensate (EBC). Various research groups demonstrated elevated levels of inflammatory markers in EBC in children with asthma. ${ }^{1-4}$ It is unclear whether these parameters are also useful in measuring inflammation in preschool children with wheezing symptoms. The aim of our study was to assess if FeNO levels, inflammatory markers in EBC, and airway resistance are associated with wheezing in preschool children.

\section{Methods}

\section{Study population}

This study included children from the ADEM study (Asthma DEtection and Monitoring study) that started in 2006 in the Netherlands (registered at clinicaltrial.gov: NCT 00422747). ${ }^{5}$ A total of 258 preschool children (mean age \pm SEM; $3.3 \pm 0.1$ years) were selected; 57 children who never wheezed, 78 children with 1-3 wheezing episodes, and 123 children who experienced more than 3 wheezing episodes during life, as assessed by the ISAAC questionnaire. ${ }^{6}$ Ethical approval was obtained from the Dutch National Medical Ethical Committee (CCMO). All parents gave written informed consent.

\section{Measurements}

If applicable, inhaled corticosteroids (ICS) administration was stopped at least four weeks before the measurements. A measurement was postponed in case of symptoms of an airway infection. Moreover, solid foods and physical exercise were not allowed one hour before the measurements.

\section{Atopy}

Venous blood was sampled for specific IgE against a mixture of inhalant and food allergens (Phadiatop infant ${ }^{\circledR}$, Pharmacia, Uppsala, Sweden). A child was considered atopic in case of a positive test. 


\section{Exhaled inflammatory markers and lung function measurements}

The off-line measurements of FeNO, the collection of EBC, and the measurements of airway resistance, are described in detail previously. ${ }^{5}$ In short, FeNO was collected offline in a $500 \mathrm{ml}$ inert balloon during tidal breathing and analysed using a nitric oxide monitoring system ( $\mathrm{NIOX}^{\circ}$, Aerocrine, Solna, Sweden). To collect EBC, a closed glass condenser system with a breath recirculation unit was used which was developed at our institute. ${ }^{5}$ This efficient condenser system enables the recirculation of exhaled breath that does not directly condense. As a result, a high amount of EBC can be collected in a short collection-time. Acidity of EBC was analysed directly after collection (Radiometer, Zoetermeer, the Netherlands). The other inflammatory markers in EBC (Interleukin (IL)-1 $\alpha$, IL-2, IL-4, IL-5, IL-8, IL-10, IL-13, soluble Intercellular Adhesion Molecule (sICAM), Tumour Necrosis Factor alpha (TNF- $\alpha$ ), Rantes (chemokine (C-C motif) ligand 5 (CCL5)), and Eotaxin (CCL11)) were measured using multiplex immunoassay (Luminex Corporation, Austin, TX, USA). ${ }^{7}$ Samples with no detectable levels of EBC markers were not considered to have a concentration of 'zero', but received a randomly generated value between zero and the detection limit taken from the uniform distribution. Airway resistance before and after a short-acting $B_{2}$ agonist (300 microgram salbutamol; Airomir , Teva Pharma NL, Haarlem, the Netherlands) was measured using the MicroRint device (Micro Medical Ltd, Rochester, United Kingdom). ${ }^{5}$

\section{Statistical analysis}

Data were analysed with SPSS 16.1 (SPSS inc., Chicago IL, USA). Differences among the three groups regarding their clinical characteristics and main outcome measurements were evaluated by means of non-parametric tests (Kruskal-Wallis or Mann-Whitney) and Chi-square test for categorical variables. Adjustment for multiple testing was conducted via False Discovery Rate (FDR). Differences among groups were considered significant when the corrected FDR $p$-value was $<0.05$.

\section{Results}

\section{Clinical characteristics}

Clinical characteristics are summarised in Table 3.1. Eczema, but not atopy, predominated in the group children who experienced $>3$ episodes of wheeze $(p<0.05)$. Recurrent wheeze was related to a higher use of ICS and short-acting $B_{2}$ agonists $(p<0.05)$. 
Table $3.1 \quad$ Patient characteristics.

$\begin{array}{lccc}\text { Characteristics } & \begin{array}{c}>3 \text { Wheezing } \\ \text { episodes }\end{array} & \begin{array}{c}1-3 \text { Wheezing } \\ \text { episodes }\end{array} & \begin{array}{c}\text { Never } \\ \text { wheezed }\end{array} \\ \text { Study population, in numbers } & 123 & 78 & 57 \\ \text { Mean age (range), in years } & 3.2(2.0-4.4) & 3.2(1.9-4.3) & 3.3(2.2-4.5) \\ \text { Male / female, in numbers } & 66 / 57 & 45 / 33 & 28 / 29 \\ \text { Mean height (range), in cm } & 97.0(82.0-111.0) & 98.2(86.0-112.0) & 98.3(81.0-112.0) \\ \text { Mean weight (range), in kg } & 15.5(9.1-22.1) & 16.0(11.7-23.0) & 15.6(10.5-20.4) \\ \text { Atopy, in \% } & 22 & 23 & 23 \\ \text { Eczema, in \%* } & 41 & 35 & 23 \\ \text { Use of ICS, in \%* } & 24 & 9 & 0 \\ \text { Use of short acting } B_{2} \text { agonist, in \%** } & 47 & 23 & 5 \\ \text { Use of long acting } B_{2} \text { agonist, in \% } & 4 & 1 & 0 \\ \text { ICS = inhaled corticosteroids; }{ }^{*} \text { p<0.05: }>3 \text { versus 1-3 episodes, and }>3 \text { versus never wheezed. ** } p<0.05:>3\end{array}$

\section{Feasibility}

From 258 children, 252 children (98\%) were able to produce sufficient EBC with a mean volume of $498 \mu \mathrm{l}$ (Range: $60-1410 \mu \mathrm{l}$ ). Sudden anxiety was the major reason for drop-out of the remaining six children. Successful FeNO, baseline airway resistance, and post-bronchodilator airway resistance measurements were achieved in respectively $99 \%, 96 \%$, and $92 \%$ of the children. For all measurements, there were no differences in success rate between children with recurrent wheeze ( $>3$ episodes), minor symptoms ( $1-3$ episodes), and no symptoms ( $p>0.05)$.

\section{Exhaled inflammatory markers and lung function measurements}

All interleukins (IL-1 $\alpha$, IL-2, IL-4, IL-5, IL-8, IL-10, IL-13) and sICAM significantly differed between groups $(p<0.05)$. Results of the post-hoc pair-wise comparisons are shown in Figure 3.1 in which the significant pair-wise comparisons are marked with an asterisk $(p<0.05)$. Levels of all interleukins and sICAM were higher in the group of children with >3 wheezing episodes compared to the children who never wheezed. In addition, levels of IL-2, IL-4 and IL-10 were higher in children with minor symptoms (1-3 wheezing episodes) compared to children who never wheezed. Both levels of IL-13 and sICAM were elevated in children with $>3$ wheezing episodes compared to the children with minor symptoms. No differences were found in levels of TNF- $\alpha$, Rantes, Eotaxin, and the $\mathrm{pH}$ of EBC between groups. Moreover, off-line collected FeNO levels and airway resistance before and after salbutamol did not differ between the three groups. In a sub-analysis, children with atopy were compared to children without atopy. There were no differences in FeNO levels, inflammatory markers in EBC (including the prototypical Th2 cytokines IL-4, IL-5, and IL-13) and airway resistance between atopic and non-atopic children. 

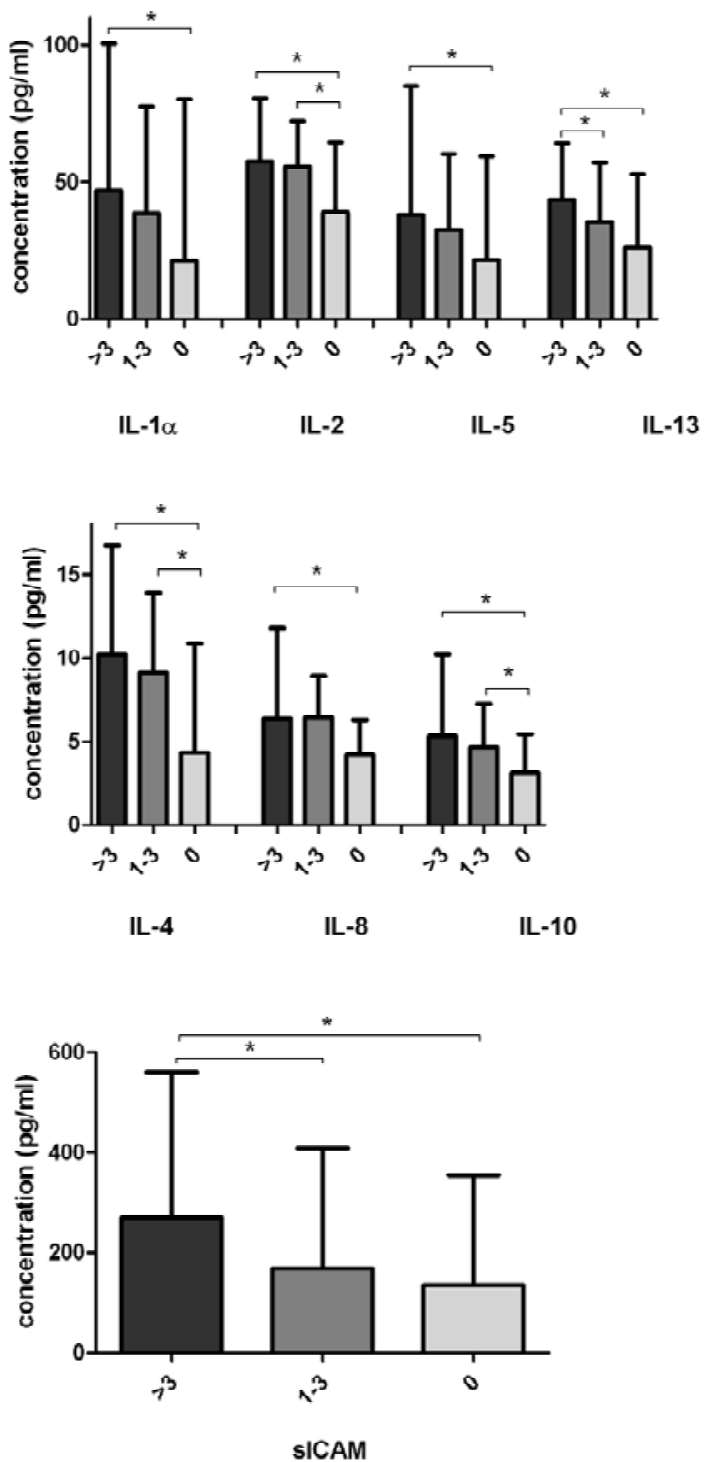

Figure 3.1 Markers in EBC of children with $>3$ wheezing episodes (dark grey), 1-3 wheezing episodes (grey), and no wheezing (light grey). Significant pair-wise comparisons are marked with an asterisk $(p<0.05)$. Markers are grouped based on their range in concentration. 


\section{Discussion}

This study shows that collection of EBC, measurement of airway resistance, and offline measurements of FeNO in preschool children are feasible non-invasive techniques to measure airway inflammation. Significant elevated levels of all measured interleukins (IL-1 $\alpha$, IL-2, IL-4, IL-5, IL-8, IL-10, IL-13) and sICAM were found in EBC of preschool children with recurrent wheeze compared to children without symptoms.

Although it is known that EBC collection is a safe and simple procedure in adults and in school children, data about the feasibility of EBC collection in preschool children are limited. ${ }^{8,9}$ The high success rate of EBC collection in our study is the result of various factors. At first, we used a closed-glass condenser that enables recirculation of exhaled breath that does not directly condense. In this way non-condensed air is not lost, in contrast to condensers with an open end. The recirculation increases the amount of collected EBC two-fold and there is no indication that it influences the levels of markers, as measurements before and after breath recirculation did not significantly differ. ${ }^{9}$ The efficient system enables sufficient EBC collection in less collection-time (10 minutes is enough), which is an important success factor in this young age group. Secondly, EBC markers were measured using multiplex immunoassay (Luminex technology ${ }^{\oplus}$. This technology is highly sensitive and is able to measure different cytokines accurately in a small sample volume. ${ }^{7}$ Finally, we increased feasibility by facilitating tools to make children feel at ease during the measurements.

The increased levels of the various exhaled inflammatory markers in condensate point to an ongoing inflammatory response in children with recurrent wheeze compared to non-wheezing controls. The elevated markers in recurrent wheezers may reflect different aspects of airway inflammation. They include Th2 cytokines (IL-4, IL-5, IL-13), a pro-inflammatory cytokine (IL-1 $\alpha$ ), a Th1 cytokine (IL-2), a chemokine (IL-8), an antiinflammatory cytokine (IL-10), and an adhesion molecule (sICAM). These markers play an important role in the inflammatory response in asthma. The elevated levels of different types of cytokines fits into the concept that in wheezing preschool children more than one immune mechanism is involved leading to a chain of inflammatory events. $^{10}$

The aetiology of preschool wheezing is heterogeneous. Some children may wheeze because of a viral infection, in others allergen provocation may trigger their symptoms. The type of inflammation differs depending on the underlying pathophysiology. 'Viral wheeze' is the most common phenotype of wheezing in preschool children. There is increasing evidence that during a viral-triggered wheezing attack, neutrophilic inflammation plays a central role. ${ }^{11,12}$ In contrast, in children with atopic asthma inflammation is predominately mediated by eosinophils. ${ }^{13}$ Some of our results point to a neutrophilic inflammation in the recurrent wheezing children. For this group, we 
found elevated levels of IL-8, a neutrophil chemoattractant. By contrast, we did not find elevated levels of Rantes and Eotaxin, two powerful chemoattractants for eosinophils, in wheezing children. Similarly, no groups' difference in off-line collected FeNO levels, known to reflect eosinophilic inflammation, was observed. However, we did find elevated levels of IL-5 in children with recurrent wheeze, a marker involved in the activation of eosinophils. Therefore, our results strengthen the current opinion that multiple mechanisms lead to episodes of wheeze at preschool age. ${ }^{10}$

No differences in FeNO levels and EBC markers in children with atopy compared to children without atopy were found. This may be due to the low prevalence of atopy to inhalant allergens in this age-group resulting in small numbers per group.

In previous studies bronchoscopy and BAL were performed to study airway inflammation in preschool wheezers. ${ }^{14,15}$ An advantage of the EBC technique over bronchoscopy and BAL is that EBC collection is a safe, non-invasive technique and can be easily performed in non-sedated preschool children. However, low detection limits and possible influences of expiratory flow, temperature of the condenser tube and dilution factor on EBC collection, remain challenging issues that need to be addressed in further investigations. Future paediatric studies comparing markers in EBC with markers in BAL and induced sputum are important to increase our knowledge about the pathophysiology of preschool wheezing.

In conclusion, we demonstrated that EBC collection, off-line FeNO, and airway resistance measurements are feasible in preschool children. The elevated EBC markers indicated increased airway inflammation in preschool children with recurrent wheezing. The analysis of EBC is helpful as a non-invasive tool for the early detection of airway inflammation in preschool children with respiratory symptoms. In the ADEM study we will follow the children until the age of six years. At that age we will be able to distinguish different wheezing phenotypes. Whether markers in EBC, FeNO, and Rint measurements are useful to distinguish between wheezing phenotypes, will be determined during this follow-up.

\section{Clinical applications}

The elevated cytokines and chemokines found in EBC of wheezing children point to multiple inflammatory pathways. The analysis of exhaled markers is a feasible, noninvasive method to assess airway inflammation in wheezing children. 


\section{References}

1. Brunetti L, Francavilla R, Tesse R, Fiermonte P, Fiore FP, Lore M, Margiotta M, Armenio L. Exhaled breath condensate cytokines and $\mathrm{pH}$ in pediatric asthma and atopic dermatitis. Allergy Asthma Proc 2008;29:461-7.

2. Carraro S, Rezzi S, Reniero F, Heberger K, Giordano G, Zanconato S, Guillou C, Baraldi E. Metabolomics applied to exhaled breath condensate in childhood asthma. Am J Respir Crit Care Med 2007;175: 986-90.

3. Shahid SK, Kharitonov SA, Wilson NM, Bush A, Barnes PJ. Exhaled 8-isoprostane in childhood asthma. Respir Res 2005;6:79.

4. Robroeks CM, Rijkers GT, Jöbsis Q, Hendriks HJ, Damoiseaux JG, Zimmermann L, van Schayck OP, Dompeling E. Increased cytokines, chemokines and soluble adhesion molecules in exhaled breath condensate of asthmatic children. Clin Exp Allergy 2010;40:77-84.

5. van de Kant KD, Klaassen EM, Jöbsis Q, Nijhuis AJ, van Schayck OC, Dompeling E. Early diagnosis of asthma in young children by using non-invasive biomarkers of airway inflammation and early lung function measurements: study protocol of a case-control study. BMC Public Health 2009;9:210.

6. Worldwide variation in prevalence of symptoms of asthma, allergic rhinoconjunctivitis, and atopic eczema: ISAAC. The International Study of Asthma and Allergies in Childhood (ISAAC) Steering Committee. Lancet 1998;351:1225-32.

7. de Jager W, te Velthuis H, Prakken BJ, Kuis W, Rijkers GT. Simultaneous detection of 15 human cytokines in a single sample of stimulated peripheral blood mononuclear cells. Clin Diagn Lab Immunol 2003;10:133-9.

8. Vogelberg C, Wurfel C, Knoetzsch A, Kahlert A, Range U, Leupold W. Exhaled breath condensate $\mathrm{pH}$ in infants and children with acute and recurrent wheezy bronchitis. Pediatr Pulmonol 2007;42:1166-72.

9. Rosias PP, Robroeks CM, van de Kant KD, Rijkers GT, Zimmermann LJ, van Schayck CP, Heynens JW, Jöbsis Q, Dompeling E. Feasibility of a new method to collect exhaled breath condensate in pre-school children. Pediatr Allergy Immunol 2010;21:e235-44.

10. Martinez FD, Godfrey S. Immunology of wheezing disorders in infants and preschool children. Martin Dunitz, New York, 2003.

11. McDougall CM, Helms PJ. Neutrophil airway inflammation in childhood asthma. Thorax 2006;61: 739-41.

12. Marguet C, Jouen-Boedes F, Dean TP, Warner JO. Bronchoalveolar cell profiles in children with asthma, infantile wheeze, chronic cough, or cystic fibrosis. Am J Respir Crit Care Med 1999;159:1533-40.

13. Drews AC, Pizzichini MM, Pizzichini E, Pereira MU, Pitrez PM, Jones MH, Sly PD, Stein RT. Neutrophilic airway inflammation is a main feature of induced sputum in nonatopic asthmatic children. Allergy 2009;64:1597-601.

14. Le Bourgeois M, Goncalves M, Le Clainche L, Benoist MR, Fournet JC, Scheinmann P, de Blic J. Bronchoalveolar cells in children $<3$ years old with severe recurrent wheezing. Chest 2002;122:791-7.

15. McNamara PS, Flanagan BF, Baldwin LM, Newland P, Hart CA, Smyth RL. Interleukin 9 production in the lungs of infants with severe respiratory syncytial virus bronchiolitis. Lancet 2004;363:1031-7. 


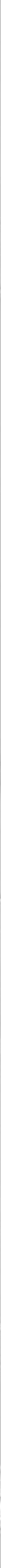




\section{Chapter 4}
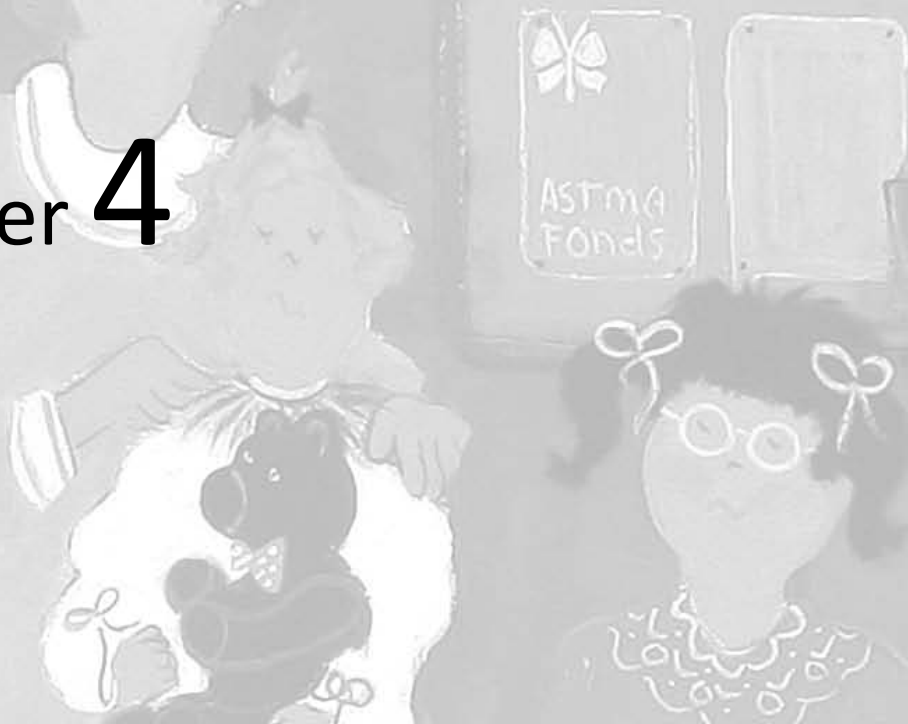

The clinical use of exhaled Volatile Organic Compounds in pulmonary diseases; a systematic review

van de Kant KDG, van der Sande LJTM, Jöbsis $Q$, van Schayck CP, Klaassen EMM, Wesseling G, Dompeling E 


\section{Abstract}

There is an increasing interest in the potential of non-invasive measurements of exhaled Volatile Organic Compounds (VOCs) for the diagnosis and management of pulmonary diseases in both adults and children. This manuscript systematically reviews the current knowledge on VOCs with respect to their potential clinical use in pulmonary diseases, such as lung cancer, asthma, chronic obstructive pulmonary disease, cystic fibrosis and respiratory tract infections. Forty-eight studies were included, counting in total 1969 healthy controls and 2656 patients. The collection and analysis of exhaled VOCs profiles is completely non-invasive and can be easily applied in the broad range of patients including severely ill subjects and children. Profiles of VOCs were able to accurately diagnose various pulmonary diseases. Despite these promising findings, multiple challenges, such as standardisation and validation, still need to be mastered before VOCs can be applied into clinical practice. Potential clinical applications of VOCs as well as their limitations are discussed. 


\section{Introduction}

\section{Background and aim}

Pulmonary diseases are important causes of morbidity in both adults and children. ${ }^{1,2}$ The various pulmonary diseases go along with clinical challenges. In adults, lung cancer is one of the leading causes of death worldwide. It is often diagnosed at an advanced stage when successful treatment is difficult, resulting in a five year mortality rate of $>85 \%$. ${ }^{3}$ Furthermore, Chronic Obstructive Pulmonary Disease (COPD) and asthma are prevalent lung diseases that account for a major burden on society in terms of morbidity and health care costs. Early (differential) diagnosis and close monitoring of both diseases are important for proper treatment decisions and good disease control and prognosis. However, the available clinical tools are not always fulfilling. In children, asthma is the most common chronic pulmonary disease, with a prevalence ranging from $1-30 \%$ in different countries. ${ }^{4}$ Although asthma is a common disease in children, only a minority of young children with respiratory symptoms, such as wheeze, will have persistent symptoms that develop into asthma. Mostly, preschool wheeze is transient and associated with viral infections. ${ }^{5}$ Currently, there are no diagnostic tools available to discriminate between true asthmatic children and children with transient, viral-induced wheeze. On account of these clinical challenges, there is a continuous search for techniques that can improve accurate diagnoses and management decisions in pulmonary diseases. A potential non-invasive technique is the analysis of volatile biomarkers in exhaled breath, so called Volatile Organic Compounds (VOCs). This manuscript systematically reviews the current knowledge on VOCs with respect to the capacity of these biomarkers to diagnose and monitor pulmonary diseases. At first, the rationale behind VOCs in pulmonary diseases and techniques to assess VOCs are discussed. Thereafter, an overview is provided of the clinical studies that were performed on VOCs in pulmonary diseases. With this knowledge we will discuss the potential applications, limitations and considerations regarding VOCs in the field of pulmonary diseases.

\section{Rationale}

Most pulmonary diseases, such as asthma, COPD and Cystic Fibrosis (CF), are characterised by inflammation and oxidative stress. Oxidative stress is also present in neoplastic processes, like in lung cancer. Monitoring of airway inflammation and oxidative stress can increase insight in the pathophysiology of these diseases. Current available techniques to directly measure inflammation and oxidative stress include bronchoscopy and bronchoalveolar lavage. These techniques are too invasive for repeated routine use, especially in children. The need for non-invasive analysis of inflammation and oxidative stress in the lungs has led to increasing interest in exhaled breath analysis. Fractional exhaled Nitric Oxide (FeNO) is the most extensively studied marker in exhaled breath. ${ }^{6}$ Although the analysis of FeNO might be a helpful clinical 
tool in pulmonary diseases, it has some limitations. ${ }^{6}$ For example in asthma, FeNO is especially a marker of allergic status and therefore of limited use in non-allergic patients. ${ }^{7}$ Consequently, additional exhaled biomarkers were studied. Next to nonvolatile biomarkers that can be assessed in Exhaled Breath Condensate (EBC), the analysis of exhaled VOCs gained popularity. ${ }^{8-10}$ VOCs are a diverse group of carbonbased chemicals that are volatile at room temperature and are formed in the body during several (patho)physiological processes. ${ }^{8,11}$ An important group of VOCs are the hydrocarbons that are formed by lipid peroxidation. During the inflammatory process, Reactive Oxygen Species (ROS) are produced by inflammatory cells. Subsequently, ROS react with lipid membrane structures and cause degradation of polyunsaturated fatty acids. As a result several stable breakdown products such as hydrocarbons are formed. ${ }^{8,11}$ Next to hydrocarbons, other VOCs can be identified, including nitrogen, oxygen or sulphur containing compounds. These VOCs are mainly formed during (patho)physiological processes in the liver and pancreas. ${ }^{8}$ As soon as VOCs are formed, they enter the bloodstream and are excreted into breath. Early findings of distinct VOCs in diseased people (e.g. with diabetes or cirrhosis) compared to healthy controls stimulated investigators to elucidate the clinical potential of exhaled VOCs in pulmonary diseases. ${ }^{8,12}$ Since exhaled VOCs are formed during inflammatory processes, the analysis of VOCs may be a promising non-invasive technique to directly monitor inflammation and oxidative stress. This information might be of help in the diagnosis and monitoring of pulmonary diseases. It can easily be applied in adults, young children and patients with a severe disease. ${ }^{13-15}$ However, techniques to collect and analyse VOCs are not standardised and validated yet.

\section{A short history}

It was already in ancient Greek times that physicians knew the importance of the odour of patients' breath and used it as diagnostic tool in for example diabetes and liver diseases. ${ }^{8}$ Modern analysis of exhaled VOCs started in the 1970s, when Pauling and colleagues determined a complex mixture of more than 200 VOCs in human breath. ${ }^{8,16}$ Due to technical improvements in analytical techniques in the 1980s and 1990s, several compounds could be correlated to various diseases such as diabetes, cirrhosis and uraemia. ${ }^{8,17}$ With respect to pulmonary diseases, exhaled breath analysis was first applied in lung cancer to study its potential for early detection. ${ }^{18}$ Multiple research groups such as those of $\mathrm{O}^{\prime}$ Neill, Gordon and Phillips identified several VOCs as candidate markers for lung cancer. ${ }^{18-20}$ Since then, VOCs have been investigated in different pulmonary diseases by several research groups.

\section{Technical analysis of exhaled breath}

One of the reasons that, in spite of their potential value, VOCs are not used in clinical practice yet is the lack of standardisation regarding collection and analysis. There are different techniques described to collect, detect, and analyse exhaled VOCs, as 
extensively reviewed previously. ${ }^{11,21,22}$ The most commonly used techniques are gas chromatography (GC) and the electronic nose (eNose).

\section{Gas chromatography}

There are two basic approaches to collect exhaled breath. The first technique is total air sampling, including sampling of dead space air, while the second technique specifically samples alveolar air. Whole air sampling is used most frequently as it is easy to perform. ${ }^{8}$ Breath samples can be collected into various containers such as gastight syringes, glass bulbs, inert bags, or metal containers. ${ }^{22}$ After collection, preconcentration of the breath sample is usually the next step due to the low concentration of VOCs in exhaled breath. It can be performed by using e.g. sorbent trapping, cryogenic trapping, or solid-phase micro extraction. ${ }^{11}$ Once the VOCs are collected and temporarily trapped, they can be released for analysis. This is often performed by solvent or thermal desorption. Subsequently, the analysis of individual molecular components can be performed by gas chromatography usually followed by mass spectrometry (GC-MS) or a flame ionization detector (GC-FID). ${ }^{11}$ The various VOCs are separated and quantified by using their specific compound characteristics. Distinct VOCs have dissimilar progression rates and reach the end of the GC column at different time points; the retention time. Based on their retention time (Figure 4.1), the VOCs can be identified in a mass-spectra library.

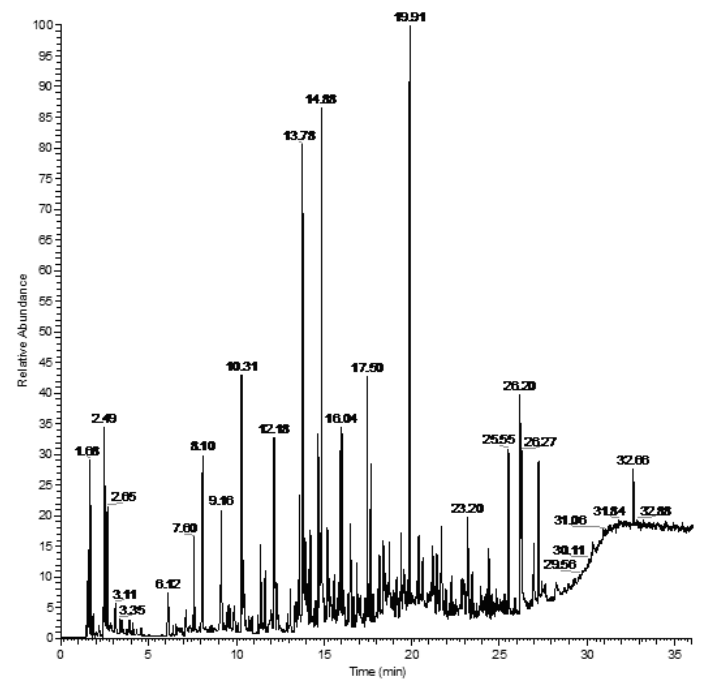

Figure 4.1 Breathogram of VOCs by gas chromatography

Example of a chromatogram of a breath sample as analysed by gas chromatography. The retention time (in minutes) is stated on the $x$ axis, while the $y$ axis shows the relative abundance of various compound signals. Published in Robroeks et al. Pediatr Res $2010 .{ }^{42}$ 


\section{Electronic nose}

Breath samples can also be analysed directly from the patient into analytical systems, such as the eNose. ${ }^{21}$ The eNose consists of an array of nanosensors. When these sensors are exposed to a mixture of VOCs, a change in their electrical resistance is induced, leading to the production of a 'breath-print' (Figure 4.2). This breath-print represents the complex mixture of exhaled VOCs and can be used for patternrecognition algorithms in multiple diseases. ${ }^{23-26} \mathrm{~A}$ limitation of the eNose is that it is unable to analyse individual molecular components.

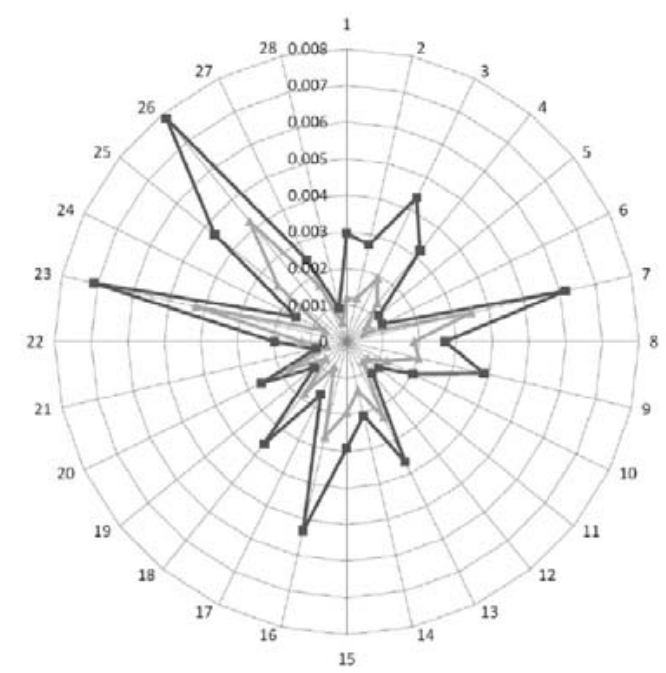

Figure 4.2 Breathogram of VOCs by the electronic Nose

Example of two exhaled breath-prints (dark line represents sample 1, light line represents sample 2 ) as analysed by the eNose. The y axis represents the change in resistance $\left(\Delta R / R_{t=0}\right)$ of each of the 28 sensors (1-28). The resulting breath-print can be used for pattern-recognition algorithms. Courtesy: Paul Brinkman, Niki Fens, Peter Sterk, University of Amsterdam, The Netherlands.

\section{Other techniques}

In addition to GC and the eNose, the analysis of VOCs can also be performed by other techniques such as proton transfer reaction mass spectrometry (PTR-MS), ${ }^{27}$ selected ion flow tube mass spectrometry (SIFT-MS), ${ }^{28}$ ion mobility spectrometry $\left(\right.$ IMS) ${ }^{29}$ and laser spectroscopy, ${ }^{30}$ as reviewed by Buszewski et al. ${ }^{11}$ 


\section{Methods}

\section{Search and review strategy}

We carried out a systematic literature search until July 2011 in PubMED (MEDLINE), EMBASE, and Cochrane Central Register of Controlled Trials. The used keywords/Mesh terms were; 'asthma', 'chronic obstructive pulmonary disease', 'COPD', 'cystic fibrosis', 'lung cancer', 'pulmonary disease', 'respiratory infection', 'electronic nose', 'diagnostics' and 'monitoring', combined with 'volatile organic compounds', 'VOC' or 'VOCs'. The reference lists of the included studies were reviewed for additional references.

\section{Criteria for the included studies}

Only clinical, in vivo studies with full text in English were included. There were no restrictions regarding the study design. Because of the expected heterogeneity of the studies, no single scale was used for excluding studies on basis of their quality. Instead, we described per study, criteria that are of importance to examine the validity; study design, study population, description of materials/methods and outcome measures (Table 4.1). Data were summarised per disease.

\section{Results}

\section{Description of included studies}

Forty-eight studies were included in the review. Characteristics of these studies are provided in Table 4.1. Of these studies, six described the potential of VOCs in asthma, three in COPD, two in both asthma and COPD, four in CF, twenty-five in lung cancer and eight studies described VOCs in other pulmonary diseases. A total of 1969 healthy controls and 2656 patients were investigated; 285 patients with asthma (including 63 children with asthma), 265 patients with COPD, 109 young patients with CF, 1191 patients with lung cancer, 148 patients with an abnormal chest radiograph, 268 persons suspected for pulmonary tuberculosis, and 390 patients with diverse pulmonary diseases (e.g. pneumonia, sarcoidosis, acute respiratory distress syndrome, emphysema, bronchitis). The included studies described several analytical techniques. Thirty-two studies reported the use of gas chromatography, usually combined with mass spectrometry, whilst the eNose was used in eleven studies. The other five studies used PTR-MS, colorimetric sensor array, laser absorption spectroscopy and IMS. In total, thirty-two studies were conducted in the last five years. 


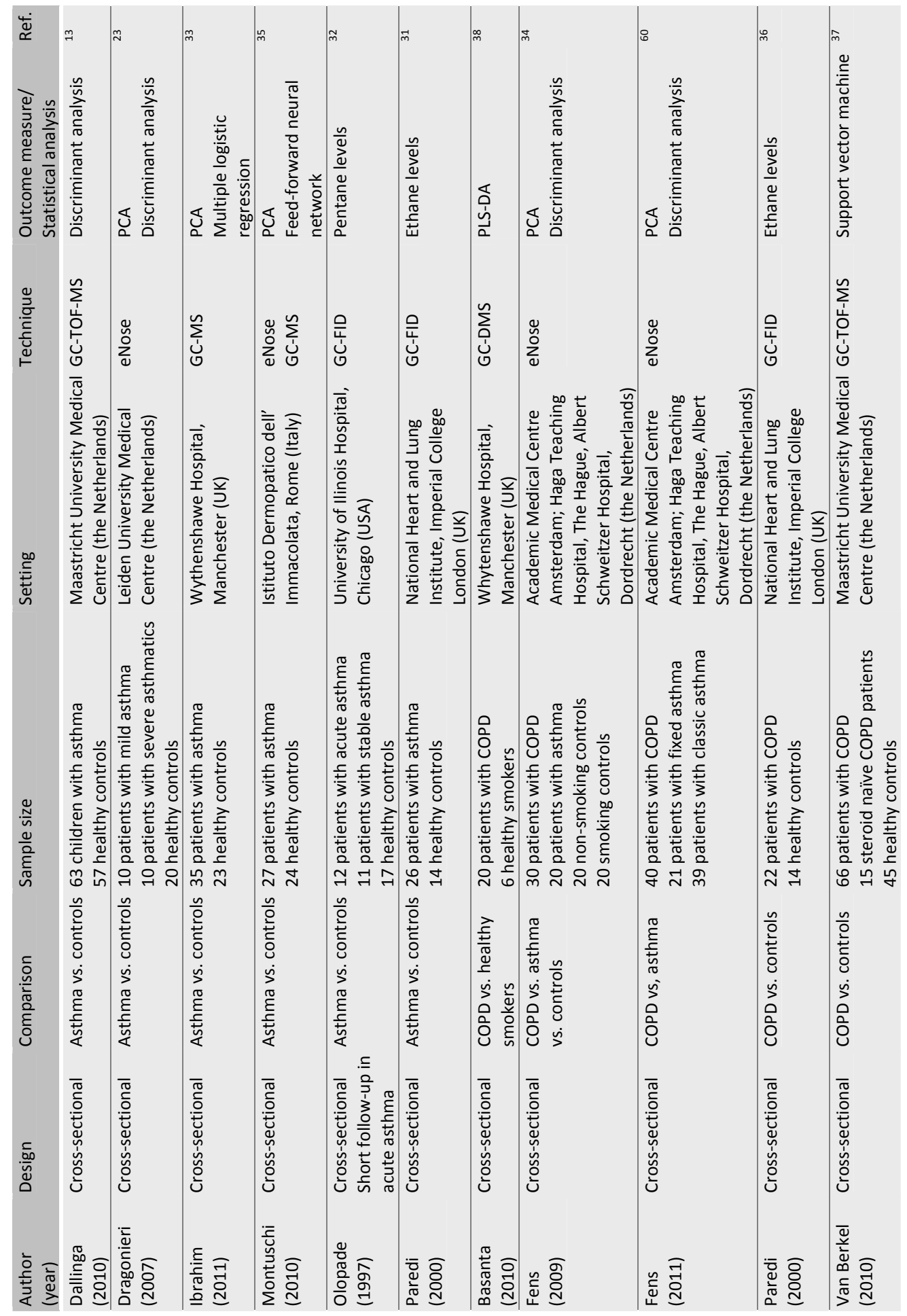




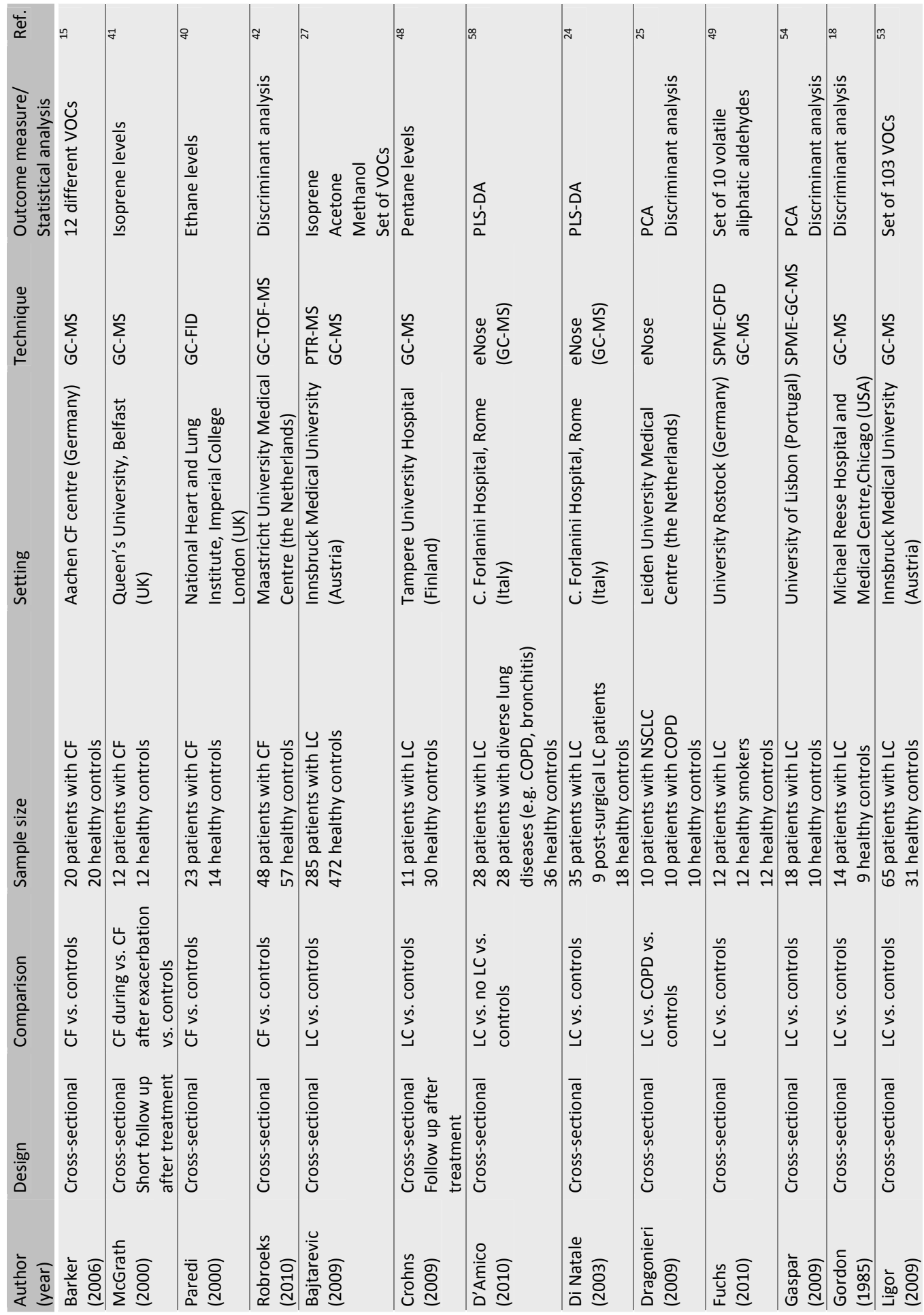




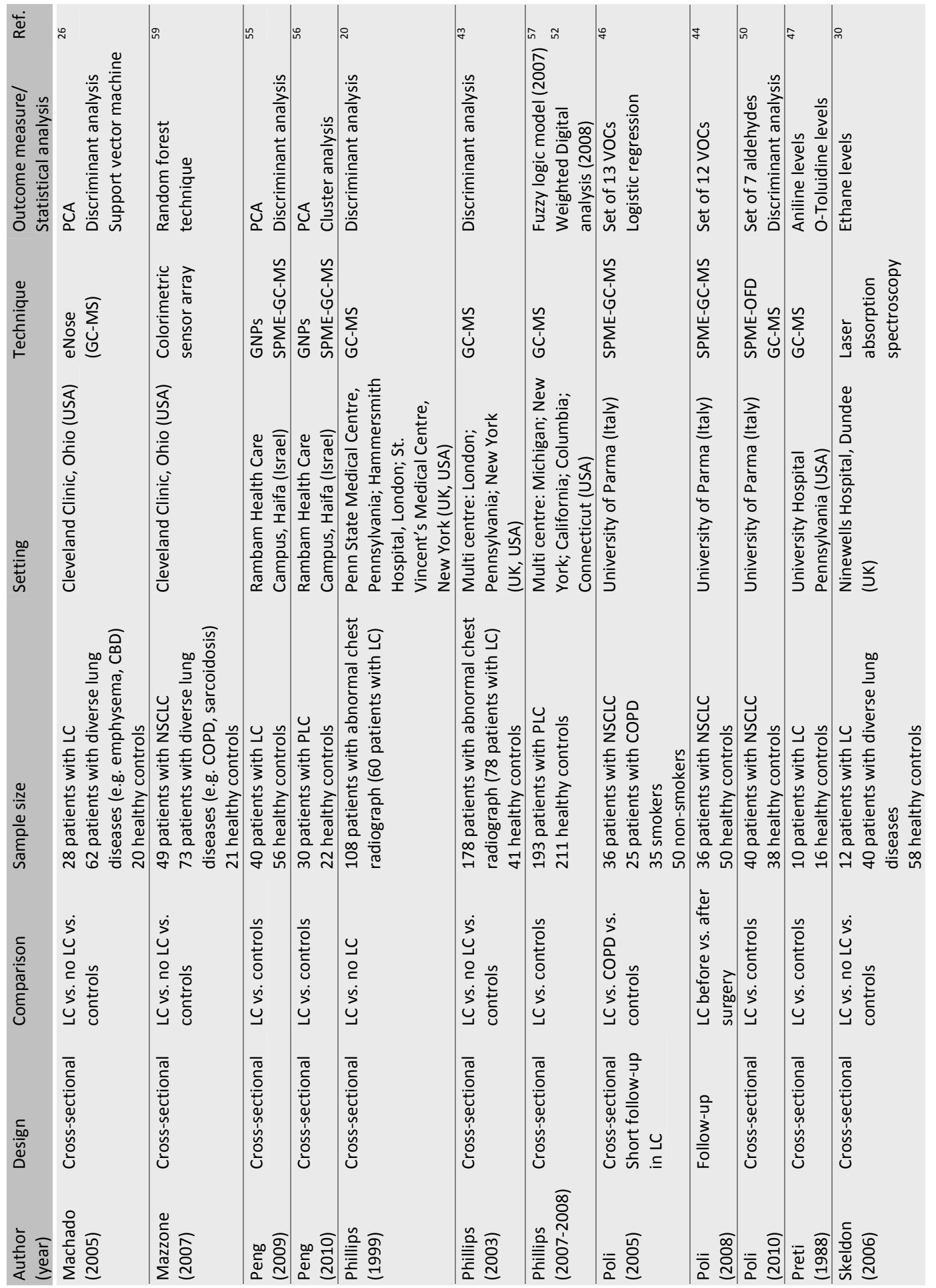




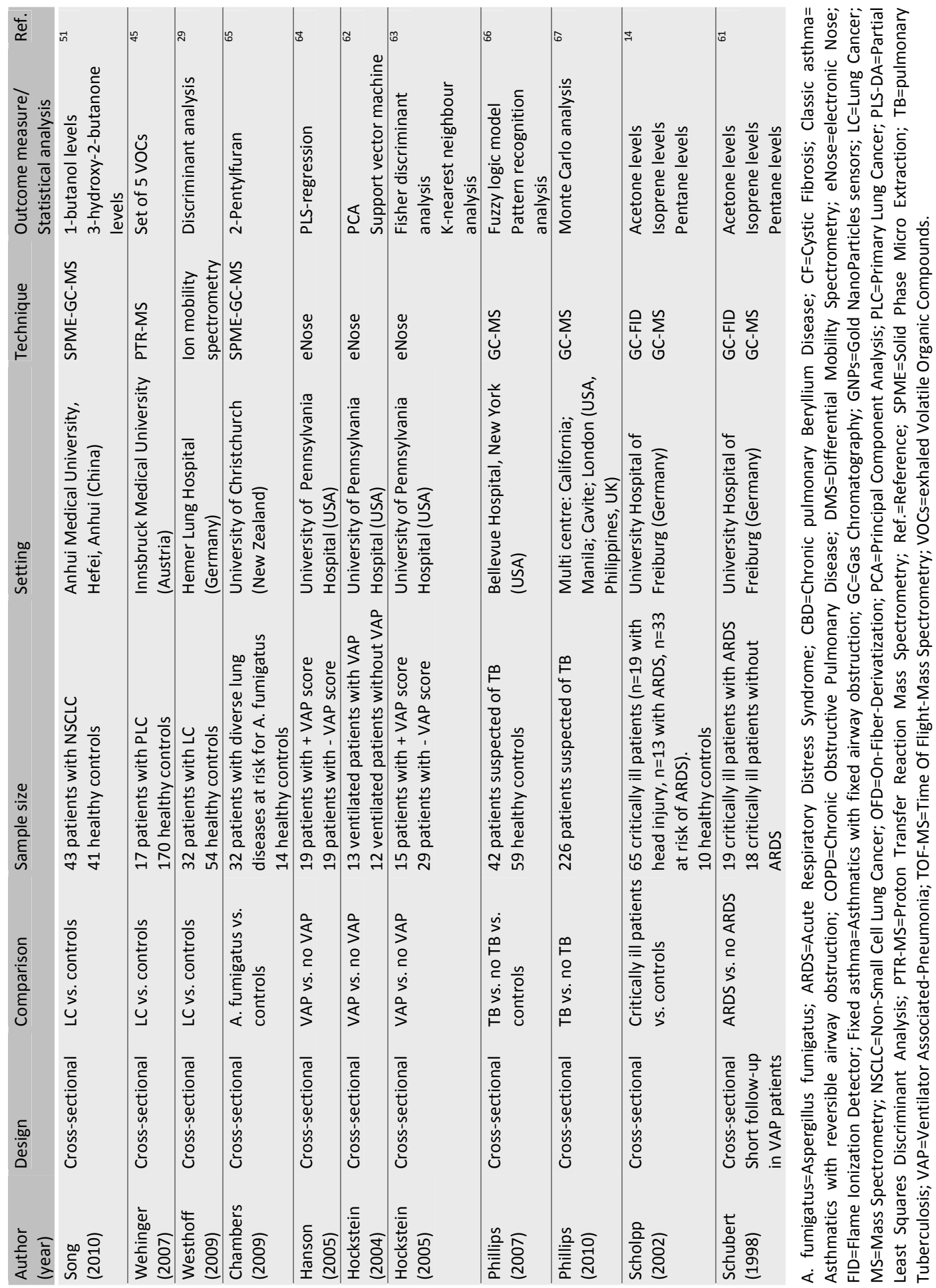




\section{VOCs in pulmonary diseases}

An overview of findings per study can be found in Table 4.2, 4.3 and 4.4. The most important findings for each pulmonary disease are summarised below.

\section{Asthma}

The groups of Olopade, Paredi, Ibrahim and Dallinga used gas chromatography to identify potential VOCs in asthma. ${ }^{13,31-33}$ Olopade et al. reported higher exhaled pentane levels in patients with acute asthma, compared to healthy controls. Once acute asthma subsidised, pentane levels decreased to levels comparable to controls. ${ }^{32}$ Paredi et al. found elevated levels of exhaled ethane in steroid-naïve patients with asthma compared to healthy controls and steroid-treated patients with asthma. Furthermore, ethane was higher in patients with severe asthma (FEV $1<60 \%)$, compared to patients with mild asthma $\left(\mathrm{FEV}_{1}>60 \%\right) .{ }^{31}$ Ibrahim et al. studied the potential of VOCs profiling to assess asthma diagnosis, sputum inflammatory cell profile and asthma control in 35 asthmatics and 23 matched controls. ${ }^{33}$ They demonstrated that a model derived from 15 VOCs was able to correctly diagnose asthma, with a cross-validated accuracy of $83 \%$. Moreover, VOCs profiles were able to accurately diagnose sputum eosinophilia and identified patients with poor disease control with cross-validated accuracies of $83 \%$ and $80 \%$, respectively. ${ }^{33}$ By using discriminant analysis, our research group demonstrated that children with asthma could be distinguished from controls by using a model of eight VOCs ( $89 \%$ sensitivity, $95 \%$ specificity). ${ }^{13}$

Dragonieri and Fens et al. found that the eNose was capable of discriminating patients with asthma from healthy controls, with cross-validation values ranging from $90-100 \%$ of the models. ${ }^{23,34}$ However, it was not possible to adequately distinguish mild and severe asthmatics. ${ }^{23}$ Montuschi and colleagues demonstrated that analysing alveolar air with the eNose better discriminated patients with asthma from healthy subjects than FeNO or lung function did $(88 \%, 79 \%$ and $71 \%$ correct classification, respectively). ${ }^{35}$

To summarise, earlier studies mainly focused on single VOCs and found two alkanes (pentane and ethane) elevated in patients with acute-, steroid-naïve- and severe asthma. More recent studies focused on modelling of VOCs and demonstrated that discriminative models were accurately able to differentiate asthmatics from healthy controls. 


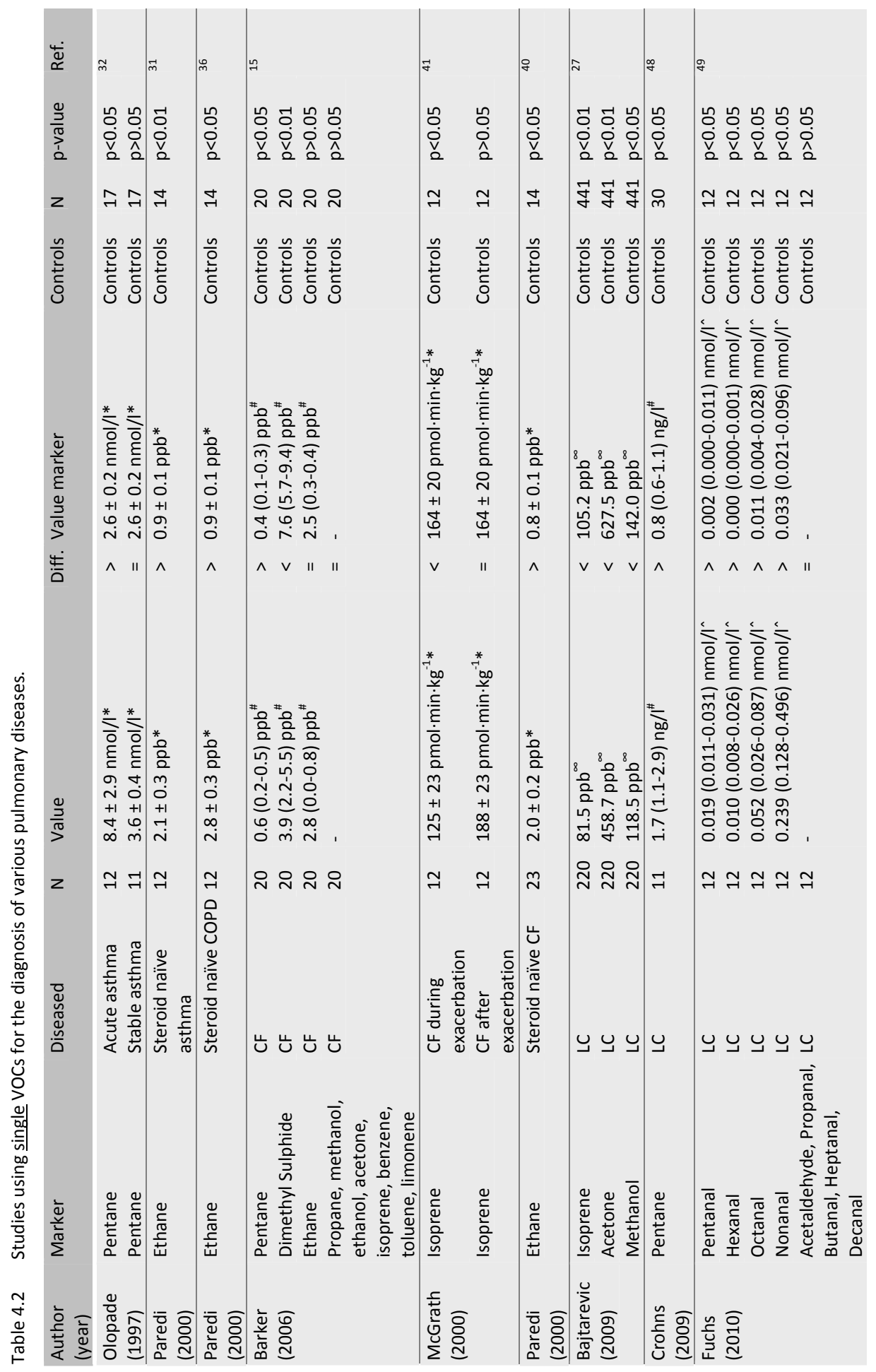




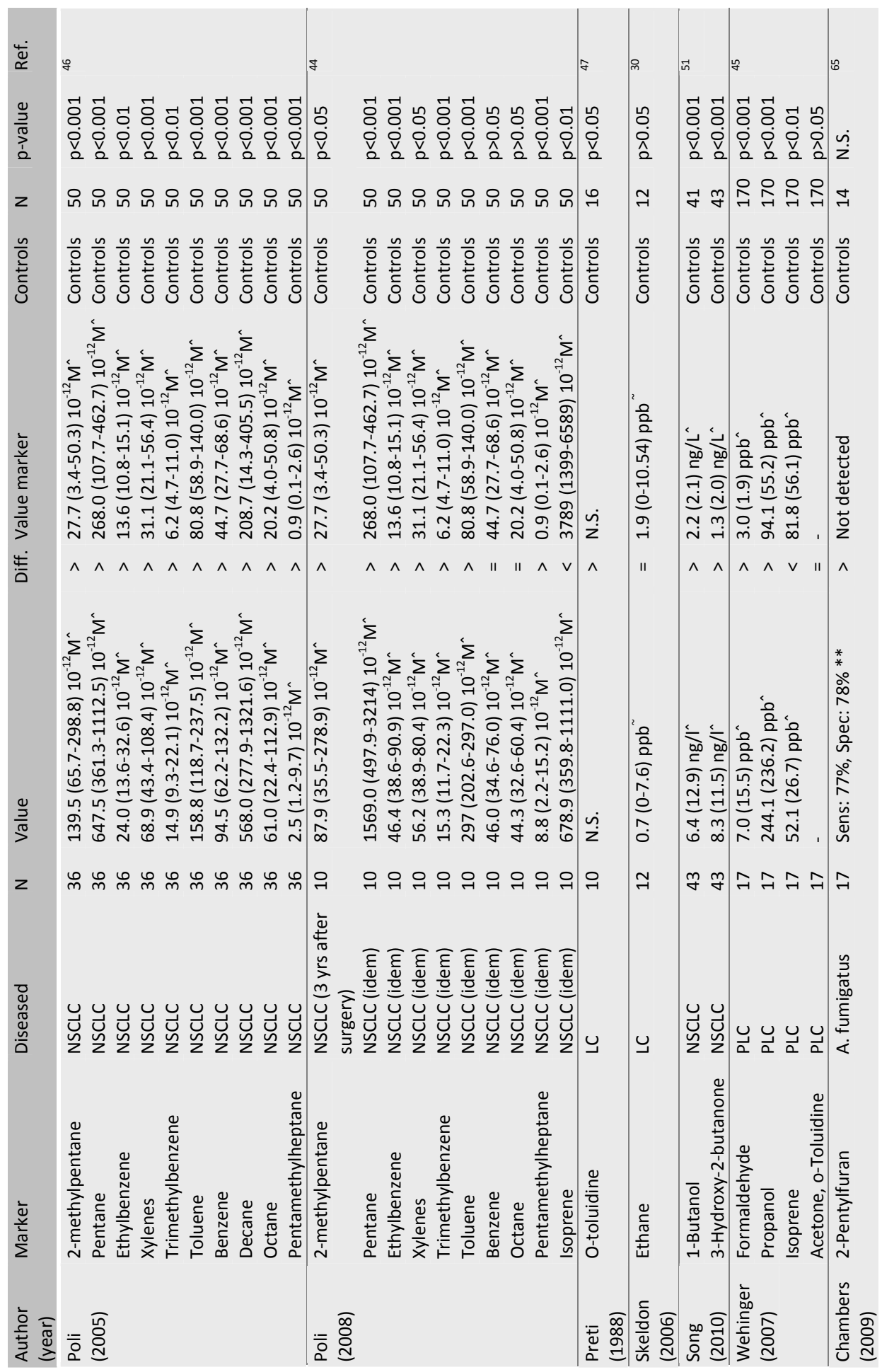




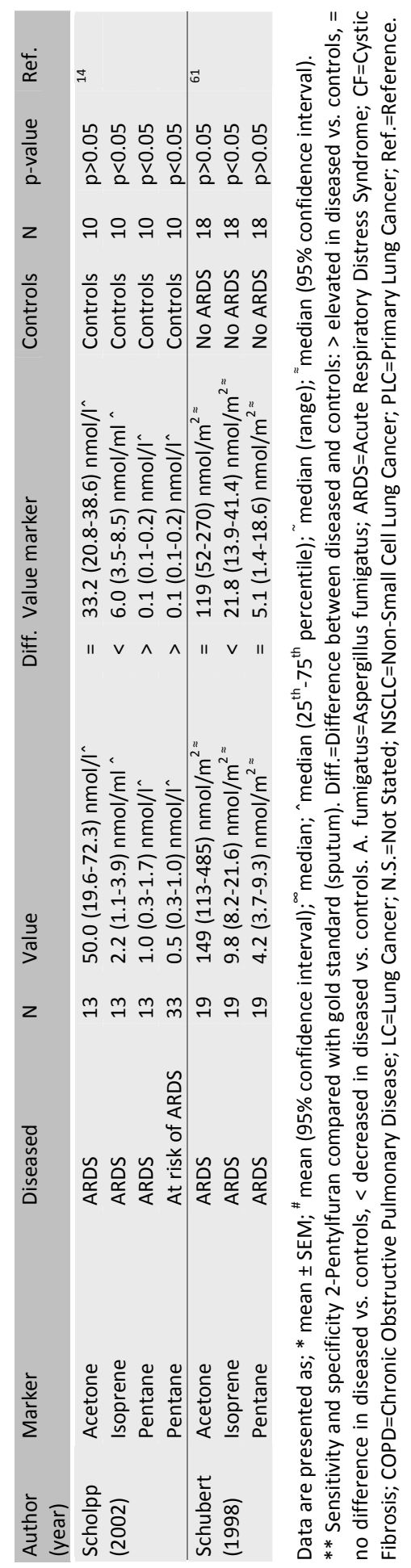




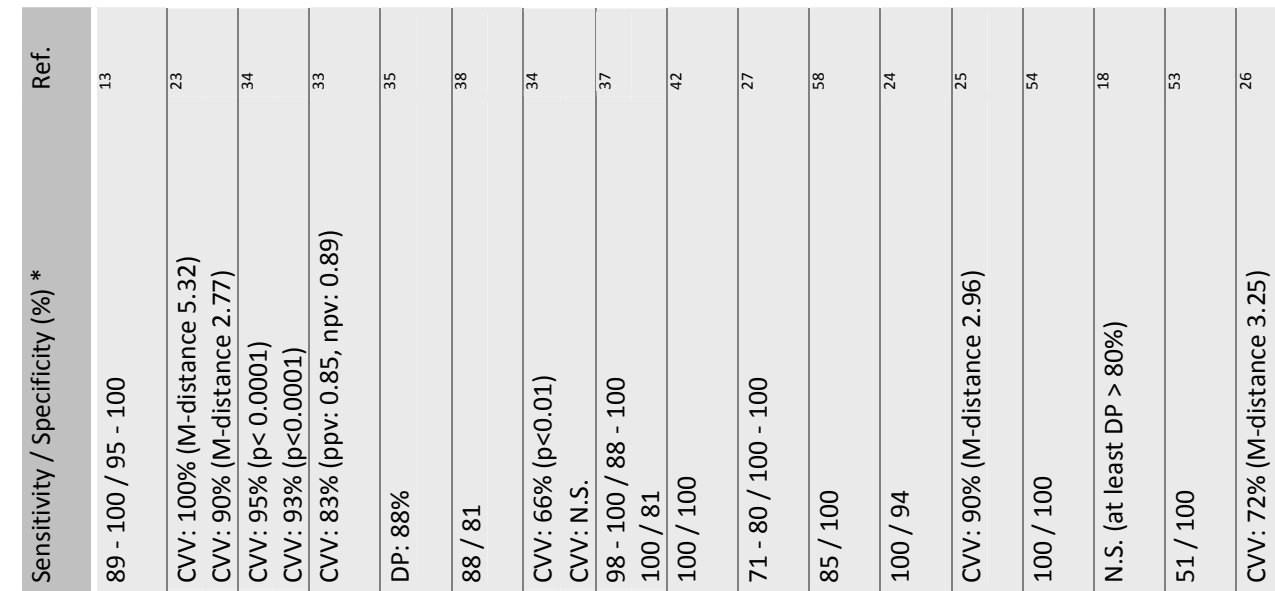

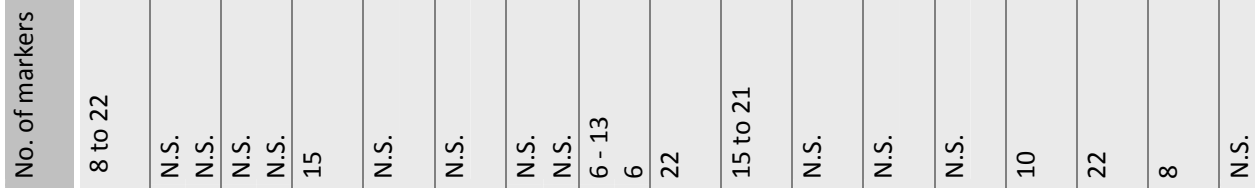

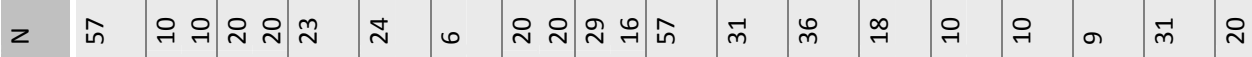

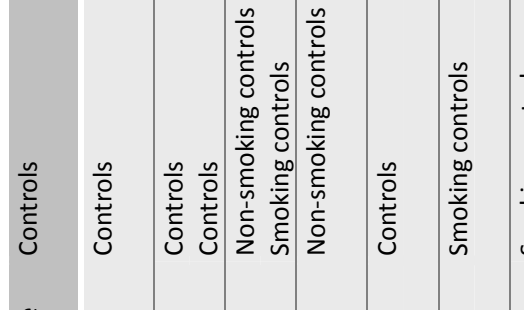

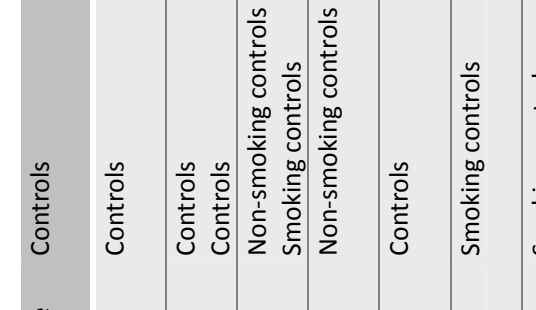
믐

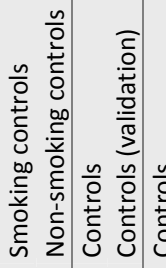

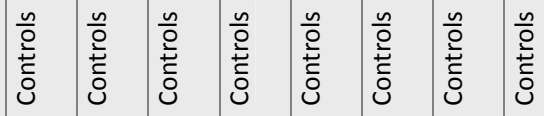

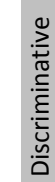

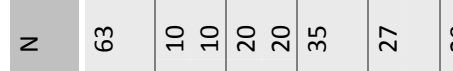

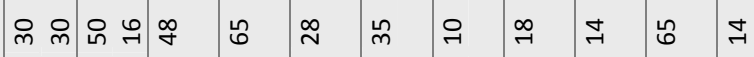
인

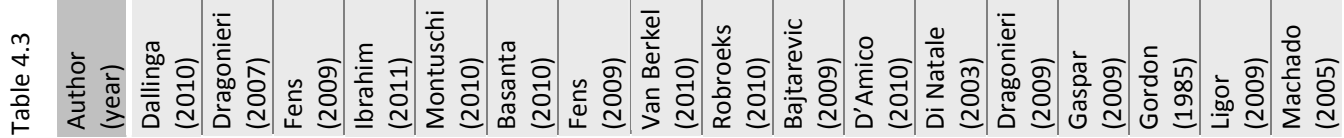




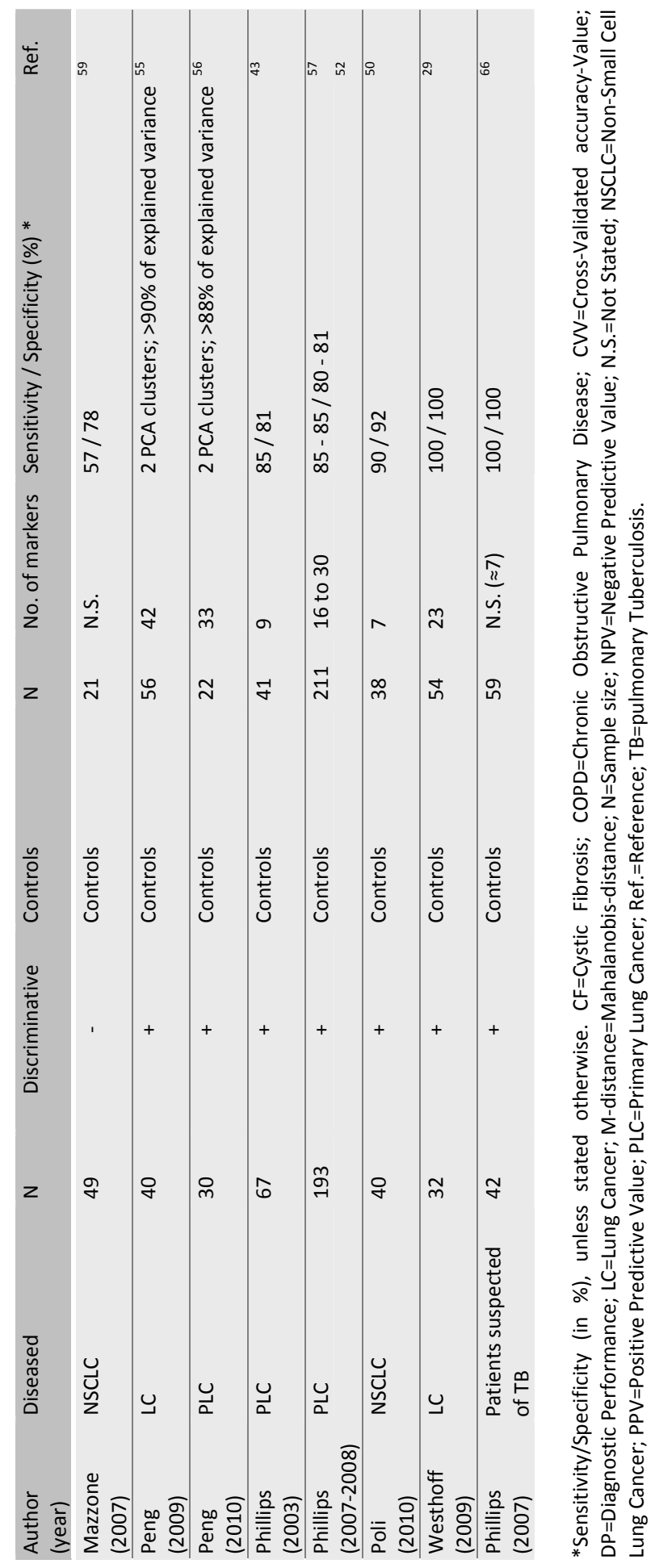




\section{Chronic obstructive pulmonary disease}

Paredi et al. observed elevated levels of ethane in steroid-naïve COPD patients compared to healthy controls and steroid-treated patients. ${ }^{36}$ Moreover, breath ethane levels correlated well with lung function and higher ethane levels were found in patients with a lower $\mathrm{FEV}_{1}$ predicted value. ${ }^{36}$ Van Berkel et al. showed that a model of thirteen VOCs was $100 \%$ able to discriminate between COPD patients and healthy controls. When this model was reduced to six components, a correct classification of $91 \%$ (100\% sensitivity, $81 \%$ specificity) was achieved in an independent validation population. ${ }^{37}$ Moreover, the authors found that their prediction model was not dependent of smoking behaviour and use of inhaled corticosteroids. This implies that the prediction model also holds for the diagnosis of COPD in a smoking population. Basanta and colleagues demonstrated that a VOCs profile obtained by GC-DMS was able to differentiate COPD patients from asymptomatic smokers (88\% sensitivity, 81\% specificity). ${ }^{38}$ By using the eNose, Fens et al. found that breath-prints from COPD patients could not be easily discriminated from smoking controls (accuracy of 66\%). ${ }^{34}$ In a recent study, Fens et al. demonstrated that breath-prints assessed with GC-MS and eNose were associated with both cell counts and markers of inflammatory cell activation (eosinophilic vs. neutrophilic) in induced sputum samples of 28 patients with mild to moderate COPD. ${ }^{39}$ These findings indicate that breath-prints can monitor both type and activity of airway inflammation.

\section{Cystic fibrosis}

Paredi demonstrated that ethane levels were elevated in steroid-naïve CF patients compared to non-smoking controls and steroid-treated CF patients. ${ }^{40}$ This finding could not be reproduced by Barker et al. who found equal levels of ethane in CF patients and controls. ${ }^{15}$ The difference in findings might be explained by dissimilar methodologies and correction for ambient ethane that was performed by Barker but not by Paredi. On the contrary, Barker did found elevated levels of pentane and 2-propanol, and diminished levels of dimethyl sulphide in CF patients. ${ }^{15}$ McGrath et al. demonstrated that CF patients with an acute exacerbation had lower levels of exhaled isoprene compared to controls. ${ }^{41}$ However, when these patients were treated with antibiotics, their isoprene levels increased to normal. ${ }^{41}$ Instead of using a single biomarker, our research group demonstrated that by using a profile of twenty-two VOCs, a $100 \%$ correct classification of CF patients and controls was possible. When the number of VOCs was limited to $10,92 \%$ of the subjects were correctly classified. ${ }^{42}$

\section{Lung cancer}

The majority of the studies that described VOCs in lung cancer did not specify the type of lung cancer that was studied. Of the studies that did clarify their patient group, the majority of patients had non-small cell lung cancer (Table 4.1). Mostly primary lung cancer was studied, whilst Phillips differentiated patients with primary and metastatic 
lung cancer. ${ }^{43}$ While several groups studied single compounds, others looked whether combining multiple VOCs with advanced statistical techniques had diagnostic potential. Regarding single compounds, lower levels of exhaled isoprene were found in lung cancer patients compared to healthy controls. ${ }^{27,44,45}$ In contrast, for various other VOCs, elevated (e.g. pentane, benzene, toluene, xylenes, octane, o-toluidine, propanol, 1-butanol, multiple aldehydes) or equal (e.g. ethane, styrene) levels were found in patients with lung cancer compared to controls (Table 4.2). ${ }^{30,45-51}$ Song et al, described that although 1-butanol and 3-hydroxy-2-butane levels were found elevated in lung cancer patients compared to controls, these levels were not different between early stage lung cancer patients and late stage lung cancer patients. ${ }^{51}$

Ten studies demonstrated that a combination of VOCs, identified by GC-MS, could differentiate patients with lung cancer from healthy controls. ${ }^{18,27,43,50,52-57}$ The number of VOCs per model ranged from 7 to 30 , with a sensitivity ranging from $71-100 \%$ and a specificity ranging from $80-100 \%$, except for Ligor et al. who reported a sensitivity of only $51 \%$ (and $100 \%$ specificity). ${ }^{53}$ Gordon et al. only mentioned the overall accuracy which was $>80 \%{ }^{18}$ Peng et al. and Gaspar et al. described that clear clusters of VOCs could be formed separating healthy controls from lung cancer patients by using principal component analysis (PCA). ${ }^{54-56}$ In general, the discriminating VOCs were predominantly alkanes (e.g. pentane, heptane, butane), alkane derivates (e.g. 1-propanol, 2-methylhexane) and benzene derivates (e.g. ethyl-, propylbenzene). Four groups used the eNose to study whether a profile of VOCs was able to discriminate patients with lung cancer from controls. ${ }^{24-26,58}$ In general, the eNose was able to pick up breath-prints of lung cancer patients, illustrated by a sensitivity ranging from 85$100 \%$, a specificity of $94-100 \%$, and a cross-validation-accuracy value of $72-90 \%$. Westhoff et al. used IMS to study VOCs and reported that a combination of twentythree VOCs was $100 \%$ able to differentiate patients with lung cancer from controls. ${ }^{29}$

In total, eight studies described the potential of VOCs to differentiate patients with lung cancer from patients with other lung diseases. ${ }^{20,25,26,30,43,46,58,59}$ These comparisons better resemble clinical practice than comparing lung cancer patients with healthy controls. The studies are described in detail below ('differential diagnosis', Table 4.4). In general, the diagnostic performance of the VOCs models was poorer in this more realistic scenario than in the studies that separated lung cancer patients from healthy controls.

Next to diagnostic purposes, two studies described the potential of VOCs to monitor lung cancer. In a follow-up study, Poli et al. measured multiple VOCs in lung cancer patients before surgery, and one month and three years after surgery of the tumour. ${ }^{44}$ All VOCs levels were unaffected one month after surgical resection, except for isoprene which levels were significantly reduced. After three years, several VOCs demonstrated to be either increased (e.g. pentane, toluene) or decreased (e.g. isoprene, benzene) compared to baseline. ${ }^{44}$ However, most post-surgical VOCs levels remained higher compared to levels of controls. Likewise, Crohns et al. studied pentane levels in reaction to radiotherapy and overall survival of lung cancer 
patients. ${ }^{48}$ Although they were not able to detect significant changes of exhaled pentane levels during radiotherapy, they did demonstrate that higher pre-treatment pentane levels predicted better survival. However, it should be noted that their sample size was small $(\mathrm{N}=11) .^{48}$ Due to the limited data, the role of VOCs as prognostic biomarkers is largely unclear and needs to be further studied.

Smoking status is an important factor that should be taken into account in the analysis of VOCs, especially for the diagnosis of lung cancer or COPD. Smoke contains profuse amounts of VOCs and is associated with alterations in exhaled VOCs patterns. Therefore, the majority of the above mentioned studies performed in lung cancer and COPD patients took smoking status into account in their analysis. These studies demonstrated that smoking status did not affect the performance of VOCs profiles regarding the diagnosis of lung cancer and COPD. ${ }^{20,34,37,38,48,50,56,57,59,60}$

To summarise, a combination of predominantly alkanes, alkane- and benzenederivates was found to be clearly discriminative between patients with lung cancer compared to healthy controls. Of all the identified VOCs, only the minority of compounds were found in two or more studies. A partial explanation for this limited agreement in outcomes is that different techniques and methodologies were used. This stresses the importance of standardisation of sampling and analytic techniques to improve inter-laboratory comparability.

\section{Other pulmonary diseases}

Eight studies described VOCs in other pulmonary diseases than stated above. The group of Schubert and Schollp studied VOCs in critically ill patients with acute respiratory distress syndrome (ARDS). ${ }^{14,61}$ Lower isoprene levels were reported in ARDS patients compared to controls. Moreover, elevated pentane levels in patients with ARDS were found in the most recent study. ${ }^{14}$ This finding is in line with their earlier work in which they reported that in critically ill patients who developed ventilatorassociated pneumonia (VAP), isoprene levels decreased, whereas pentane levels increased, compared to patients without pneumonia. ${ }^{61}$ Also Hockstein, Hanson and colleagues studied the potential of VOCs in VAP patients and demonstrated that the eNose is a promising technique for diagnosing this form of pneumonia. ${ }^{62-64}$ Chambers and colleagues demonstrated that 2-pentylfuran (a small VOC) was commonly present in breath of patients with a chronic pulmonary disease (such as asthma or CF) with Aspergilus fumigatus in their respiratory specimens (77\% sensitivity, $78 \%$ specificity), whereas this VOC was not detected in breath of healthy controls. ${ }^{65}$ Philips et al. investigated the potential role of VOCs in detecting pulmonary tuberculosis (TB). ${ }^{66,67}$ By using various statistical techniques (including fuzzy logic- and Monte Carlo analysis), they observed that in a group of patients with suspicion of TB, VOC patterns were sensitive and specific enough to distinguish patients with TB from those without active TB. However, it should be noted that the accuracy was not perfect and ranged from 65 to $85 \%$ depending on the gold standard that was chosen (sputum culture, microscopy and/or chest radiography). ${ }^{67}$ 

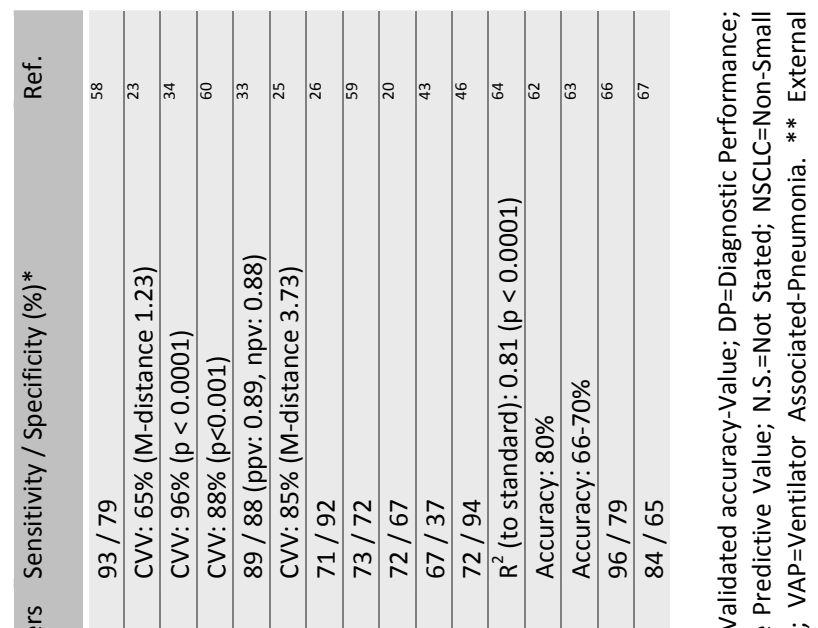

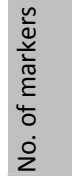
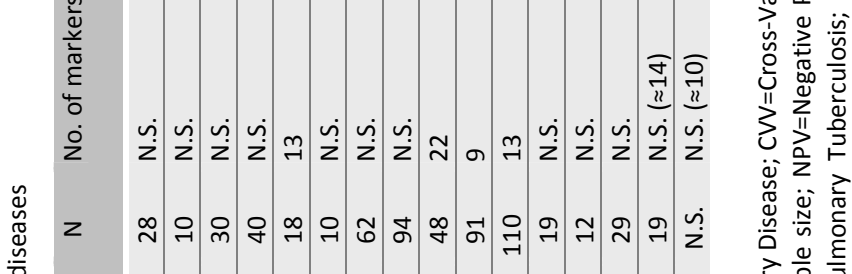

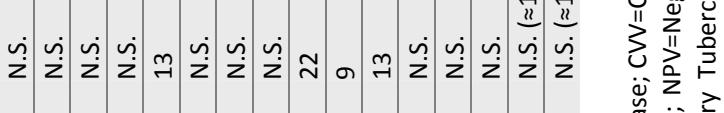

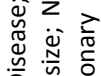
$\geq \frac{0}{3}$ ช है 유 윰

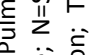

$\frac{\sqrt{0}}{\stackrel{0}{0}}$ 西

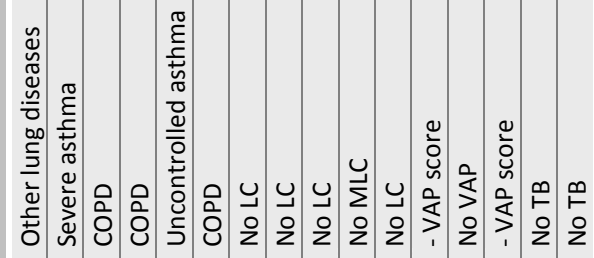

$\frac{n}{4}$

일

告

¿

몬.

$\stackrel{00}{5}$

$\frac{\sqrt{n}}{5}$

$\frac{\mathscr{\alpha}}{\frac{0}{3}}$

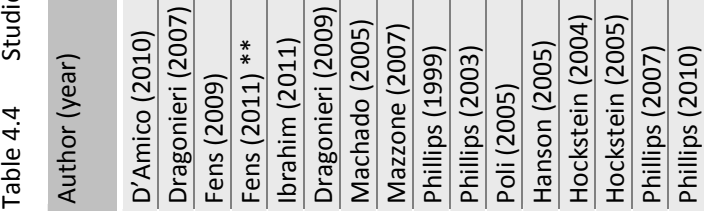

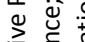
密

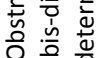
낭

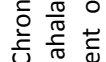

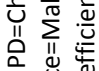

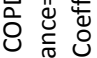
is $\sum_{\substack{0 \\ \sum}}^{i} \frac{j}{\partial}$

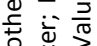

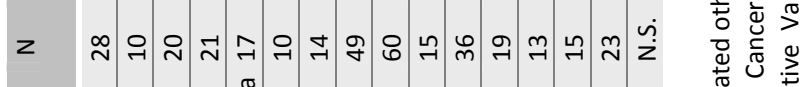

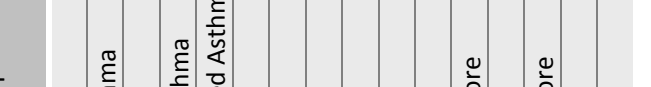

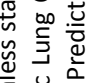

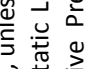

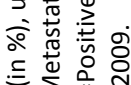

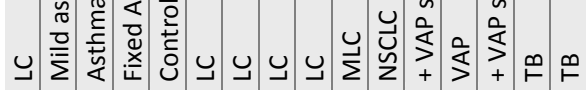
$\geqslant \sum_{11}^{\infty} \prod_{n}^{11}$

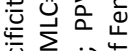
离这岕

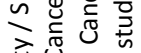
>

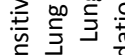
* 


\section{Differential diagnosis}

Several studies investigated the role of VOCs in discriminating between different pulmonary diseases (see Table 4.4). Poli et al. studied thirteen VOCs in lung cancer patients, healthy smokers/non-smokers, and patients with COPD. ${ }^{46}$ Although they observed multiple VOCs (e.g. 1-methylpentane, isoprene and styrene) either elevated or diminished in lung cancer patients compared to COPD patients and healthy controls, none of the VOCs alone was able to properly separate the study groups. However, combining these VOCs by using multiple regression analysis enabled the researchers to correctly classify $80 \%$ of the cases. ${ }^{46}$ This might point to the lack of a single specific biomarker for lung cancer, which is strengthened by the finding of Skeldon et. al who found that ethane was not associated with lung cancer when compared to other pulmonary diseases. ${ }^{30}$ Possibly not a single compound but a combination of VOCs is necessary to correctly diagnose lung cancer. By using an eNose, D'Amico et al. demonstrated that a combination of VOCs could discriminate patients with lung cancer from patients with diverse non-cancer pulmonary diseases (e.g. COPD, pleurisy, bronchitis) with a sensitivity of $93 \%$ and a specificity of $79 \% .{ }^{58}$ A lower accuracy was reported by Mazzone et al. who demonstrated that lung cancer patients could be separated from those with other pulmonary diseases (e.g. COPD, sarcoidosis and idiopathic fibrosis) with a sensitivity of $73 \%$ and a specificity of $72 \%$. $^{59}$ Phillips et al. demonstrated that in subjects with an abnormal chest radiograph, primary lung cancer patients could be distinguished from patients without cancer with a cross-validated sensitivity ranging from 72 to $85 \%$ and a specificity ranging from 67 to $81 \% .^{20,43}$ Besides, he demonstrated that a VOCs model could predict patients with metastatic lung cancer with a sensitivity of $67 \% .{ }^{43}$ Machado et al. demonstrated that breath-prints generated with the eNose were able to detect lung cancer patients with $71 \%$ sensitivity and $92 \%$ specificity in a population also including control subjects without cancer (healthy controls, patients with e.g. emphysema and pulmonary beryllium disease). ${ }^{26}$ In addition, Dragonieri and colleagues demonstrated that eNose generated breath-prints accurately discriminated patients with lung cancer from COPD patients in $85 \%$ of the cases. ${ }^{25}$

Fens et al. found that eNose breath-prints from asthmatic patients could be separated from patients with COPD, with an accuracy of $96 \% .{ }^{34}$ In order to verify this diagnostic accuracy, they performed an external validation study in a new group of patients with asthma and COPD. ${ }^{60}$ They demonstrated that their previous generated breath-print could adequately differentiate newly recruited patients with a classic asthma phenotype (characterized by reversible airway obstruction) and COPD patients with $83 \%$ correct classification. Moreover, this breath-print was able to separate asthmatic patients with fixed airway obstruction from COPD patients with an accuracy of $88 \%{ }^{60}$ As these latter two groups usually have similar symptoms and overlapping spirometry due to an equal degree of fixed airway obstruction, the differential diagnosis is often difficult. These findings implies that VOCs profiling can be of important additional value in the differential diagnosis of (fixed) asthma and COPD. 


\section{Discussion}

\section{Conclusions from this review}

The promising results of research performed in the 1990s stimulated more and more research groups to study the clinical use of VOCs for the diagnosis of various pulmonary diseases. As a consequence, a substantial increase of clinical studies on VOCs was observed in the last decade. Breath analysis was firstly and most extensively applied in lung cancer. Thereafter, this type of research was extended to other pulmonary diseases such as asthma, COPD and CF. The initial studies on VOCs identified biomarkers in a traditional way by focusing on single compounds based on biological insight. Several levels of VOCs were demonstrated to be distinct in people with a pulmonary disease compared to healthy controls. These markers mainly included alkanes for asthma and COPD; alkanes, alkenes and alkene-derivates for CF and analogous compounds plus benzene derivates and aldehydes in lung cancer patients. Due to the overlap in markers, one may argue whether a disease specific biomarker is discovered yet. For example, ethane was not only elevated in asthmatic patients, but also in patients with COPD and CF. Similarly, decreased levels of isoprene were found in both children with $\mathrm{CF}$, lung cancer patients and in people suffering from ARDS. However, despite the lack of a single discriminative biomarker, these studies did demonstrate that the exhaled breath of patients with a particular lung disease could be distinguished from breath of healthy controls. This finding evolved in a new hypothesis that pulmonary diseases are characterized by a distinctive breath-print that is not based on single markers, but on a profile of exhaled breath including numerous VOCs. Instead of a knowledge based strategy, recent studies mainly support an inductive strategy to discover potentially new VOCs. Owing to recent technical and analytical advancements, hundreds of VOCs can be analysed to characterise the 'biomolecular signature' of a pulmonary disease. Various research groups demonstrated that, either by using the eNose or gas chromatography, exhaled breath profiles of patients with several pulmonary diseases could be well distinguished from breath of controls. These are promising results and pave the way for the development of a noninvasive diagnostic tool on the basis of exhaled VOCs. However, there is still a long way to go, as the diagnostic performance of the models was less pronounced when used for differential diagnosis in pulmonary disease, most studies had a limited sample size, little longitudinal data (for monitoring of diseases) were available, and potential confounding factors were not well studied yet. Potential applications of VOCs, as well as constraints that need to be resolved before it can be applied into clinical practice, will be elaborated below.

\section{Advantages and drawbacks of using VOCs in clinical practice}

The vast majority of the studies demonstrated the potential of VOCs to improve diagnostic clinical decision making in various pulmonary diseases. Before discussing the 
potential (other) clinical applications of VOCs and the future efforts in research that need to be performed, we will first summarise the advantages and drawbacks of using VOCs in clinical practice.

Advantages: At first, collection of breath samples is safe, non-invasive and easy to perform even in infants and severely ill patients. Breath collection does not require skilled medical staff and, as sampling is not invasive, obtaining large quantities or repeated measurements are not as bothersome for patients compared to e.g. blood sampling, sputum induction, bronchial biopsy or bronchoalveolar lavage. Secondly, the matrix of exhaled breath is less complex than blood or urine. When analysing the whole 'breath-print', no complicated work-up of the breath sample is needed as is often necessary for blood or urine samples. Thirdly, since VOCs are blood-borne they can reflect different processes in the body and thus may assess different body functions in a flexible manner. If proven to be reliable, the use of VOCs might better mirror the underlying disease than indirect measures such as symptoms and lung function. Fourthly, the available techniques to measure VOCs, such as GC-MS, are very sensitive to detect compounds. Although the initial apparatus is expensive, the costs for analysis are relatively low compared to analytical kits for blood and urine. Finally, techniques such as the eNose allow real-time measurement of compounds in the body.

Drawbacks: Possibly the greatest drawback in the assessment and analysis of VOCs is that techniques are not standardised and validated yet. Due to the heterogeneity of the studies (in selection of controls, study design, sampling and analytical techniques) a variety of results was reported which makes it difficult to draw firm conclusions or to calculate an algorithm for the most important compounds in the diverse pulmonary diseases. Secondly, considerable work needs to be done in order to understand the biochemical origin and physiological meaning of the specific VOCs. This might be difficult since the origin of VOCs is blood-borne and therefore can be the result of widely different biochemical pathways (so the previously mentioned advantage of VOCs can be seen as a disadvantage as well). Thirdly, due to the available high throughput analysis, hundreds of compounds can be identified leaving a challenging task for statistical analysis and interpretation of results. Fourthly, each technique has its specific limitations. For example with the eNose it is not possible to identify single compounds, whether the use of the GC-MS technique is time-consuming and involves bulky equipment. Finally, an important point of consideration is the fact that exhaled compounds can be affected by various factors including ambient VOCs, exhaled flow, and prior consumed food. The effect of these potential confounders (see Table 4.5) needs to be explored before considering VOCs as a clinical tool. 
Table 4.5 Examples of factors that can influence exhaled VOCs in pulmonary diseases.

\begin{tabular}{ll} 
Source & Factor \\
Environment & Ambient VOCs \\
& Temperature of environment \\
& Humidity of inhaled and exhaled air \\
& Season \\
\hline Subject & Personal characteristics: e.g. age, gender, weight, length \\
& Nutrition \\
& Tobacco smoking \\
& Medication use \\
& Circadian rhythm \\
& Non-pulmonary chronic diseases (liver impairment, diabetes) \\
& Breathing pattern: e.g. exhaled flow, minute ventilation, breath hold \\
& Overall lifestyle and physical condition \\
& Time and way of storage \\
& Pre-concentration \\
Breath collection: mixed air or alveolar air \\
Collection method: e.g. tedlar bags, metal containers \\
Analytical methods: e.g. eNose, GC-MS
\end{tabular}

\section{Potential applications and future efforts}

Current research has mainly focused on the diagnostic potential of VOCs. However, there are multiple other conceivable applications of VOCs in the field of pulmonary diseases, such as monitoring of disease status, predicting disease exacerbations, evaluating treatment and screening in population-wide studies (see Table 4.6). In the paediatric field, VOCs might be of special help in the early diagnosis of asthma. It can help to distinct true asthmatics from children with transient, viral-induced wheeze at preschool age. At least two studies are currently performed in which VOC profiling is used for an early asthma diagnosis in preschool children. The preliminary data demonstrated that VOCs profiling was able to objectively diagnose preschool wheeze, either by using the eNose or GC-MS technique. ${ }^{68,69}$ Whether VOCs profiling is useful for the early diagnosis of wheezing phenotypes needs to be determined during the followup.

Although VOCs might be a potential 'discriminative' technique, considerable work needs to be done before they can be applied as diagnostic or monitoring biomarkers. Currently, we are mainly in an observing phase regarding the discovery of VOCs in pulmonary diseases rather than really understanding the meaning and biological origin of these VOCs. An important step that needs to be taken is the validation of the current available models. Otherwise, potential VOCs will be 'trapped' in this discovery phase and will not be used as clinical parameters in the near future. As stated by Koulman et al., "the process of biomarker discovery covers more than finding differentiating metabolites. After the discovering of differentiating (patterns) of metabolites an extensive validation process has to take place. Only after sufficient proof of precision, accuracy and biological relevance, the differentiating metabolite can move to the status of "biomarker'", ${ }^{70}$ Next to (external) validation, standardisation 
(e.g. of collection, analysing, controlling for confounders), is necessary to enhance inter-laboratory comparability. A list of recommendations for measurements composed by experts, as was provided for markers in Exhaled Breath Condensate, will facilitate this standardisation. ${ }^{71}$ Thirdly, more insight is needed in the physiological meaning and biochemical origin of VOCs. This may be a complex task as probably a wide spectrum of markers is important instead of individual markers as previously stated. Fourthly, more research is needed on the potential of VOCs in differential diagnosis and monitoring purposes. Next to these four major 'missions', others aspects of VOCs assessment and analysis can be improved, including further refinement of sampling techniques, exploring the advanced statistical techniques on the multi-data of VOCs and developing new tools that combine the strengths of the eNose (cheap, hand held, real-time) and GC-MS (sensitive, compound identification).

Table 4.6 Potential applications of exhaled VOCs in pulmonary diseases.

\begin{tabular}{ll} 
Application & Example \\
\hline Diagnosing & (Early) Diagnosing of pulmonary diseases (e.g. early asthma diagnosis in children) \\
& $\begin{array}{l}\text { Differential diagnosing (e.g. asthma versus chronic obstructive pulmonary disease) } \\
\text { Phenotyping }\end{array}$ \\
Phenotyping within a pulmonary disease (e.g. wheezing phenotypes in children) \\
Monitoring & Monitoring disease severity and control \\
Predicting of risk & Predicting exacerbations and prognosis of a disease \\
Evaluating & Evaluating treatment/surgery (e.g. checking compliance of prescribed medication) \\
Screening & Screening for different diseases in population based studies (e.g. predicting risk \\
& COPD or lung cancer)
\end{tabular}

\section{Conclusion}

There is an increasingly interest in non-invasive measurement of exhaled VOCs in the diagnosis and management of multiple pulmonary diseases. Due to the complex pathophysiology of most pulmonary diseases, current research has mainly focused on profiles of exhaled breath rather than on individual compounds. Promising findings were reported of VOCs profiles that were able to accurately diagnose and monitor various pulmonary diseases. Although progress has been made, multiple constraints need to be resolved before VOCs can be applied into clinical practice. The route from differentiating VOCs to a clinical useful biomarker is long. Although many potential candidate profiles have emerged, presumably only the minority can be used for diagnostic and monitoring purposes. Analytical expertise, biological knowledge, medical experience and dedicated scientists are essential in order to establish wellvalidated VOCs patterns. 


\section{References}

1. Rabe KF, Hurd S, Anzueto A, Barnes PJ, Buist SA, Calverley P, Fukuchi Y, Jenkins C, Rodriguez-Roisin R, van Weel C, Zielinski J. Global strategy for the diagnosis, management, and prevention of chronic obstructive pulmonary disease: GOLD executive summary. Am J Respir Crit Care Med 2007;176: 532-555.

2. Bateman ED, Hurd SS, Barnes PJ, Bousquet J, Drazen JM, FitzGerald M, Gibson P, Ohta K, O'Byrne P, Pedersen SE, Pizzichini E, Sullivan SD, Wenzel SE, Zar HJ. Global strategy for asthma management and prevention: GINA executive summary. Eur Respir J 2008;31:143-178.

3. Jemal A, Siegel R, Ward E, Hao Y, Xu J, Thun MJ. Cancer statistics, 2009. CA Cancer J Clin 2009;59: 225-249.

4. Global Initiative for asthma (GINA). Global strategy for asthma management and prevention. National Institute of Health, National Heart, Lung, and Blood Institute 2009.

5. Martinez FD, Wright AL, Taussig LM, Holberg CJ, Halonen M, Morgan WJ. Asthma and wheezing in the first six years of life. The Group Health Medical Associates. N Engl J Med 1995;332:133-138.

6. Pijnenburg MW, de Jongste JC. Exhaled nitric oxide in childhood asthma: a review. Clin Exp Allergy 2008;38:246-259.

7. Scott M, Raza A, Karmaus W, Mitchell F, Grundy J, Kurukulaaratchy RJ, Arshad SH, Roberts G. Influence of atopy and asthma on exhaled nitric oxide in an unselected birth cohort study. Thorax 2010;65: 258-262.

8. Miekisch W, Schubert JK, Noeldge-Schomburg GF. Diagnostic potential of breath analysis--focus on volatile organic compounds. Clin Chim Acta 2004;347:25-39.

9. Cao W, Duan Y. Breath analysis: potential for clinical diagnosis and exposure assessment. Clin Chem 2006;52:800-811.

10. Horvath I, Lazar Z, Gyulai N, Kollai M, Losonczy G. Exhaled biomarkers in lung cancer. Eur Respir J 2009;34:261-275.

11. Buszewski B, Kesy M, Ligor T, Amann A. Human exhaled air analytics: biomarkers of diseases. Biomed Chromatogr 2007; 21:553-566.

12. Mazzone PJ. Analysis of volatile organic compounds in the exhaled breath for the diagnosis of lung cancer. J Thorac Oncol 2008;3:774-780.

13. Dallinga JW, Robroeks CM, van Berkel JJ, Moonen EJ, Godschalk RW, Jöbsis Q, Dompeling E, Wouters $E F$, van Schooten FJ. Volatile organic compounds in exhaled breath as a diagnostic tool for asthma in children. Clin Exp Allergy 2010;40:68-76.

14. Scholpp J, Schubert JK, Miekisch W, Geiger K. Breath markers and soluble lipid peroxidation markers in critically ill patients. Clin Chem Lab Med 2002;40:587-594.

15. Barker M, Hengst M, Schmid J, Buers HJ, Mittermaier B, Klemp D, Koppmann R. Volatile organic compounds in the exhaled breath of young patients with cystic fibrosis. Eur Respir J 2006;27:929-936.

16. Pauling L, Robinson AB, Teranishi R, Cary P. Quantitative analysis of urine vapor and breath by gasliquid partition chromatography. Proc Natl Acad Sci U S A 1971;68:2374-2376.

17. Manolis A. The diagnostic potential of breath analysis. Clin Chem 1983;29:5-15.

18. Gordon SM, Szidon JP, Krotoszynski BK, Gibbons RD, O'Neill HJ. Volatile organic compounds in exhaled air from patients with lung cancer. Clin Chem 1985;31:1278-1282.

19. O'Neill HJ, Gordon SM, O'Neill MH, Gibbons RD, Szidon JP. A computerized classification technique for screening for the presence of breath biomarkers in lung cancer. Clin Chem 1988;34:1613-1618.

20. Phillips M, Gleeson K, Hughes JM, Greenberg J, Cataneo RN, Baker L, McVay WP. Volatile organic compounds in breath as markers of lung cancer: a cross-sectional study. Lancet 1999;353:1930-1933.

21. Pavlou AKTAPF. Sniffing out the truth: Clinical diagnosis using the electronic nose. Clinical Chemistry and Laboratory Medicine 2000;38:99-112.

22. Ras MR, Borrull F, Marce RM. Sampling and preconcentration techniques for determination of volatile organic compounds in air samples. TrAC 2009;28:347-361.

23. Dragonieri S, Schot R, Mertens BJ, Le Cessie S, Gauw SA, Spanevello A, Resta O, Willard NP, Vink TJ, Rabe KF, Bel EH, Sterk PJ. An electronic nose in the discrimination of patients with asthma and controls. J Allergy Clin Immunol 2007;120:856-862. 
24. Di Natale C, Macagnano A, Martinelli E, Paolesse R, D'Arcangelo G, Roscioni C, Finazzi-Agro A, D'Amico A. Lung cancer identification by the analysis of breath by means of an array of non-selective gas sensors. Biosens Bioelectron 2003;18:1209-1218.

25. Dragonieri S, Annema JT, Schot R, van der Schee MP, Spanevello A, Carratu P, Resta O, Rabe KF, Sterk PJ. An electronic nose in the discrimination of patients with non-small cell lung cancer and COPD. Lung Cancer 2009;64:166-170.

26. Machado RF, Laskowski D, Deffenderfer O, Burch T, Zheng S, Mazzone PJ, Mekhail T, Jennings C, Stoller JK, Pyle J, Duncan J, Dweik RA, Erzurum SC. Detection of lung cancer by sensor array analyses of exhaled breath. Am J Respir Crit Care Med 2005;171:1286-1291.

27. Bajtarevic A, Ager C, Pienz M, Klieber M, Schwarz K, Ligor M, Ligor T, Filipiak W, Denz H, Fiegl M, Hilbe W, Weiss W, Lukas P, Jamnig H, Hackl M, Haidenberger A, Buszewski B, Miekisch W, Schubert J, Amann A. Noninvasive detection of lung cancer by analysis of exhaled breath. BMC Cancer 2009;9:348.

28. Spanel P, Smith D. Selected ion flow tube mass spectrometry for on-line trace gas analysis in biology and medicine. Eur J Mass Spectrom 2007;13:77-82.

29. Westhoff M, Litterst P, Freitag L, Urfer W, Bader S, Baumbach JI. Ion mobility spectrometry for the detection of volatile organic compounds in exhaled breath of patients with lung cancer: results of a pilot study. Thorax 2009;64:744-748.

30. Skeldon KD, McMillan LC, Wyse CA, Monk SD, Gibson G, Patterson C, France T, Longbottom C, Padgett MJ. Application of laser spectroscopy for measurement of exhaled ethane in patients with lung cancer. Respir Med 2006;100:300-306.

31. Paredi P, Kharitonov SA, Barnes PJ. Elevation of exhaled ethane concentration in asthma. Am J Respir Crit Care Med 2000;162:1450-1454.

32. Olopade CO, Zakkar M, Swedler WI, Rubinstein I. Exhaled pentane levels in acute asthma. Chest 1997;111:862-865.

33. Ibrahim B, Basanta M, Cadden P, Singh D, Douce D, Woodcock A, Fowler SJ. Non-invasive phenotyping using exhaled volatile organic compounds in asthma. Thorax 2011:doi:10.1136/thx.2010.156695

34. Fens N, Zwinderman AH, van der Schee MP, de Nijs SB, Dijkers E, Roldaan AC, Cheung D, Bel EH, Sterk PJ. Exhaled Breath Profiling Enables Discrimination of Chronic Obstructive Pulmonary Disease and Asthma. Am J Respir Crit Care Med 2009;180:1076-1082.

35. Montuschi P, Santonico M, Mondino C, Pennazza G, Mantini G, Martinelli E, Capuano R, Ciabattoni G, Paolesse R, Di Natale C, Barnes PJ, D'Amico A. Diagnostic performance of an electronic nose, fractional exhaled nitric oxide, and lung function testing in asthma. Chest 2010;137:790-796.

36. Paredi P, Kharitonov SA, Leak D, Ward S, Cramer D, Barnes PJ. Exhaled ethane, a marker of lipid peroxidation, is elevated in chronic obstructive pulmonary disease. Am J Respir Crit Care Med 2000;162:369-373.

37. van Berkel JJ, Dallinga JW, Moller GM, Godschalk RW, Moonen EJ, Wouters EF, van Schooten FJ. A profile of volatile organic compounds in breath discriminates COPD patients from controls. Respir Med 2010;104:557-563.

38. Basanta M, Jarvis RM, Xu Y, Blackburn G, Tal-Singer R, Woodcock A, Singh D, Goodacre R, Thomas CL, Fowler SJ. Non-invasive metabolomic analysis of breath using differential mobility spectrometry in patients with chronic obstructive pulmonary disease and healthy smokers. Analyst 2010;135:315-320.

39. Fens N, de Nijs SB, Peters S, Dekker T, Knobel HH, Vink TJ, Willard NP, Zwinderman AH, Krouwels FH, Janssen HG, Lutter R, Sterk PJ. Exhaled air molecular profiling in relation to inflammatory subtype and activity in COPD. Eur Respir J 2011:doi: 10.1183/09031936.00032911.

40. Paredi P, Kharitonov SA, Leak D, Shah PL, Cramer D, Hodson ME, Barnes PJ. Exhaled ethane is elevated in cystic fibrosis and correlates with carbon monoxide levels and airway obstruction. Am J Respir Crit Care Med 2000;161:1247-1251.

41. McGrath LT, Patrick R, Mallon P, Dowey L, Silke B, Norwood W, Elborn S. Breath isoprene during acute respiratory exacerbation in cystic fibrosis. Eur Respir J 2000;16:1065-1069.

42. Robroeks CM, van Berkel JJ, Dallinga JW, Jöbsis Q, Zimmermann L, Hendriks HJ, Wouters MF, van der Grinten CP, van de Kant KD, van Schooten FJ, Dompeling E. Metabolomics Of Volatile Organic Compounds In Cystic Fibrosis Patients and Controls. Pediatr Res 2010;68:75-80.

43. Phillips M, Cataneo RN, Cummin AR, Gagliardi AJ, Gleeson K, Greenberg J, Maxfield RA, Rom WN. Detection of lung cancer with volatile markers in the breath. Chest 2003;123:2115-2123. 
44. Poli D, Goldoni M, Caglieri A, Ceresa G, Acampa O, Carbognani P, Rusca M, Corradi M. Breath analysis in non small cell lung cancer patients after surgical tumour resection. Acta Biomed 2008;79 Suppl 1: 64-72.

45. Wehinger A, Schmid A, Mechtcheriakov S, Ledochowski M, Grabmer C, Gastl GA, Amann A. Lung cancer detection by proton transfer reaction mass-spectrometric analysis of human breath gas. Int J Mass Spectrom 2007;265:49-59.

46. Poli D, Carbognani P, Corradi M, Goldoni M, Acampa O, Balbi B, Bianchi L, Rusca M, Mutti A. Exhaled volatile organic compounds in patients with non-small cell lung cancer: cross sectional and nested short-term follow-up study. Respir Res 2005;6:71.

47. Preti G, Labows JN, Kostelc JG, Aldinger S, Daniele R. Analysis of lung air from patients with bronchogenic carcinoma and controls using gas chromatography-mass spectrometry. J Chromatogr 1988;432:1-11.

48. Crohns M, Saarelainen S, Laitinen J, Peltonen K, Alho H, Kellokumpu-Lehtinen P. Exhaled pentane as a possible marker for survival and lipid peroxidation during radiotherapy for lung cancer--a pilot study. Free Radic Res 2009;43:965-974.

49. Fuchs P, Loeseken C, Schubert JK, Miekisch W. Breath gas aldehydes as biomarkers of lung cancer. Int J Cancer 2010;126:2663-2670.

50. Poli D, Goldoni M, Corradi M, Acampa O, Carbognani P, Internullo E, Casalini A, Mutti A. Determination of aldehydes in exhaled breath of patients with lung cancer by means of on-fiber-derivatisation SPMEGC/MS. J Chromatogr B Analyt Technol Biomed Life Sci 2010;878:2643-2651.

51. Song G, Qin T, Liu H, Xu GB, Pan YY, Xiong FX, Gu KS, Sun GP, Chen ZD. Quantitative breath analysis of volatile organic compounds of lung cancer patients. Lung Cancer 2010;67:227-231.

52. Phillips M, Altorki N, Austin JH, Cameron RB, Cataneo RN, Kloss R, Maxfield RA, Munawar MI, Pass HI, Rashid A, Rom WN, Schmitt $P$, Wai J. Detection of lung cancer using weighted digital analysis of breath biomarkers. Clin Chim Acta 2008;393:76-84.

53. Ligor M, Ligor T, Bajtarevic A, Ager C, Pienz M, Klieber M, Denz H, Fiegl M, Hilbe W, Weiss W, Lukas P, Jamnig H, Hackl M, Buszewski B, Miekisch W, Schubert J, Amann A. Determination of volatile organic compounds in exhaled breath of patients with lung cancer using solid phase microextraction and gas chromatography mass spectrometry. Clin Chem Lab Med 2009;47:550-560.

54. Gaspar EM, Lucena AF, Duro da Costa J, Chaves das Neves H. Organic metabolites in exhaled human breath--a multivariate approach for identification of biomarkers in lung disorders. J Chromatogr A 2009;1216:2749-2756.

55. Peng G, Tisch U, Adams O, Hakim M, Shehada N, Broza YY, Billan S, Abdah-Bortnyak R, Kuten A, Haick $\mathrm{H}$. Diagnosing lung cancer in exhaled breath using gold nanoparticles. Nat Nanotechnol 2009;4: 669-673.

56. Peng G, Hakim M, Broza YY, Billan S, Abdah-Bortnyak R, Kuten A, Tisch U, Haick H. Detection of lung, breast, colorectal, and prostate cancers from exhaled breath using a single array of nanosensors. BJC 2010;103:542-551.

57. Phillips M, Altorki N, Austin JH, Cameron RB, Cataneo RN, Greenberg J, Kloss R, Maxfield RA, Munawar MI, Pass HI, Rashid A, Rom WN, Schmitt P. Prediction of lung cancer using volatile biomarkers in breath. Cancer Biomark 2007;3:95-109.

58. D'Amico A, Pennazza G, Santonico M, Martinelli E, Roscioni C, Galluccio G, Paolesse R, Di Natale C. An investigation on electronic nose diagnosis of lung cancer. Lung Cancer 2010;68:170-176.

59. Mazzone PJ, Hammel J, Dweik R, Na J, Czich C, Laskowski D, Mekhail T. Diagnosis of lung cancer by the analysis of exhaled breath with a colorimetric sensor array. Thorax 2007;62:565-568.

60. Fens N, Roldaan AC, van der Schee MP, Boksem RJ, Zwinderman AH, Bel EH, Sterk PJ. External validation of exhaled breath profiling using an electronic nose in the discrimination of asthma with fixed airways obstruction and chronic obstructive pulmonary disease. Clin Exp Allergy 2011:doi: 10.1111/j.1365-2222.2011.03800.x.

61. Schubert JK, Muller WP, Benzing A, Geiger K. Application of a new method for analysis of exhaled gas in critically ill patients. Intensive Care Med 1998;24:415-421.

62. Hockstein NG, Thaler ER, Torigian D, Miller WT, Jr., Deffenderfer O, Hanson CW. Diagnosis of pneumonia with an electronic nose: correlation of vapor signature with chest computed tomography scan findings. Laryngoscope 2004;114:1701-1705. 
63. Hockstein NG, Thaler ER, Lin Y, Lee DD, Hanson CW. Correlation of pneumonia score with electronic nose signature: A prospective study. Ann Otol Rhinol Laryngol 2005;114:504-508.

64. Hanson CW, 3rd, Thaler ER. Electronic nose prediction of a clinical pneumonia score: biosensors and microbes. Anesthesiology 2005;102:63-68.

65. Chambers ST, Syhre M, Murdoch DR, McCartin F, Epton MJ. Detection of 2-pentylfuran in the breath of patients with Aspergillus fumigatus. Med Mycol 2009;47:468-476.

66. Phillips M, Cataneo RN, Condos R, Ring Erickson GA, Greenberg J, La Bombardi V, Munawar MI, Tietje O. Volatile biomarkers of pulmonary tuberculosis in the breath. Tuberculosis 2007;87:44-52.

67. Phillips M, Basa-Dalay V, Bothamley G, Cataneo RN, Lam PK, Natividad MP, Schmitt P, Wai J. Breath biomarkers of active pulmonary tuberculosis. Tuberculosis 2010;90:145-151.

68. van der Schee MP, Haarmans EG, Fens N, van Aalderen WM, Sprikkelman AB, Sterk PJ. Exhaled breath molecular profiles by electronic nose can discriminate doctor-confiremd wheezy infants from controls. Am J Respir Crit Care Med 2009;179:A4786.

69. van de Kant KDG, van Berkel JJ, de Jongste JC, Jöbsis Q, Klaassen EMM, Dallinga JW, van Schayck CP, van Schooten FJ, Dompeling E. Volatile organic compounds in exhaled breath differentiate between children with and without recurrent wheeze. Allergy 2010;65 suppl 92:138.

70. Koulman A, Lane GA, Harrison SJ, Volmer DA. From differentiating metabolites to biomarkers. Anal Bioanal Chem 2009;394:663-670.

71. Horvath I, Hunt J, Barnes PJ, Alving K, Antczak A, Baraldi E, Becher G, van Beurden WJ, Corradi M, Dekhuijzen R, Dweik RA, Dwyer T, Effros R, Erzurum S, Gaston B, Gessner C, Greening A, Ho LP, Hohlfeld J, Jöbsis Q, Laskowski D, Loukides S, Marlin D, Montuschi P, Olin AC, Redington AE, Reinhold P, van Rensen EL, Rubinstein I, Silkoff P, Toren K, Vass G, Vogelberg C, Wirtz H. Exhaled breath condensate: methodological recommendations and unresolved questions. Eur Respir J 2005;26: 523-548. 



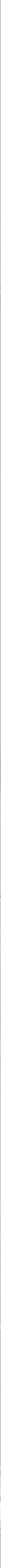




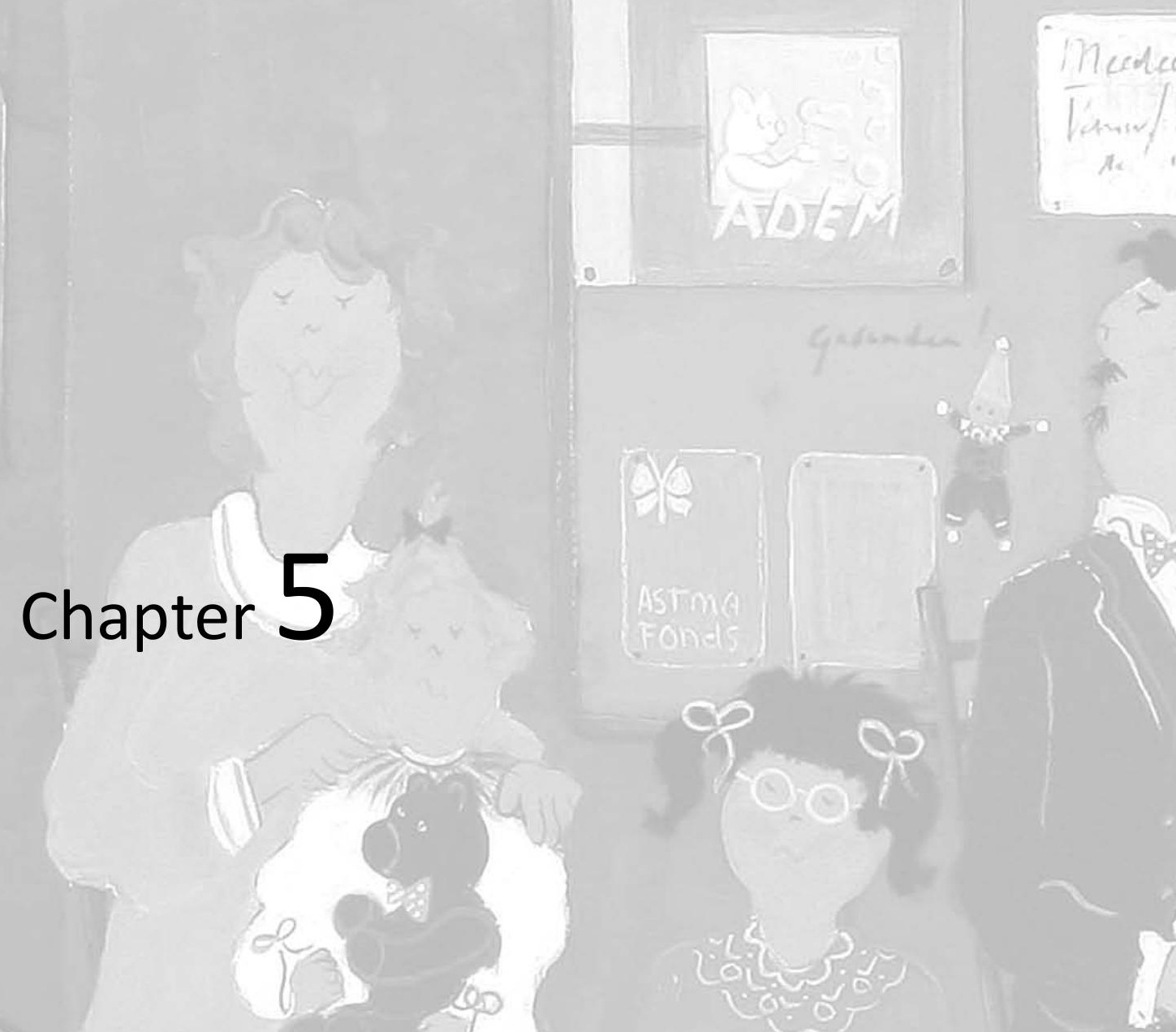

Exhaled breath profiling in the diagnosis of wheezy preschool children: a proof of principle study

van de Kant KDG, van Berkel JJBN, Jöbsis Q, Lima Passos V, Klaassen EMM, van der Sande L, van Schayck CP, de Jongste JC, van Schooten FJ, Dompeling E, Dallinga JW 


\section{Abstract}

\section{Background}

Although wheeze is a common symptom in preschool children, the underlying pathophysiology is heterogeneous and not disentangled yet. Volatile Organic Compounds (VOCs) in exhaled breath may serve as non-invasive markers of early wheeze. The aim of this study was to assess the feasibility of VOCs collection in preschool children, and to study whether a VOCs profile can differentiate between preschool children with and without recurrent wheeze.

\section{Methods}

We included preschool children (mean age, range: 3.3, 2.0-4.5 years) with ( $\mathrm{N}=202)$ and without $(\mathrm{N}=50)$ recurrent wheeze. Tedlar bags were filled during tidal breathing and transported onto desorption tubes. Samples were analysed by gas chromatographytime of flight-mass spectrometry. VOCs profiles were generated with ANOVAsimultaneous-component-analysis (ASCA) and sparse-logistic-regression (SLR).

\section{Results}

Exhaled breath collection was possible in $98 \%$ of the children. In total, 913 different VOCs with a prevalence of at least $7 \%$ could be detected. The signal to noise ratio of the data was improved after correction for age, gender and season using ASCA preprocessing. A final SLR model with eleven VOCs correctly classified $84 \%$ of the children ( $85 \%$ sensitivity, $80 \%$ specificity). After six-fold cross-validation, $77 \%$ was correctly classified ( $84 \%$ sensitivity, $57 \%$ specificity).

\section{Conclusions}

Assessment of VOCs in exhaled breath is feasible in young children. A profile of exhaled VOCs is able to discriminate between children with and without recurrent wheeze with a reasonable accuracy. This proof of principle paves the way to explore other applications of VOCs in preschool wheezers, such as inflammatory 'phenotyping' to improve treatment. 


\section{Introduction}

In preschool children, wheeze is a frequent reason for consultation of a doctor. The group of wheezing preschool children is diverse including children with asthma and children with transient, virus-induced symptoms. Due to this heterogeneity, different wheezing phenotypes have been defined. ${ }^{1}$ These phenotypes are mainly based on the course of symptoms and their triggers. They do not represent biologically plausible classifications, since the underlying pathophysiology of preschool wheeze is not yet disentangled.

High-throughput techniques, such as proteomics, genomics and metabolomics, become of increasing importance in elucidating pathways of multiple diseases. ${ }^{2}$ In recent years, interest has emerged to apply the 'omics' techniques in a non-invasive mode by using exhaled breath as a medium to assess biomarker profiles. Exhaled breath consists of hundreds of Volatile Organic Compounds (VOCs), which are formed during various inflammatory and metabolic pathways. ${ }^{3}$ In adults and older children the study of metabolomics by using exhaled VOCs is known to be a safe and non-invasive procedure to evaluate biological processes such as inflammation and oxidative stress. ${ }^{3,4}$ Profiling VOCs in exhaled breath has been successfully applied in the diagnosis of different lung diseases, such as lung cancer, ${ }^{5}$ cystic fibrosis, ${ }^{6}$ asthma, ${ }^{4}$ and chronic obstructive pulmonary disease (COPD). ${ }^{7,8}$ Analysing the full range of VOCs in exhaled breath from wheezing preschool children can increase insight in the complex and heterogeneous character of early wheeze. However, no studies in preschool children have been performed so far. In this proof of principle study we aimed to assess whether collection of exhaled VOCs is feasible in preschool children and whether profiles of VOCs can differentiate preschool children with recurrent wheeze from healthy controls.

\section{Methods}

\section{Study population}

We included children from the ADEM study (Asthma DEtection and Monitoring study) in the Province of Limburg, the Netherlands (registered at clinicaltrial.gov: NCT 00422747). In this study children with recurrent wheezing symptoms ( $N=202)$ and control subjects with no wheezing symptoms $(\mathrm{N}=50)$ are included the age of two and three years and are studied prospectively until six years of age. Recurrent wheeze was assessed using the ISAAC questionnaire and was defined as at least two episodes of wheeze during life. ${ }^{9}$ The presence of atopy was determined by a positive Phadiatop Infant test (Phadia, Uppsala, Sweden). The study protocol is described in detail before. $^{10}$ The primary objective of the ADEM study is to assess an early asthma diagnosis by using exhaled biomarkers of airway inflammation and early lung function measurements. Ethical approval was obtained from the Dutch National Medical Ethical 
Committee (CCMO:NL17407.000.07/2007-001817-40, the Hague, the Netherlands). All parents gave written informed consent.

\section{Exhaled breath analysis}

Inhaled corticosteroids (ICS) were stopped at least four weeks before the start of the measurements. Measurements were postponed for four weeks in case of an airway infection. Solid foods and exercise were not allowed one hour before the measurements.

\section{Sample collection and analysis}

Children breathed tidally through a facemask connected to a non-rebreathing valve system, while watching cartoons. On the expiratory port of the valve a one-litre polycarbonate bag (Tedlar bag ${ }^{\circledR}$, SKC Ltd., Dorset, UK) was connected to collect exhaled breath. When the bag was filled, it was emptied across a stainless steel two-bed sorption tube, filled with carbograph 1 TD/Carbopack X (Markes International, Llantrisant) for rapid adsorption and stabilisation of volatile compounds. The tubes were airtight capped and stored at room temperature until analysis. VOCs were released from the tube using thermal desorption (Marks Unity desorption unit, Marks International Limited, Llantrisant, Wales, UK). Next, the sample was injected into the gas chromatograph (GC)-capillary (Trace GC, ThermoFischer Scientific, Austin, Texas, USA). In the GC-capillary, VOCs were separated and subsequently detected and identified using time-of-flight mass spectrometry (TOF-MS) (Tempus Plus, ThermoFischer Scientific, Austin, Texas, USA). Detailed information about the conditions and settings of the GC-TOF-MS measurements was provided before. ${ }^{11}$

\section{Data pre-processing}

The pre-processing of the raw GC-TOF-MS output files included automatic peak detection, baseline correction and normalisation of retention times. ${ }^{11}$ Thereafter, identical compounds in all corrected files were combined into a large database file. Complementary compounds in different samples were linked based on similarity of retention times and mass spectra. Similarity of mass spectral data was based on calculating match factors. ${ }^{11}$ Finally, normalization of the peak area was performed allowing to compare the different peak areas and accompanying intensities of the different compounds.

\section{Statistical analysis}

Data were analysed using R (version 2.10.1) and GLMnet toolbox (version 1.4). Clinical variables were expressed as mean and standard error of the mean (SEM) or range. Categorical variables were presented in numbers and percentages. Differences in clinical characteristics between children with and without recurrent wheeze were 
evaluated by means of independent T-tests and Chi-square test for continuous and categorical variables, respectively. A significance level of $p<0.05$ was used. Our dataset is characterised by a large number of variables measured compared to the number of subjects in the study (number of $V O C s=913$ and children=252). This raises multicollinearity and singularity problems, which cannot be adequately solved by conventional statistical methods (neither multivariable nor multivariate). Therefore, we applied modern techniques to handle the high-dimensionality of the data: ANOVAsimultaneous component analysis (ASCA) and Sparse Logistic Regression (SLR). ASCA was used as pre-processing tool. ASCA worked by splitting up the VOCs total variation and assigning it to known sources unrelated to wheezing, i.e. factors: gender, length, weight, age, season of measurements and their interactions. The VOCs residuals, obtained from ASCA, were subsequently entered as classifiers in a SLR model to study their effectiveness in predicting recurrent wheeze. The objective was to select a subset of VOCs that is highly discriminative between recurrent vs. non-recurrent wheezers. SLR selected the most predictive VOCs by suppressing the noisy correlated VOCs, i.e. by pruning them from the model and therefore protects against high false positive rates (see Figure 5.1). In this way the most informative VOCs are selected. SRL is a classification method that gives a sparse solution with high accuracy. More details about SLR are described by Hastie et al. ${ }^{12}$ Only VOCs with a prevalence of at least seven percent in the population were included in the SLR analysis. ${ }^{11}$ Weights were applied to correct for class imbalance ( $\mathrm{N}=202$ wheezers, $\mathrm{N}=50$ non-wheezers). Moreover, a sixfold cross-validation was applied. The most predictive VOCs for recurrent wheeze were identified by using the National Institute of Standards and Technology (NIST) library as described previously. ${ }^{11}$

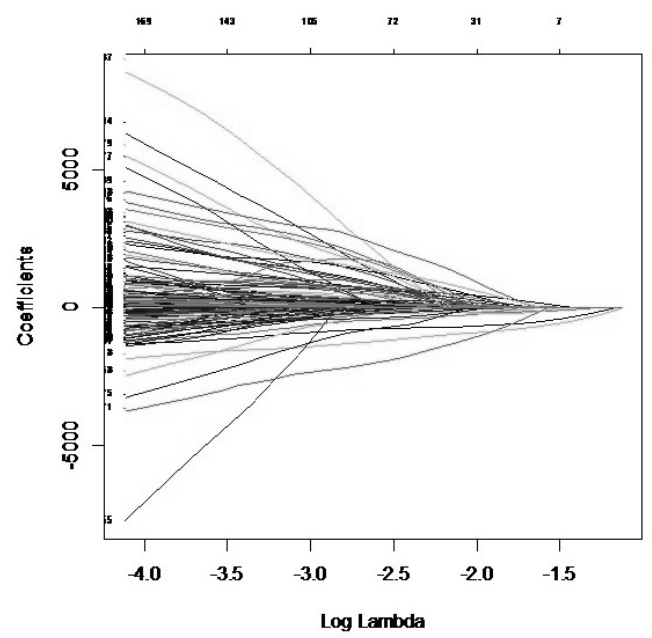

Figure 5.1 Sparse Logistic Regression (SLR) is a biomarker selection method that suppresses noisy correlated VOCs to zero. Coefficients of the single VOCs are represented versus the penalty of SLR (Lambda). 


\section{Results}

\section{Clinical characteristics and feasibility}

A total number of 258 children were invited to participate in the study. We were able to successfully collect exhaled breath in $98 \%(\mathrm{~N}=252)$ of the children. Sudden anxiety was the major reason for drop-out of the remaining six children. Of the included children, 202 children had recurrent wheezing symptoms (mean age: 3.2, range: 2.0-4.5 years) while 50 children did not experience recurrent wheeze (mean age (range) 3.3 (2.2-4.5) years). Clinical characteristics are described in Table 5.1. Eczema was more frequent in children with recurrent wheeze compared to non-wheezers $(p<0.05)$. Around $40 \%$ of the wheezing children used short acting $B_{2}$ agonist as rescue medication, and $19 \%$ of the wheezing children were on maintenance treatment with ICS. ICS were stopped four weeks before the measurements and short acting $B_{2}$ agonists at least eight hours before the measurements. In seven patients, stopping of ICS was not permitted by the responsible physician because of severe asthma symptoms.

Table $5.1 \quad$ Clinical characteristics of the study population.

\begin{tabular}{lcc} 
& With recurrent & No recurrent \\
& wheeze & 50 \\
\hline Number & 202 & $3.3(2.2-4.5)$ \\
Mean age (range), in years & $3.2(2.0-4.5)$ & $24 / 26$ \\
Sex: male / female, in n & $112 / 90$ & $11 / 45(24)$ \\
Atopy, in n / N (\%) & $47 / 191(25)$ & $11 / 50(22)$ \\
Eczema, in n / N (\%) * & $77 / 197(39)$ & $1.4(0.05)$ \\
Airway resistance (mean (SEM)), in kPa·s/L & $1.5(0.03)$ & $8.3(3.4-13.1)$ \\
Fractional exhaled Nitric Oxide (median (IQR)), in ppb & $7.3(3.9-13.3)$ & $0 / 50(0)$ \\
Use of inhaled corticosteroids, in n / N (\%) * & $38 / 202(19)$ & $0 / 50(0)$ \\
Use of short acting B agonists, in n / N (\%) * & $79 / 202(39)$ & $8 / 50(16)$ \\
Parental asthma, in n / N (\%) & $70 / 202(35)$ & $13 / 50(26)$ \\
Parental smoking, in n / N (\%) & $75 / 202(37)$ & \\
Season of measurements (\%): * & & $24: 40: 34: 2$ \\
winter, spring, summer, autumn & $25: 24: 32: 19$ &
\end{tabular}

SEM = Standard Error of the Mean, IQR = Inter Quartile Range..$^{+}$Atopy was defined as a positive Phadiatop infant (Pharmacia, Uppsala, Sweden); numbers may not add up to 202 or 50 in respectively wheezers and non-wheezers due to missing values. ${ }^{*} p<0.05$.

\section{Exhaled Volatile Organic Compounds}

VOCs profiles could be determined in all samples. In total, 913 different VOCs with a prevalence of at least seven percent could be detected. The number of exhaled VOCs per child was on average 350 . 


\section{Covariates}

An initial principal component analysis demonstrated that the data were divided in clear clusters irrespectively of wheezing. We performed ASCA to determine which covariates were predictive for this clustering, but were not predictive for recurrent wheeze. The responsible covariate variables included gender, age and season. Therefore, data variability explained by these three variables was subtracted from the VOCs data in order to improve the signal-to-noise ratio.

\section{Sparse logistic regression}

Sparse logistic regression was applied on the ASCA-residuals (VOCs data corrected for gender, age and seasonal effects). Linear weights were computed to correct for class imbalance (202 wheezers; weight 0.62, 50 non-wheezers; weight 2.52). The SLR model for recurrent wheeze including eleven most discriminative VOCs (with a lambda of 0.13 ) demonstrated a classification error of 0.16 , with a sensitivity of $85 \%$ and a specificity of $80 \%$. Internal cross-validation of the data had a limited effect on sensitivity (84\%) but diminished the specificity $(57 \%)$, with an overall cross-validated classification error of 0.23 . The eleven most discriminative VOCs of the SLR model are demonstrated in Table 5.2.

Table $5.2 \quad$ Most discriminative VOCs for recurrent wheeze.

\begin{tabular}{|lccc|}
\hline Identified as & $\begin{array}{c}\text { Percentage in } \\
\text { recurrent wheeze }\end{array}$ & $\begin{array}{c}\text { Percentage in } \\
\text { no wheeze* }\end{array}$ & $\begin{array}{c}\text { Percentage in } \\
\text { total group * }\end{array}$ \\
\hline 2-methyl-1-butene & 2 & 28 & 7 \\
3-methyl-pentane & 6 & 16 & 8 \\
2,4,6-trimethyl-decane & 3 & 32 & 9 \\
p-xylene & 4 & 28 & 9 \\
1,4-dichloro-benzene & 6 & 22 & 10 \\
3-hexen-1-ol-acetate & 9 & 12 & 10 \\
unknown & 6 & 24 & 10 \\
methyl-cyclopentane & 8 & 26 & 12 \\
2,4,4-trimethyl-1-pentene & 9 & 30 & 13 \\
pentadecafluoro-octanal & 10 & 34 & 15 \\
acetophenone & 17 & 44 & 22
\end{tabular}

* The percentage of subjects (wheezers, non-wheezers, total group) in which the compound was detected. 


\section{Discussion}

This is the first study that explored the discriminative value of exhaled VOCs in preschool children with respiratory symptoms. We demonstrated that VOCs can easily and safely be collected and determined in exhaled breath of preschool children. Moreover, a profile of eleven exhaled VOCs was able to differentiate children with recurrent wheeze from children without wheeze with an acceptable cross-validated classification error and sensitivity, though with a limited specificity.

Preschool wheeze is a common, though complex symptom. The underlying causes for preschool wheezing are heterogeneous and are not sufficiently understood. ${ }^{1}$ Knowledge about the underlying pathophysiology of preschool wheeze is needed for proper treatment decisions. There is increasing evidence that different forms of airway inflammation play a significant role in preschool wheeze, including neutrophilic inflammation in virus-induced wheezers and eosinophilic inflammation in wheezing children who are prone to develop asthma. ${ }^{13-15}$ However, data are scarce since the current techniques to assess airway inflammation, such as a biopsy and bronchoalveolar lavage, are too invasive for routine use in children. The need for noninvasive assessment of airway inflammation has led to increasing interest in breath analysis. Whereas exhaled Nitric Oxide is the most extensively studied marker in exhaled breath, ${ }^{16}$ the analysis of exhaled VOCs gained popularity. VOCs are a diverse group of carbon-based chemicals that are volatile at ambient temperature and are formed in the body during several (patho)physiological processes, such as airway inflammation. During the inflammatory process, Reactive Oxygen Species (ROS) are formed by inflammatory cells. These ROS react with lipid membrane structures, leading to degradation of polyunsaturated fatty acids. As a consequence, several stable breakdown products are formed, so called VOCs. ${ }^{3,17}$ After entering the bloodstream, VOCs are excreted into breath due to the low solubility. Therefore, analysis of exhaled VOCs is believed to be a potential technique to study ongoing processes of airway inflammation.

In this study we demonstrated that measuring VOCs in exhaled breath is feasible in preschool children. Our high success rate was the consequence of three main factors. At first, we achieved a high success rate for the collection of exhaled breath by facilitating tools to make children feel at ease during the measurements. Secondly, we used the GC-TOF-MS technique for the analysis of VOCs. This is a highly sensitive technique capable to detect a wide range of VOCs. Thirdly, we used the raw mass spectra to match similar compounds in all children. In most studies, compounds are firstly identified in a library and thereafter compared between subjects. However, this approach is vulnerable for mistakes and improper identification of compounds can hamper the quality of databases. Our innovative procedure that matches compounds 
on basis of the raw mass spectra and retention time creates a more reliable database. ${ }^{8,11}$

We demonstrated that profiles of VOCs were able to distinct wheezing children from healthy controls. However, it should be noted that we achieved an acceptable prediction model after deducting of data variability explained by gender, age and season. In so doing, the predictive value of our model improved. The fact that season of measurement, gender and age are major sources of variability in our data, stresses the importance to further explore these, and possible other, confounding factors, in future studies using SLR.

One of the strengths of our study is that we have studied the entire range of exhaled VOCs instead of pre-selected inflammatory markers. This enables us to explore all potential compounds of interest. When analysing the entire range of exhaled VOCs, hundreds of components can be identified, leaving a challenging task regarding the statistical analysis to interpret and understand the data. We analysed our data using sparse logistic regression. Conventional logistic regression can easily be applied on small-scale and well-designed problems but will generally fail for mega-variate collinear data. SLR can be considered as a biomarker selection method that suppresses noisy correlated VOCs (Figure 5.1). This results in more sparse models that provide protection against high false positive rates. Despite this advanced statistical technique, the results are still easy to interpret. Other modelling techniques that were previously applied on VOCs data included discriminant analysis (either with or without principal component analysis as pre-processing tool), ${ }^{4,6,7,18}$ support vector machine analysis, ${ }^{8,19}$ and fuzzy logic models. ${ }^{20}$ Currently, there is no consensus about the optimal statistical technique to analyse VOCs data.

Although this is the first study in wheezing preschool children, the analysis of exhaled VOCs has been successfully applied in children with asthma and cystic fibrosis (CF). ${ }^{4,6,21}$ In a previous study we demonstrated that asthmatic children could be distinguished from healthy children using a discriminant model of eight VOCs, with a sensitivity of $89 \%$ and a specificity of $95 \% .{ }^{4}$ Besides, children with CF could be distinguished from healthy controls with $92 \%$ correct classification using ten VOCs in a discriminant model. ${ }^{6}$ The better discriminative performance of these 'asthma' and 'CF' models compared to the 'wheezing' model might be explained by the fact that our group of wheezing preschool children is very heterogeneous. Whilst some of the children wheeze due to recurrent viral respiratory tract infections, in other children asthma is the underlying cause of their symptoms.

The most important discriminative compounds for recurrent wheeze mainly included hydrocarbons. These hydrocarbons were less prevalent in exhaled breath of children with recurrent wheeze compared to children without wheezing symptoms. This is 
comparable to our previous findings in COPD patients and children with asthma. ${ }^{4,8}$ The complicated biological equilibrium of formation and removal of VOCs in the human body might be a possible explanation for this finding. As VOCs are believed to be formed during processes of inflammation and oxidative stress, the relative composition of VOCs in exhaled breath can change due to a disease, and this change can be either an increase or a decrease of certain compounds. ${ }^{4}$ For example, it is conceivable that children with wheezing symptoms have enhanced oxidative stress. This enhanced oxidative stress might lead to enhanced lipid peroxidation in which certain VOCs, especially long chain hydrocarbons, are further oxidized into smaller components and consequently are exhaled in lower concentrations. In a former study we found different hydrocarbons in asthmatic children to be most discriminative. ${ }^{4}$ As it remains difficult to distinct asthmatic children already at preschool age, the potential of VOCs in discrimination between wheezing phenotypes remains to be determined during the longitudinal follow-up of the ADEM study.

Various techniques can be performed to analyse exhaled VOCs. The most commonly used techniques are electronic nose detection and gas chromatography-mass spectrometry. The electronic nose creates a 'breath-print' that can be distinct in different diseases and can therefore be used to differentiate between various pulmonary diseases. ${ }^{5,22}$ The technique is rapid, easy to use and not very expensive. However with the electronic nose it is not possible to identify single compounds in exhaled breath. In our study we used GC-TOF-MS, which is able to detect single compounds both quantitative and qualitative, and therefore provides the most detailed and complete information on the different exhaled VOCs. Once the discriminative VOCs profiles have been properly validated in large scale clinical studies, technologies as for instance dedicated gas chromatographic devices and/or other sensor technologies will speed up analysis and becoming cost-effective as a diagnostic tool.

Despite the potential use of VOCs in paediatric lung diseases, multiple constraints need to be resolved before the analysis of VOCs can be applied in clinical practice. At first, future efforts should be directed towards standardisation of the collection and analysis of data. The development of international recommendations for standardised procedures, as developed for exhaled Nitric Oxide and markers in Exhaled Breath Condensate, would be useful in order to enhance the inter-laboratory comparability. ${ }^{23,24}$ Secondly, validation is important. Although, most studies included cross-validation, the next step to be taken is the use of an external validation set in order to validate the results. Many VOCs models are derived by different research groups, but hardly any of them are applied in separate populations to check their validity. Thirdly, more insight is needed in the physiological meaning and biochemical origin of VOCs. As described before, VOCs can be formed during lipid peroxidation as the result of airway inflammation. Moreover, since VOCs are blood borne, it is likely 
that they are formed during other processes in the body with a more systemic origin as well. Finally, the refinement of sampling techniques would enhance the potential use of VOCs in the diagnosis and monitoring of pulmonary diseases in the future.

In conclusion, a profile of VOCs in exhaled breath was able to discriminate between preschool children with and without recurrent wheeze. Although our model showed an acceptable classification error and sensitivity it had a limited specificity. However, in this proof of principle study we demonstrated the potential of VOCs as a technique that can provide valuable information about disease status in wheezing children. Hopefully, this will pave the way for additional research on VOCs in the field of preschool wheezing. Potential future applications of VOCs include objectively defining preschool wheezing phenotypes (based on underlying pathophysiology), assessing an early asthma diagnosis and evaluating treatment. 


\section{References}

1. Henderson J, Granell R, Sterne J. The search for new asthma phenotypes. Arch Dis Child 2009;94: 333-6.

2. Vinayavekhin N, Homan EA, Saghatelian A. Exploring disease through metabolomics. ACS Chem Biol 2010;5:91-103.

3. Buszewski B, Kesy M, Ligor T, Amann A. Human exhaled air analytics: biomarkers of diseases. Biomed Chromatogr 2007;21:553-66.

4. Dallinga JW, Robroeks CM, van Berkel JJ, Moonen EJ, Godschalk RW, Jöbsis Q, Dompeling E, Wouters $\mathrm{EF}$, van Schooten FJ. Volatile organic compounds in exhaled breath as a diagnostic tool for asthma in children. Clin Exp Allergy 2010;40:68-76.

5. Dragonieri S, Annema JT, Schot R, van der Schee MP, Spanevello A, Carratu P, Resta O, Rabe KF, Sterk PJ. An electronic nose in the discrimination of patients with non-small cell lung cancer and COPD. Lung Cancer 2009;64:166-70.

6. Robroeks CM, van Berkel JJ, Dallinga JW, Jöbsis Q, Zimmermann LJ, Hendriks HJ, Wouters MF, van der Grinten $\mathrm{CP}$, van de Kant KD, van Schooten FJ, Dompeling E. Metabolomics Of Volatile Organic Compounds In Cystic Fibrosis Patients and Controls. Pediatr Res 2010;68:75-80.

7. Fens N, Zwinderman AH, van der Schee MP, de Nijs SB, Dijkers E, Roldaan AC, Cheung D, Bel EH, Sterk PJ. Exhaled Breath Profiling Enables Discrimination of Chronic Obstructive Pulmonary Disease and Asthma. Am J Respir Crit Care Med 2009;180:1076-82.

8. Van Berkel JJ, Dallinga JW, Moller GM, Godschalk RW, Moonen EJ, Wouters EF, van Schooten FJ. A profile of volatile organic compounds in breath discriminates COPD patients from controls. Respir Med 2010;104:557-63.

9. Worldwide variations in the prevalence of asthma symptoms: the International Study of Asthma and Allergies in Childhood (ISAAC). Eur Respir J 1998;12:315-35.

10. van de Kant KD, Klaassen EM, Jöbsis Q, Nijhuis AJ, van Schayck OC, Dompeling E. Early diagnosis of asthma in young children by using non-invasive biomarkers of airway inflammation and early lung function measurements: study protocol of a case-control study. BMC Public Health 2009;9:210.

11. van Berkel JJ, Dallinga JW, Moller GM, Godschalk RW, Moonen E, Wouters EF, van Schooten FJ. Development of accurate classification method based on the analysis of volatile organic compounds from human exhaled air. J Chromatogr B Analyt Technol Biomed Life Sci 2008;861:101-7.

12. Hastie T, Tibshirani R, Friedman J. The Elements of Statistical Learning. Data Mining, Inference and Prediction. Philadelphia: Springer Series in Statistics 2009.

13. Stevenson EC, Turner G, Heaney LG, Schock BC, Taylor R, Gallagher T, Ennis M, Shields MD. Bronchoalveolar lavage findings suggest two different forms of childhood asthma. Clin Exp Allergy 1997;27:1027-35.

14. Oommen A, Patel R, Browning M, Grigg J. Systemic neutrophil activation in acute preschool viral wheeze. Arch Dis Child 2003;88:529-31.

15. Marguet C, Jouen-Boedes F, Dean TP, Warner JO. Bronchoalveolar cell profiles in children with asthma, infantile wheeze, chronic cough, or cystic fibrosis. Am J Respir Crit Care Med 1999;159:1533-40.

16. Pijnenburg MW, de Jongste JC. Exhaled nitric oxide in childhood asthma: a review. Clin Exp Allergy 2008;38:246-59.

17. Miekisch W, Schubert JK, Noeldge-Schomburg GF. Diagnostic potential of breath analysis--focus on volatile organic compounds. Clin Chim Acta 2004;347:25-39.

18. Dragonieri S, Schot R, Mertens BJ, Le Cessie S, Gauw SA, Spanevello A, Resta O, Willard NP, Vink TJ, Rabe KF, Bel EH, Sterk PJ. An electronic nose in the discrimination of patients with asthma and controls. J Allergy Clin Immunol 2007;120:856-62.

19. Machado RF, Laskowski D, Deffenderfer O, Burch T, Zheng S, Mazzone PJ, Mekhail T, Jennings C, Stoller JK, Pyle J, Duncan J, Dweik RA, Erzurum SC. Detection of lung cancer by sensor array analyses of exhaled breath. Am J Respir Crit Care Med 2005;171:1286-91.

20. Phillips M, Altorki N, Austin JH, Cameron RB, Cataneo RN, Greenberg J, Kloss R, Maxfield RA, Munawar MI, Pass HI, Rashid A, Rom WN, Schmitt P. Prediction of lung cancer using volatile biomarkers in breath. Cancer Biomark 2007;3:95-109. 
21. Barker M, Hengst M, Schmid J, Buers HJ, Mittermaier B, Klemp D, Koppmann R. Volatile organic compounds in the exhaled breath of young patients with cystic fibrosis. Eur Respir J 2006;27:929-36.

22. Fens N, Zwinderman AH, van der Schee MP, de Nijs SB, Dijkers E, Roldaan AC, Cheung D, Bel EH, Sterk PJ. Exhaled breath profiling enables discrimination of chronic obstructive pulmonary disease and asthma. Am J Respir Crit Care Med 2009;180:1076-82.

23. ATS/ERS Recommendations for Standardized Procedures for the Online and Offline Measurement of Exhaled Lower Respiratory Nitric Oxide and Nasal Nitric Oxide, 2005. Am J Respir Crit Care Med 2005;171:912-30.

24. Horvath I, Hunt J, Barnes PJ, Alving K, Antczak A, Baraldi E, Becher G, van Beurden WJ, Corradi M, Dekhuijzen R, Dweik RA, Dwyer T, Effros R, Erzurum S, Gaston B, Gessner C, Greening A, Ho LP, Hohlfeld J, Jöbsis Q, Laskowski D, Loukides S, Marlin D, Montuschi P, Olin AC, Redington AE, Reinhold P, van Rensen EL, Rubinstein I, Silkoff P, Toren K, Vass G, Vogelberg C, Wirtz H. Exhaled breath condensate: methodological recommendations and unresolved questions. Eur Respir J 2005;26: 523-48. 


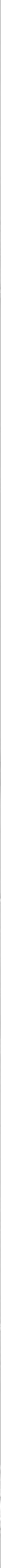




\section{Chapter 6}

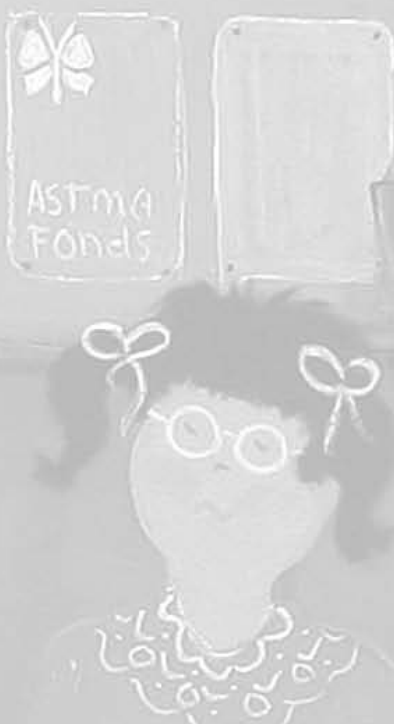

Mechanisms of preschool wheeze: the role of bacteria, regulatory T-cells, and airway inflammation

van de Kant KDG, Klaassen EMM, van Aerde KJ, Damoiseaux J, Bruggeman CA, Stelma FF, Stobberingh EE, Muris JWM, Jöbsis Q, van Schayck CP, Dompeling E 


\section{Abstract}

\section{Background}

Wheeze is a common symptom in preschool children. The role of bacteria, regulatory $\mathrm{T}$ $\left(T_{\text {reg }}\right)$ cells and their association with atopy and airway inflammation in preschool wheeze is largely unknown.

\section{Objectives}

To evaluate bacterial colonisation, $\mathrm{T}_{\text {reg }}$ cells, atopy, and inflammatory markers in Exhaled Breath Condensate (EBC) in preschool children with and without recurrent wheeze.

\section{Methods}

We recruited 252 children (aged two and three years) with ( $\mathrm{N}=202)$ and without $(\mathrm{N}=50)$ recurrent wheeze. Nasal and throat swabs were analysed for the presence of Streptococcus pneumoniae, Haemophilus (para)influenzae and Staphylococcus aureus. Serology for Chlamydia pneumoniae and Mycoplasma pneumoniae was assessed. Proportions of $\mathrm{T}_{\text {reg }}$ cells $\left(\mathrm{CD} 4^{+} \mathrm{CD} 25^{+} \mathrm{CD} 127^{-}\right)$were quantified by flow cytometry. Atopy was defined as a positive Phadiatop Infant test. EBC was collected using a closed-glass condenser and markers (Interleukin(IL)-4, IL-8, IL-10, IL-13) were assessed using multiplex immunoassay.

\section{Results}

Bacterial species and $T_{\text {reg }}$ cells were not differently present in wheezers and nonwheezers. Children with recurrent wheeze had elevated EBC levels of IL-4, IL-10 and IL13 compared to non-wheezers $(p<0.05)$. No interaction between bacteria, $T_{\text {reg }}$ cells and atopy was demonstrated. Wheezing children colonised with $H$. influenzae had mildly elevated levels of IL-4 and IL- 8 compared to wheezing children without colonisation $(p=0.09)$, while wheezing children colonised with $H$. parainfluenzae had mildly elevated levels of IL-8 compared to non-colonised wheezing children $(p=0.06)$.

\section{Conclusions}

We found no convincing evidence for an association between bacterial colonisation and preschool wheeze. However, wheezing children colonised with $H$. (para)influenzae had slightly elevated cytokines and chemokines which might indicate enhanced, bacterial-induced airway inflammation. 


\section{Introduction}

Respiratory symptoms such as wheeze are a major health problem that affect about one third of preschool children. ${ }^{1}$ The aetiology of preschool wheeze is complex and develops due to the interaction between genetic predisposition and environmental exposure (Figure 6.1). ${ }^{2}$ Viral infections are predominant triggers of wheeze and can induce airway inflammation. ${ }^{2,3}$ Likewise, bacterial micro-organisms may be important contributors to preschool wheeze, although they have received less attention. Recently, Bisgaard and colleagues demonstrated that positive bacterial cultures were associated with wheezing episodes in young children independent of viral infections. ${ }^{4}$ The underlying pathological mechanisms by which bacteria contribute to the development of preschool wheeze are still largely unknown. It is hypothesized that bacteria may induce neutrophilic airway inflammation (Figure 6.1), ${ }^{5,6}$ which is believed to play a central role in preschool wheeze. ${ }^{7}$ However, data on airway inflammation in wheeze are limited since the current available techniques to measure airway inflammation, such as biopsy and bronchoalveolar lavage, are too invasive for regular use in children. Accordingly there is an increasing interest in the non-invasive assessment of inflammation using inflammatory markers in Exhaled Breath Condensate $(\mathrm{EBC})$.

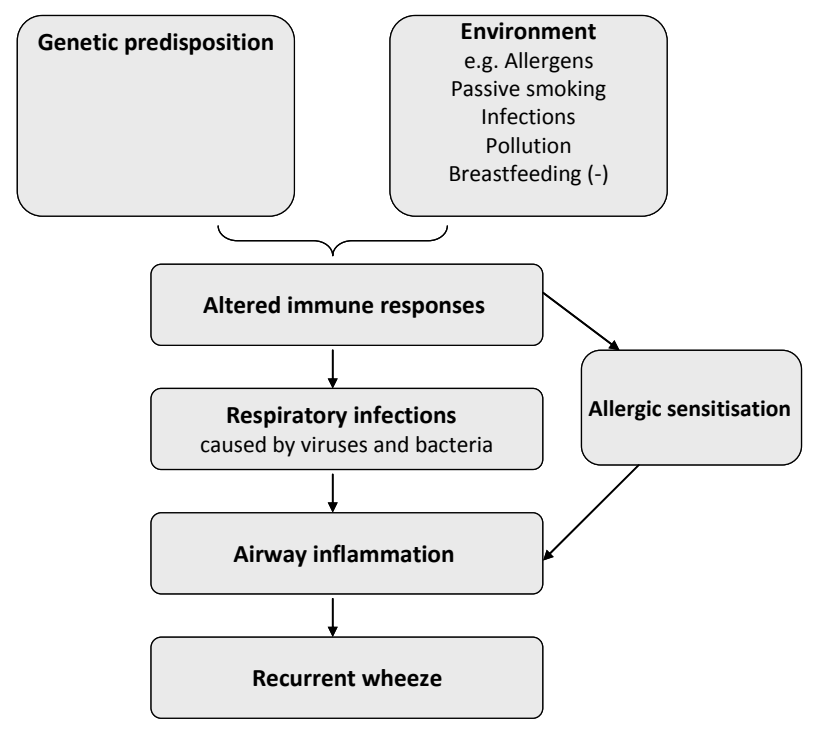

Figure 6.1 Hypothetical model of the aetiology of preschool wheeze.

Influence of genetic predisposition and environmental agents, viruses, bacteria and allergic sensitisation in the development of recurrent wheeze.

The presence of bacteria in the airways can lead to inflammation and subsequently to wheezing symptoms in some, but not all children. It can be hypothesized that contact 
with certain bacteria only induces inflammatory responses in the airways of children with an impaired immune responsiveness, for example due to allergic sensitisation. A subgroup of T-cells, so called regulatory $\mathrm{T}\left(\mathrm{T}_{\text {reg }}\right)$ cells, could play a role in this process. Borrego et al., demonstrated lower $T_{\text {reg }}$ cell counts in wheezing infants compared to their healthy counterparts. ${ }^{8}$ However, data about $\mathrm{T}_{\text {reg }}$ cells in relation to bacteria and airway inflammation in young wheezing children are scanty.

In this study we investigated the relation between bacterial colonisation, $T_{\text {reg }}$ cells, atopy and airway inflammation assessed with inflammatory markers in EBC, in preschool children with and without wheezing symptoms.

\section{Methods}

\section{Study population}

The study population consists of children from the ADEM study (Asthma DEtection and Monitoring study: registered at clinicaltrial.gov: NCT 00422747) that started in 2006 in the province of Limburg, the Netherlands. In the ADEM study, children who experienced at least two wheezing episodes during life ( $N=202$, assessed by the ISAAC questionnaire $\left.{ }^{9}\right)$, and control subjects $(\mathrm{N}=50)$ who never wheezed were included at two and three years of age and were studied prospectively until six years of age. The primary objective of the ADEM study was to develop a non-invasive instrument for an early asthma diagnosis using exhaled inflammatory markers and early lung function measurements. The study protocol was described previously. ${ }^{10}$ For the current study, we analysed the cross-sectional data at inclusion. Ethical approval was obtained from the Dutch National Medical Ethical Committee (CCMO; NL17407.000.07/2007-00181740). All parents gave written informed consent.

\section{Measurements}

If applicable, inhaled corticosteroids (ICS) administration was stopped four weeks before the start of the measurements. A measurement was postponed for four weeks in case of symptoms of an airway infection.

\section{Atopy}

Venous blood was sampled for specific IgE against a mixture of the most common inhalant and food allergens. A child was considered atopic when the value of specific IgE equals or exceeded $0.35 \mathrm{kU}$ per litre (Phadiatop infant ${ }^{\circledR}$, Phadia, Uppsala, Sweden).

\section{Bacterial cultures and positive serology}

Nasal and throat swabs were analysed for the presence of Streptococcus pneumoniae, Haemophilus (para) influenzae, and Staphylococcus aureus, using standard 
microbiological methods. ${ }^{11}$ Moreover, antibodies (IgA and IgG) to Chlamydia pneumoniae and Mycoplasma pneumoniae were analysed in venous blood, using commercially available enzyme-linked immunosorbent assay (ELISA) kits. $C$. pneumoniae and $M$. pneumoniae IgG titres of $\geq 45 \mathrm{iu} / \mathrm{ml}$ were considered as evidence of past infection, while serum IgA antibody titres to $C$. pneumoniae and M. pneumonia of $\geq 12 \mathrm{iu} / \mathrm{ml}$ were considered positive for a recent infection (Ani labsystems Ltd, Vantaa, Finland; Virion/Serion GmbH, Würzburg, Germany, respectively).

\section{Regulatory T-cells and related T-cell subsets}

Heparin blood was incubated with monoclonal antibodies for CD4, CD8, CD25, CD127 and CD45RC. Proportions of $T_{\text {reg }}$ cells and $T$ helper cell subset were quantified by flow cytometry, according to the procedure described previously. ${ }^{12}$ The phenotype of $T_{\text {reg }}$ cells was defined as $\mathrm{CD} 4^{+} \mathrm{CD} 127^{-} \mathrm{CD} 25^{+}$, since this phenotype has been shown to be positive for FoxP3, a transcription factor which is closely related to the suppressive function of $\mathrm{T}_{\text {reg }}$ cells. ${ }^{13}$ In addition, T-cell subsets defined by the expression of CD45RC were studied. Both within the CD4 and CD8 T-cell compartment only the CD45RC low cells, but not the CD45RC high cells characteristically produce anti-inflammatory cytokines. ${ }^{14}$ Results are presented as percentage of total CD4 or CD8 T-cells.

\section{Markers in Exhaled Breath Condensate}

To collect EBC, a closed glass condenser system with a breath recirculation unit was used that was developed at our institute. ${ }^{10}$ This efficient condenser system enables the collection of EBC in a short collection-time (10 minutes). The procedure has been described previously. ${ }^{10}$ Inflammatory markers in EBC (Interleukin(IL)-4, IL-8, IL-10, IL13) were assayed by multiplex immunoassay (Luminex Corporation, Austin, TX, USA) as described before. ${ }^{15}$ Samples with levels of EBC markers below the detection limit received a randomly generated value taken from the uniform distribution between zero and the detection limit. ${ }^{16}$

\section{Statistical analysis}

Data were analysed with SPSS 16.1 (SPSS inc., Chicago IL, USA). Differences in baseline characteristics were tested by means of Chi-square tests in case of proportions and independent T-tests or Mann-Whitney U-tests for symmetric and non-symmetric distributed continuous variables, respectively. Univariable logistic regression models were performed to test for differences in the presence of bacteria, $T_{\text {reg }}$ cells and $E B C$ markers in children with wheeze and those without wheeze. Due to skewed distributions, EBC markers were log-transformed before entered in the regression models. A multivariable model was fitted to study the combined effects of the parameters on wheeze. Since EBC markers were highly correlated with each other, a principal component analysis (PCA) with orthogonal rotation (varimax) was conducted, reducing the four markers to two uncorrelated composite variables. These variables, 
instead of the original EBC markers, were, together with bacteria, atopy and $\mathrm{T}_{\text {reg }}$ cells entered in a multivariable model, avoiding thereby multicollinearity. For a sub-analysis in the wheezing group, similar univariable logistic regression models were used to test for differences in $\mathrm{T}_{\text {reg }}$ cells and EBC markers in the presence and absence of bacteria. In addition, Spearman correlation coefficients between EBC markers and $\mathrm{T}_{\text {reg }}$ cells were calculated in the wheeze group. Adjustment for multiple testing was conducted via the false discovery rate (FDR). A significance level of 0.05 was used.

\section{Power analysis}

The sample size was calculated for an unmatched case control study design. Previous research showed that wheezing episodes were associated with positive bacterial cultures in the airways (e.g. $H$. influenzae and S. pneumoniae) with an odds ratio of 2.9. ${ }^{4}$ Positive bacterial cultures in children without wheeze ranged from $20-38 \%{ }^{4}$ When considering an odds ratio of 2.9 , exposure in controls of $20 \%$, and a ratio of cases and controls of $4: 1$, at least 48 controls and 190 wheezing children were needed for the analysis, with an alpha of 0.05 and a beta of $80 \%$.

\section{Results}

\section{Clinical characteristics}

A total number of 252 children participated in the study; 202 children with recurrent wheeze (mean age \pm Standard Error of the Mean (SEM): $3.2 \pm 0.04$ years) and 50 children without wheezing symptoms (mean age \pm SEM: $3.3 \pm 0.07$ years). Clinical characteristics are summarised in Table 6.1. ICS were used in 19\% of the recurrent wheezers. ICS were stopped four weeks prior to the measurements in all but seven children. In these children stopping was not permitted by the responsible physician because of severe asthma symptoms.

\section{Primary analysis: Wheezers versus non-wheezers}

\section{Atopy}

Atopy was not differently present in children with recurrent wheeze compared to nonwheezing children.

\section{Presence of bacteria and serology}

Nasal and throat swabs could be successfully collected in 249 children (99\%). Venous blood sampling for serology for $C$. pneumoniae and $M$. pneumoniae was successful in 224 children (89\%). In the children with recurrent wheeze, between $16 \%$ and $52 \%$ 
scored positive on the presence of S. pneumoniae, $H$. influenzae, $H$. (para)influenzae and/or S. aureus (Table 6.1). These percentages did not differ from non-wheezing children, of whom between $16 \%$ and $50 \%$ scored positive on the presence of at least one of these bacteria. Similarly, no differences in positive serology for $C$. pneumoniae and $M$. pneumoniae were found between wheezing children and non-wheezing children (Table 6.1).

Table 6.1 Patient characteristics.

\begin{tabular}{|c|c|c|}
\hline & $\begin{array}{l}\text { Recurrent wheezers } \\
\qquad(\mathrm{N}=202)\end{array}$ & $\begin{array}{l}\text { Non-wheezers } \\
\qquad(\mathrm{N}=50)\end{array}$ \\
\hline Mean age (SEM), in years & $3.2(0.04)$ & $3.3(0.07)$ \\
\hline Sex: male / female, in $\mathrm{N}$ & 112 / 90 & $24 / 26$ \\
\hline Atopy $^{+}$ & 25 & 24 \\
\hline Eczema $* *$ & 39 & 22 \\
\hline Use of ICS ** & 19 & 0 \\
\hline Use of short acting $B_{2}$ agonist $* *$ & 39 & 0 \\
\hline \multicolumn{3}{|l|}{ Positive culture with: } \\
\hline S. pneumoniae & 25 & 27 \\
\hline H. influenzae & 31 & 31 \\
\hline H. parainfluenzae & 52 & 50 \\
\hline S. aureus & 16 & 16 \\
\hline \multicolumn{3}{|l|}{ Positive serology for: } \\
\hline C. pneumonia (IgA) & 4 & 10 \\
\hline C. pneumonia (IgG) & 9 & 12 \\
\hline M. pneumonia (IgA) & 11 & 2 \\
\hline M. pneumonia (IgG) & 58 & 59 \\
\hline $\mathrm{CD}^{+} \mathrm{CD} 45 \mathrm{RC}^{\text {low }}$, in mean \% (SEM) & $40.2(0.9)$ & $39.3(2.2)$ \\
\hline $\mathrm{CD}^{+} \mathrm{CD} 45 \mathrm{RC} \mathrm{C}^{\text {low }}$, in mean \% (SEM) & $20.4(0.8)$ & $16.4(1.4)$ \\
\hline $\mathrm{CD}^{+} \mathrm{CD} 127^{-} \mathrm{CD} 25^{+}$, in mean $\%$ (SEM) & $7.7(0.2)$ & $7.0(0.3)$ \\
\hline $\mathrm{IL}-4$, in $\mathrm{pg} / \mathrm{ml}$, in median (IQR) ** & $9.4(4.6-15.4)$ & $4.5(3.0-12.1)$ \\
\hline IL-8, in $\mathrm{pg} / \mathrm{ml}$, in median (IQR) ** & $6.3(3.7-10.3)$ & $4.2(3.1-6.8)$ \\
\hline IL-10, in $\mathrm{pg} / \mathrm{ml}$, in median (IQR) ** & $5.0(2.9-9.1)$ & $3.3(2.1-5.5)$ \\
\hline $\mathrm{IL}-13$, in $\mathrm{pg} / \mathrm{ml}$, in median (IQR) ** & $38.5(23.2-61.0)$ & $26.2(13.2-54.9)$ \\
\hline
\end{tabular}

Data are presented in percentages unless stated otherwise. Abbreviations: ICS = Inhaled Corticosteroids; IL = Interleukin; IQR = Inter Quartile Range; $\mathrm{N}=$ Number; $\mathrm{SEM}=$ Standard Error of the Mean. ${ }^{+}$Atopy is defined as a positive Phadiatop Infant test. $* *$ p $<0.05$.

\section{Regulatory T-cells and CD45RC T-cell subsets}

No differences in percentage of $T_{\text {reg }}$ cells were found in children with recurrent wheeze compared to non-wheezing children (Table 6.1). A slightly higher percentage of CD45RC ${ }^{\text {low }}$ CD8 T-cells, but not CD4 T-cells, was found in wheezing children compared to children without wheeze (Odds Ratio (OR): 1.04, 95\% Confidence Interval (Cl): 1.01 1.08, $p=0.05$, Table 6.1). 


\section{Inflammatory markers in Exhaled Breath Condensate}

EBC levels of IL-4, IL-10 and IL-13 were significantly elevated in the group of children with wheezing symptoms compared to non-wheezing children ( $p<0.05$, Table 6.1). Levels of IL-8 were borderline significantly different between both groups (OR: 1.33, $95 \% \mathrm{Cl}: 1.00-1.76, \mathrm{p}=0.05$, Table 6.1 ).

\section{Multivariable model}

Prior to multivariable logistic regression modelling, PCA was conducted on the four EBC markers. Markers could be summarised in two components that both had eigenvalues over Kaiser's criterion of 1 and in combination explained $94.2 \%$ of the variance. PCA component 1 had high loadings on IL-8, IL-10 and IL-13, while component 2 had the highest loading on IL-4. The two EBC components, atopy, bacteria, $T_{\text {reg }}$ cells and CD45RC T-cell subsets were included in a multiple regression model with wheeze/non-wheeze as dependent variable. The multivariable regression modelling revealed comparable results as the univariable modelling, with no apparent influence of bacteria, atopy, $T_{\text {reg }}$ and $C D 45 R C^{\text {low }} C D 4$ cells on wheezing. No interaction between atopy and bacteria and $T_{\text {reg }}$ cells was demonstrated in the multivariable model. With the backward procedure only $C D 45 R C^{\text {low }} \mathrm{CD} 8 \mathrm{~T}$-cells were significantly associated with wheezing symptoms (OR: $1.06,95 \% \mathrm{Cl}: 1.01-1.11, \mathrm{p}=0.03$ ), while EBC component 1 (representing IL-8, IL-10, IL-13) was mildly positively associated in the final model (OR: $1.40,95 \% \mathrm{Cl}: 0.98-1.89, \mathrm{p}=0.07)$.

\section{Sub-analysis in wheezers}

\section{EBC markers and Tcells in the presence and absence of bacteria}

Recurrent wheezing children who scored positive on the presence of $H$. para influenzae had mildly elevated levels of exhaled IL-8 (FDR corrected $p=0.06$ ), while recurrent wheezers with a positive score on $H$. influenzae had mildly elevated levels of exhaled IL-4 and IL-8 (FDR corrected $\mathrm{p}=0.09$, Figure 6.2) compared to wheezing children without presence of $H$. (para) influenzae. For the other micro-organisms, no elevated levels of inflammatory biomarkers or differences in $T_{\text {reg }}$ cells were demonstrated in wheezing children with a positive test compared to wheezing children with a negative test.

\section{Correlation T-cells and airway inflammation}

In children with wheezing symptoms, we found a negative correlation between the percentage of the CD45RC ${ }^{\text {low }}$ CD8 T-cells and IL-4 and IL-13 $\left(r_{s}=-0.291, p<0.01, r_{s}=\right.$ $-0.203, p=0.03$, respectively). Comparably, a negative correlation between $C D 45 R C^{\text {low }}$ CD4 T-cells and IL-4 was found $\left(r_{s}=-0.219, p=0.03\right)$. 


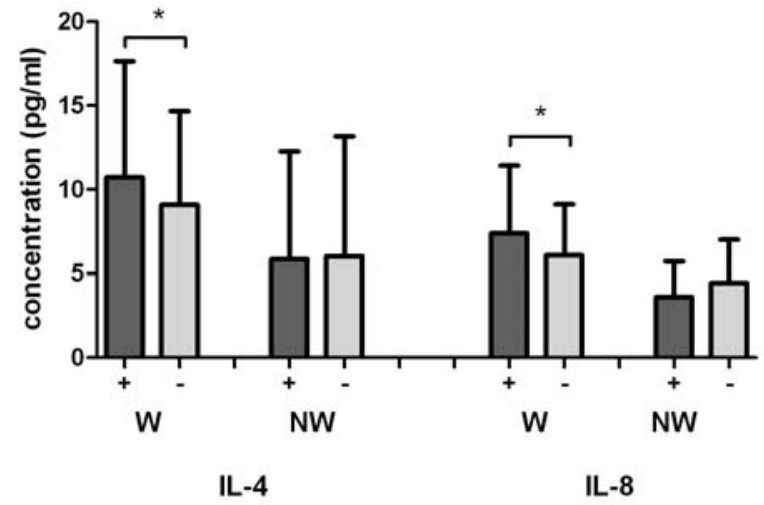

Figure 6.2 Markers in Exhaled Breath Condensate.

Interleukin (IL)-4 and IL-8 in wheezing (W) and non-wheezing (NW) children colonised (+) and non-colonised (-) with $H$. influenzae $\left({ }^{*} p<0.10\right)$.

\section{Discussion}

We have studied the relation between presence of bacteria in nasal and throat swabs, $\mathrm{T}_{\text {reg }}$ cells, CD45RC T-cell subsets and inflammatory markers in wheezing and nonwheezing preschool children. We did not find differences in presence of bacteria and $T_{\text {reg }}$ cells between wheezers and children without wheeze. The relative presence of

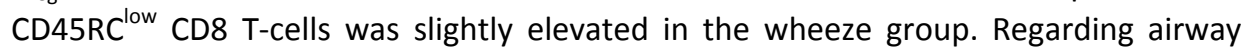
inflammation, we demonstrated that children with recurrent wheeze had higher levels of EBC markers (IL-4, IL-8, IL-10, IL-13) compared to children without symptoms. Moreover, in the wheeze group, children with a positive $H$. (para) influenzae score had slightly elevated levels of EBC markers compared to non-colonised children.

Although viral infections are well-known triggers for recurrent wheeze in preschool children, the role of bacteria is less understood. Despite the increasing interest in the relation between bacteria and wheezing, it is still unclear whether bacteria in the respiratory tract are important contributors to recurrent wheeze or just bystanders. In our study, positive bacterial cultures and serology were common and equally present in children with and without recurrent wheeze, with comparable prevalence as reported previously. ${ }^{4,17-20}$ Our findings are in concordance with those of Nagayama et al. who reported frequent bacterial colonisation of S. pneumoniae and $H$. influenzae in acute-, recurrent- and non-wheezing children, with no difference in prevalence between groups. ${ }^{18}$ In contrast, Bisgaard et al. reported that in children aged four weeks to three years, bacterial colonisation with S. pneumoniae and $H$. influenzae was more prevalent during acute wheezing episodes than in periods without wheeze. This 
association was independent of viral infections. ${ }^{4}$ In a former study, Bisgaard et al. demonstrated an increased risk for developing recurrent wheeze in case of neonatal colonisation of $S$. pneumoniae or $H$. influenzae. However, at one year of age, colonisation was no longer associated with recurrent symptoms and asthma, indicating a particular vulnerable period in the first weeks of life. Jartti et al. reported in children hospitalised for their first wheezing episode that those colonised with $S$. pneumoniae and $H$. influenzae, needed longer hospitalisation time and more often relapsed within two months after discharge, than non-colonised children. However, bacterial colonisation was not associated with recurrent wheezing within a year. ${ }^{17}$ Taken together, typical bacteria like S. pneumoniae and $H$. influenzae seem to commonly inhabit the respiratory tract of children with and without respiratory symptoms. Although they are frequently present in acute wheezing episodes in infants, our data and those of others do not suggest that these bacteria significantly contribute to chronic, recurrent wheezing symptoms in older children. ${ }^{17,18,21}$

In addition, no differences in frequency of seropositivity for $M$. pneumoniae and $C$. pneumoniae were observed when comparing children with and without wheezing symptoms. Our findings are in accordance with findings of two case-control studies that did not find higher antibody titres for $C$. pneumoniae in young wheezing children compared to controls. ${ }^{22,23}$ In contrast, other studies supported a role for positive serology for $C$. pneumoniae and $M$. pneumoniae in relation to wheezing episodes, as recently reviewed. ${ }^{21,24}$ So the role of $M$. pneumoniae and $C$. pneumoniae in the aetiology of preschool wheeze needs to be further elucidated.

We did not find differences in presence of atopy in wheezers and non-wheezers. Moreover, atopy did not significantly interact with bacteria or $T_{\text {reg }}$ cells in a multivariable model of wheeze. Persistent wheeze is often associated with atopic sensitisation in early life. ${ }^{25}$ We hypothesized that atopic children with wheezing symptoms might have an inadequate immune response to bacteria, which eventually can result in enhanced airway inflammation (Figure 6.1). However, our findings do not support this hypothesis. In contrast, Ferrari et al. demonstrated a positive association between antibodies to $C$. pneumoniae and atopic status. ${ }^{26}$ The authors argued that atopy might be associated with less efficient clearance of bacteria leading to higher antibody titres than in non-atopic persons. ${ }^{26}$ Hence the relation between atopic sensitisation, immune responses, and presence of bacteria needs to be further elaborated in longitudinal studies.

Currently, data about airway inflammation in relation to bacterial colonisation are scarce since techniques to assess inflammation are rather invasive. Assessing airway inflammation by using markers in $\mathrm{EBC}$ is a promising, non-invasive technique. We demonstrated that children with recurrent wheeze had elevated levels of EBC markers compared to non-wheezing children. In a previous report we demonstrated that levels 
of these markers increased with frequency of symptoms. ${ }^{16}$ Presently, we studied whether enhanced airway inflammation was related to presence of bacteria. In the presence of wheeze, we demonstrated that children colonised with $\mathrm{H}$. parainfluenzae had mildly elevated levels of IL-8, while children colonised with $H$. influenzae had elevated levels of IL-4 and IL-8. This finding fits into the concept that bacteria can induce pro-inflammatory cytokines, thereby promoting the development of recurrent wheezing symptoms. ${ }^{19,27,28}$

It can be argued that bacteria only induce an inflammatory response in the airways of children with impaired immunity. We have studied the presence of $\mathrm{T}_{\text {reg }}$ cells in children with recurrent wheeze and non-wheezing children. $T_{\text {reg }}$ cells play an important role in the maturation of the infant immune system as they control T-helper (Th) 1 and Th2 immune responses. ${ }^{14,29}$ An imbalance between Th1 and Th2, can lead to an increased inflammatory response as seen in asthma. ${ }^{30,31}$ It is hypothesized that this imbalance is caused by a decrease in number or function of $\mathrm{T}_{\text {reg }}$ cells. ${ }^{14,32}$ We did not find different counts of $T_{\text {reg }}$ cells in wheezing children compared to non-wheezers. Thereby we could not confirm the findings of Borrego et al. who did report lower $T_{\text {reg }}$ cell counts in wheezing infants compared to healthy controls. ${ }^{8}$ For future studies, it is warranted to look not only at the number, but also at the functionality of $\mathrm{T}_{\text {reg }}$ cells, in order to elucidate the contribution of these cells in wheezing illness. ${ }^{33}$ The negative correlation between CD45RC ${ }^{\text {low }}$ T-cell subsets and IL-4 and IL-13 that we found, is in conflict with the concept that $C D 45 R C^{\text {low }}$ T-cell subsets produce these interleukins. ${ }^{14}$ This contradiction might be explained by the fact that we are sampling from two different body compartments, namely blood and lungs. In wheezing children, it is conceivable that CD45RClow T-cell subsets are relatively more present in the target organ than in the circulation.

The strength of our study is that we investigated markers of bacterial, immunological and inflammatory status to unravel the background of preschool wheeze in a considerable number of children. However, our study has some limitations. Firstly, for certain pathogens we studied positive cultures whilst for others we looked at antibodies in sera. Moreover, bacterial micro-organisms from the upper airways might not reflect the bacterial status in the lower airways. In the present study, it was not possible to study both sera and cultures for all pathogens due to practical and ethical reasons. For future studies, data based on sera and cultures in combination with sensitive polymerase chain reaction (PCR) methods will provide a more complete picture. Secondly, the group of wheezing children that we have studied is very heterogeneous. Some of the children experience transient symptoms probably due to infections, while others wheeze because of underlying asthma. Differentiating these wheezing phenotypes will be possible after our four years of follow-up. Finally, we did not study the role of viruses. It is speculated that viral infections increase susceptibility to bacterial co-infections e.g. by damaging the lung epithelia that leads to increasing 
bacterial influx allowing enhanced infection. ${ }^{2}$ For future studies, it is important to elucidate whether bacteria are contributors to chronic wheeze in preschool children, apart from viruses.

In conclusion, we did not find an association between bacterial colonisation and preschool recurrent wheeze. Neither was the number of $\mathrm{T}_{\text {reg }}$ cells different in children with recurrent wheeze compared to non-wheezing children. We demonstrated that wheezing children had elevated levels of various exhaled inflammatory markers compared to children without symptoms. Moreover, wheezing children colonised with $H$. (para) influenzae had mildly elevated pro-inflammatory cytokines and chemokines, which may point to a bacterial induced airway inflammation. Whether this enhanced inflammation is independently stimulated by bacteria or whether these bacteria synergistically interact with virus-induced infections needs to be further studied. 


\section{References}

1. Henderson J, Granell R, Heron J, Sherriff A, Simpson A, Woodcock A, Strachan DP, Shaheen SO, Sterne JA. Associations of wheezing phenotypes in the first 6 years of life with atopy, lung function and airway responsiveness in mid-childhood. Thorax 2008;63:974-980.

2. Tregoning JS, Schwarze J. Respiratory viral infections in infants: causes, clinical symptoms, virology, and immunology. Clin Microbiol Rev 2010;23:74-98.

3. Silvestri M, Sabatini F, Defilippi AC, Rossi GA. The wheezy infant -- immunological and molecular considerations. Paediatr Respir Rev 2004;5 Suppl A:S81-87.

4. Bisgaard H, Hermansen MN, Bonnelykke K, Stokholm J, Baty F, Skytt NL, Aniscenko J, Kebadze T, Johnston SL. Association of bacteria and viruses with wheezy episodes in young children: prospective birth cohort study. BMJ 2010;341:c4978.

5. Bisgaard H, Hermansen MN, Buchvald F, Loland L, Halkjaer LB, Bonnelykke K, Brasholt M, Heltberg A, Vissing NH, Thorsen SV, Stage M, Pipper CB. Childhood asthma after bacterial colonization of the airway in neonates. N Engl J Med 2007;357:1487-1495.

6. Hauk PJ, Krawiec M, Murphy J, Boguniewicz J, Schiltz A, Goleva E, Liu AH, Leung DY. Neutrophilic airway inflammation and association with bacterial lipopolysaccharide in children with asthma and wheezing. Pediatr Pulmonol 2008;43:916-923.

7. McDougall CM, Helms PJ. Neutrophil airway inflammation in childhood asthma. Thorax 2006;61: 739-741.

8. Borrego LM, Arroz MJ, Videira P, Martins C, Guimaraes H, Nunes G, Papoila AL, Trindade H. Regulatory cells, cytokine pattern and clinical risk factors for asthma in infants and young children with recurrent wheeze. Clin Exp Allergy 2009;39:1160-1169.

9. Worldwide variation in prevalence of symptoms of asthma, allergic rhinoconjunctivitis, and atopic eczema: ISAAC. The International Study of Asthma and Allergies in Childhood (ISAAC) Steering Committee. Lancet 1998;351:1225-1232.

10. van de Kant KD, Klaassen EM, Jöbsis Q, Nijhuis AJ, van Schayck OC, Dompeling E. Early diagnosis of asthma in young children by using non-invasive biomarkers of airway inflammation and early lung function measurements: study protocol of a case-control study. BMC Public Health 2009;9:210.

11. Isenberg HD. Clinical microbiology procedures handbook, 2nd edn. Washington: ASM Press; 2004.

12. Smolders J, Thewissen M, Peelen E, Menheere P, Tervaert JW, Damoiseaux J, Hupperts R. Vitamin D status is positively correlated with regulatory $T$ cell function in patients with multiple sclerosis. PLoS One 2009;4:e6635.

13. Liu W, Putnam AL, Xu-Yu Z, Szot GL, Lee MR, Zhu S, Gottlieb PA, Kapranov P, Gingeras TR, Fazekas de St Groth B, Clayberger C, Soper DM, Ziegler SF, Bluestone JA. CD127 expression inversely correlates with FoxP3 and suppressive function of human CD4+ T reg cells. J Exp Med 2006;203:1701-1711.

14. Damoiseaux J. Regulatory T cells: back to the future. Neth J Med 2006;64:4-9.

15. de Jager W, te Velthuis H, Prakken BJ, Kuis W, Rijkers GT. Simultaneous detection of 15 human cytokines in a single sample of stimulated peripheral blood mononuclear cells. Clin Diagn Lab Immunol 2003;10:133-139.

16. van de Kant KD, Klaassen EM, Jöbsis Q, Koers K, Rijkers GT, van der Grinten CP, van Schayck OC, Passos $\mathrm{VL}$, Dompeling E. Wheezing in preschool children is associated with increased levels of cytokines/chemokines in exhaled breath condensate. J Allergy Clin Immunol 2010;126:669-671.

17. Jartti T, Kuneinen S, Lehtinen P, Peltola V, Vuorinen T, Leinonen M, Ruuskanen O. Nasopharyngeal bacterial colonization during the first wheezing episode is associated with longer duration of hospitalization and higher risk of relapse in young children. Eur J Clin Microbiol Infect Dis 2011;30: 233-241.

18. Nagayama Y, Tsubaki T, Nakayama S, Sawada K, Taguchi K, Toba T, Kohno Y. Bacterial colonization in respiratory secretions from acute and recurrent wheezing infants and children. Pediatr Allergy Immunol 2007;18:110-117.

19. Esposito S, Droghetti R, Bosis S, Claut L, Marchisio P, Principi N. Cytokine secretion in children with acute Mycoplasma pneumoniae infection and wheeze. Pediatr Pulmonol 2002;34:122-127. 
20. Normann E, Gnarpe J, Wettergren B, Janson C, Wickman M, Nordvall L. Association between Chlamydia pneumoniae antibodies and wheezing in young children and the influence of sex. Thorax 2006;61:1054-1058.

21. Korppi M. Bacterial infections and pediatric asthma. Immunol Allergy Clin North Am 2010;30:565-574.

22. Mills GD, Lindeman JA, Fawcett JP, Herbison GP, Sears MR. Chlamydia pneumoniae serological status is not associated with asthma in children or young adults. Int J Epidemiol 2000;29:280-284.

23. Korppi M, Paldanius M, Hyvarinen A, Nevalainen A, Husman T. Chlamydia pneumoniae and newly diagnosed asthma: a case-control study in 1 to 6-year-old children. Respirology 2004;9:255-259.

24. Xepapadaki P, Koutsoumpari I, Papaevagelou V, Karagianni C, Papadopoulos NG. Atypical bacteria and macrolides in asthma. Allergy Asthma Clin Immunol 2008;4:111-116.

25. Illi S, von Mutius E, Lau S, Niggemann B, Gruber C, Wahn U. Perennial allergen sensitisation early in life and chronic asthma in children: a birth cohort study. Lancet 2006;368:763-770.

26. Ferrari M, Poli A, Olivieri M, Verlato G, Tardivo S, Nicolis M, Campello C. Respiratory symptoms, asthma, atopy and Chlamydia pneumoniae IgG antibodies in a general population sample of young adults. Infection 2002;30:203-207.

27. Choi IS, Byeon JH, Yoo Y, Lee KC, Choung JT. Increased serum interleukin-5 and vascular endothelial growth factor in children with acute mycoplasma pneumonia and wheeze. Pediatr Pulmonol 2009;44:423-428.

28. Patel KK, Vicencio AG, Du Z, Tsirilakis K, Salva PS, Webley WC. Infectious Chlamydia pneumoniae is associated with elevated interleukin-8 and airway neutrophilia in children with refractory asthma. Pediatr Infect Dis J 2010;29:1093-1098.

29. Lloyd CM, Hawrylowicz CM. Regulatory T cells in asthma. Immunity 2009;31:438-449.

30. Robinson DS, Hamid Q, Ying S, Tsicopoulos A, Barkans J, Bentley AM, Corrigan C, Durham SR, Kay AB. Predominant TH2-like bronchoalveolar T-lymphocyte population in atopic asthma. N Engl J Med 1992;326:298-304.

31. Busse WW, Lemanske RF, Jr. Asthma. N Engl J Med 2001;344:350-362.

32. Xystrakis $\mathrm{E}$, Boswell SE, Hawrylowicz CM. T regulatory cells and the control of allergic disease. Expert Opin Biol Ther 2006;6:121-133.

33. Yamamoto $Y$, Negoro $T$, Hoshi A, Wakagi A, Shimizu S, Banham AH, Ishii M, Akiyama $H$, Kiuchi $Y$, Sunaga S, Tobe T, Roncador G, Itabashi K, Nakano Y. Impaired Ca Regulation of CD4(+)CD25(+) Regulatory T Cells from Pediatric Asthma. Int Arch Allergy Immunol 2011;156:148-158. 



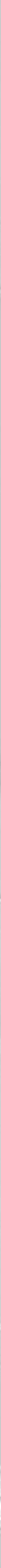


Chapter 7
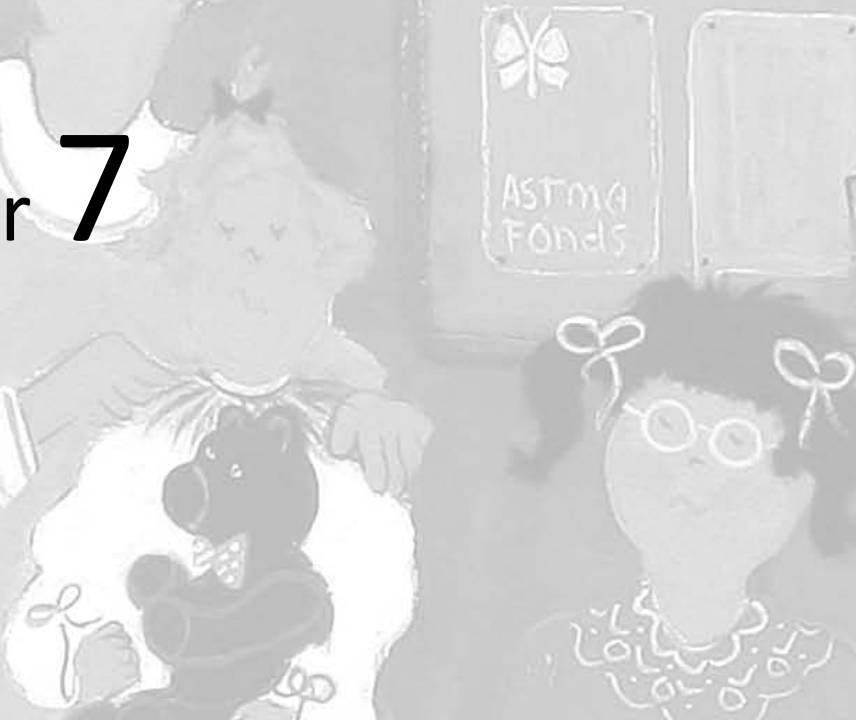

Can exhaled inflammatory markers predict a steroid response in wheezing preschool children?

van de Kant KDG, Koers K, Rijkers GT, Lima Passos V, Klaassen EMM, Mommers M, Dagnelie PC, van Schayck CP, Dompeling E, Jöbsis Q 


\section{Abstract}

\section{Background}

The efficacy of inhaled corticosteroids (ICS) varies among wheezing preschool children. Currently, it is not possible to predict which fraction of wheezing children will benefit from an ICS treatment.

\section{Objectives}

We explored whether Fractional exhaled Nitric Oxide (FeNO) and inflammatory markers in Exhaled Breath Condensate (EBC) can predict an ICS response in preschool wheezers.

\section{Methods}

An eight weeks ICS study (registered at Clinicaltrial.gov: NCT 00422747; $200 \mu \mathrm{g}$; Beclomethasone extra-fine daily) was performed in 93 wheezing children (age range $2.0-4.4$ years). At baseline, FeNO was determined off-line. EBC was collected using a closed glass-condenser. Acidity of EBC was determined and other EBC markers (Interleukin(IL)-1 $\alpha$, IL-2, IL-4, IL-5, IL-10, soluble Intercellular Adhesion Molecule, Interferon- $\gamma$, Eotaxin) were measured using multiplex immunoassay. The change in airway resistance (using MicroRint ${ }^{\circ}$ ) and symptom score following ICS treatment was related to atopy (positive Phadiatop Infant test), FeNO and EBC markers.

\section{Results}

Airway resistance and symptoms mildly improved after ICS treatment (median (IQR): $1.4(1.2$ - 1.7) to $1.3(1.1-1.5) \mathrm{kPa} \cdot \mathrm{s} / \mathrm{L}$, symptom-score: $26(23-28)$ to $28(24-29)$, $\mathrm{p}<0.01$, respectively). Only $\mathrm{IL}-10$ and atopy had limited predictive value regarding a change in symptoms $(\beta(S E)=-0.13(0.07), p=0.08, \quad \beta(S E)=2.05 \quad(1.17), p=0.08$, respectively).

\section{Conclusions}

We did not find convincing evidence that FeNO and EBC markers could predict an ICS response in preschool wheezers. Recommendations for future studies on this topic are given. 


\section{Introduction}

Wheeze is a common symptom in preschool children. About one third of children will experience intermittent wheeze during preschool life. ${ }^{1}$ The underlying cause of childhood wheeze can differ substantially. Various phenotypes of childhood wheeze have been defined. ${ }^{2}$ These phenotypes differ in pathophysiology and show a differential response to inhaled corticosteroids (ICS). ${ }^{3-5}$ ICS are effective in preschool children who wheeze due to asthma. ${ }^{3}$ In contrast, ICS are not very effective in preschool children who wheeze due to a viral respiratory tract infection, so-called viral or transient wheezers. ${ }^{4,5}$ Since a reliable distinction between asthmatic children and viral wheezers cannot be made before the age of six years, it is currently not possible to predict which fraction of the wheezing children will benefit from an ICS treatment. An early, reliable prediction of an ICS response can optimise treatment in preschool children with respiratory symptoms.

Eosinophilic airway inflammation is a central feature in asthma. In contrast, in transient wheezers neutrophilic inflammation is believed to play a central role. ${ }^{6}$ The assessment of (different forms of) airway inflammation in preschool wheezers might therefore improve the prediction as to which children will respond to ICS treatment.

The currently available techniques to measure airway inflammation, such as biopsy and bronchoalveolar lavage, are too invasive for routine use in children. Consequently, there is an increasing interest in the non-invasive assessment of exhaled inflammatory markers, such as Fractional exhaled Nitric Oxide (FeNO) and solutes in Exhaled Breath Condensate (EBC). We previously showed that the analysis of inflammatory markers in $E B C$ is a feasible and non-invasive method to assess airway inflammation in preschool children, and demonstrated an increased inflammatory response in preschool children with recurrent wheeze. ${ }^{7}$ Whether these markers are clinically useful to predict a response to anti-inflammatory treatment has not been studied as yet. Our objective was to investigate whether exhaled inflammatory markers are able to predict an ICS response in wheezing preschool children.

\section{Methods}

\section{Study population}

We included children from the ADEM study (Asthma DEtection and Monitoring study: registered at clinicaltrial.gov: NCT 00422747) that started in 2006 in the Netherlands. In the ADEM study, children who experienced at least two wheezing episodes during life (assessed by the ISAAC questionnaire) ${ }^{8}$ and control subjects who never wheezed are included at two and three years of age and are studied prospectively until six years of age. The primary objective of the ADEM study is to develop a non-invasive 
instrument for an early asthma diagnosis using exhaled inflammatory biomarkers and early lung function measurements. The study protocol has been described previously. ${ }^{9}$ Figure 7.1 presents the flow chart of the current study. We included children who experienced respiratory symptoms (wheeze, cough or dyspnoea) during the preceding month, as assessed by a questionnaire. ${ }^{10}$ If applicable, the administration of prescribed ICS was stopped four weeks before the initial visit. Children were excluded if ICS could not be stopped. Ethical approval was obtained from the Dutch National Medical Ethical Committee (CCMO). All parents gave written informed consent.

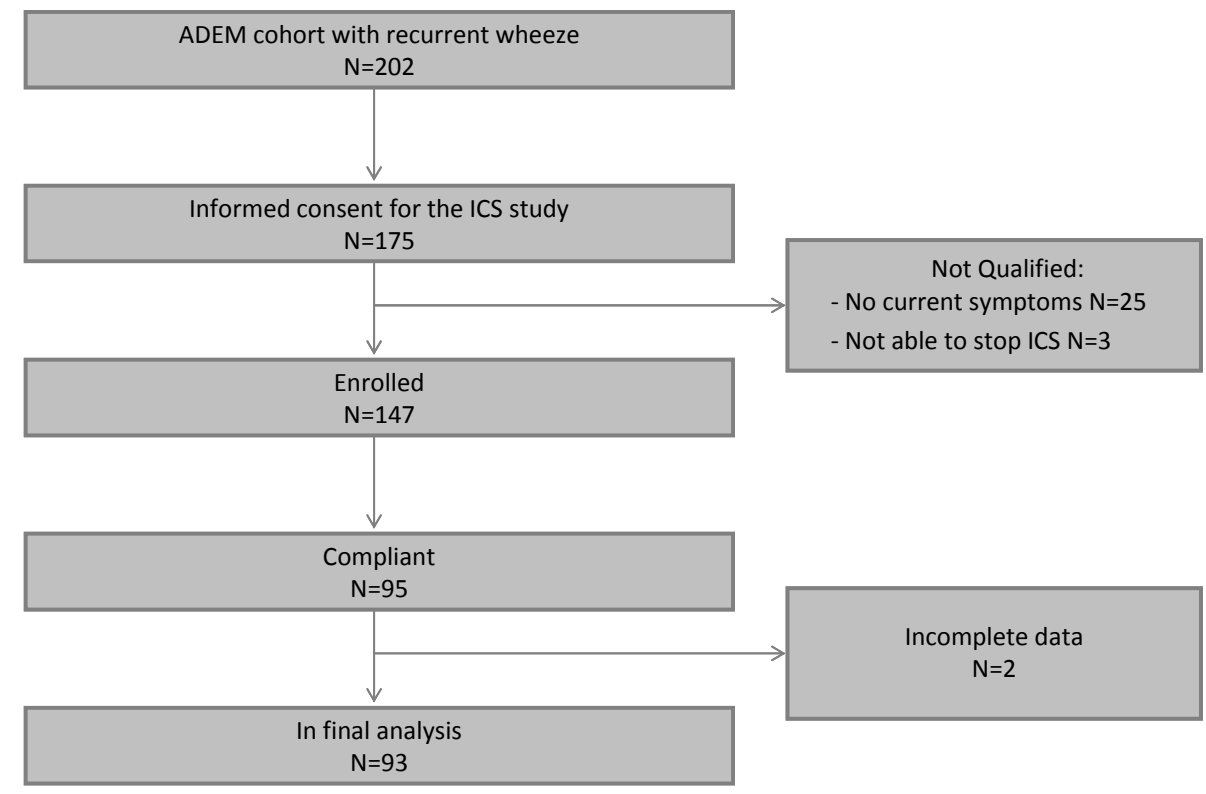

Figure 7.1 Study flow chart.

Current symptoms were defined as experiencing respiratory symptoms during the preceding month. Compliance to the study medication was defined when children used at least $80 \%$ of the prescribed study medication.

\section{Study Design}

During an initial visit, EBC was collected and FeNO was measured. In addition, symptoms were assessed and lung function measurements were performed (details are described below). Measurements were postponed in case of an airway infection. Solid foods and physical exercise were not allowed for one hour before the measurements. The presence of atopy was determined using a Phadiatop Infant test (Phadia, Uppsala, Sweden). Subsequently, children received ICS for eight weeks (Beclomethasone extrafine, two times 100 microgram daily, via the Aerochamber, provided by Teva Pharma NL, Haarlem, the Netherlands). Parents were allowed to give 
salbutamol (Airomir , Teva Pharma NL, Haarlem, the Netherlands) to their child for symptom relief. No other asthma medication was allowed. Compliance to the study medication was measured by weighing the ICS canisters before and after therapy. Children were excluded when less than $80 \%$ of the prescribed study medication was used. After eight weeks of ICS treatment, all measurements were repeated. We did not include a control group refrained from ICS since this was not approved by the Dutch National Medical Ethical Committee.

\section{Airway resistance and symptoms}

The outcome variable was defined as change in airway resistance and symptoms before and after ICS treatment.

\section{Airway resistance}

Lung function was assessed using airway resistance measurements (MicroRint, Micro Medical Ltd, Rochester, United Kingdom). Children breathed tidally through a facemask while sitting in an upright position. Airflow interruptions were made on the expiratory peak flow. The median value of at least five successful interruptions before and after treatment was used for analysis.

\section{Symptoms}

Parents completed a questionnaire to record patterns of wheeze and other respiratory symptoms. ${ }^{10}$ Parents scored three items (cough, wheeze, dyspnoea) on day-time symptoms and on night-time symptoms. Each item had five possible, graded responses (symptoms experienced: every day $=1$, most days $=2$, some days $=3$, a few days $=4$, not at all=5). A total symptom score (ranging from six points for children with the most severe symptoms to thirty points for those with no symptoms) before and after therapy was calculated.

\section{Cut-off point for illustrative purposes}

From a clinical perspective, a cut-off point can be helpful to determine whether a child should be treated with ICS or not. A child was considered to be a responder when there was a decrease in respiratory symptoms of $\geq 30 \%$ and/or an improvement in airway resistance of $\geq 10 \%$, based on ICS responses reported in similar populations. ${ }^{5,11}$

\section{Fractional exhaled Nitric Oxide assessment}

FeNO was sampled before EBC collection and lung function assessments. FeNO was collected off-line in a $500 \mathrm{ml}$ inert balloon during tidal breathing and analysed using a Nitric Oxide monitoring system, as described previously (NIOX ${ }^{\bullet}$, Aerocrine, Solna, Sweden). ${ }^{9}$ 


\section{Exhaled Breath Condensate collection}

To collect EBC, a closed glass condenser system with a breath recirculation unit was used which was developed at our institute. ${ }^{9,12}$ This efficient closed condenser system enables sufficient EBC collection in less collection-time (10 minutes), as described previously. ${ }^{9,12}$ Directly after collection, the acidity $(\mathrm{pH})$ of $E B C$ was analysed (Radiometer, Zoetermeer, the Netherlands). Inflammatory markers in EBC (Interleukin(IL)-1 $\alpha$, IL-2, IL-4, IL-5, IL-10, soluble Intercellular Adhesion Molecule (sICAM), Interferon-gamma (IFN- $\gamma$ ) and Eotaxin (CCL-11)) were assayed using the multiplex immunoassay (Luminex Corporation, Austin, TX, USA). ${ }^{13}$

\section{Statistical analysis}

Data were analysed with SPSS 16.1 (SPSS inc., Chicago, IL, USA). Because the airway resistance values, symptoms scores, FeNO levels, and EBC markers were skewed to the right, they were expressed as medians and Inter Quartile Ranges (IQR). Samples with levels of EBC markers below the detection limit received a randomly generated value taken from the uniform distribution between zero and the detection limit. ${ }^{7}$

Differences in baseline characteristics between responders and non-responders (secondary analysis) were evaluated using independent t-tests for parametric variables, Mann-Whitney tests for non-parametric variables and the Chi-square test for categorical variables. Wilcoxon' signed-rank tests were used to test for differences in parameters before and after ICS treatment. Differences were considered statistically significant when the $p$-value was $<0.05$.

The effect of each individual inflammatory marker on the ICS outcome was tested via separate linear regression models adjusted for possible confounders. The influence of possible confounders (gender, atopy, eczema, history of ICS use, season of measurements, parental asthma, parental smoking, and number of wheezing episodes from birth until present) was studied using linear regression models. Parameters were considered to be confounders when they changed the association between EBC markers and ICS outcome by more than ten percent when included in the model. Only atopy altered the association between the majority of markers and change in symptoms with more than ten percent and was therefore included in the subsequent regression models. In addition, a multivariable model was fitted to study the combined effects of inflammatory markers. Because EBC markers were highly correlated with each other, a principal component analysis (PCA) with orthogonal rotation (varimax) was conducted, reducing the nine markers to fewer uncorrelated composite variables. These variables, instead of the original EBC markers, were, together with atopy and FeNO, used in a multivariable model, thereby avoiding multicollinearity. A backward procedure was used for variable selection with a significance level of five percent. 


\section{Power analysis}

A sample size calculation for correlation between two quantitative variables was performed (formula: $\left.\mathrm{N}=6+\left[\left(\mathrm{Z}_{1-\alpha / 2}+\mathrm{Z}_{1-\beta}\right)^{2} *\left(1-\rho^{2} / \rho^{2}\right)\right]\right){ }^{14}$ Previous research in asthmatic adults (paediatric data are lacking), showed correlation coefficients ranging from 0.3 to 0.6 between exhaled markers and improvement in lung function after ICS. ${ }^{15-17}$ When using a correlation of 0.3 , at least 85 children were required for the analysis, with an alpha of 0.05 and a power of $80 \%$. When considering a noncompliance rate of $30 \%{ }^{18}$ at least 111 children had to be enrolled.

\section{Results}

A total number of 147 children participated in the study. For the analysis 93 children (mean age 3.3, range 2.0-4.4 years) were included, see Table 7.1 for the baseline characteristics. The rest of the children were excluded because of non-compliance $(\mathrm{N}=52)$ or incomplete data $(\mathrm{N}=2)$. Figure 7.1 presents the study flow chart. The reasons for non-compliance were withdrawn consent of parents $(\mathrm{N}=6)$, refusal of the child to take ICS $(\mathrm{N}=9)$, personal constraints $(\mathrm{N}=5)$, forgot to give ICS daily $(\mathrm{N}=20)$ and unknown reasons $(\mathrm{N}=12)$. Children who were not compliant did not differ in symptoms, airway resistance, atopy, FeNO and markers in EBC at the baseline compared with children who were compliant.

\section{Inhaled corticosteroid treatment}

In general, both airway resistance and symptoms significantly improved after eight weeks of ICS treatment. Airway resistance decreased from 1.4 (1.2-1.7) to 1.3 (1.1-1.5) $\mathrm{kPa} \cdot \mathrm{s} / \mathrm{L}$ (median (IQR), $\mathrm{p}<0.01$, Table 7.2). Symptom scores improved from a total score of 26 (23-28) to 28 (24-29) (median (IQR), p<0.01, Table 7.2). Changes in airway resistance and symptoms scores after ICS treatment were significantly different from zero $(p<0.05)$. None of the inflammatory marker concentrations changed significantly after ICS treatment (Table 7.2). When we divided children into responders and nonresponders for a secondary analysis ( $\geq 30 \%$ decrease in symptoms and/or $\geq 10 \%$ decrease in airway resistance), ICS responders had higher airway resistance at baseline than ICS non-responders (Table 7.1, $\mathrm{p}<0.01$ ). There were no other baseline differences between both groups (Table 7.1).

\section{Confounders}

Of all possible confounders tested (see statistical analysis), only atopy was modestly associated with an ICS response regarding symptoms ( $\beta=2.05$, SE $\beta=1.17, p=0.08)$, and altered the association between most markers and change in symptoms with more than ten percent. Therefore, atopy was included in the regression models with inflammatory markers. 
Table 7.1 Clinical characteristics at baseline.

\begin{tabular}{|c|c|c|c|}
\hline & Responders & Non-responders & Total group \\
\hline Study population, in $\mathrm{N}$ & 47 & 46 & 93 \\
\hline Mean age (range), in years & $3.2(2.0-4.3)$ & $3.4(2.1-4.4)$ & $3.3(2.0-4.4)$ \\
\hline Gender: male / female, in $n$ & $21 / 26$ & $26 / 20$ & $47 / 46$ \\
\hline Atopy, in $\mathrm{n} / \mathrm{N}(\%)^{+}$ & 12 / 46 (26) & 9 / $44(20)$ & $21 / 90(23)$ \\
\hline Eczema, in $\mathrm{n} / \mathrm{N}(\%)$ & $15 / 45$ (33) & $13 / 46(28)$ & $28 / 91(31)$ \\
\hline Wheezing episodes, in $n(\mathrm{IQR})^{++}$ & $8(3-8)$ & $8(3-8)$ & $8(3-8)$ \\
\hline Use of ICS, in $\mathrm{n} / \mathrm{N}(\%)$ & 12 / $47(26)$ & $9 / 46(20)$ & 21 / 93 (23) \\
\hline Use of short acting $B_{2}$ agonist, $n / N(\%)$ & 23 / 47 (49) & $21 / 46(46)$ & 44 / 93 (47) \\
\hline Use of long acting $B_{2}$ agonist, $n / N(\%)$ & $1 / 47(2)$ & $0 / 46(0)$ & 1 / 93 (1) \\
\hline Total symptom score & $25(20-27)$ & $26(24-28)$ & $26(23-28)$ \\
\hline Airway resistance, in $\mathrm{kPa} \cdot \mathrm{s} / \mathrm{L} * * *$ & $1.5(1.3-1.9)$ & $1.3(1.1-1.5)$ & $1.4(1.2-1.7)$ \\
\hline $\mathrm{IL}-1 \alpha$, in $\mathrm{pg} / \mathrm{ml}$ & $40.2(11.4-125.1)$ & $51.5(21.6-79.1)$ & 41.9 (19.2 - 90.8) \\
\hline $\mathrm{IL}-2$, in $\mathrm{pg} / \mathrm{ml}$ & $57.0(29.0-103.0)$ & $55.8(42.7-77.4)$ & $56.8(38.9-78.5)$ \\
\hline $\mathrm{IL}-4$, in $\mathrm{pg} / \mathrm{ml}$ & $9.7(6.8-18.5)$ & $9.8(5.6-15.5)$ & $9.7(6.7-15.2)$ \\
\hline $\mathrm{IL}-5$, in $\mathrm{pg} / \mathrm{ml}$ & $28.4(18.0$ - 91.7) & 38.7 (19.7 - 66.5) & $33.4(18.9-66.5)$ \\
\hline IL-10, in pg/ml & $5.1(2.6-8.6)$ & $5.1(3.1-7.8)$ & $5.1(3.1-8.4)$ \\
\hline sICAM, in $\mathrm{pg} / \mathrm{ml}$ & $204.2(86.6-614.7)$ & $238.4(117.0-393.1)$ & $220.0(95.8-423.0)$ \\
\hline IFN- $\nu$, in $p g / m l$ & 28.5 (19.4 - 57.6) & 29.1 (18.9 - 45.9) & 28.6 (19.4 - 46.9) \\
\hline CCL-11, in $\mathrm{pg} / \mathrm{ml}$ & $8.6(5.9-18.3)$ & $9.1(6.0-13.2)$ & $8.6(6.0-15.0)$ \\
\hline $\mathrm{pH}$ & $6.0(5.7-6.4)$ & $5.9(5.6-6.3)$ & $5.9(5.7-6.3)$ \\
\hline FeNO, in $p p b$ & $8.4(3.9-14.5)$ & $6.9(3.2-12.7)$ & $7.8(3.9-13.4)$ \\
\hline
\end{tabular}

CCL-11 = Eotaxin, FeNO = Fractional exhaled Nitric Oxide, ICS = Inhaled Corticosteroids, IFN $-\nu=$ Interferongamma, IL = Interleukin, IQR = Inter Quartile Range, sICAM = soluble Intercellular Adhesion Molecule. ${ }^{+}$Atopy is defined as a positive Phadiatop Infant test. Numbers may not add up to 47, 46 or 93 in respectively responders, non-responders and total group, due to missing values. ${ }^{++}$Numbers of wheezing episodes from birth until present. Symptom scores, airway resistance and inflammatory markers are expressed as medians and IQR. ${ }^{* * *} \mathrm{p}<0.01$ between responders and non-responders (Mann-Whitney test).

Table 7.2 Parameters before and after steroid treatment.

\begin{tabular}{|c|c|c|c|}
\hline \multirow[b]{2}{*}{ Parameter } & \multicolumn{2}{|c|}{ Steroid therapy } & \multirow[b]{2}{*}{ P-value } \\
\hline & Before & After & \\
\hline Symptom score & $26(23-28)$ & $28(24-29)$ & $<0.01$ \\
\hline Airway resistance, in $\mathrm{kPa} \cdot \mathrm{s} / \mathrm{L}$ & $1.4(1.2-1.7)$ & $1.3(1.1-1.5)$ & $<0.01$ \\
\hline IL-1 $\alpha$, in $\mathrm{pg} / \mathrm{ml}$ & 41.9 (19.2 - 90.8) & $59.4(15.7-55.8)$ & 0.09 \\
\hline $\mathrm{IL}-2$, in $\mathrm{pg} / \mathrm{ml}$ & $56.8(38.9-78.5)$ & $57.8(42.4-104.1)$ & 0.22 \\
\hline IL-4, in $\mathrm{pg} / \mathrm{ml}$ & $9.7(6.7-15.2)$ & $9.8(7.2-17.6)$ & 0.62 \\
\hline IL-5, in pg/ml & $33.4(18.9-66.5)$ & $37.0(20.0-120.8)$ & 0.07 \\
\hline IL-10, in pg/ml & $5.1(3.1-8.4)$ & $5.5(3.3-9.1)$ & 0.36 \\
\hline sICAM, in $\mathrm{pg} / \mathrm{ml}$ & $220.0(95.8-423.0)$ & $260.4(106.6-754.9)$ & 0.14 \\
\hline IFN- $\nu$, in $p g / m l$ & $28.6(19.4-46.9)$ & $30.6(16.9-60.8)$ & 0.36 \\
\hline $\mathrm{CCL}-11$, in $\mathrm{pg} / \mathrm{ml}$ & $8.6(6.0-15.0)$ & $9.8(5.6$ - 19.6) & 0.09 \\
\hline $\mathrm{pH}$ & $5.9(5.7-6.3)$ & $5.8(5.6-6.2)$ & 0.27 \\
\hline FeNO, in $p p b$ & $7.8(3.9-13.4)$ & $9.1(4.1-15.8)$ & 0.51 \\
\hline
\end{tabular}

CCL-11 = Eotaxin, FeNO = Fractional exhaled Nitric Oxide, IFN- $\gamma=$ Interferon-gamma, IL = Interleukin, sICAM = soluble Intercellular Adhesion Molecule. Wilcoxon' signed-rank tests. Data are presented in Median (Inter Quartile Range). 


\section{Exhaled inflammatory markers}

We could successfully measure FeNO and collect EBC in all children. The mean EBC volume was $485 \mu \mathrm{l}$ (range: 60-1260 $\mu \mathrm{l}$ ). EBC markers could be detected in $97-100 \%$ of the samples.

The analysis of separate parameters demonstrated that none of the inflammatory markers significantly predicted an improvement in lung function after ICS treatment $(p>0.05)$. In addition, none of the markers were significant predictors for an improvement in symptoms, although IL-10 showed a negative trend $(\beta=-0.13, \mathrm{SE}$ $\left.\beta=0.07, p=0.08, R^{2}=0.07\right)$.

Before multivariable linear regression modelling, PCA was conducted on the nine markers in EBC. Markers could be summarised in three components that both had eigenvalues over Kaiser's criterion of one and in combination explained $93.6 \%$ of the variance. Table 7.3 shows the factor loadings after rotation. Component 1 had high loadings on various inflammatory markers including a pro-inflammatory cytokine (IL-

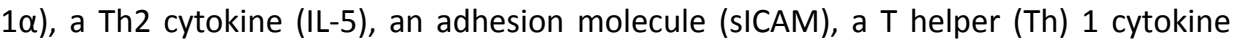
(IFN- $\gamma$ ) and a chemokine (CCL-11). Component 2 had the highest loading on the Th2 cytokine IL-4, while component 3 had the highest loading on the anti-inflammatory cytokine IL-10. The three EBC components, FeNO and atopy were included in two multiple regression models with change in symptoms and lung function as dependent variables. In both models, none of the parameters were significant in the initial model (Table 7.4). With the backward procedure only presence of atopy was mildly positively associated with an improvement in symptoms after ICS in the final model $(\beta=2.05, \mathrm{SE}$ $\beta=1.17, p=0.08, R^{2}=0.06$ ). As the PCA loading pattern did not change after log transformation, results are reported in the original scale.

Table 7.3 Factor loadings of the principal components.

\begin{tabular}{|c|c|c|c|}
\hline & Component 1 & Component 2 & Component 3 \\
\hline IL-1 $\alpha$ & 0.90 & 0.20 & 0.36 \\
\hline IL-2 & 0.69 & 0.29 & 0.65 \\
\hline IL-4 & 0.44 & 0.84 & 0.29 \\
\hline IL-5 & 0.88 & 0.36 & 0.24 \\
\hline IL-10 & 0.54 & 0.41 & 0.72 \\
\hline sICAM & 0.88 & 0.29 & 0.27 \\
\hline IFN- $\gamma$ & 0.78 & 0.44 & 0.38 \\
\hline CCL-11 & 0.78 & 0.42 & 0.32 \\
\hline $\mathrm{pH}$ & -0.03 & 0.01 & 0.00 \\
\hline
\end{tabular}

CCL-11 = Eotaxin, IFN- $\gamma=$ Interferon-gamma, IL = Interleukin, sICAM = soluble Intercellular Adhesion Molecule. Rotation Method $=$ Varimax with Kaiser' normalisation. 
Table 7.4 Multivariable regression for change in symptoms and lung function.

\begin{tabular}{|lcccc|} 
Outcome: & \multicolumn{2}{c}{$\Delta$ Symptoms } & \multicolumn{2}{c|}{$\Delta$ Lung function } \\
Parameter & $\beta+$ SE & $p$-value & $\beta+S E$ & $p$-value \\
\hline EBC component 1 & $-0.04+0.56$ & 0.94 & $-0.04+0.05$ & 0.41 \\
EBC component 2 & $-0.96+0.87$ & 0.27 & $0.02+0.07$ & 0.77 \\
EBC component 3 & $-0.69+0.51$ & 0.18 & $-0.04+0.04$ & 0.40 \\
FeNO & $-0.00+0.06$ & 0.96 & $0.00+0.05$ & 0.86 \\
Atopy & $2.00+1.19$ & $\mathbf{0 . 0 9}$ & $-0.10+0.10$ & 0.35 \\
\hline
\end{tabular}

$\mathrm{EBC}=$ Exhaled Breath Condensate, FeNO = Fractional exhaled Nitric Oxide. $\mathrm{R}^{2}$ model with symptoms = 0.08; $R^{2}$ model with lung function $=0.03$. Table represents initial models, with backward procedure, only atopy remained in the final model for $\Delta$ symptoms $\left(\beta+S E=2.05+1.17, p=0.08, R^{2}=0.06\right)$.

\section{Discussion}

At present, there are no validated biomarkers that can predict a treatment response to ICS in wheezing preschool children. ICS are believed to improve symptoms and lung function due to their anti-inflammatory effect. The incorporation of non-invasive markers of airway inflammation in the therapy strategy may facilitate the choice of proper treatment.

This is the first study in wheezing preschool children that has explored the value of exhaled inflammatory markers in directing therapy. We showed that symptoms mildly improved after an eight week period of ICS treatment in preschool children with wheezing symptoms. In addition, lung function improved, although it can be argued whether the improvement in lung function is clinically relevant. Whether these improvements can be attributed to ICS is somewhat contentious, due to the lack of a control group. However, in contrast to compliant children, non-compliant children (who might be considered as controls because they hardly received ICS) did not show any improvement in both symptoms and lung function ( $N=52$, data not shown). This strengthens the finding that improvement in symptoms and lung function was ICS induced. From all studied inflammatory biomarkers and potential confounders, only IL-10 and atopy were shown to be associated with an ICS response, although not in a multivariable approach.

From a clinical viewpoint the negative predictive trend between IL-10 and improvement in symptoms is meaningful. IL-10 is an anti-inflammatory cytokine and is believed to play an important inflammatory down-regulating role in asthma. ${ }^{19,20}$ Possibly, wheezing preschool children with lower levels of IL-10 might have an enhanced inflammatory status and therefore might react more strongly on ICS. Although one should keep in mind that our population in general demonstrated only mild clinical improvement after ICS. Equally plausible is the positive predictive trend regarding atopy and improvement in symptoms after ICS. In atopic wheezing children, 
mainly eosinophilic airway inflammation is present. Conversely, in viral-induced wheeze, neutrophilic inflammation is believed to play a central role. ${ }^{6}$ ICS mainly target eosinophilic airway inflammation, which might explain why atopic wheezing children responded slightly better to ICS.

Whereas this is the first study in wheezing preschool children, more studies were performed in older children and adults with asthma to explore the value of exhaled inflammatory markers in directing therapy. The majority of studies conducted hitherto with FeNO, support its predictive role for an ICS response either in adults or in children with asthma. ${ }^{15,16,21,22}$ In contrast, there are some studies that could not demonstrate a predictive role of FeNO either in asthmatic adults or in children, ${ }^{23,24}$ in concordance with our findings. In our specific case, however, it is important to emphasise that we collected FeNO off-line during tidal breathing. One of the factors that can influence FeNO is the expiratory flow rate. A single breath on-line manoeuvre is recommended in older children but not feasible in preschool children. ${ }^{25}$ The tidal breathing method has been successfully used previously, but standardisation is less developed than for the single breath on-line method.

Regarding markers in EBC, only Matsunaga and colleagues investigated whether these markers were able to predict an ICS response in adults with asthma. ${ }^{26}$ Although their sample size was small ( $\mathrm{N}=18)$, they found that increased levels of IL-4 and Rantes and reduced levels of IFN-gamma-inducible protein (IP)-10 were significantly correlated with a steroid-induced improvement in lung function. We showed previously the clinical potential of EBC markers in asthmatic children when using these markers in the evaluation of the anti-inflammatory effects of ICS. ${ }^{27}$ EBC collection has huge diagnostic potential, as there is cumulative evidence that the analysis of exhaled inflammatory markers is a non-invasive technique to study airway inflammation in young children. ${ }^{7,12,28,29}$ Nevertheless, their clinical role in the guidance of ICS treatment in young children has not been studied previously. This is partly due to the fact that the collection of EBC is notoriously difficult in preschool children. In the present study, the high success rate of $E B C$ collection is a result of two factors. Firstly, the efficient system enables sufficient EBC collection in a short collection time. Secondly, EBC markers were measured using multiplexed liquid bead arrays (Luminex technology, see methods). This technology is highly sensitive and is able to measure different cytokines accurately in a small sample of EBC. ${ }^{13}$

Given the body of evidence and the sound theoretical underpinning regarding the clinical role of EBC, the lack of their significant predictive value in our study should not be over-interpreted. Methodological issues concerning the composition of our study population may explain the non-significant results. For instance, the majority of our children had minor acute symptoms and therefore had little room for improvement after ICS (symptom scores were bounded upwards). Children with severe symptoms 
and high airway resistance, in contradistinction, would have been expected to improve more significantly. Moreover, we cannot fully discard the possibility that minor improvements in symptoms and lung function were related to habitual ICS use in the minority of our study population (although their ICS administration was stopped four weeks before the study).

To test these hypotheses, we performed two additional sub-analyses: (1) including children with severe symptoms (symptom score of $\leq 24, \mathrm{~N}=36$ ), and (2) including steroid-naïve children $(\mathrm{N}=74)$. In the former, EBC markers remained non-significant (possibly due to loss of power - data not shown). In the latter, we found that next to IL-10, IL-4 also showed a negative trend with improvement in symptoms, and that $\mathrm{pH}$ of EBC was negatively associated with improvement in lung function after ICS ( $\beta=-0.06$, $p=0.07, R^{2}=0.10 ; \beta=-0.20, p=0.01, R^{2}=0.11$, respectively). Therefore, it is warranted to assess the predictive role of exhaled inflammatory markers regarding an ICS response in a large cohort of steroid-naïve children with more severe symptoms.

In order to analyse an ICS response, we included children who received at least $80 \%$ of the subscribed ICS. Because children who were not compliant did not differ in symptoms, airway resistance, atopy and exhaled markers at baseline compared with children who were compliant, we believe that excluding these children did not influence our results.

Next to exhaled biomarkers, inflammatory markers in induced sputum have been successfully used in asthmatics as clinical parameters to predict an ICS response. ${ }^{15,17,22}$ However, sputum is a semi-invasive method that needs co-operation of the child and technical expertise, leading to a lower success rate and more side effects than EBC collection. The collection of inflammatory markers in EBC is non-invasive and can be easily performed in non-sedated preschool children. Although an American/European Taskforce presented recommendations about the methodology of EBC collection, the technique needs further standardisation. Besides, challenging issues, such as the influence of expiratory flow and the dilution factor on EBC collection, need to be addressed in further investigations. ${ }^{30}$

\section{Clinical Relevance}

At present, no clinical test is available to determine which young children with wheeze will benefit from an ICS treatment. We hypothesized that non-invasive markers of airway inflammation could be of added value to proper treatment decisions in wheezing preschool children. However, we did not find convincing evidence that exhaled inflammatory markers can predict an ICS response in preschool wheezers. Hence, the search for a reliable, non-invasive and feasible technique in young children needs to be continued. In asthmatic adults and older children, there is increasing evidence for the clinical value of exhaled inflammatory markers regarding ICS 
treatment. The clinical use of these markers still needs to be established in young children. For this purpose, it is advisable to use large cohort studies of preschool children with (more severe) recurrent wheezing symptoms. 


\section{References}

1. Martinez FD, Wright AL, Taussig LM, Holberg CJ, Halonen M, Morgan WJ. Asthma and wheezing in the first six years of life. The Group Health Medical Associates. N Engl J Med 1995:332:133-8.

2. Henderson J, Granell R, Sterne J. The search for new asthma phenotypes. Arch Dis Child 2009:94:333-6.

3. Castro-Rodriguez JA, Rodrigo GJ. Efficacy of inhaled corticosteroids in infants and preschoolers with recurrent wheezing and asthma: a systematic review with meta-analysis. Pediatrics 2009:123:e519-25.

4. Bisgaard H, Hermansen MN, Loland L, Halkjaer LB, Buchvald F. Intermittent inhaled corticosteroids in infants with episodic wheezing. N Engl J Med 2006:354:1998-2005.

5. Bacharier LB, Phillips BR, Zeiger RS, Szefler SJ, Martinez FD, Lemanske RF, Sorkness CA, Bloomberg GR, Morgan WJ, Paul IM, Guilbert T, Krawiec M, Covar R, Larsen G, Mellon M, Moss MH, Chinchilli VM, Taussig LM, Strunk RC. Episodic use of an inhaled corticosteroid or leukotriene receptor antagonist in preschool children with moderate-to-severe intermittent wheezing. J Allergy Clin Immunol 2008:122: 1127-35.

6. McDougall CM, Helms PJ. Neutrophil airway inflammation in childhood asthma. Thorax 2006:61: 739-41.

7. van de Kant KD, Klaassen EM, Jöbsis Q, Koers K, Rijkers GT, van der Grinten $C P$, van Schayck OC, Passos VL, Dompeling E. Wheezing in preschool children is associated with increased levels of cytokines/chemokines in exhaled breath condensate. J Allergy Clin Immunol 2010:126:669-71.

8. Worldwide variation in prevalence of symptoms of asthma, allergic rhinoconjunctivitis, and atopic eczema: ISAAC. The International Study of Asthma and Allergies in Childhood (ISAAC) Steering Committee. Lancet 1998:351:1225-32.

9. van de Kant KD, Klaassen EM, Jöbsis Q, Nijhuis AJ, van Schayck OC, Dompeling E. Early diagnosis of asthma in young children by using non-invasive biomarkers of airway inflammation and early lung function measurements: study protocol of a case-control study. BMC Public Health 2009:9:210.

10. Powell CV, McNamara P, Solis A, Shaw NJ. A parent completed questionnaire to describe the patterns of wheezing and other respiratory symptoms in infants and preschool children. Arch Dis Child 2002: 87:376-9.

11. Nielsen KG, Bisgaard $\mathrm{H}$. The effect of inhaled budesonide on symptoms, lung function, and cold air and methacholine responsiveness in 2- to 5-year-old asthmatic children. Am J Respir Crit Care Med 2000: 162:1500-6.

12. Rosias PP, Robroeks CM, van de Kant KD, Rijkers GT, Zimmermann LJ, van Schayck CP, Heynens JW, Jöbsis Q, Dompeling E. Feasibility of a new method to collect exhaled breath condensate in pre-school children. Pediatr Allergy Immunol 2010:21:e235-44.

13. de Jager W, te Velthuis H, Prakken BJ, Kuis W, Rijkers GT. Simultaneous detection of 15 human cytokines in a single sample of stimulated peripheral blood mononuclear cells. Clin Diagn Lab Immunol 2003:10:133-9.

14. Lachin JM. Introduction to sample size determination and power analysis for clinical trials. Control Clin Trials 1981:2:93-113.

15. Little SA, Chalmers GW, MacLeod KJ, McSharry C, Thomson NC. Non-invasive markers of airway inflammation as predictors of oral steroid responsiveness in asthma. Thorax 2000:55:232-4.

16. Smith AD, Cowan JO, Brassett KP, Filsell S, McLachlan C, Monti-Sheehan G, Peter Herbison G, Robin Taylor D. Exhaled nitric oxide: a predictor of steroid response. Am J Respir Crit Care Med 2005:172: 453-9.

17. Meijer RJ, Postma DS, Kauffman HF, Arends LR, Koeter GH, Kerstjens HA. Accuracy of eosinophils and eosinophil cationic protein to predict steroid improvement in asthma. Clin Exp Allergy 2002:32: 1096-103.

18. Ducharme FM, Lemire C, Noya FJ, Davis GM, Alos N, Leblond H, Savdie C, Collet JP, Khomenko L, Rivard $\mathrm{G}$, Platt RW. Preemptive use of high-dose fluticasone for virus-induced wheezing in young children. $\mathrm{N}$ Engl J Med 2009:360:339-53.

19. Oh JW, Seroogy CM, Meyer EH, Akbari O, Berry G, Fathman CG, Dekruyff RH, Umetsu DT. CD4 T-helper cells engineered to produce IL-10 prevent allergen-induced airway hyperreactivity and inflammation. J Allergy Clin Immunol 2002:110:460-8. 
20. Hawrylowicz CM, O'Garra A. Potential role of interleukin-10-secreting regulatory T cells in allergy and asthma. Nat Rev Immunol 2005:5:271-83.

21. Szefler SJ, Phillips BR, Martinez FD, Chinchilli VM, Lemanske RF, Strunk RC, Zeiger RS, Larsen G, Spahn JD, Bacharier LB, Bloomberg GR, Guilbert TW, Heldt G, Morgan WJ, Moss MH, Sorkness CA, Taussig LM. Characterization of within-subject responses to fluticasone and montelukast in childhood asthma. J Allergy Clin Immunol 2005:115:233-42.

22. Zacharasiewicz A, Wilson N, Lex C, Erin EM, Li AM, Hansel T, Khan M, Bush A. Clinical use of noninvasive measurements of airway inflammation in steroid reduction in children. Am J Respir Crit Care Med 2005:171:1077-82.

23. Martin RJ, Szefler SJ, King TS, Kraft M, Boushey HA, Chinchilli VM, Craig TJ, Dimango EA, Deykin A, Fahy JV, Israel E, Lazarus SC, Lemanske RF, Jr., Leone FT, Pesola GR, Peters SP, Sorkness CA, Szwejbka LA, Wechsler ME. The Predicting Response to Inhaled Corticosteroid Efficacy (PRICE) trial. J Allergy Clin Immunol 2007:119:73-80.

24. Zielen S, Christmann M, Kloska M, Dogan-Yildiz G, Lieb A, Rosewich M, Schubert R, Rose MA, Schulze J. Predicting short term response to anti-inflammatory therapy in young children with asthma. Curr Med Res Opin 2010:26:483-92.

25. ATS/ERS Recommendations for Standardized Procedures for the Online and Offline Measurement of Exhaled Lower Respiratory Nitric Oxide and Nasal Nitric Oxide, 2005. Am J Respir Crit Care Med 2005: 171:912-30.

26. Matsunaga K, Ichikawa T, Yanagisawa S, Akamatsu K, Koarai A, Hirano T, Sugiura H, Minakata Y, Ichinose M. Clinical Application of Exhaled Breath Condensate Analysis in Asthma: Prediction of FEV(1) Improvement by Steroid Therapy. Respiration 2009:78:393-98.

27. Robroeks CM, van de Kant KD, van Vliet D, Kester AD, Hendriks HJ, Damoiseaux JG, Wodzig WK, Rijkers GT, Dompeling E, Jöbsis Q. Comparison of the anti-inflammatory effects of extra-fine hydrofluoroalkane-beclomethasone vs fluticasone dry powder inhaler on exhaled inflammatory markers in childhood asthma. Ann Allergy Asthma Immunol 2008:100:601-7.

28. Vogelberg C, Wurfel C, Knoetzsch A, Kahlert A, Range U, Leupold W. Exhaled breath condensate pH in infants and children with acute and recurrent wheezy bronchitis. Pediatr Pulmonol 2007:42:1166-72.

29. Pijnenburg MW, de Jongste JC. Exhaled nitric oxide in childhood asthma: a review. Clin Exp Allergy 2008:38:246-59.

30. Horvath I, Hunt J, Barnes PJ, Alving K, Antczak A, Baraldi E, Becher G, van Beurden WJ, Corradi M, Dekhuijzen R, Dweik RA, Dwyer T, Effros R, Erzurum S, Gaston B, Gessner C, Greening A, Ho LP, Hohlfeld J, Jöbsis Q, Laskowski D, Loukides S, Marlin D, Montuschi P, Olin AC, Redington AE, Reinhold P, van Rensen EL, Rubinstein I, Silkoff P, Toren K, Vass G, Vogelberg C, Wirtz H. Exhaled breath condensate: methodological recommendations and unresolved questions. Eur Respir J 2005:26: 523-48. 


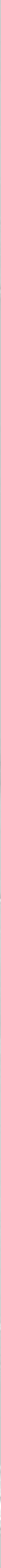


Chapter 8

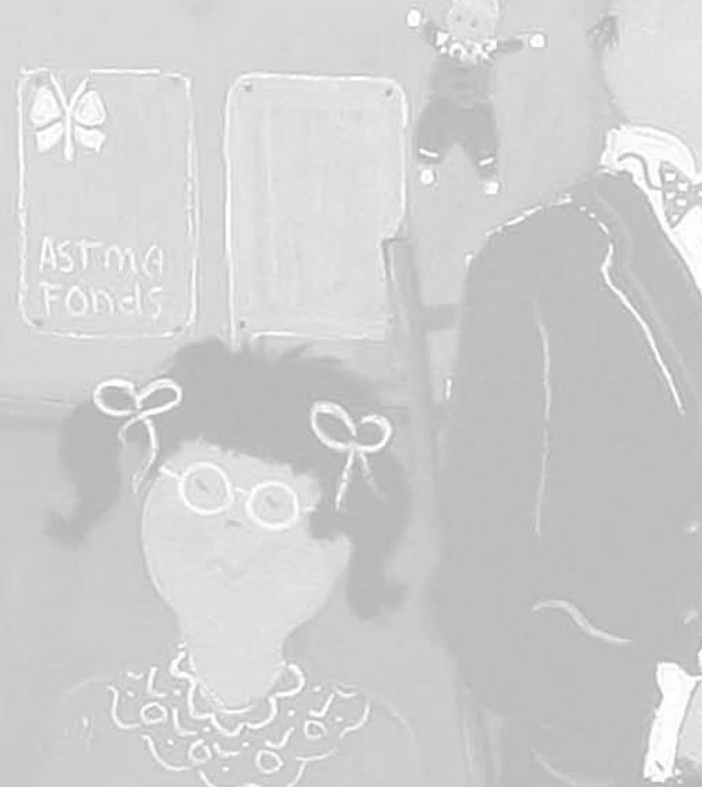

Elevated inflammatory markers at preschool age precede persistent wheezing at school age

van de Kant KDG, Jansen MA, Klaassen EMM, van der Grinten CP, Rijkers GT, Muris JWM, van Schayck CP, Jöbsis $Q$, Dompeling $E$ 


\section{Abstract}

\section{Background}

Wheeze is a common and heterogeneous symptom in preschool children. At preschool age it is hard to predict whether symptoms will be transient or whether they will persist and develop into asthma.

\section{Objectives}

To prospectively study whether inflammatory markers in Exhaled Breath Condensate (EBC) and pre- and post-bronchodilator interrupter resistance (Rint) assessed at preschool age, are associated with wheezing phenotypes at five years of age.

\section{Methods}

Children ( $\mathrm{N}=230)$ were recruited from the Asthma DEtection and Monitoring study (ADEM: clinicaltrial.gov: NCT 00422747). At preschool age (mean (SE): 3.3 (0.1) years), pre- and post-bronchodilator Rint was assessed and EBC was collected using a closedglass condenser. Inflammatory markers ((Interleukin (IL)-2, IL-4, IL-8, IL-10, soluble Intercellular Adhesion Molecule 1) were measured using multiplex immunoassay. Wheezing phenotypes at five years of age were determined based on longitudinal assessment.

\section{Results}

Children were classified as: never $(\mathrm{N}=47)$, early-transient $(\mathrm{N}=89)$ or persistent wheezers $(\mathrm{N}=94)$. Persistent wheezers at age five years had significantly elevated levels of all interleukins at preschool age compared to children who never wheezed (median (IQR) in pg/ml: IL-2; 58.2 (44.8-75.1) vs. 40.0 (26.9-69.0), IL-4; 10.1 (6.3-16.2) vs. 4.4 (2.9-10.9), IL-8; 6.5 (4.1-10.3) vs. 4.2 (3.1-6.3), IL-10; 5.2 (3.7-9.2) vs. 3.1 (2.4-5.4), $\mathrm{p}<0.05$, respectively). EBC markers did not differ between the persistent and transient wheezing phenotypes. There was no marked difference in pre- and post bronchodilator Rint between the wheezing phenotypes.

\section{Conclusions}

Five year old children with persistent wheeze already had elevated exhaled inflammatory markers at preschool age compared to never wheezers, indicating augmented airway inflammation in these children. 


\section{Introduction}

In preschool children, wheeze is a common respiratory symptom, though with a complex and heterogeneous character. Whereas the majority of wheezing preschool children will experience transient symptoms, around $30 \%$ of the children have persistent wheeze that develops into asthma. ${ }^{1}$ Currently it is not possible to easily distinguish children with transient symptoms from persistent wheezers. This leaves physicians with a challenging task concerning the diagnosis and management of preschool wheeze. Different wheezing phenotypes have been defined that classify children on basis of time course, frequency, severity, or triggers of their symptoms. ${ }^{2,3} \mathrm{~A}$ widely used classification system is developed by researchers of the Tucson birth cohort study, dividing children into early transient, late-onset, persistent and non wheezing phenotypes. ${ }^{1}$ Although it is generally assumed that these phenotypes have a different underlying pathophysiology, research in this direction is hampered due to problems with measurements of airway inflammation and lung function in young children. Most lung function measurements are hard to assess in young children since active cooperation is necessary. Further, the currently available techniques to measure airway inflammation such as bronchial biopsies and bronchoalveolar lavages are invasive and therefore not appropriate for routine use. To avoid these invasive techniques, there is increasing interest in the non-invasive assessment of inflammatory markers in exhaled breath. Besides measurements of exhaled Nitric Oxide, ${ }^{4}$ the analysis of solutes in Exhaled Breath Condensate (EBC) gained popularity. We previously showed that the analysis of markers in EBC is a non-invasive and feasible technique to assess airway inflammation in wheezing preschool children.,

Different forms of airway inflammation are believed to play a significant role in preschool wheeze. There is increasing evidence that in children with transient, viralinduced wheeze, neutrophil mediated inflammation plays a central role. ${ }^{7-9}$ In asthmatic children, a T helper (Th) 2 mediated immune response is believed to be of importance. ${ }^{10}$ Therefore, it can be hypothesized that EBC levels of interleukin (IL)-8, the major neutrophil chemoattractant, are elevated in children with transient wheeze, while EBC levels of IL-4, a prototype Th2 cytokine, are elevated in children with persistent symptoms, prone to develop asthma. In case children with distinct wheezing phenotypes differ in these and/or other exhaled inflammatory markers at preschool age, this technique might be useful to early identify children at risk to develop asthma. However, this has not been studied yet.

Besides measurements of airway inflammation, lung function measurements can give insight in the underlying pathophysiology of preschool wheeze. A potential useful lung function technique that can easily be applied in young children is the measurement of airway resistance using the interrupter resistance technique (Rint). ${ }^{11-13}$ Previous studies demonstrated increased airway resistance (assessed with Rint and forced 
oscillation technique) in children with persistent wheezing symptoms compared to children with transient wheeze. ${ }^{12,14}$ In these studies, wheezing patterns and airway resistance measurements were both assessed at school age. The potential role of preschool Rint to predict the future course of wheezing symptoms is hardly studied.

The aim of this study was to define prospectively whether inflammatory markers in EBC (including IL-4 and IL-8) and Rint values assessed at preschool age, are associated with wheezing phenotypes at the age of five years.

\section{Methods}

\section{Study design}

Children were included from the ADEM study (Asthma DEtection and Monitoring study). This case control study started in 2006 at the Maastricht University Medical Centre, the Netherlands. In this study, children who experienced at least two wheezing episodes during life ( $N=202$, assessed by the International Study of Asthma and Allergies in Childhood (ISAAC) questionnaire) ${ }^{15}$, and control subjects $(\mathrm{N}=50$ ) who never wheezed were included at two and three years of age and were prospectively studied until six years of age. The current analysis is based on data from inclusion until five years of age. The primary objective of the ADEM study is to develop a non-invasive instrument for an early asthma diagnosis by using exhaled inflammatory biomarkers and early lung function measurements. The study protocol was described in detail before. ${ }^{16}$ Ethical approval was obtained from the Dutch National Medical Ethical Committee (CCMO: NL17407.000.07/2007-001817-40, the Hague, the Netherlands). All parents gave written informed consent. This study is registered by clinicaltrial.gov (NCT 00422747).

\section{Measurements}

At inclusion (age two and three years), measurements of lung function and exhaled inflammatory markers were performed. If applicable, inhaled corticosteroids (ICS) administration was stopped four weeks before the start of the measurements. In case of symptoms of an airway infection, a measurement was postponed for four weeks. Physical exercise and solid foods were not allowed one hour before the measurements.

\section{Atopy}

Venous blood was collected and serum was tested for specific IgE against a mixture of inhalant and food allergens (Phadiatop infant ${ }^{\circ}$, Phadia, Uppsala, Sweden). A child was 
considered atopic when the values of the Phadiatop Infant test equals or exceeded $0.35 \mathrm{kU} / \mathrm{l}$.

\section{Lung function measurements}

To assess lung function we measured interrupter resistance, by using the MicroRint device (Micro Medical Ltd, Rochester, United Kingdom). Children were sitting in an upright position and were asked to breathe tidally through a facemask. Interruptions were made on the expiratory peak flow and the median value of at least five successful airflow interruptions was used for analysis. To assess the reversibility to a short acting $B_{2}$ agonist, Rint measurements were repeated fifteen minutes after inhalation of 300 microgram of salbutamol inhaled via an Aerochamber (Airomir ${ }^{\circledR}$, Teva Pharma NL, Haarlem, the Netherlands). Reversibility was expressed as absolute difference in interrupter resistance before and after the application of salbutamol.

\section{Exhaled Breath Condensate}

A closed glass condenser system with a breath recirculation, developed at our institute, was used to collect EBC. ${ }^{16}$ This efficient condenser system ensures a sufficient volume of EBC collected in a short collection-time (ten minutes). The sampling- and collection procedures were described previously. ${ }^{16}$ Inflammatory markers in EBC (IL-2, IL-4, IL-8, IL-10, soluble Intercellular Adhesion Molecule 1 (sICAM)) were assayed with the multiplex immunoassay (Luminex Corporation, Austin, TX, USA). ${ }^{17}$ Samples with levels of EBC markers below the detection limit received a randomly generated value taken from the uniform distribution between zero and the detection limit. ${ }^{6}$

\section{Wheezing phenotypes}

Data on symptoms of wheeze were collected yearly from inclusion until five years of age by using the ISAAC questionnaire. ${ }^{15}$ Data from birth until inclusion were reclaimed retrospectively. Based on these longitudinal data, children were divided into three wheezing phenotypes: 'never wheeze' (children who never wheezed during the first five years of life); 'early transient wheeze' (at least two wheezing episodes during the first three years of life, no wheeze in the fourth and fifth year) and 'persistent wheeze' (multiple wheezing episodes during the first five years).

\section{Statistical analysis}

Data were analysed with SPSS 16.1 (SPSS inc., Chicago IL, USA). Differences in baseline characteristics, EBC markers and Rint values among wheezing phenotypes were evaluated using the Kruskall Wallis (overall test), Mann-Whitney or Chi-square analysis. Adjustment for multiple testing was conducted via the false discovery rate (FDR). A significance level of $5 \%$ was used. 


\section{Power analysis}

In an earlier study in children with asthma and healthy controls aged six to sixteen years, we found differences in concentrations of IL-2, IL-4, and IL-8 ranging from 2.9 to $13.2 \mathrm{pg} / \mathrm{ml}$ (see reference for accompanied standard deviations)..$^{18}$ If we assume comparable differences in the present population, we need at least 43 children in each category of wheeze to detect a difference in mean concentration of $2.9 \mathrm{pg} / \mathrm{ml}$, with a power of $90 \%$ and a two-sided alpha of 0.05 .

\section{Results}

\section{Baseline characteristics and wheezing phenotypes}

Of the 252 children included in the ADEM study, longitudinal data of respiratory symptoms were available in 230 children (91\%). Reasons for lack of longitudinal data were: lost-to follow up due to personal constraints $(\mathrm{N}=19)$, and not yet reached the age of five years at the time of analysis $(\mathrm{N}=3)$. Children who were excluded due to lack of data did not differ in Rint, EBC markers and baseline characteristics compared to included children, except for age. The included children were divided into those who never wheezed $(N=47,20 \%)$, those with early transient wheeze $(N=89,39 \%)$ and those with persistent wheeze $(\mathrm{N}=94,41 \%)$. The sampling procedure of Rint and $\mathrm{EBC}$ was successfully employed in $97 \%(\mathrm{~N}=223)$ and $98 \%(\mathrm{~N}=226)$ of the children, respectively. Baseline characteristics are given in the table. More than half of the children with persistent wheeze used short acting $B_{2}$ agonist as rescue medication, whereas ICS was used in $27 \%$ of the children, respectively. As can be expected, these percentages were significantly higher compared to the never and transient wheeze group. Seven of the persistent wheezers were not able to stop ICS prior to the measurements. A sensitivity analysis excluding these children did not reveal different results. Therefore these children were kept in the analysis. Moreover, two children of the never wheeze group used inhalation medication for recurrent cough (one child used ICS and a short acting $B_{2}$ agonist, the other one only used a short acting $B_{2}$ agonist as rescue medication). As these children might be misclassified, we performed an additional analysis excluding these children. Since no differences in results were found, these children were kept in the analysis. Eczema was more present in persistent wheezers compared to never wheezers. There were no differences in age, gender and atopy between wheezing phenotypes.

\section{Exhaled biomarkers}

Interleukins and soluble adhesion molecules could be detected in respectively $96 \%$ and $97 \%$ of the samples. Apart from sICAM, all interleukins (IL-2, IL-4, IL-8 and IL-10) were significantly different in the wheezing phenotypes (corrected for multiple testing). 
Figure 8.1 illustrates that the overall difference in IL-2, IL-4, IL-8 and IL-10 was mainly due to higher levels in the persistent wheeze group compared to the never wheeze group (FDR corrected p-values: $0.01,<0.01,0.02,0.01$, respectively). Children with transient wheeze had insignificantly higher levels of all interleukins (IL-2, IL-4, IL-8 and IL-10) compared to children who never wheezed (FDR corrected p-values: 0.06, 0.07, $0.08,0.06$, respectively, Figures 8.1). No differences in markers were found between the children with persistent wheeze compared to children with transient symptoms (FDR corrected $p$-values $>0.05$, Figures 8.1 ). In a sub-analysis, children with atopy and/or eczema were compared to children without atopy and/or eczema. There were no differences in biomarkers between atopic children and children without atopy, neither in the total group nor when stratified for wheezing phenotypes. Comparable results were found for eczema.

Table 8.1 Baseline characteristics of wheezing phenotypes.

$\begin{array}{lccc} & \text { Never Wheeze } & \begin{array}{c}\text { Early Transient } \\ \text { Wheeze }\end{array} & \begin{array}{c}\text { Persistent Wheeze } \\ \text { Study population, in N }\end{array} \\ \text { Median age (IQR),in years } & 47 & 89 & 94 \\ \text { Gender: male / female, in N } & 3.5(2.8-3.8) & 3.4(2.9-3.8) & 3.1(2.8-3.7) \\ \text { Atopy, in \% } & 25 / 22 & 49 / 40 & 53 / 41 \\ \text { Eczema, in \% } & 29 & 23 & 27 \\ \text { ICS use, in \% } & 19 & 33 & 42^{*} \\ \text { Short acting B } \text { B }_{2} \text { agonist use, \% } & 2 & 10 & 27^{* *}\end{array}$

ICS = Inhaled Corticosteroids; IQR = Inter Quartile Range. ${ }^{\triangle}$ Age at time of inclusion (assessment of inflammatory markers and Rint). ${ }^{+}$Atopy is defined as a positive Phadiatop Infant test. * FDR corrected $p$ value $<0.05$ relative to never wheezers, ${ }^{* *}$ FDR corrected $p$-value $<0.05$ relative to never wheezers and transient wheezers.

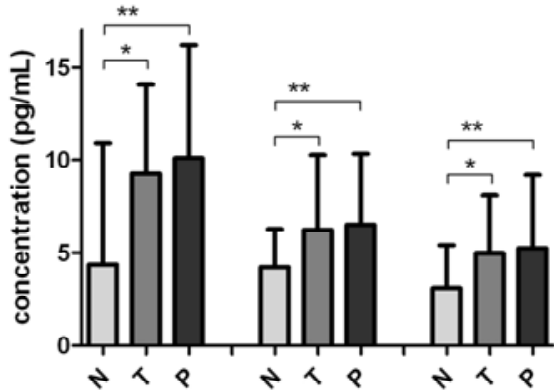
IL- 4
IL-8
IL-10

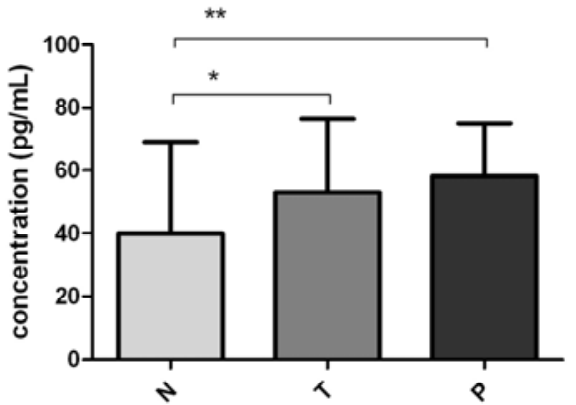

IL-2

Figure 8.1 Markers in EBC in never wheeze ( $N$, light grey), transient wheeze ( $\mathrm{T}$, grey) and persistent wheeze groups ( $\mathrm{P}$, dark grey). Pair-wise comparisons; ${ }^{* *} \mathrm{p}$-value $<0.05,{ }^{*} \mathrm{p}$-value $<0.10$ (FDR corrected). Markers are grouped based on their range in concentration. 


\section{Interrupter resistance}

The overall test showed a borderline significance of differences in baseline Rint values between wheezing phenotypes (FDR corrected p-value: 0.05 ). This overall mild difference was due to higher levels of Rint in children with persistent wheeze compared to never wheezers and children with transient symptoms (FDR corrected p-values: $0.06,0.07$, Figure 8.2 ). There were no differences in reversibility between the wheezing phenotypes. A sub-analysis revealed no differences in both lung function parameters between children with atopy compared to children without atopy, which holds true for eczema as well.

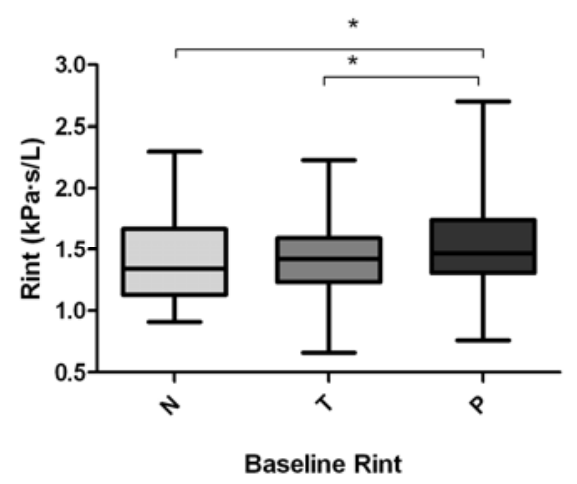

Figure 8.2 Baseline Rint values in never wheeze ( $N$, light grey), transient wheeze ( $\mathrm{T}$, grey) and persistent wheeze groups ( $\mathrm{P}$, dark grey). Pair-wise comparison; * $\mathrm{p}$-value $<0.10$ (FDR corrected).

\section{Discussion}

We demonstrated that inflammatory markers in EBC at preschool age were related to wheezing phenotypes at five years of age: children with a persistent wheezing phenotype already had elevated levels of most cytokines/chemokines in EBC at preschool age compared to the never wheezing phenotype. However, based on EBC measurements at two and three years, it was difficult to differentiate between the transient and persistent wheezing phenotype. No marked difference in Rint was found between the wheezing phenotypes.

To our knowledge, this is the first study that prospectively explored whether noninvasive inflammatory markers in EBC are related to wheezing patterns in young children. We found that children with different wheezing patterns have elevated levels of multiple inflammatory markers at preschool age compared to children who never wheezed, with the highest levels in children with persistent wheeze. This is in accordance with a previous cross-sectional analysis of our data, in which we found elevated levels of multiple inflammatory markers in wheezing preschool children 
compared to healthy controls. ${ }^{6}$ The elevated inflammatory markers may point to a broad inflammatory response in children with persistent wheeze, with involvement of Th1/2 cytokines and the chemokine IL- 8 . This multiple inflammatory response is in agreement with the hypothesis that in wheezing preschool children multiple immune mechanisms are involved that lead to a sequence of inflammatory responses. ${ }^{19}$ Although levels of markers were elevated in wheezing children compared to children who never wheezed, these markers were not able to differentiate children with transient symptoms from children with persistent symptoms prone to develop asthma. As transient wheezers are believed to have viral-induced symptoms in which neutrophilic airway inflammation plays a central role, ${ }^{7-9}$ we would have expected elevated levels of IL-8, a neutrophil chemoattractant, in the group of children with transient wheeze. However, this was not the case.

In our study baseline Rint values assessed at preschool age, were slightly elevated in children with persistent wheeze compared to children who never wheezed and children with transient symptoms. However, there was a considerable overlap in Rint distributions between the groups. In previous performed studies a more pronounced difference in airway resistance (assessed with Rint and forced oscillation technique) between wheezing phenotypes was found, with elevated levels in children with persistent wheeze compared to children with transient symptoms. ${ }^{12,14}$ This might indicate that children with persistent symptoms experience airway obstruction, a characteristic of asthma, while children with transient, virus-induced symptoms do not have a diminished airway calibre at school age. In contrast to our study these studies assessed Rint values and wheezing phenotypes at the same age. They did not prospectively study whether Rint assessed at preschool age was related to the future course of wheezing symptoms. Recent data from the 'Prevention and Incidence of Asthma and Mite Allergy (PIAMA)' birth cohort study demonstrated that Rint assessed in four-year-old children was associated with wheezing at age six. However, at the age of eight years this association vanished. ${ }^{20}$ Taken together, we might conclude that although airway resistance is increased in school children with current, persistent symptoms compared to children who experienced symptoms in the past, the power of preschool Rint to predict whether wheezing symptoms will persist or fade out is limited.

EBC markers and Rint levels did not differ between a transient and a persistent wheezing phenotype. The lack of this discriminative ability can be due to several reasons. At first, it might be explained by methodological issues. One may argue that selection bias has occurred due to incomplete data as a result of loss-to-follow-up or unsuccessful measurements. However, this is very unlikely since children who did not complete the study did not differ in EBC markers at preschool age compared to children who completed the study. Besides, the success rate of EBC collection was high and general reasons for failure (fear and unwillingness of the child) were unrelated to 
$E B C$ levels. A second methodological issue might be the fact that assessing markers in EBC can still be optimized. Although an American/European Taskforce has presented recommendations about the methodology of EBC collection, ${ }^{21}$ there is still considerable room for improvement in collection methods and assays. Our research group has substantial experience in measuring exhaled inflammatory markers in children and progress has been made. 5,6,18,22 This has resulted in the development of an efficient glass-condenser system that enables the collection of EBC in a short collection time in a reproducible way. ${ }^{5}$ Moreover, we can accurately measure different cytokines in a small sample of EBC $(60 \mu \mathrm{l})$ by using highly sensitive multiplexed liquid bead arrays. ${ }^{17}$ This makes our technique highly suitable for young children. However, the validity of measuring EBC markers may be further increased by controlling for factors such as expiratory flow rate or dilution factor. Although we did not consider these factors four years ago when the first EBC samples were collected for the ADEM study, our research group is currently studying the influence of these factors. A third methodological issue might be possible misclassification of wheezing phenotypes, since phenotypes were based on parental-reported symptoms. However, recall bias was minimized by annual assessment of symptoms, and the ISAAC questionnaire that was used is validated and commonly used for similar purposes. ${ }^{15}$

Besides methodological issues, there is an alternative and perhaps more plausible explanation for the lack of differences in exhaled inflammatory markers in distinct wheezing phenotypes. Preschool wheeze is a heterogeneous condition and there are multiple ways to classify wheezing children, as recently reviewed by Spycher et al. ${ }^{3}$ In this review, they questioned whether wheezing phenotypes based on a single characteristic, such as retrospective symptom history, represent distinct underlying disease entities. Our data might support this issue. We demonstrated that children with wheezing patterns classified on basis of course of symptoms, do not markedly differ in underlying airway inflammation assessed by exhaled inflammatory markers at preschool age. Instead of classification on symptom history, it would be interesting to study whether wheezing preschool children could be divided into 'inflammatory' phenotypes, and whether these phenotypes differ in response to treatment and prognosis in later childhood. If that is the case, classifying children based on their inflammatory 'breath-print', might better separate the underlying diseases that causes wheezing symptoms in children. This can improve diagnosis and treatment of preschool wheeze. Moreover, these phenotypes can already be assessed at preschool age whilst classifying children on basis of wheezing patterns can only be determined retrospectively.

In conclusion, we demonstrated that children with persistent wheeze at five years of age already have elevated levels of exhaled inflammatory markers compared to children without wheeze at preschool age. This finding points to an increased inflammatory response in these preschool wheezers. Classifying children based on 
inflammatory- and lung function characteristics instead of retrospective symptom history, might provide a better biological basis to unravel the heterogeneous character of wheeze. We demonstrated that there are potential, non-invasive and feasible techniques available that can provide information on underlying airway inflammation and airway obstruction in preschool children. Whether the use of these techniques to classify wheezing preschool children is helpful to improve diagnosis and treatment of preschool wheeze needs to be proven in future research. 


\section{References}

1. Martinez FD, Wright AL, Taussig LM, Holberg CJ, Halonen M, Morgan WJ. Asthma and wheezing in the first six years of life. The Group Health Medical Associates. N Engl J Med 1995;332:133-138.

2. Henderson J, Granell R, Sterne J. The search for new asthma phenotypes. Arch Dis Child 2009;94: 333-6.

3. Spycher BD, Silverman M, Kuehni CE. Phenotypes of childhood asthma: are they real? Clin Exp Allergy 2010;40:1130-41.

4. Pijnenburg MW, de Jongste JC. Exhaled nitric oxide in childhood asthma: a review. Clin Exp Allergy 2008;38:246-59.

5. Rosias PP, Robroeks CM, van de Kant KD, Rijkers GT, Zimmermann LJ, van Schayck CP, Heynens JW, Jöbsis Q, Dompeling E. Feasibility of a new method to collect exhaled breath condensate in pre-school children. Pediatr Allergy Immunol 2010;21:e235-44.

6. van de Kant KD, Klaassen EM, Jöbsis Q, Koers K, Rijkers GT, van der Grinten CP, van Schayck OC, Passos $\mathrm{VL}$, Dompeling E. Wheezing in preschool children is associated with increased levels of cytokines/chemokines in exhaled breath condensate. J Allergy Clin Immunol 2010;126:669-71.

7. Oommen A, Patel R, Browning M, Grigg J. Systemic neutrophil activation in acute preschool viral wheeze. Arch Dis Child 2003;88:529-31.

8. McDougall CM, Helms PJ. Neutrophil airway inflammation in childhood asthma. Thorax 2006;61: 739-41.

9. Marguet C, Jouen-Boedes F, Dean TP, Warner JO. Bronchoalveolar cell profiles in children with asthma, infantile wheeze, chronic cough, or cystic fibrosis. Am J Respir Crit Care Med 1999;159:1533-40.

10. Shahid SK, Kharitonov SA, Wilson NM, Bush A, Barnes PJ. Increased interleukin-4 and decreased interferon-gamma in exhaled breath condensate of children with asthma. Am J Respir Crit Care Med 2002;165:1290-3.

11. Merkus PJ, Stocks J, Beydon N, Lombardi E, Jones M, McKenzie SA, Kivastik J, Arets BG, Stanojevic S. Reference ranges for interrupter resistance technique: the asthma UK initiative. Eur Respir J 2010;36:157-63.

12. Brussee JE, Smit HA, Koopman LP, Wijga AH, Kerkhof M, Corver K, Vos AP, Gerritsen J, Grobbee DE, Brunekreef B, Merkus PJ, de Jongste JC. Interrupter resistance and wheezing phenotypes at 4 years of age. Am J Respir Crit Care Med 2004;169:209-13.

13. Kooi EM, Schokker S, van der Molen T, Duiverman EJ. Airway resistance measurements in pre-school children with asthmatic symptoms: the interrupter technique. Respir Med 2006;100:955-64.

14. Oostveen E, Dom S, Desager K, Hagendorens M, de Backer W, Weyler J. Lung function and bronchodilator response in 4-year-old children with different wheezing phenotypes. Eur Respir J 2010;35:865-72.

15. Worldwide variation in prevalence of symptoms of asthma, allergic rhinoconjunctivitis, and atopic eczema: ISAAC. The International Study of Asthma and Allergies in Childhood (ISAAC) Steering Committee. Lancet 1998;351:1225-32.

16. van de Kant KD, Klaassen EM, Jöbsis Q, Nijhuis AJ, van Schayck OC, Dompeling E. Early diagnosis of asthma in young children by using non-invasive biomarkers of airway inflammation and early lung function measurements: study protocol of a case-control study. BMC Public Health 2009;9:210.

17. de Jager W, te Velthuis H, Prakken BJ, Kuis W, Rijkers GT. Simultaneous detection of 15 human cytokines in a single sample of stimulated peripheral blood mononuclear cells. Clin Diagn Lab Immunol 2003;10:133-9.

18. Robroeks CM, Rijkers GT, Jöbsis Q, Hendriks HJ, Damoiseaux JG, Zimmermann LJ, van Schayck OP, Dompeling E. Increased cytokines, chemokines and soluble adhesion molecules in exhaled breath condensate of asthmatic children. Clin Exp Allergy 2010;40:77-84.

19. Martinez FD, Godfrey S. Immunology of wheezing disorders in infants and preschool children. New York: Martin Dunitz; 2003.

20. Caudri D, Wijga AH, Hoekstra MO, Kerkhof M, Koppelman GH, Brunekreef B, Smit HA, de Jongste JC. Prediction of asthma in symptomatic preschool children using exhaled nitric oxide, Rint and specific IgE. Thorax 2010;65:801-7. 
21. Horvath I, Hunt J, Barnes PJ, Alving K, Antczak A, Baraldi E, Becher G, van Beurden WJ, Corradi M, Dekhuijzen R, Dweik RA, Dwyer T, Effros R, Erzurum S, Gaston B, Gessner C, Greening A, Ho LP, Hohlfeld J, Jöbsis Q, Laskowski D, Loukides S, Marlin D, Montuschi P, Olin AC, Redington AE, Reinhold P, van Rensen EL, Rubinstein I, Silkoff P, Toren K, Vass G, Vogelberg C, Wirtz H. Exhaled breath condensate: methodological recommendations and unresolved questions. Eur Respir J 2005;26: 523-48.

22. Rosias PP, Robroeks CM, Kester A, den Hartog GJ, Wodzig WK, Rijkers GT, Zimmermann LJ, van Schayck $\mathrm{CP}$, Jöbsis $\mathrm{Q}$, Dompeling $\mathrm{E}$. Biomarker reproducibility in exhaled breath condensate collected with different condensers. Eur Respir J 2008;31:934-42. 


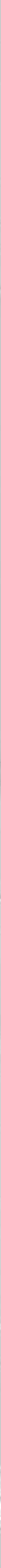




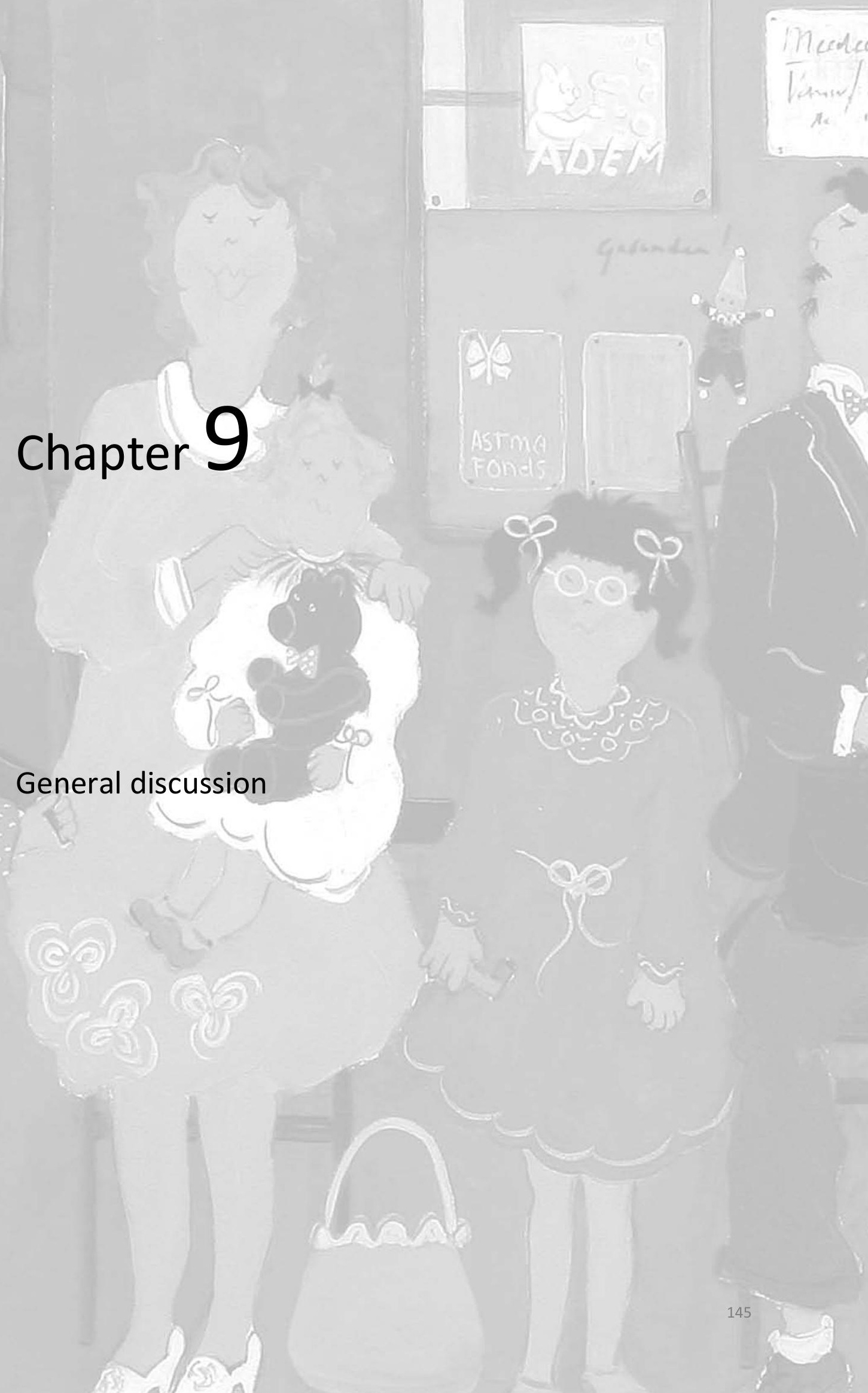




\section{Introduction: problems in preschool wheeze}

Despite the high prevalence of wheezing symptoms in preschool children, little is known about the underlying pathophysiology. As a consequence, physicians are facing clinical challenges in the diagnosis and management of preschool wheeze; Does this child suffer from asthma and will inhaled corticosteroids (ICS) be beneficial? Or does this child have transient, viral-induced symptoms and is other medication more appropriate? The lack of proper clinical tools to objectively assess underlying mechanisms is the source of these clinical difficulties. Such a tool can only be successfully applied in clinical practice in case it is non-invasive, feasible, reliable, valid, cost-effective and quickly provides results. Non-invasive 'inflammometry' by using markers in exhaled breath is increasingly advocated as potential useful diagnostic and monitoring tool in adults and school children with pulmonary diseases. Whether this holds true for wheezing preschool children is hardly studied. The studies in this thesis were performed to assess whether exhaled inflammatory markers and early lung function measurements (Rint) can be of additive value in the assessment of inflammatory pathways, wheezing phenotypes, and response to treatment in preschool children with recurrent wheeze. In this chapter our main findings are highlighted and put into perspectives.

\section{Inflammatory mechanisms of preschool wheeze}

It is known that airway inflammation is a central feature in asthma. As it is recognized that only the minority of wheezing preschool children develops asthma, it is the question whether and, if so, to which extent airway inflammation is already a characteristic in preschool wheeze. Limited data of biopsy and bronchoalveolar lavage (BAL) studies demonstrated the presence of airway inflammation in preschool children with wheezing symptoms. ${ }^{1-4}$ These studies indicated that viral-induced wheezing symptoms are predominately associated with neutrophilic inflammation as opposed to eosinophilic inflammation in atopic preschool wheezers prone to develop asthma. ${ }^{1-4}$ The invasive nature of the current available techniques to measure inflammation, does not promote an increase in knowledge about the underlying pathophysiology of preschool wheeze. Non-invasive techniques such as the analysis of inflammatory markers in exhaled breath are potentially the way forward to establish this increase in knowledge.

\section{What can exhaled biomarkers and lung function measurements add to the pathophysiological knowledge?}

Of all measured inflammatory markers in exhaled breath, Fractional exhaled Nitric Oxide (FeNO) is the most studied compound. In order to assess FeNO in preschool 
children, we performed an off-line, tidal-breathing procedure as described by an American/European Taskforce. ${ }^{5}$ This procedure enabled us to determine FeNO in almost all children (99\%). We did not find different FeNO levels between children with recurrent wheezing symptoms compared to children without symptoms (Chapter 3 ). These findings are in contrast to those reported by Gabriele et al., who did find elevated levels of FeNO in wheezing children compared to controls. ${ }^{6}$ As FeNO, mainly reflects eosinophilic airway inflammation, potentially the emphasis in our study population is more on other inflammatory pathways, such as neutrophilic inflammation.

There are limited data about inflammatory markers in Exhaled Breath Condensate (EBC) to assess inflammatory pathways in preschool children with respiratory symptoms. A possible explanation for this is that, despite its non-invasive character, collection of EBC is still notoriously difficult in preschool children. Moeller and Walsh et al. demonstrated that both nasal and oral EBC collection was possible in sedated infants. ${ }^{7,8}$ Vogelberg and colleagues, were able to collect EBC in young, non-sedated children with wheezy bronchitis. They modified the ventilation unit of a commercially available EBC-sampler to reduce the dead space ventilation. ${ }^{9}$ In a previous study, we successfully collected EBC in 70 non-sedated preschool children using the same closedglass condenser with breath recirculation as described in the studies presented in this thesis. ${ }^{10-13}$ The high success rates of EBC collection in both the previous study $(83 \%)$ and present study (97\%) are the result of three main factors. Firstly, we developed a closed-glass condenser that enables recirculation of exhaled breath that does not directly condense. Consequently, the loss of non-condensed air is limited when compared to other (commercially available) condensers with an open end. This recirculation process does not influence concentration of EBC markers, but does significantly increase the volume of collected EBC. ${ }^{13}$ Secondly, we used a highly sensitive analysing technique, so called multiplexed liquid bead array (Luminex technology ), to analyse inflammatory markers in EBC. This technique requires only a small sample of EBC $(60 \mu \mathrm{l})$. Together with the efficiency of our system, sufficient EBC can be collected in limited collection-time (10 minutes). Finally, we created a child friendly setting in order to make children feel at ease during the measurements.

We found elevated levels of various inflammatory markers (Interleukin (IL)-1 $\alpha$, IL-2, IL4, IL-5, IL-8, IL-10, IL-13, soluble Intercellular Adhesion Molecule (sICAM)) in EBC of children with recurrent wheeze compared to children without wheezing symptoms (Chapter 3). ${ }^{10}$ The diversity of elevated EBC markers indicates an assorted inflammatory response which is in line with the hypothesis that in wheezing preschool children multiple immune mechanisms are involved, that will lead to a chain of inflammatory events. ${ }^{14}$ In concordance to FeNO, we did not find elevated levels of Rantes (CCL5) and Eotaxin (CCL11), two chemokines involved in eosinophilic inflammatory pathways. As we did find elevated levels of IL-8, a neutrophil chemoattractant, our findings might indicate a predominately neutrophilic airway 
inflammation rather than an eosinophilic airway inflammation in our group of wheezers. However, it should be noted that we did find elevated levels of IL-5, an activator of eosinophils. Therefore an eosinophilic component can not be excluded. Our findings demonstrate that EBC markers may assist in an early diagnosis of airway inflammation in young children. Bloemen and colleagues applied a proteomic approach on EBC samples of three-year old children. ${ }^{15}$ They demonstrated that a potential biomarker profile of eight peptides differentiated preschool children at risk for asthma from children without that risk. ${ }^{15}$ In medical science, the use of highthroughput techniques, such as proteomics, become of increasing importance to unravel pathways of multiple diseases. ${ }^{16}$ The non-invasive application of these 'omics' techniques by using exhaled breath as a medium to assess biomarker profiles, can enhance our knowledge about the complex mechanisms of preschool wheeze even further.

The focus on profiles of exhaled breath rather than on individual compounds, evolved also in the field of exhaled Volatile Organic Compounds (VOCs). With respect to VOCs, we were the first that demonstrated the potential value of this technique in preschool wheezing children (Chapter 5). In our study, VOCs collection was highly feasible with a success rate of $98 \%$, due to a child friendly environment. We achieved a high feasibility regarding the analysis of VOCs because of two main factors. Firstly, we used gas chromatography - time of flight - mass spectrometry for the analysis of VOCs. This technique is highly sensitive and able to detect a wide range of VOCs. Secondly, we used an innovative analysis procedure. In most studies, compounds are first identified and thereafter compared between subjects. By using this approach, improper identification of compounds can hamper the quality of the databases. In contrast, we matched compounds by using the raw mass spectra and retention times, and identified the compounds thereafter. This approach is less vulnerable for mistakes and thereby creates a more reliable database. ${ }^{17}$ In our proof of principle study we demonstrated that a profile of eleven exhaled VOCs was fairly capable to distinct children with recurrent wheeze from children without wheezing symptoms. Although this was the first study that was performed in preschool children, we previously demonstrated the discriminative value of VOCs patterns in children with asthma and CF. ${ }^{18,19}$ Hydrocarbons were important discriminative compounds in these three studies. However, it is difficult to trace back the pathological origin of these compounds, as VOCs are breakdown products of various pathways. Our findings, together with the body of evidence of discriminative patterns of VOCs in adults with various pulmonary diseases (Chapter 4), are a stimulus to further explore potential applications of VOCs in the field of preschool wheezing.

We achieved a high success rate of Rint measurements in preschool children (96\%) as well (Chapter 3). ${ }^{10}$ Rint measurements provide information about airway resistance and might therefore be a proxy measure of airway obstruction. We did not find higher 
baseline and post-bronchodilator Rint values in preschool children with recurrent wheezing symptoms compared to children without symptoms. However, we did demonstrate slightly elevated levels of baseline Rint values in five year old children with persistent wheeze, though with a considerable overlap in values, compared to non-wheezing school children (see section 'Phenotyping of preschool wheeze'). In addition, when we compared non-wheezing children with preschool children with current wheeze, defined as wheezing symptoms during at least a few days in the last month, we found elevated Rint values in the latter group (data not published). Altogether, these findings may imply that baseline airway resistance in preschool children with a history of wheezing symptoms, but without an acute episode of wheeze, is normal compared to non-wheezing children. However, this assumption is not in accordance with findings of McKenzie et al., who demonstrated elevated baseline Rint values in two to five year old children with previous wheezing symptoms (but no symptoms in the month before testing) compared to children without a history of respiratory symptoms. ${ }^{20}$ These inconclusive findings warrant more research.

\section{Aetiology of preschool wheeze: bacteria and regulatory T cells}

In this thesis we shortly touched the aetiology of preschool wheeze by studying bacteria and regulatory $T\left(T_{\text {reg }}\right)$ cells (Chapter 6$)$. Although viruses are believed to be the cause of most wheezing exacerbations, bacteria may also play an important role in the induction of symptoms in preschool children. However, their role is not extensively studied yet. In concordance to other case-control studies, we did not find differences in prevalence of Streptococcus pneumoniae, Haemophilus (para)influenzae, Staphylococcus aureus, Chlamydia pneumoniae and Mycoplasma pneumoniae in preschool children with recurrent wheezing symptoms compared to children without symptoms. ${ }^{21-23}$ In contrast, other studies did support a role for these bacteria in relation to wheezing episodes, as recently reviewed. ${ }^{24,25}$ For example, Bisgaard et al. reported that bacterial colonisation with S. pneumoniae and $H$. influenzae was more present in young children experiencing an acute wheezing episode than in periods without wheeze. ${ }^{26}$ The difference in findings might be due to variation in acuteness of symptoms, as we measured presence of bacteria in recurrent wheezing children and not primarily during a wheezing exacerbation. Taken together, it is conceivable that bacteria are commonly present during acute wheezing episodes, but it remains questionable whether they significantly contribute to chronic, recurrent wheezing symptoms in preschool children. ${ }^{24}$ Therefore, the role of bacteria in preschool wheeze, and their potential relation with viral infections needs to be further explored in longitudinal studies.

In order to study the immunological status in preschool wheeze, we explored whether children with wheezing symptoms differed in $\mathrm{T}_{\text {reg }}$ cells compared to children without symptoms (Chapter 6). We did not find different counts of $T_{\text {reg }}$ cells between both 
groups. This was not in line with findings of Borrego et al. who reported lower $\mathrm{T}_{\text {reg }}$ cell counts in wheezing preschool children when compared with healthy controls. ${ }^{27}$ In future studies, it is advisable not only to look at differences in number, but also in functionality of $T_{\text {reg }}$ cells in order to unravel the involvement of these cells in preschool wheeze. $^{28}$

\section{Phenotyping of preschool wheeze}

It is recognised that 'not all that wheeze is asthma'. Mostly, preschool children with respiratory symptoms outgrow these symptoms at school age. Only the minority of children will have persistent symptoms that develop into asthma. The heterogeneity of preschool wheeze is described by multiple wheezing phenotypes in which children are divided on basis of time of onset, triggers, frequency and severity of symptoms. In order to challenge the difficulty of diagnosing asthma in young children, clinical indices such as the Asthma Predictive Index have been developed. ${ }^{29}$ This checklist includes items such as parental history of asthma or eczema, eosinophilia, and wheezing apart from colds and allergic rhinitis. The checklist can be used to identify young children at risk for persistent asthma. Other asthma indices were established from the Isle of Wight and the Prevention and Incidence of Asthma and Mite Allergy (PIAMA) birth cohorts, and included additional risk factors, such as atopic sensitisation at four years of age, male sex and recurrent chest infections. ${ }^{30,31}$ In addition, Eysink and colleagues developed a prediction index for general practice, and demonstrated that adding an objective measure such as specific immunoglobin $E$ to risk factors including age, wheeze and atopic family history, considerably improves the asthma prediction. ${ }^{32}$ Although these four indices can be of help in the decision making of physicians, they should be handled with care as not all children with a positive index will develop asthma, nor can a negative test fully rule out asthma, due to the modest positive and negative predictive value of these indices. At present, there are no reliable tests available that include objective, non-invasive, 'inflammatory' measures to assist physicians in the diagnosis of wheezing phenotypes.

\section{What can exhaled biomarkers and lung function measurements add to phenotyping?}

A widely used classification system is developed by researchers of the Tucson birth cohort study dividing children into early transient, late-onset, persistent and nonwheezing phenotypes. ${ }^{33}$ It is assumed that these phenotypes have different pathological processes. However, this assumption is based on limited evidence due to difficulties in measuring airway inflammation and lung function. 
Brussee et al. examined whether wheezing phenotypes differed in FeNO, and demonstrated that FeNO levels did not differentiate between the transient, late-onset, persistent and non-wheezing phenotypes. ${ }^{34}$ In contrast, Caudri et al. demonstrated that FeNO levels assessed at preschool age could predict the persistence of wheezing symptoms at eight years of age. ${ }^{35}$ These inconclusive findings need to be clarified with additional research.

We reported the first study that prospectively explored whether preschool children with different wheezing patterns differed in inflammatory status by using markers in EBC (Chapter 8). We demonstrated that children with persistent wheezing symptoms at five years of age already had elevated levels of multiple inflammatory markers (IL-2, IL-4, IL-8, IL-10) in EBC at preschool age compared to children who never wheezed. This finding indicates a broad, enhanced inflammatory response in this group of wheezing preschool children. In contrast, levels of these EBC markers did not differ between children with transient symptoms and children with persistent symptoms. We anticipated to find increased levels of IL-8, a neutrophil chemo-attractant, in the group or transient wheezers, as they are believed to have neutrophilic airway inflammation, but that was not the case. .,2,36

Up till now, VOCs profiles have not yet been applied in defining the pathological status of wheezing phenotypes.

With respect to lung function, we examined whether preschool Rint values differed in wheezing phenotypes at school age (Chapter 8). Although preschool Rint values were slightly elevated in children with persistent wheeze compared to never and transient wheezers, there was a considerable overlap in Rint values between the groups. In contrast, previous cross-sectional studies, demonstrated more markedly elevated levels of airway resistance in children with persistent wheeze compared to children who experienced symptoms in the past. ${ }^{37,38}$ These findings might point to airway obstruction in children with persistent but not transient symptoms. However, similarly to our findings, data from the PIAMA birth cohort study demonstrated no predictive value of Rint assessed at young age and wheezing symptoms at older age. ${ }^{35}$ Altogether, we might conclude that although airway resistance is increased in school children with current, persistent symptoms compared to children with previous, transient symptoms, the power of preschool Rint to predict the persistence of symptoms is limited.

The fact that exhaled inflammatory markers and early lung function measurements do not markedly correlate with clinical phenotypes, does not mean that they have no 'phenotyping-value' in wheezing preschool children. In fact, these findings might raise the question whether wheezing phenotypes based on a single characteristic, such as symptom history, represent distinct pathological phenotypes of wheezing illness. ${ }^{39}$ It 
would be interesting to study whether an alternative approach of wheezing subgrouping guided by non-invasive inflammatory markers and lung function parameters would provide a better biological basis to disentangle the heterogeneous character of wheeze. Potentially, classifying children on basis of their inflammatory 'breath-print' might better separate the underlying causes of preschool wheeze and will therefore be helpful in the proper treatment of wheezing children.

\section{Management of preschool wheeze}

Two large long-term clinical trials demonstrated that the early use of ICS is not able to modify progression of wheezing symptoms and therefore is not able to prevent asthma. ${ }^{40,41}$ Due to the lack of disease-modifying effects, treatment in this age group is aimed at symptom relief. Next to ICS, current available therapies in preschool wheezers include cysteinyl leukotriene receptor antagonists or bronchodilators. The latter two therapies are proposed to be beneficial in children at the start of a viralinduced episode of wheeze, although the rationale behind this is based on limited evidence. ${ }^{42}$ ICS are recommended in young children who wheeze because of asthma. Due to the heterogeneity of preschool wheeze, there is a large variability in ICS response. As it is a challenge to assess the best treatment in young symptomatic children, management in this age group is still sub-optimal. An important step forward in the treatment of preschool wheeze, is the use of a biological test that can predict treatment response.

\section{What can exhaled biomarkers and lung function measurements add to treatment?}

An important effect of ICS is the inhibition of the inflammatory response in various cell types including eosinophils. ${ }^{43}$ On account of this anti-inflammatory effect we hypothesised that the use of inflammatory markers in exhaled breath may identify ICS responders in a heterogeneous sample of preschool wheezers. We performed an eight week ICS study and assessed FeNO and multiple inflammatory markers (IL-1 $\alpha$, IL-2, IL-4, IL-5, IL-10, sICAM, IFN- $\gamma$, Eotaxin) in EBC (Chapter 7). We demonstrated that only a low concentration of IL-10, an anti-inflammatory cytokine, and atopy had limited predictive value regarding improvement in symptoms after ICS. ${ }^{12}$ We did not find convincing evidence that FeNO and other EBC markers were associated with an ICS response in preschool wheezers.

Our study is the first that was performed in wheezing preschool children to evaluate the value of exhaled inflammatory markers in directing therapy. However, with respect to FeNO a variety of studies were performed in adults and older children with asthma to explore the predictive monitoring value of FeNO. Our study findings were in line 
with those of Martin et al. and Zielen et al. who demonstrated that FeNO could not predict an ICS response in asthmatic adults and children. ${ }^{44,45}$ In contrast, Szefler and colleagues did report a predictive value of FeNO for an ICS response in asthmatic children. ${ }^{46}$ Moreover, Little et al. reported in adults with asthma that an elevated level of FeNO in combination with sputum eosinophilia predicted an improvement in lung function after ICS treatment. ${ }^{47}$ Additionally, Smith et al. showed that in patients with undiagnosed respiratory symptoms, FeNO was predictive for an ICS response. ${ }^{48}$

With respect to the predictive value of markers in EBC, only data of one Japanese study were reported. ${ }^{49}$ They demonstrated that increased EBC levels of IL-4 and Rantes and a reduced level of IFN-gamma-inducible protein (IP)-10 significantly correlated with a steroid-induced improvement in lung function in adults with asthma. ${ }^{49}$ Taken into account these promising findings in adults and school children, the lack of predictive value of FeNO and EBC in our study should not be over-interpreted. As our study population had minor symptoms, and therefore limited room for improvement, a clinical ICS trial including preschool children with more severe symptoms may come up with more appealing results.

There were no data reported on VOCs and its potential to predict an ICS response in children or in adults with respiratory symptoms. The only data that were reported on VOCs and ICS were from Paredi et al., who showed reduced levels of exhaled ethane in adults with asthma treated with ICS compared to steroid-naïve patients. ${ }^{50}$ These findings indicate the steroid responsiveness of this marker, and might be a clue to explore the potential predictive role of this and other VOCs.

In our study, Rint was used as an outcome measure for an ICS response instead of a predictive marker. This is in concordance with other clinical ICS studies in children, that used change in airway resistance as measure to objectively assess treatment response rather than studying its possible predictive value. ${ }^{51-53}$ Therefore the use of baseline and post-bronchodilator airway resistance values as a predictive marker for an ICS response in wheezing preschool children still needs to be established.

\section{Route from a differentiating metabolite in research to a biomarker in clinical practice}

Despite their potential, compounds in exhaled breath are not used in clinical practice yet, with FeNO as an exception. Both in the available literature as in this thesis the exhaled compounds are called 'biomarkers'. However, it can be argued whether that is correct. According to the Biomarker Definition Working Group a biomarker is defined as "a characteristic that can be objectively measured and evaluated as an indicator of normal biological processes, pathogenic processes or pharmacological responses to a 
therapeutic intervention" ${ }^{54}$ Biomarkers can play multiple roles in clinical practice, such as facilitating diagnosis, prognosis and guidance of treatment. However, of all potential metabolites discovered, only a few will attain the privileged status of a biomarker. ${ }^{55} \mathrm{~A}$ successful biomarker should meet many requirements. Table 9.1 illustrates whether these requirements are met by FeNO, compounds in EBC and VOCs. Although the majority of criteria seems to be fulfilled by FeNO, we demonstrated that FeNO is not perfectly able to differentiate between (a heterogeneous group of) wheezing preschool children and healthy controls. As noted before, due to the heterogeneous character of preschool wheeze and the multiple potential immunological pathways involved, probably one specific (eosinophilic) compound is not fulfilling to capture the broad spectrum of preschool wheeze. This is supported by our findings that a profile of VOCs and multiple compounds in EBC were able to distinct between wheezers and non-wheezers. However, although promising, these exhaled compounds still have a long way to go, as illustrated by the many question marks in Table 9.1.

Table 9.1 Requirements for a successful biomarker in children fulfilled by exhaled biomarkers.

$\begin{array}{lcccl}\text { Criteria } & \text { FeNO } & \text { VOCs } & \text { EBC } & \text { Ref. } \\ \text { Minimally invasive } & V & V & V & 9,10,13,35,61 \\ \text { Outcome easy to interpret } & V & X & ? & 10,61-63 \\ \text { Provide a rapid result } & V & V & V & 10,18,61-63 \\ \text { Change in marker precedes clinical outcome * } & ? & ? & ? & 34,35,64 \\ \text { Lead to better patient outcomes ** } & ? & ? & ? & 12,44-46,49 \\ \text { Have a pathophysiological explanation } & V & ? & V & 10,15,61-63, \\ \text { Narrow intra individual variation } & V & V & ? & 18,63,65-67 \\ \text { High sensitivity, specificity, npv, ppv *** } & ? & \text { V } & \text { V } & 19,68-72 \\ \text { High inter observer and intra observer reliability } & ? & ? & ? & \end{array}$

Ref. = References including data of preschool children, if not available valuable data of school children and adults are stated; $n p v=$ negative predictive value, $p p v=$ positive predictive value. $v=$ requirement met, $?=$ requirement not extensively studied yet or inconclusive data, $\mathrm{X}=$ requirement not yet met; *For example predict persistence of symptoms; ${ }^{* *}$ For example predict treatment outcome to better titrate treatment; $* * *$ For example regarding diagnosis of persistent asthma symptoms.

A substantial body of additional evidence and a structured approach is needed to 'promote' differentiating metabolite(s) to valid and reliable biomarkers. As Koulmann stated; "after the discovering of potential compound, an extensive validation process is needed. Only after sufficient proof of precision, accuracy and biological relevance, this compounds can move to the status of biomarker" ${ }^{56}$ Thus, although compounds in exhaled breath (condensate) fulfil certain criteria of a successful biomarker, an extensive validation process is still essential. Therefore, labelling them as biomarkers might be somewhat preterm. However, once an exhaled compound endures the validation route and attained the status of a biomarker, a broad scale of clinical applications is conceivable (Table 9.2). A non-invasive, reliable and objectively measured biomarker can provide insight in the underlying causes and mechanism of preschool wheeze. This information can help clinicians to better deal with diagnostic, prognostic and management challenges in the field of preschool wheeze. 
Table 9.2 Potential application of non-invasive biomarkers in preschool wheeze.

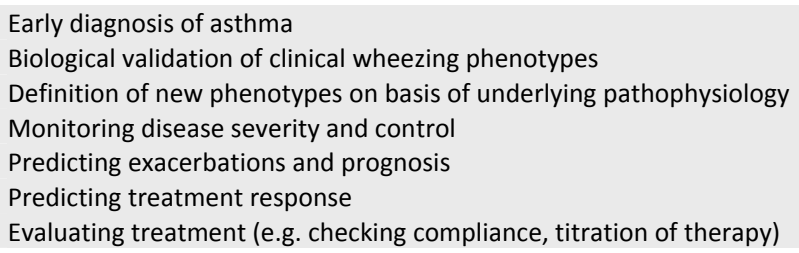

\section{Future research perspectives}

There is cumulative evidence for the diagnostic and monitoring potential of exhaled inflammatory 'biomarkers'. Nevertheless, considerable works needs to be done before the analysis of exhaled breath is useful in clinical practice.

\section{Future methodological studies}

Although an American/European Taskforce presented recommendations about the methodology of off-line collected FeNO and EBC collection, both techniques needs further standardisation. ${ }^{5,57}$

In preschool children, FeNO is mostly collected off-line during tidal breathing. One of the factors that influences FeNO is the expiratory flow rate. A single breath on-line manoeuvre with constant flow is recommended in older children but mostly not feasible in preschool children. The development of a feasible device that allows measuring FeNO during tidal breathing at a constant flow in a reproducible manner will facilitate the introduction of FeNO into clinical practice in this age group.

In this thesis we demonstrated that the collection and analysis of EBC can be safely and easily applied in preschool children, due to a highly efficient condenser and a very sensitive analysing array. Still, in concordance to FeNO, the collection and analysis of EBC deals with methodological issues that need to be resolved. Although we made considerable progress in the refinement of the sampling and analysing technique of EBC, further improvement is warranted. For example EBC sampling can be advanced by optimising condenser coating properties. We previously demonstrated a variable influence of condenser coatings on different inflammatory markers, which implies that the optimal inner condenser coating varies for each specific biomarker. ${ }^{58}$ Moreover, a sampling technique that can separate exhaled breath from proximal and distal airways, can increase insight in the exact origin of inflammatory compounds. Thirdly, analysing techniques can be refined by the development of highly sensitive assays as the concentrations of inflammatory markers in EBC are low and often just above the detection limit of most assays. Although we are able to measure various cytokines and 
chemokines in a small amount of EBC $(60 \mu \mathrm{l})$, multiple other interesting compounds, such as nitrate and 8-isoprostane, require a larger volume of EBC. More sensitive analytical techniques will enable to study a broad scale of interesting compounds in preschool children. Another important area of future research in EBC is to study the potential influence of 'confounding' factors on levels of inflammatory EBC markers, such as dilution, medication, circadian rhythm, flow rate, diet, age, gender and season of measurement. ${ }^{59}$ Reproducibility studies that take these factors into account will contribute to the development of a standardised protocol to collect and analyse EBC in preschool children. A standardised procedure in EBC measurements will enhance the current limited inter-laboratory comparability. A higher inter-laboratory comparability will subsequently facilitate external validation of EBC markers. The discriminative cytokines and chemokines for preschool wheeze that we reported in this thesis should be confirmed in new populations. Moreover, in order to clinically validate inflammatory markers in EBC, these compounds should be compared with compounds in for example BAL fluid, the current gold standard. Although, an initial study demonstrated a positive correlation between inflammatory markers in EBC and BAL fluid in patients with chronic obstructive pulmonary disease (COPD) and sarcoidosis, more research is required in paediatric populations. ${ }^{60}$ When the collection and analysing procedures are optimised, standardised and validated, reference values for each marker need to be developed. Only when all these requirements are met, EBC markers can be of added value in clinical practice.

The collection and analysis of VOCs in exhaled breath is even a more recent field in paediatric research. Therefore, analogue methodological studies as in EBC are needed to be performed regarding exhaled VOCs, including studies on reproducibility, standardisation (e.g. on collection, analysing and controlling for confounders) and (external) validation. A taskforce of experts that provides recommendations for VOCs measurements will accelerate this process. Of special interest are studies that can increase insight in the physiological meaning and biochemical origin of VOCs. As VOCs are breakdown products of various (patho)physiological processes, this will be a challenging task. Furthermore, studies that explore the advanced statistical techniques on the multi-data that are generated with VOCs analysis are required.

\section{Future clinical studies}

Despite the steep increase in clinical studies on non-invasive measurements of compounds in exhaled breath in adults and school children, studies in preschool children are still limited. The methodological improvements, such as an efficient condenser and sensitive analytical methods, assist in the feasible collection of exhaled breath (condensate) in this relatively non-cooperative patient group. These improvements will probably result in a substantial increase in clinical studies in preschool wheezing children. The potential applications of non-invasive biomarkers in 
preschool wheeze (Table 9.2), including preschool wheezing phenotyping on underlying pathophysiology, early asthma diagnosis, and evaluation of treatment, need to be further elaborated. The clinical use of non-invasive, feasible and objectively measured biomarkers can provide insight and even might revise our knowledge in the complex phenomena of preschool wheeze.

\section{Future directions of the ADEM study}

The studies described in this thesis encompass data from the ADEM study. The primary objective of the ADEM study is to develop a non-invasive instrument for an early asthma diagnosis by using exhaled inflammatory biomarkers and early lung function measurements. The 252 children of the ADEM study will be followed until the age of six years. At that age, a definite diagnosis of asthma is made upon the presence of current asthma symptoms in combination with characteristic lung function abnormalities (such as reversibility on $a B_{2}$ agonist and bronchial hyper responsiveness). At that stage, the early measurements of non-invasive inflammatory markers in exhaled breath (condensate) and Rint measurements (at two and three years of age) are related to the final diagnosis of asthma. Potentially this will enable us to select a profile of biomarkers that can reliable predict asthma in young children. Besides, next to early infections and $\mathrm{T}_{\text {reg }}$ cells, other aetiological factors such as gene polymorphisms and gene expression will be studied in relation to the early development of asthma. Hopefully, the new diagnostic techniques applied in this study will facilitate an early asthma diagnosis. This will circumvent both over-treatment of children with transient wheezing symptoms and under-treatment of children with asthma, and thereby have a beneficial influence on the prognosis of asthma in these young children. 


\section{References}

1. Oommen A, Patel R, Browning M, Grigg J. Systemic neutrophil activation in acute preschool viral wheeze. Arch Dis Child 2003;88:529-31.

2. Marguet C, Jouen-Boedes F, Dean TP, Warner JO. Bronchoalveolar cell profiles in children with asthma, infantile wheeze, chronic cough, or cystic fibrosis. Am J Respir Crit Care Med 1999;159:1533-40.

3. Barbato A, Turato G, Baraldo S, Bazzan E, Calabrese F, Panizzolo C, Zanin ME, Zuin R, Maestrelli P, Fabbri LM, Saetta M. Epithelial damage and angiogenesis in the airways of children with asthma. Am J Respir Crit Care Med 2006;174:975-81.

4. Saglani S, Payne DN, Zhu J, Wang Z, Nicholson AG, Bush A, Jeffery PK. Early detection of airway wall remodeling and eosinophilic inflammation in preschool wheezers. Am J Respir Crit Care Med 2007;176:858-64.

5. ATS/ERS Recommendations for Standardized Procedures for the Online and Offline Measurement of Exhaled Lower Respiratory Nitric Oxide and Nasal Nitric Oxide, 2005. Am J Respir Crit Care Med 2005;171:912-30.

6. Gabriele C, Nieuwhof EM, van der Wiel EC, Hofhuis W, Moll HA, Merkus PJ, de Jongste JC. Exhaled nitric oxide differentiates airway diseases in the first two years of life. Pediatr Res 2006;60:461-65.

7. Moeller A, Franklin P, Hall GL, Horak F, Jr., Wildhaber JH, Stick SM. Measuring exhaled breath condensates in infants. Pediatr Pulmonol 2006;41:184-7.

8. Walsh BK, Mackey DJ, Pajewski T, Yu Y, Gaston BM, Hunt JF. Exhaled-breath condensate pH can be safely and continuously monitored in mechanically ventilated patients. Respir Care 2006;51:1125-31.

9. Vogelberg C, Wurfel C, Knoetzsch A, Kahlert A, Range U, Leupold W. Exhaled breath condensate $\mathrm{pH}$ in infants and children with acute and recurrent wheezy bronchitis. Pediatr Pulmonol 2007;42:1166-72.

10. van de Kant KD, Klaassen EM, Jöbsis Q, Koers K, Rijkers GT, van der Grinten CP, van Schayck OC, Passos VL, Dompeling E. Wheezing in preschool children is associated with increased levels of cytokines/chemokines in exhaled breath condensate. J Allergy Clin Immunol 2010;126:669-71.

11. van de Kant KD, Klaassen EM, Jöbsis Q, Nijhuis AJ, van Schayck OC, Dompeling E. Early diagnosis of asthma in young children by using non-invasive biomarkers of airway inflammation and early lung function measurements: study protocol of a case-control study. BMC Public Health 2009;9:210.

12. van de Kant KD, Koers K, Rijkers GT, Lima Passos V, Klaassen EM, Mommers M, Dagnelie PC, van Schayck $C P$, Dompeling $E$, Jobsis $Q$. Can exhaled inflammatory markers predict a steroid response in wheezing preschool children? Clin Exp Allergy 2011;41:1076-83.

13. Rosias PP, Robroeks CM, van de Kant KD, Rijkers GT, Zimmermann LJ, van Schayck CP, Heynens JW, Jöbsis Q, Dompeling E. Feasibility of a new method to collect exhaled breath condensate in pre-school children. Pediatr Allergy Immunol 2010;21:e235-44.

14. Martinez FD, Godfrey S. Immunology of wheezing disorders in infants and preschool children. New York: Martin Dunitz; 2003.

15. Bloemen K, van den Heuvel R, Govarts E, Hooyberghs J, Nelen V, Witters E, Desager K, Schoeters G. A new approach to study exhaled proteins as potential biomarkers for asthma. Clin Exp Allergy 2010;41:346-56.

16. Vinayavekhin N, Homan EA, Saghatelian A. Exploring disease through metabolomics. ACS Chem Biol 2010;5:91-103.

17. van Berkel JJ, Dallinga JW, Moller GM, Godschalk RW, Moonen EJ, Wouters EF, van Schooten FJ. A profile of volatile organic compounds in breath discriminates COPD patients from controls. Respir Med 2010;104:557-63.

18. Robroeks CM, van Berkel JJ, Dallinga JW, Jöbsis Q, Zimmermann L, Hendriks HJ, Wouters MF, van der Grinten CP, van de Kant KD, van Schooten FJ, Dompeling E. Metabolomics Of Volatile Organic Compounds In Cystic Fibrosis Patients and Controls. Pediatr Res 2010;68:75-80.

19. Dallinga JW, Robroeks CM, van Berkel JJ, Moonen EJ, Godschalk RW, Jöbsis Q, Dompeling E, Wouters $\mathrm{EF}$, van Schooten FJ. Volatile organic compounds in exhaled breath as a diagnostic tool for asthma in children. Clin Exp Allergy 2010;40:68-76.

20. McKenzie SA, Bridge PD, Healy MJ. Airway resistance and atopy in preschool children with wheeze and cough. Eur Respir J 2000;15:833-8. 
21. Nagayama Y, Tsubaki T, Nakayama S, Sawada K, Taguchi K, Toba T, Kohno Y. Bacterial colonization in respiratory secretions from acute and recurrent wheezing infants and children. Pediatr Allergy Immunol 2007;18:110-7.

22. Mills GD, Lindeman JA, Fawcett JP, Herbison GP, Sears MR. Chlamydia pneumoniae serological status is not associated with asthma in children or young adults. Int J Epidemiol 2000;29:280-4.

23. Korppi M, Paldanius M, Hyvarinen A, Nevalainen A, Husman T. Chlamydia pneumoniae and newly diagnosed asthma: a case-control study in 1 to 6-year-old children. Respirology 2004;9:255-9.

24. Korppi M. Bacterial infections and pediatric asthma. Immunol Allergy Clin North Am 2010;30:565-74.

25. Xepapadaki P, Koutsoumpari I, Papaevagelou V, Karagianni C, Papadopoulos NG. Atypical bacteria and macrolides in asthma. Allergy Asthma Clin Immunol 2008;4:111-6.

26. Bisgaard H, Hermansen MN, Bonnelykke K, Stokholm J, Baty F, Skytt NL, Aniscenko J, Kebadze T, Johnston SL. Association of bacteria and viruses with wheezy episodes in young children: prospective birth cohort study. BMJ 2010;341:c4978.

27. Borrego LM, Arroz MJ, Videira P, Martins C, Guimaraes H, Nunes G, Papoila AL, Trindade H. Regulatory cells, cytokine pattern and clinical risk factors for asthma in infants and young children with recurrent wheeze. Clin Exp Allergy 2009;39:1160-9.

28. Yamamoto $Y$, Negoro T, Hoshi A, Wakagi A, Shimizu S, Banham AH, Ishii M, Akiyama H, Kiuchi $Y$, Sunaga S, Tobe T, Roncador G, Itabashi K, Nakano Y. Impaired Ca Regulation of CD4(+)CD25(+) Regulatory T Cells from Pediatric Asthma. Int Arch Allergy Immunol 2011;156:148-58.

29. Castro-Rodriguez JA. The Asthma Predictive Index: a very useful tool for predicting asthma in young children. J Allergy Clin Immunol 2010;126:212-6.

30. Kurukulaaratchy RJ, Matthews S, Holgate ST, Arshad SH. Predicting persistent disease among children who wheeze during early life. Eur Respir J 2003;22:767-71.

31. Caudri D, Wijga A, CM AS, Hoekstra M, Postma DS, Koppelman GH, Brunekreef B, Smit HA, de Jongste JC. Predicting the long-term prognosis of children with symptoms suggestive of asthma at preschool age. J Allergy Clin Immunol 2009;124:903-910 e901-7.

32. Eysink PE, ter Riet G, Aalberse RC, van Aalderen WM, Roos CM, van der Zee JS, Bindels PJ. Accuracy of specific IgE in the prediction of asthma: development of a scoring formula for general practice. $\mathrm{Br} J$ Gen Pract 2005;55:125-31.

33. Martinez FD, Wright AL, Taussig LM, Holberg CJ, Halonen M, Morgan WJ. Asthma and wheezing in the first six years of life. The Group Health Medical Associates. N Engl J Med 1995;332:133-8.

34. Brussee JE, Smit HA, Kerkhof M, Koopman LP, Wijga AH, Postma DS, Gerritsen J, Grobbee DE, Brunekreef B, de Jongste JC. Exhaled nitric oxide in 4-year-old children: relationship with asthma and atopy. Eur Respir J 2005;25:455-61.

35. Caudri D, Wijga AH, Hoekstra MO, Kerkhof M, Koppelman GH, Brunekreef B, Smit HA, de Jongste JC. Prediction of asthma in symptomatic preschool children using exhaled nitric oxide, Rint and specific IgE. Thorax 2010;65:801-807.

36. McDougall CM, Helms PJ. Neutrophil airway inflammation in childhood asthma. Thorax 2006;61: 739-41.

37. Brussee JE, Smit HA, Koopman LP, Wijga AH, Kerkhof M, Corver K, Vos AP, Gerritsen J, Grobbee DE, Brunekreef B, Merkus PJ, de Jongste JC. Interrupter resistance and wheezing phenotypes at 4 years of age. Am J Respir Crit Care Med 2004;169:209-13.

38. Oostveen E, Dom S, Desager K, Hagendorens M, de Backer W, Weyler J. Lung function and bronchodilator response in 4-year-old children with different wheezing phenotypes. Eur Respir J 2010;35:865-72.

39. Spycher BD, Silverman M, Kuehni CE. Phenotypes of childhood asthma: are they real? Clin Exp Allergy 2010;40:1130-41.

40. Guilbert TW, Morgan WJ, Zeiger RS, Mauger DT, Boehmer SJ, Szefler SJ, Bacharier LB, Lemanske RF, Jr., Strunk RC, Allen DB, Bloomberg GR, Heldt G, Krawiec M, Larsen G, Liu AH, Chinchilli VM, Sorkness CA, Taussig LM, Martinez FD. Long-term inhaled corticosteroids in preschool children at high risk for asthma. N Engl J Med 2006;354:1985-97.

41. Murray CS, Woodcock A, Langley SJ, Morris J, Custovic A. Secondary prevention of asthma by the use of Inhaled Fluticasone propionate in Wheezy INfants (IFWIN): double-blind, randomised, controlled study. Lancet 2006;368:754-62. 
42. Brand PL, Baraldi E, Bisgaard H, Boner AL, Castro-Rodriguez JA, Custovic A, de Blic J, de Jongste JC, Eber E, Everard ML, Frey U, Gappa M, Garcia-Marcos L, Grigg J, Lenney W, Le Souef P, McKenzie S, Merkus PJ, Midulla F, Paton JY, Piacentini G, Pohunek P, Rossi GA, Seddon P, Silverman M, Sly PD, Stick S, Valiulis A, van Aalderen WM, Wildhaber JH, Wennergren G, Wilson N, Zivkovic Z, Bush A. Definition, assessment and treatment of wheezing disorders in preschool children: an evidence-based approach. Eur Respir J 2008;32:1096-10.

43. Gibson PG, Saltos N, Fakes K. Acute anti-inflammatory effects of inhaled budesonide in asthma: a randomized controlled trial. Am J Respir Crit Care Med 2001;163:32-6.

44. Martin RJ, Szefler SJ, King TS, Kraft M, Boushey HA, Chinchilli VM, Craig TJ, Dimango EA, Deykin A, Fahy JV, Israel E, Lazarus SC, Lemanske RF, Jr., Leone FT, Pesola GR, Peters SP, Sorkness CA, Szwejbka LA, Wechsler ME. The Predicting Response to Inhaled Corticosteroid Efficacy (PRICE) trial. J Allergy Clin Immunol 2007;119:73-80.

45. Zielen S, Christmann M, Kloska M, Dogan-Yildiz G, Lieb A, Rosewich M, Schubert R, Rose MA, Schulze J. Predicting short term response to anti-inflammatory therapy in young children with asthma. Curr Med Res Opin 2010;26:483-92.

46. Szefler SJ, Phillips BR, Martinez FD, Chinchilli VM, Lemanske RF, Strunk RC, Zeiger RS, Larsen G, Spahn JD, Bacharier LB, Bloomberg GR, Guilbert TW, Heldt G, Morgan WJ, Moss MH, Sorkness CA, Taussig LM. Characterization of within-subject responses to fluticasone and montelukast in childhood asthma. J Allergy Clin Immunol 2005;115:233-42.

47. Little SA, Chalmers GW, MacLeod KJ, McSharry C, Thomson NC. Non-invasive markers of airway inflammation as predictors of oral steroid responsiveness in asthma. Thorax 2000;55:232-4.

48. Smith AD, Cowan JO, Brassett KP, Filsell S, McLachlan C, Monti-Sheehan G, Peter Herbison G, Robin Taylor D. Exhaled nitric oxide: a predictor of steroid response. Am J Respir Crit Care Med 2005;172:453-9.

49. Matsunaga K, Ichikawa T, Yanagisawa S, Akamatsu K, Koarai A, Hirano T, Sugiura H, Minakata Y, Ichinose M. Clinical Application of Exhaled Breath Condensate Analysis in Asthma: Prediction of FEV(1) Improvement by Steroid Therapy. Respiration 2009;78:393-8.

50. Paredi P, Kharitonov SA, Barnes PJ. Elevation of exhaled ethane concentration in asthma. Am J Respir Crit Care Med 2000;162:1450-4.

51. Nielsen KG, Bisgaard $\mathrm{H}$. The effect of inhaled budesonide on symptoms, lung function, and cold air and methacholine responsiveness in 2- to 5-year-old asthmatic children. Am J Respir Crit Care Med 2000;162:1500-6.

52. Straub DA, Minocchieri S, Moeller A, Hamacher J, Wildhaber JH. The effect of montelukast on exhaled nitric oxide and lung function in asthmatic children 2 to 5 years old. Chest 2005;127:509-14.

53. Murray CS, Custovic A, Lowe LA, Aldington S, Williams M, Beasley R, Woodcock A. Effect of addition of salmeterol versus doubling the dose of fluticasone propionate on specific airway resistance in children with asthma. Allergy Asthma Proc 2010;31:415-21.

54. Biomarker Definitions Working Group. Biomarkers and surrogate endpoints: preferred definitions and conceptual framework. Clin Pharmacol Ther 2001;69:89-95.

55. Puntmann VO. How-to guide on biomarkers: biomarker definitions, validation and applications with examples from cardiovascular disease. Postgrad Med J 2009;85:538-45.

56. Koulman A, Lane GA, Harrison SJ, Volmer DA. From differentiating metabolites to biomarkers. Anal Bioanal Chem 2009;394:663-70.

57. Horvath I, Hunt J, Barnes PJ, Alving K, Antczak A, Baraldi E, Becher G, van Beurden WJ, Corradi M, Dekhuijzen R, Dweik RA, Dwyer T, Effros R, Erzurum S, Gaston B, Gessner C, Greening A, Ho LP, Hohlfeld J, Jöbsis Q, Laskowski D, Loukides S, Marlin D, Montuschi P, Olin AC, Redington AE, Reinhold P, van Rensen EL, Rubinstein I, Silkoff P, Toren K, Vass G, Vogelberg C, Wirtz H. Exhaled breath condensate: methodological recommendations and unresolved questions. Eur Respir J 2005;26: 523-48.

58. Rosias PP, Robroeks CM, Niemarkt HJ, Kester AD, Vernooy JH, Suykerbuyk J, Teunissen J, Heynens J, Hendriks HJ, Jöbsis Q, Dompeling E. Breath condenser coatings affect measurement of biomarkers in exhaled breath condensate. Eur Respir J 2006;28:1036-41.

59. Rosias PP, Dompeling E, Hendriks HJ, Heijnens JW, Donckerwolcke RA, Jöbsis Q. Exhaled breath condensate in children: Pearls and pitfalls. Pediatr Allergy Immunol 2004;15:4-19. 
60. Antczak A, Piotrowski W, Marczak J, Ciebiada M, Gorski P, Barnes PJ. Correlation between eicosanoids in bronchoalveolar lavage fluid and in exhaled breath condensate. Dis Markers 2011;30:213-20.

61. van de Kant KD, van Berkel JJ, de Jongste JC, Jöbsis Q, Klaassen EMM, Dallinga JW, van Schayck CP, van Schooten FJ, Dompeling E. Volatile organic compounds in exhaled breath differentiate between children with and without recurrent wheeze. Allergy 2010; 65 suppl 92:138.

62. Pijnenburg MW, de Jongste JC. Exhaled nitric oxide in childhood asthma: a review. Clin Exp Allergy 2008;38:246-59.

63. Robroeks CM, Rijkers GT, Jöbsis Q, Hendriks HJ, Damoiseaux JG, Zimmermann LJ, van Schayck OP, Dompeling E. Increased cytokines, chemokines and soluble adhesion molecules in exhaled breath condensate of asthmatic children. Clin Exp Allergy 2010;40:77-84.

64. van de Kant KD, Jansen MA, Klaassen EM, van der Grinten CP, Rijkers GT, Muris JW, van Schayck CP, Jöbsis Q, Dompeling E. Elevated inflammatory markers at preschool age precede persistent wheezing at school age. Çhapter 8 of this thesis. submitted.

65. Gabriele C, de Benedictis FM, de Jongste JC. Exhaled nitric oxide measurements in the first 2 years of life: methodological issues, clinical and epidemiological applications. Ital J Pediatr 2009;35:21.

66. van Berkel JJ, Dallinga JW, Moller GM, Godschalk RW, Moonen E, Wouters EF, van Schooten FJ. Development of accurate classification method based on the analysis of volatile organic compounds from human exhaled air. J Chromatogr B Analyt Technol Biomed Life Sci 2008;861:101-7.

67. Bloemen K, Lissens G, Desager K, Schoeters G. Determinants of variability of protein content, volume and $\mathrm{pH}$ of exhaled breath condensate. Respir Med 2007;101:1331-7.

68. Avital A, Uwyyed K, Berkman N, Godfrey S, Bar-Yishay E, Springer C. Exhaled nitric oxide and asthma in young children. Pediatr Pulmonol 2001;32:308-13.

69. Dragonieri S, Schot R, Mertens BJ, Le Cessie S, Gauw SA, Spanevello A, Resta O, Willard NP, Vink TJ, Rabe KF, Bel EH, Sterk PJ. An electronic nose in the discrimination of patients with asthma and controls. J Allergy Clin Immunol 2007;120:856-62.

70. Fens N, Zwinderman AH, van der Schee MP, de Nijs SB, Dijkers E, Roldaan AC, Cheung D, Bel EH, Sterk PJ. Exhaled Breath Profiling Enables Discrimination of Chronic Obstructive Pulmonary Disease and Asthma. Am J Respir Crit Care Med 2009;180:1076-82.

71. Montuschi P, Santonico M, Mondino C, Pennazza G, Mantini G, Martinelli E, Capuano R, Ciabattoni G, Paolesse R, Di Natale C, Barnes PJ, D'Amico A. Diagnostic performance of an electronic nose, fractional exhaled nitric oxide, and lung function testing in asthma. Chest 2010;137:790-6.

72. Robroeks CM, van de Kant KD, Jöbsis Q, Hendriks HJ, van Gent R, Wouters EF, Damoiseaux JG, Bast A, Wodzig WK, Dompeling E. Exhaled nitric oxide and biomarkers in exhaled breath condensate indicate the presence, severity and control of childhood asthma. Clin Exp Allergy 2007;37:1303-11. 


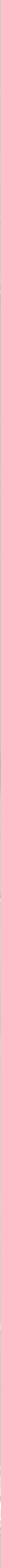




$$
23^{7}
$$




\section{Summary}

In this thesis, the value of exhaled inflammatory markers and early lung function measurements to assess inflammatory pathways, response to treatment and phenotypes in wheezing preschool children was evaluated.

In chapter 1 the clinical challenges in preschool wheeze were introduced. Respiratory symptoms, such as wheeze, are very common in preschool children. Preschool wheeze is a complex and heterogeneous symptom. While some children suffer from transient symptoms due to viral respiratory tract infections, others wheeze because of underlying asthma. Despite the high prevalence of wheezing symptoms, little is known about the underlying pathophysiology. As a consequence, physicians are dealing with problems in the diagnosis and monitoring of preschool wheeze. Measurements of biomarkers in exhaled breath are increasingly advocated as non-invasive tools to assess the inflammatory status in children with a pulmonary disease. In exhaled breath, volatile inflammatory markers including Fractional exhaled Nitric Oxide (FeNO) and Volatile Organic Compounds (VOCs) can be measured. Moreover, non-volatile inflammatory compounds (such as cytokines and chemokines) can be measured in Exhaled Breath Condensate (EBC). In addition, lung function measurements, such as measurements of airway resistance (Rint), can provide information about the airway geometry and underlying pathophysiology. Data in adults and older children demonstrated the potential clinical use of inflammatory markers in exhaled breath (condensate) in the diagnosis and monitoring of various pulmonary diseases. However, whether this also applies to preschool children with respiratory symptoms is hardly studied.

The research described in this thesis is conducted within the context of the Asthma DEtection and Monitoring (ADEM) study. In chapter 2, the study protocol of the ADEM study was discussed. The ADEM study is a case-control study that started in 2006 in Maastricht, the Netherlands. In this study, children with recurrent wheezing symptoms $(\mathrm{N}=202)$ and control subjects with no wheezing symptoms $(\mathrm{N}=50)$ were included at the age of two and three years and are studied prospectively until six years of age. The primary objective of the ADEM study is to early diagnose asthma by using biomarkers of airway inflammation and oxidative stress in exhaled breath (condensate) and early lung function measurements. Moreover, possible aetiological factors (such as regulatory $T\left(T_{\text {reg }}\right)$ cells, gene polymorphisms and gene expression of inflammatory markers and bacterial micro flora in the airways at an early age) are studied in relation to the early development of asthma. The research performed in the current thesis is based on the data at inclusion (two and three years of age), a two-month trial with inhaled corticosteroids (ICS), and the follow-up data to five years of age. 
In chapter $\mathbf{3}$ we demonstrated that EBC could easily be collected in preschool children with a closed glass condenser system. Moreover, we demonstrated the feasibility of off-line collected FeNO and Rint measurements in preschool children. Although FeNO and Rint levels were not different between children with and without recurrent wheeze, we did find different levels of interleukins (IL-1 $\alpha$, IL-2, IL-4, IL-5, IL-8, IL-10, IL13) and soluble Intercellular Adhesion Molecule (sICAM) in EBC in both groups. We demonstrated that levels of these markers increased with frequency of symptoms. The elevated levels of EBC markers in wheezing children might point to ongoing inflammatory pathways within the airways of these children. Thereby, the analysis of markers in EBC may assist in an early detection of airway inflammation in preschool children with respiratory symptoms.

Next to FeNO and markers in EBC, the analysis of exhaled VOCs gained popularity in various pulmonary diseases. However, the analysis of exhaled VOCs has not been applied in preschool children with respiratory symptoms. In chapter $\mathbf{4}$ we performed a systematic review to evaluate the current knowledge on VOCs and their potential clinical use in pulmonary diseases. The analysis of VOCs could be easily applied in a broad range of patients, including severely ill patients and children. Promising results were reported on VOCs profiles that were able to accurately (differential) diagnose and monitor various pulmonary diseases, including asthma, chronic obstructive pulmonary disease, cystic fibrosis and lung cancer. This provides evidence that VOCs profiling can be of significant additional value in the clinical decision making in pulmonary diseases. However, before VOCs can be used into clinical practice, emphasis on standardisation and validation of VOCs profiling is essential. The noninvasive character of VOCs profiling and the promising results in adults and school children paves the way to explore the potential clinical use in wheezing preschool children.

Chapter 5 described the first study that is reported on the use of VOCs profiles in preschool wheezing children. In this proof of principle study, we demonstrated that VOCs profiling was highly feasible in preschool children. We employed gas chromatography-time of flight-mass spectrometry, a highly sensitive technique, that is able to identify single most discriminative VOCs. Moreover, we assessed sophisticated statistical techniques, including sparse logistic regression, to handle the high dimensionality of our data. We reported that a profile of eleven VOCs (mainly hydrocarbons) was able to distinct between children with recurrent wheezing symptoms and children without recurrent wheeze. This VOCs profile had an adequate cross-validated classification error and sensitivity, though a suboptimal specificity. Nonetheless, this proof of principle revealed that VOCs profiling can provide valuable information about disease status in wheezing children. The assessment of the value of VOCs in an early asthma diagnosis will be the next step. 
In chapter 6 we shortly touched on the aetiology of preschool wheeze by evaluating bacterial colonisation, $\mathrm{T}_{\text {reg }}$ cells, atopy and EBC markers in relation to preschool wheeze. Although viruses are known to be predominant triggers of wheezing symptoms, bacteria may play a significant role as well. It is argued that bacteria in the airways can lead to inflammation in children with an impaired immunity, for example due to allergic sensitisation. $T_{\text {reg }}$ cells may play a role in this process. We observed that bacteria commonly inhabit the upper respiratory tract of preschool children, regardless of wheeze. Although bacteria may contribute to acute wheezing episodes (as previously demonstrated) we did not find convincing evidence that bacterial micro flora in the upper airways contribute to chronic recurrent wheezing illness. Nor was the number of $\mathrm{T}_{\text {reg }}$ cells different in wheezing children compared to non-wheezers. However, we did demonstrate that wheezing children colonised with Haemophilus (para) influenzae had mildly elevated pro-inflammatory cytokines and chemokines. This may point to a bacterial induced airway inflammation. Further research should reveal whether this enhanced inflammation is independently stimulated by bacteria or whether there is a synergistic interaction with virus-induced infections.

A potential clinical application of exhaled inflammatory markers by evaluating treatment in preschool wheezing children was discussed in chapter 7. In this chapter we elaborated whether exhaled inflammatory markers can predict a steroid response in wheezing preschool children. The efficacy of ICS varies among wheezing preschool children. Currently it is not possible to predict which child will benefit from ICS and which child will not. As ICS have an anti-inflammatory effect, we hypothesised that levels of FeNO and inflammatory markers in EBC can predict the ICS response. We demonstrated that the use of ICS for eight weeks resulted in a mild improvement of symptoms and airway resistance in wheezing preschool children. Of all inflammatory markers (FeNO, IL-1 $\alpha$, IL-2, IL-4, IL-5, IL-10, sICAM, Interferon-gamma (IFN- $\gamma$ ) and Eotaxin (CCL-11)), only IL-10 and atopy had limited predictive value regarding an improvement in symptoms. However, it should be noted that children in the ADEM study had minor symptoms and therefore little room for improvement. The search for a reliable, non-invasive and feasible technique to predict an ICS response needs to be continued. Larger studies with more severely wheezing children should be performed to further assess the value of EBC markers and exhaled VOCs in predicting the ICS response.

A potential other application of exhaled inflammatory markers was described in chapter 8. Currently, it is hard to predict whether wheezing symptoms will be transient or whether they have a more persistent nature due to underlying asthma. In the study described in this chapter we prospectively assessed whether inflammatory markers in $\mathrm{EBC}$ and Rint measurements at preschool age can predict wheezing phenotype at age five years. We assessed levels of EBC markers (IL-2, IL-4, IL-8, IL-10, sICAM) and Rint in two and three year old children and determined at five years of age whether a child 
could be classified as a 'never wheezer', 'transient wheezer' or 'persistent wheezer'. We demonstrated that children with persistent wheeze already had elevated levels of multiple inflammatory markers at preschool age compared to never wheezers. This indicates augmented airway inflammation in these children. However, it was difficult to differentiate between the transient and persistent wheezing phenotype. The lack of discriminative ability might be due to methodological issues. For example, we have studied only a limited set of EBC markers at preschool age. Moreover, although progress has been made, there is still substantial room for improvement in the collection and analysis of EBC markers as discussed by an American/European taskforce. However, an alternative and perhaps more conceivable explanation is possible. In chapter 8 we threw out a feeler for an alternative, biological conceivable phenotype classification guided by non-invasive inflammatory markers and lung function parameters instead of retrospective symptom history. We hypothesised that this might provide a better biological basis to disentangle the heterogeneous character of wheeze.

Chapter 9 encompassed the general discussion of this thesis. In this chapter we discussed what exhaled biomarkers and lung function measurements can add to pathophysiological knowledge, to wheezing phenotyping, and to treatment of preschool wheeze. When considering our findings and those of others, we can draw the conclusion that a complex pulmonary disease, such as preschool wheeze, can not be easily captured by a single biomarker such as FeNO. As potentially multiple immunological pathways are involved, it is important to consider the complete 'breath-print'. Owing to technical and analytical advancements, hundreds of compounds, such as VOCs, can be analysed to assess a disease specific breath-print. Despite the promising findings of the potential clinical use of exhaled compounds, there is still a long way to go. Future methodological studies on validation and standardisation of exhaled compounds are essential. Moreover, future clinical studies that explore whether exhaled compounds can be of use in the early diagnosis of asthma in children are of important value. This will be determined during the followup of the ADEM study. An early asthma diagnose will facilitate proper treatment decisions, and thereby improves the prognosis of asthma in young children. 



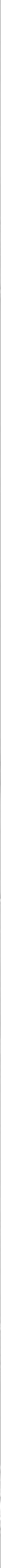





\section{Samenvatting}

In dit proefschrift wordt beschreven wat de potentiële waarde is van longfunctiemetingen en het meten van ontstekingsstoffen in uitgeademde lucht bij het vaststellen van ontstekingspatronen, reactie op medicatie, en fenotypes bij jonge kinderen met piepen/zagen op de borst.

Luchtwegklachten, zoals piepen/zagen op de borst (in het engels: wheeze), komen bij kinderen onder de zes jaar regelmatig voor. In hoofdstuk 1 worden de klinische problemen bij jonge kinderen met luchtwegklachten besproken. Wheeze is bij jonge kinderen een complexe en heterogene klacht. De meeste kinderen hebben voorbijgaande klachten veroorzaakt door virale luchtweginfecties. Bij een aantal kinderen wijzen de klachten echter op astma. Ondanks de hoge prevalentie van wheeze is er nog weinig bekend over de onderliggende pathofysiologie. Dit heeft als gevolg dat het stellen van de juiste diagnose en het monitoren van wheeze-klachten bij jonge kinderen lastig is. Het meten van ontstekingsstoffen in de uitgeademde lucht wordt steeds vaker voorgesteld als niet-invasief hulpmiddel om de mate van luchtwegontsteking bij jonge kinderen met longziekten in kaart te brengen. In de uitgeademde lucht kunnen vluchtige stoffen, zoals stikstofmonoxide (in het engels: Fractional exhaled Nitric Oxide, FeNO) en Vluchtige Organische Componenten (VOCs), worden gemeten. Ook kunnen niet-vluchtige stoffen worden gemeten, zoals cytokines en chemokines, wanneer uitgeademde lucht wordt afgekoeld tot condensaat (in het engels: Exhaled Breath Condensate; EBC). Daarnaast kunnen vroege longfunctiemetingen, zoals het meten van de luchtwegweerstand (Rint), aanvullende informatie geven over de luchtweg-geometrie en onderliggende pathofysiologie. Onderzoek bij volwassenen en oudere kinderen laat zien dat de analyse van ontstekingsstoffen in de uitgeademde lucht en condensaat van potentiële waarde kan zijn bij het diagnosticeren en monitoren van verschillende longziekten. Of dit ook geldt voor jonge kinderen met luchtwegklachten is nauwelijks onderzocht.

Dit proefschrift beschrijft de eerste resultaten van de ADEM studie (in het engels: Asthma DEtection and Monitoring study). In hoofdstuk 2 wordt het protocol van de ADEM studie beschreven. De ADEM studie is een case-control studie die in 2006 op de afdeling kinderlongziekten van het Maastricht Universitair Medisch Centrum (MUMC+) is gestart. In totaal zijn 202 kinderen met herhaalde episodes van wheeze en 50 kinderen zonder wheeze klachten geïncludeerd op 2 en 3 jarige leeftijd. Vervolgens zijn deze kinderen tot 6 jarige leeftijd gevolgd. Het primaire doel van de ADEM studie is om een vroege astma diagnose te stellen, door gebruik te maken van ontstekingsstoffen in uitgeademde lucht, condensaat en vroege longfunctiemetingen. Daarnaast zijn mogelijke etiologische factoren onderzocht in relatie tot de vroege ontwikkeling van astma, zoals regulatoire $T\left(T_{\text {reg }}\right)$ cellen, genpolymorfismen en genexpressie van ontstekingsstoffen, en de aanwezigheid van bacteriën in de bovenste luchtwegen. Het 
onderzoek van het huidige proefschrift is gebaseerd op data van inclusie, data van een twee maanden durende interventie met inhalatie corticosteroïden (ICS) en de vervolg data tot 5 jarige leeftijd.

In hoofdstuk 3 wordt beschreven dat bij jonge kinderen EBC veilig en gemakkelijk kan worden verzameld met behulp van een gesloten glazen condensor (patent: 07102586). Ook off-line FeNO en Rint metingen waren succesvol bij jonge kinderen uit te voeren. Er waren geen verschillen in concentraties van FeNO en Rint waarden tussen kinderen met en kinderen zonder terugkerende wheeze klachten. De concentraties van verschillende interleukines (IL-1 $\alpha$, IL-2, IL-4, IL-5, IL-8, IL-10, IL-13) en van 'soluble Intercellular Adhesion Molecule' (sICAM) waren wel verschillend tussen beide groepen. De concentraties van deze interleukines en sICAM nam toe met de mate van klachten. De verhoogde concentraties van ontstekingsstoffen bij kinderen met wheeze klachten kan wijzen op de aanwezigheid van ontstekingsprocessen in de luchtwegen van deze kinderen. Mogelijk kan de analyse van uitgeademde ontstekingsstoffen helpen bij een vroege detectie van luchtwegontsteking bij jonge kinderen met klachten.

Naast het meten van FeNO en markers in EBC heeft de analyse van uitgeademde VOCs aan populariteit gewonnen bij het onderzoek naar verschillende longziekten. De analyse van uitgeademde VOCs is echter nog niet toegepast bij jonge kinderen met luchtwegklachten. Hoofdstuk 4 bestaat uit een systematische review waarbij de huidige kennis over VOCs en de potentiële klinische toepassing in longziekten worden beschreven. Uit de review blijkt dat de analyse van VOCs eenvoudig kan worden toegepast bij een brede groep patiënten, zoals ernstig zieke patiënten en kinderen. Diverse onderzoeksgroepen lieten zien dat VOCs profielen in staat zijn tot een accurate (differentiële) diagnose en het monitoren van verschillende longziekten zoals astma, chronische obstructieve longziekte (COPD), taaislijmziekte en longkanker. Dit laat zien dat VOCs profielen mogelijk een toegevoegde waarde hebben in de klinische besluitvorming van longziekten. Echter, voordat VOCs profielen klinisch toepasbaar zijn is het standaardiseren en valideren van deze profielen essentieel. Het niet-invasieve karakter van de analyse van uitgeademde VOCs en de veelbelovende resultaten bij volwassenen en schoolkinderen maakt het aantrekkelijk om deze techniek te onderzoeken bij jonge kinderen met luchtwegklachten.

In hoofdstuk $\mathbf{5}$ wordt de eerste studie beschreven waarin VOCs profielen toepast worden bij jonge kinderen met wheeze klachten. In deze haalbaarheidsstudie hebben we laten zien dat het vaststellen van VOCs profielen bij jonge kinderen goed mogelijk is. $\mathrm{Er}$ is hierbij gebruik gemaakt van een gas chromatografische scheiding van de componenten en identificatie van de componenten met time-of-flight massa spectrometrie. Dit is een zeer gevoelige techniek. Daarnaast hebben we geavanceerde statistische technieken gebruikt om op een juiste manier om te gaan met de grote 
hoeveelheid aan data. Een profiel van 11 componenten (voornamelijk koolwaterstoffen) was in staat om kinderen met en kinderen zonder terugkerend wheeze van elkaar te onderscheiden met een hoge kruisgevalideerde correcte classificatie en sensitiviteit, echter met een minder goede specificiteit. Deze 'proof of principle' studie laat zien dat VOCs profielen mogelijk waardevolle informatie kunnen geven over de onderliggende mechanismen bij jonge kinderen met luchtwegklachten. De volgende stap is het bepalen van de waarde van uitgeademde VOCs profielen bij het vaststellen van een vroege astma diagnose.

In hoofdstuk 6 wordt kort de etiologie van wheeze besproken door de relatie met bacteriële kolonisatie, $T_{\text {reg }}$ cellen, atopie en EBC markers te bestuderen. Hoewel bekend is dat virussen een belangrijke prikkel zijn voor wheeze klachten, zouden ook bacteriën een rol kunnen spelen. Er wordt geopperd dat bacteriën in de luchtwegen kunnen leiden tot ontstekingsprocessen bij kinderen met een verminderde immuniteit door bijvoorbeeld allergische sensitisatie. $T_{\text {reg }}$ cellen spelen mogelijk een rol in dit proces. In onze studie werd gevonden dat bacteriën veel voorkomen in de bovenste luchtwegen bij jonge kinderen, ongeacht of deze kinderen wel of geen terugkerende wheeze klachten hadden. Hoewel bacteriën mogelijk bijdragen aan een acute episode van wheeze (zoals aangetoond in eerdere onderzoeken), vonden wij geen bewijs dat de aanwezigheid van bacteriën in de bovenste luchtwegen een bijdrage levert aan chronische wheeze klachten. Ook het aantal $\mathrm{T}_{\text {reg }}$ cellen was niet verschillend tussen kinderen met en zonder wheeze klachten. Uit de data bleek dat kinderen met wheeze die gekoloniseerd waren met Haemophilus (para) influenzae, licht verhoogde ontstekingsstoffen hadden in het EBC vergeleken met kinderen met wheeze die niet gekoloniseerd waren. Dit duidt mogelijk op een door bacteriën geïnduceerde luchtwegontsteking. Verder onderzoek zal moeten uitwijzen of deze toegenomen ontsteking onafhankelijk wordt gestimuleerd door bacteriën of dat er een synergetische interactie is met virale infecties.

Een potentiële klinische toepassing van uitgeademde ontstekingsstoffen is het gebruik van deze stoffen bij het instellen en evalueren van een behandeling. In hoofdstuk 7 wordt beschreven of uitgeademde ontstekingsstoffen de reactie op een ICS behandeling kunnen voorspellen bij jonge kinderen met terugkerende wheeze klachten. De effectiviteit van ICS verschilt tussen kinderen met wheeze klachten. Op dit moment is het niet mogelijk om te voorspellen of een kind wel of geen baat heeft bij een ICS behandeling. Onze hypothese was dat aangezien ICS een ontstekingsremmend effect hebben, de concentraties van FeNO en ontstekingsstoffen in EBC een ICS respons konden voorspellen. Een behandeling met ICS van 8 weken zorgde voor een milde verbetering in klachten en luchtwegweerstand bij kinderen met terugkerende wheeze klachten. Van alle onderzochte ontstekingsstoffen (FeNO, IL-1 $\alpha$, IL-2, IL-4, IL-5, IL-10, sICAM, Interferon-gamma (IFN- $\gamma$ ) en Eotaxin (CCL-11), hadden alleen IL-10 en atopie een beperkte voorspellende waarde voor de verbetering in klachten. Echter, de 
kinderen in de ADEM studie hadden aan de start van de studie weinig klachten en daarom weinig ruimte voor verbetering. De zoektocht naar een betrouwbare, nietinvasieve en makkelijk toepasbare techniek om een ICS respons te voorspellen moet worden voortgezet. Grotere studies met kinderen met meer ernstig wheeze moeten worden uitgevoerd om de waarde van EBC markers en uitgeademde VOCs bij het voorspellen van een ICS reactie verder te onderzoeken.

Een mogelijk andere toepassing van uitgeademde ontstekingsstoffen is beschreven in hoofdstuk 8. Op dit moment is het lastig om te voorspellen of wheeze klachten van voorbijgaande aard zijn of dat ze aanhouden vanwege onderliggend astma. In de studie die beschreven wordt in dit hoofdstuk, wordt prospectief onderzocht of ontstekingsstoffen in EBC en Rint metingen bepaald op jonge leeftijd het klachtenpatroon (fenotype van wheeze) op 5 jarige leeftijd kunnen voorspellen. EBC markers (IL-2, IL-4, IL-8, IL-10, sICAM) en Rint metingen werden uitgevoerd op 2 en 3 jarige leeftijd. Op 5 jarige leeftijd werd bepaald of een kind ingedeeld kon worden in de groep met 'nooit wheeze gehad', 'voorbijgaande wheeze klachten gehad', of 'persisterende wheeze klachten'. Kinderen met persisterend wheeze bleken al op jonge leeftijd verhoogde ontstekingsstoffen te hebben in hun EBC vergeleken met kinderen die nooit wheeze klachten hadden gehad. Dit wijst mogelijk op een verhoogde luchtwegontsteking bij kinderen met persisterend wheeze. Het was niet mogelijk om op basis van een beperkt aantal EBC markers en longfunctiemetingen een onderscheid te maken tussen kinderen met voorbijgaande en met persisterende klachten. Het gebrek aan discriminerend vermogen kan mogelijk komen door methodologische beperkingen. Hoewel er al veel vooruitgang is geboekt in het verzamelen en analyseren van EBC markers, valt er nog veel te verbeteren zoals recentelijk gerapporteerd door een Amerikaanse en Europese werkgroep. Er is echter ook een alternatieve en wellicht meer plausibele verklaring mogelijk. In hoofdstuk 8 opperen we een meer biologische classificatie met behulp van niet-invasieve ontstekingsstoffen en longfunctieparameters. De hypothese is dat deze indeling mogelijk een betere biologische basis vormt om het heterogene karakter van wheeze te ontrafelen.

Hoofdstuk 9 omvat de algemene discussie van het proefschrift. In dit hoofdstuk bespreken we of de uitgeademde ontstekingsstoffen en longfunctiemetingen bij kunnen dragen aan de pathofysiologische kennis, het fenotyperen en het behandelen van wheeze bij jonge kinderen. Wanneer we onze bevindingen samenvoegen met wat eerder is beschreven, kunnen we concluderen dat complexe luchtwegklachten zoals wheeze bij jonge kinderen, niet eenvoudig kunnen worden omschreven met behulp van een enkele biomarker zoals FeNO. Aangezien er vermoedelijk meerdere immunologische processen betrokken zijn, is het belangrijk om de hele 'ademafdruk' ('breath-print') te bestuderen. Door de recente technische en analytische verbeteringen is het mogelijk om honderden uitgeademde componenten, zoals VOCs, 
in een keer te meten om een ziekte specifieke ademafdruk vast te stellen. Ondanks de veelbelovende resultaten over het potentiële klinische gebruik van uitgeademde profielen, is er nog een lange weg te gaan. Methodologische studies naar validatie en standaardisatie van de uitgeademde componenten zijn essentieel. Daarnaast zullen toekomstige klinische studies moeten uitwijzen of de uitgeademde componenten van waarde zijn bij een vroege astma diagnose bij jonge kinderen met luchtwegklachten. Dit zal worden bepaald tijdens het vervolg van de ADEM studie. Een vroege en betrouwbare astma diagnose stelt de arts in staat de juiste behandeling in te zetten waarmee de kwaliteit van leven en de prognose van astma bij jonge kinderen zal verbeteren. 



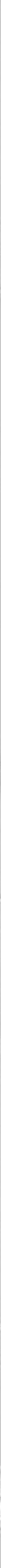





\section{Dankwoord}

In een onderhoudend artikel beschrijven Mireles-Cabodevila en Stoller de tien geboden van het doen van onderzoek. ${ }^{1} \mathrm{Er}$ staan een aantal herkenbare geboden tussen zoals; 'Everything takes longer than you think', en 'Murphy's law applies to equipment: if it can break, it will break'. Het meest toepasselijke gebod voor mij is nummer vijf: 'Everyone needs help; it takes a village to do research'. Ik wil iedereen bedanken die heeft geholpen bij de totstandkoming van dit proefschrift. Een aantal mensen wil ik hierbij in het bijzonder noemen.

Mijn eerste dank gaat uit naar de kinderen en hun ouders die hebben deelgenomen aan de ADEM studie. Zonder jullie enthousiaste en bereidwillige hulp was dit onderzoek niet mogelijk geweest. De transitie van vrolijke en ietwat eigenwijze peuters naar behulpzame en leergierige kleuters was bijzonder om mee te maken. Jullie hebben met alle vrolijke verhalen, schattige interpretaties en stoere inzet, mijn werk uitdagend en kleurrijk gemaakt.

Grote dank gaat ook uit naar de 'burgemeesters' van het onderzoek, mijn promotoren prof. dr. Edward Dompeling, prof. dr. Onno van Schayck en mijn copromotor dr. Quirijn Jöbsis. Beste Edward, ik ben je ontzettend dankbaar voor je intensieve, inspirerende en persoonlijke begeleiding. Ik heb erg veel van je geleerd. Dank voor je vertrouwen en steun. Rijn, samen met Edward vorm je een sterk team waar ik altijd op terug kan vallen. Bedankt voor je kritische noten en je enthousiaste begeleiding. Beste Onno, bedankt voor de scherpe helikopterview en motiverende gesprekken. Ik dank je voor het in mij gestelde vertrouwen, wat mij in staat stelt om als postdoc mijn interesse voor de wetenschap verder te ontwikkelen.

Ik dank de leden van de beoordelingscommissie prof. dr. Cathrien Bruggeman, prof. dr. Wim van Aalderen, dr. Monique Mommers, prof. dr. Peter Sterk en prof. dr. Geertjan Wesseling voor hun bereidheid om dit proefschrift op wetenschappelijke inhoud te beoordelen.

Charlotte en Phillipe, als derde in de rij ben ik jullie erg dankbaar voor de vele tips en adviezen die ik van jullie heb mogen ontvangen. Jullie harde werken heeft voor een 'luchtig' en stevig fundament gezorgd waar ik verder op heb kunnen bouwen.

Mijn directe 'medestanders'; Ester, Bob, Sasha, Maartje, Cynthia, Inge, Marlou en Dillys. Samen hebben we naast vele lunches en gezellige avonden ook lief, leed en soms wat frustratie met elkaar gedeeld, dank daarvoor. Ester, samen draaien we geroutineerd de ADEM studie. We zijn een sterk team en vullen elkaar goed aan, ik werk graag met je samen. Ik vind het erg fijn dat je mijn paranimf bent, bedankt voor al 
je hulp. Dillys, naast lieve vriendin ben je nu ook een directe collega. Daar ben ik erg blij mee. Ook dank ik Coen, Nico, Lilian en Jennifer voor hun gezelligheid en interesse.

De ADEM studie wordt gedragen door goede hulptroepen. Karen, als research nurse ben je van grote waarde gebleken bij het opstarten van de ADEM studie. Je betrokkenheid, daadkracht en positiviteit heb ik enorm gewaardeerd, dank je! Daarnaast heb ik hulp gehad van vele goede studenten. Annedien, Karlijn, Linda en Maran, jullie waren enthousiaste, leergierige en hardwerkende studentes. De kinderen waren altijd gek op jullie. Ik vind het erg leuk dat jullie van de vele aspecten van onderzoek hebben kunnen proeven en een belangrijke bijdrage hebben geleverd aan de verschillende artikelen die uit dit onderzoek zijn voortgevloeid. Esther, Brenda, Emily, Kiki, Nedim en Imke, jullie hebben ons goed geholpen met het uitvoeren van de metingen, dank voor jullie bereidwilligheid en enthousiasme.

Judith, Manon en Kirstin van de longfunctieafdeling wil ik bedanken voor de vakkundige hulp bij de metingen. Jullie vriendelijkheid en geduld naar ouders en kinderen toe hebben een belangrijke bijdrage geleverd aan het hoge slagingspercentage van de metingen. Paul en Marie-Jose dank ik voor de hulp bij het inplannen van ruimte en personeel. Chris en Stefan, bedankt voor jullie hulp en uitleg bij technische vragen en problemen. De rest van het longfunctiepersoneel wil ik hartelijk bedanken voor de gastvrijheid op de afdeling.

Jacqueline en Paula van het MEMIC ben ik erg dankbaar voor het opzetten van het logistiek systeem en de nauwkeurige datacleaning. Peggy en Tamara, bedankt voor de onmisbare secretariële ondersteuning. Erie, bedankt voor je adequate hulp bij de financiële zaken van de ADEM studie.

Door de grote verscheidenheid aan 'biomarkers' die tijdens de ADEM studie zijn bestudeerd ben ik dankbaar voor de prettige, directe en vakkundige samenwerking met veel verschillende afdelingen. Bedankt: dr. Ger Rijkers en Nathalie van Uden (Gastro-intestinale Chirurgie, UMC Utrecht; Medische Microbiologie en Immunologie, St. Antonius Ziekenhuis Nieuwegein); dr. Jan Damoiseaux en Josien Jaspers (Klinische Immunologie, MUMC+); Loe Donselaar, dr. Paul Menheere en dr. Will Wodzig (Klinische Chemie, MUMC+); prof. dr. Frederik-Jan van Schooten, dr. Jan Dallinga, dr. Joep van Berkel, Koos Luijk en Edwin Moonen (Toxicologie, MUMC+); prof. dr. Cathrien Bruggeman, dr. Ellen Stobberingh, dr. Foekje Stelma en Christel Driessen (Medische Microbiologie, MUMC+); prof. dr. Aalt Bast en dr. Gertjan den Hartog (Toxicologie, MUMC+); Frank Nijpels en Frans Smeets (Maastricht Instruments, MUMC+). Eduard Derks (DSM Resolve) en Valéria Lima Passos (Methodologie en Statistiek, MUMC+). Ook ben ik de huisartsen van het RNH netwerk erg dankbaar voor hun hulp bij de inclusie van de 'ADEM-kinderen'. Marjan en Jos, dank voor de coördinatie hiervan. 
Mijn dank gaat tevens uit naar alle co-auteurs van mijn publicaties voor het delen van hun expertise. Nog niet eerder in het dankwoord genoemd en daarom bij deze: prof. dr. Johan de Jongste, dr. Pieter Dagnelie, Koen van Aerde en dr. Jean Muris.

Lieve vrienden; Petra, Rimke, Rieneke, Anoek, Helmi, Martine, Joep, Jessie, Nicky, Anouk, Miranda, Miriam, Anke, Adrienne, Maaike, Chantal, Marloes en Nienke. Bedankt voor jullie gezelligheid en steun. Ik prijs me rijk en gelukkig met zulke goede vrienden.

Lieve Bep, samen met Gerrit heb jij ervoor gezorgd dat ik mij vanaf het begin welkom heb gevoeld in jullie gezin. Ik wil jou, Susanne en Maarten ontzettend bedanken voor de gezelligheid, steun en interesse.

Papa en mama, ik ben erg dankbaar voor jullie steun, voor de liefde en het onvoorwaardelijk vertrouwen. Bedankt voor de veilige haven waar ik altijd op terug kan vallen. Papa, jij bent al sinds ik mij kan herinneren mijn sterkste en grootste held. De kracht waarmee je jezelf door dit genezingsproces slaat, kenmerkt je en ik zie je als een groot voorbeeld. Lieve Mama, je liefde, betrokkenheid, zorgzaamheid en vrolijkheid loodsen me altijd overal doorheen.

Lieve Puck, mijn mooiste zusje, beste vriendin en gezelligste maatje. Ik wil je erg bedanken voor alle gezelligheid, ontspanning en luisterend oor. Je bent ontzettend belangrijk voor me, dat weet je. Ik ben er erg trots op dat je mijn paranimf bent en naast me staat vandaag.

Als laatste wil ik jou bedanken, Hans. Dank je, dat je het als Amsterdammer hebt aangedurfd voor mij te verhuizen naar Maastricht. Dank je, dat je er altijd voor me bent. Zelfs in dit donkere jaar met het overlijden van je lieve vader, kan ik altijd op je steun en hulp rekenen. Ik ben gelukkig met je.

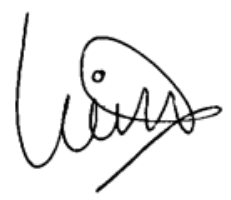

Oktober 2011

${ }^{1}$ Mireles-Cabodevila E, Stoller JK. Research During Fellowship: Ten Commandments. Chest 2009;135;1395-1399 


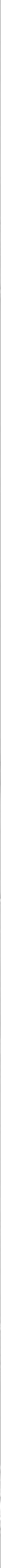





\section{Curriculum Vitae}

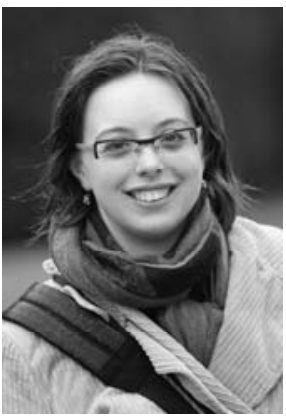

Kim van de Kant was born on $8^{\text {th }}$ January 1983 in Laren, the Netherlands. After obtaining her diploma at 'Laar en Berg' in Laren, she started in 2001 with the bachelor Health Sciences at the Faculty of Health, Medicine and Life Sciences of the Maastricht University Medical Centre (MUMC+). In 2002 she graduated Cum Laude. Thereafter, she did her Master in Human Movement Sciences at the MUMC+. In 2004, she attended an internship at the School of Physical Education and Sports Sciences at the Aristotle University of Thessaloniki, Greece under the supervision of prof. dr. A. Deligiannis. During this internship she studied the effects of exercise training programs in patients with chronic heart failure. In 2005, she completed five additional Master courses at the Free University Medical Centre in Amsterdam (Sports and Law, Social- and Clinical Psychology, Neuropsychology, Rehabilitation psychology, and Exercise physiology). She performed her final internship at the Paediatric Department of the MUMC+ under supervision of dr. C. Robroeks-Bootsma, dr. Q. Jöbsis and prof. dr. E. Dompeling. Due to this internship, she became interested in the non-invasive measurement of airway inflammation in children with asthma. In 2006 she finished the Master Cum Laude. She continued her research by starting a PhD project at the Paediatric Department of the MUMC+ and the School for Public Health and Primary Care (CAPHRI) (Head: prof. dr. CP van Schayck) under the supervision of dr. Q. Jöbsis, prof. dr. E. Dompeling, and prof. dr. CP van Schayck. Her research has resulted in several WI1 publications and multiple personal grants, including two poster awards at the European Academy of Allergy and Clinical Immunology (EAACI) conference in London (2010), best oral presentation award from the 'RVE EVK Erfelijkheid, Voortplanting en het Kind' of the MUMC+, and a young scientist sponsorship of the European Respiratory Society (2009) and EAACl (2010). Next to her PhD project she did the Master Epidemiology at the MUMC+ and graduated Cum Laude in 2010. In 2009, she was a joint applicant of the honoured Dutch Asthma Foundation grant: 'Secondary prevention of asthma in obese children by combined dietary-behavioural-physical activity intervention.' Since 2010, Kim is one of the PhD-supervisors of this RCT, called the MIKADO study. In 2011, Kim acquired a CAPHRI post-doc grant that enables her to continue her research activities in the field of paediatric respiratory research. 


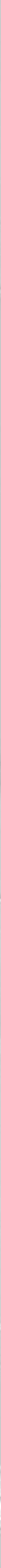




\section{International peer-reviewed publications}

van de Kant KDG, Koers K, Rijkers GT, Lima Passos V, Klaassen EM, Mommers M, Dagnelie PC, van Schayck CP, Dompeling E, Jöbsis $Q$. Can exhaled inflammatory markers predict a steroid response in wheezing preschool children? Clin Exp Allergy. 2011;41:1076-83.

van de Kant KDG, Klaassen EM, Jöbsis Q, Koers K, Rijkers GT, van der Grinten CP, van Schayck CP, Lima Passos V, Dompeling E. Wheezing in preschool children is associated with increased levels of cytokines / chemokines in exhaled breath condensate. J Allergy Clin Immunol. 2010;126:669-71.

van de Kant KDG, Klaassen EM, Jöbsis Q, Nijhuis AJ, van Schayck CP, Dompeling E. Early diagnosis of asthma in young children by using non-invasive biomarkers of airway inflammation and early lung function measurements: study protocol of a case-control study. BMC Public Health 2009;9:210.

van de Kant KDG, Jansen M, Klaassen EMM, van der Grinten CP, Rijkers GT, Muris JWM, van Schayck CP, Jöbsis $Q$, Dompeling $E$. Elevated inflammatory markers at

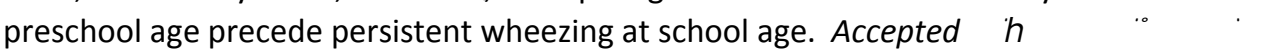

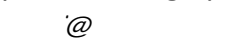

Robroeks CM, van Berkel JJ, Dallinga JW, Jöbsis Q, Zimmermann LJ, Hendriks HJ, Wouters MF, van der Grinten CP, van de Kant KDG, van Schooten FJ, Dompeling E. Metabolomics of volatile organic compounds in cystic fibrosis patients and controls. Pediatr Res $2010 \mathrm{Jul} ; 68(1): 75-80$.

Rosias PP, Robroeks CM, van de Kant KDG, Rijkers GT, Zimmermann LJ, van Schayck $\mathrm{CP}$, Heynens JW, Jöbsis Q, Dompeling E. Feasibility of a new method to collect exhaled breath condensate in pre-school children. Pediatr Allergy Immunol 2010;21:e235-44.

Robroeks CM, van de Kant KDG, van Vliet D, Kester AD, Hendriks HJ, Damoiseaux JG, Wodzig WK, Rijkers GT, Dompeling E, Jöbsis Q. Comparison of the anti-inflammatory effects of extra-fine hydrofluoroalkane-beclomethasone vs fluticasone dry powder inhaler on exhaled inflammatory markers in childhood asthma. Ann Allergy Asthma Immunol 2008;100:601-7.

Rosias PP, Jöbsis Q, van de Kant KDG, Robroeks C, van Schayck CP, Zimmermann L, Dompeling E. Global condensation: a "climate change" towards better standardisation of exhaled breath condensate measurements. Eur Respir J 2008;31:684-5. 
Kotz D, van de Kant KDG, Jöbsis Q, Schayck C. Effects of tobacco exposure on lung health and pulmonary biomarkers in young, healthy smokers aged 12-25 years: a systematic review. Expert Rev Resp 2007;1:403-418.

Robroeks CM, van de Kant KDG, Jöbsis $Q$, Hendriks HJ, van Gent R, Wouters EF, Damoiseaux JG, Bast A, Wodzig WK, Dompeling E. Exhaled nitric oxide and biomarkers in exhaled breath condensate indicate the presence, severity and control of childhood asthma. Clin Exp Allergy 2007;37:1303-11.

\section{National peer-reviewed publications}

Dompeling E, Jöbsis Q, van de Kant KDG, Dallinga J, van Berkel J, van Schooten FJ. Profielen van vluchtige stoffen in uitademingslucht: een nieuw middel voor de diagnostiek en monitoring van chronische longziekten? Nederlands Tijdschrift voor Allergie 2008;8:156-62.

\section{Submitted manuscripts}

van de Kant KDG, van der Sande LJTM, Jöbsis Q, van Schayck CP, Klaassen EMM, Wesseling G, Dompeling E. The clinical use of exhaled volatile organic compounds in pulmonary diseases; a systematic review.

van de Kant KDG, van Berkel JBN, Jöbsis Q, Lima Passos V, Klaassen EMM, van der Sande L, van Schayck CP, de Jongste JC, van Schooten FJ, Dompeling E, Dallinga JW. Exhaled breath profiling in the diagnosis of wheezy preschool children: a proof of principle study.

van de Kant KDG, Klaassen EMM, van Aerde KJ, Damoiseaux J, Bruggeman CA, Stelma FF, Stobberingh EE, Muris JWM, Jöbsis Q, van Schayck CP, Dompeling E. Mechanisms of preschool wheeze: the role of bacteria, regulatory T-cells, and airway inflammation.

(

Wanrooij V, Willeboordse M, Dompeling E, van de Kant KDG. The beneficial effects of exercise on asthmatic children: a systematic review. 